Unlimited Release

Printed November 1990

\title{
COAL COMBUSTION SCIENCE
}

\section{QUARTERLY PROGRESS REPORT}

JULY-SEPTEMBER 1990

Submitted By: Donald R. Hardesty

Sandia National Laboratories, Livermore Combustion Research Facility

Submitted To: James D. Hickerson

Pittsburgh Energy Technology Center

* Research supported by the United States Department of Energy, Office of Fossil Energy, Pittsburgh Energy Technology Center 


\title{
COAL COMBUSTION SCIENCE
}

\section{QUARTERLY PROGRESS REPORT JULY - SEPTEMBER 1990}

\author{
Donald R. Hardesty \\ Combustion Research Facility \\ Sandia National Laboratories \\ Livermore, California
}

This document provides a quarterly status report of the Coal Combustion Science Program that is being conducted at the Combustion Research Facility, Sandia National Laboratories, Livermore, California. The information reported is for the period JulySeptember 1990.

The objective of this activity is to support the Office of Fossil Energy in executing research on coal combustion science. This activity consists of basic research on coal combustion that supports both the Pittsburgh Energy Technology Center (PETC) Direct Utilization Advanced Research and Technology Development Program, and the International Energy Agency (IEA) Coal Combustion Science Project. Specific tasks for this activity include:

\section{Task 1: Coal Devolatilization}

The objeciive of this task is to characterize the physical and chemical processes that constitute the early devolatilization phase of coal combustion as a function of coal type, heating rate, particle size and temperature, and gas phase temperature and oxidizer concentration.

The principal investigator on this task is Dr. Thomas H. Fletcher.

\section{Task 2: Coal Char Combustion}

The objective of this task is to characterize the physical and chemical processes involved during coal combustion as a function of coal type, particle size and temperature, and gas phase temperature and oxygen concentration.

The principal investigator on this task is Dr. Reginald E. Mitchell.

\section{Task 3: Fate of Mineral Matter During Coal Combustion}

The objective of this task is to establish a quantitative understanding of the mechanisms and rates of transformation of mineral matter in coal combustion environments as a function of coal type, particle size and temperature, the initial forms and distribution of mineral species in the unreacted coal, and the local gas temperature and composition. A particular goal is determining the importance of fragmentation in the evolution of the particle size distribution during coal combustion.

The principal investigator on this task is Dr. Larry L. Baxter. 
TABLE OF CONTENTS

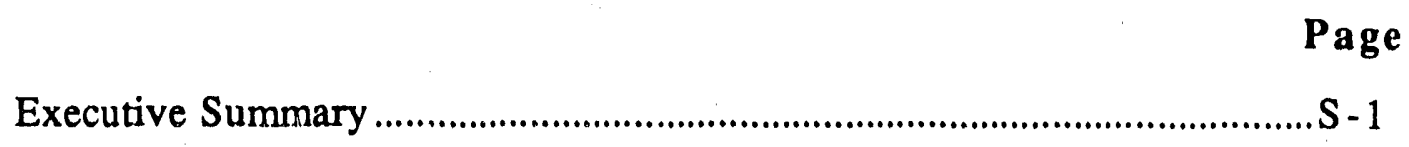

\section{TASK 1: COAL DEVOLATILIZATION}

\section{T. H. Fletcher and D. R. Hardesty}

Objective For Task 1........................................................................... 1-1

Summary of Technical Progress During This Quarter............................ 1-2

Subtask 1.1. Pyrolysis Product Compositions and Heating Values ........................................................1-2

Subtask 1.2. Chemical Structure of Coal During Devolatilization............................................... 1-3

Subtask 1.3. Transition from Coal Devolatilization to Char Combustion ...................................................... 1-28

Plans for Next Quarter.....................................................................1-28

Acknowledgments.................................................................... $1-28$

References for Task 1 Section.............................................................1-29

Publications, Fapers, and Presentations ..............................................1-29

Milestone Schedule and Status Report ...............................................1-32

\section{TASK 2: THE RATES AND MECHANISMS OF COAL CHAR COMBUSTION}

\section{R. E. Mitchell and D. R. Hardesty}

Objective For Task 2 .........................................................................2-1

Summary of Technical Progress During This Quarter...........................2-2

Subtask 2.1. Determination of Apparent Char Particle Burning Rates...............................................................2-4

Subtask 2.2 Determination of the Intrinsic

Chemical Reactivity of Chars ...................................2-12

Subtask 2.3 Determination of Nitrogen and

Sulfur Release Rates .............................................2-12

Plans for Next Quarter.......................................................................

References for Task 2 Section..........................................................2-31

Nomenclature for Task 2 Section ....................................................... $2-32$

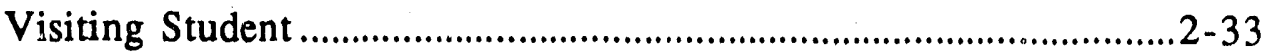

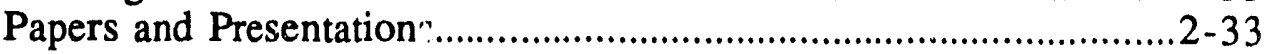

Appendix for Task 2 Section.............................................................. 2-34

Milestone Schedule and Status Report .............................................2-41 


\title{
TASK 3: THE FATE OF MINERAL MATTER
}

\author{
L. L. Baxter and D. R. Hardesty
}

Objectives For Task 3 ….................................................................. 3-1

Summary of Technical Progress During This Quarter............................3-2

Subtask 3.1. Release of Inorganic Material During Coal

Devolatilization and Char Oxidation..........................3-2

Subtask 3.2. The Evolution of Particle and Flyash Size

Distributions and......................................................... 3-2

Subtask 3.3 Theoretical and Experimental Studies of Flyash

Technology Exchange for Task 3.........................................................3-33

Plans for Next Quarter.....................................................................3-35

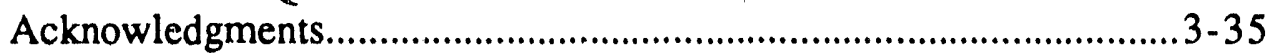

References for Task 3 ……............................................................ 3-35

Nomenclature for Task 3.................................................................3-40

Publications, Papers, and Presentations ...............................................3-42

Appendix for Task 3 Section..................................................................3-43

Milestone Schedule and Status Report ..............................................3-54 


\title{
COAL COMBUSTION SCIENCE
}

\author{
QUARTERLY PROGRESS REPORT \\ JULY - SEPTEMBER 1990
}

EXECUTIVE SUMMARY

\section{Task 1. Coal Devolatilization}

Quantitative experimental investigations of the evolution of the chemical structure of solid and condensible pyrolysis products (char and tar) are critical to the understanding of coal devolatilization mechanisms. In particular, it is important to analyze tar and char samples that have been collected simultaneously under a known set of conditions; i.e., matched tar/char pairs. ${ }^{13} \mathrm{C}$ NMR data on char samples and ${ }^{1} \mathrm{H}$ NMR data on corresponding tar samples produced from an Illinois No. 6 coal (PSOC1493D) were presented in a previous quarterly report. This report includes a discussion of additional ${ }^{13} \mathrm{C}$ NMR data for the chars and new ${ }^{13} \mathrm{C}$ NMR data for the corresponding tars derived from Illinois No. 6 coal (PSOC-1493D), along with new ${ }^{1} \mathrm{H}$ and ${ }^{13} \mathrm{C}$ NMR data for char and tar samples from Beulah Zap lignite (PSOC-1507D). These data, together with information on the total mass release and elemental analysis for each char, are used to evaluate the evolution of the tar and char structures as a function of residence time and temperature. A paper describing the NMR data for these two coals has been accepted for publication in Fuel.

The ${ }^{13} \mathrm{C}$ NMR analyses of the chars from both coals indicate that significant amounts of aliphatic material are released from the coal during devolatilization with little initial change to the aromatic cluster size or number of cross links per cluster. The evolution of the char structure following tar release is a function of the temperature history of the char. ${ }^{13} \mathrm{C}$ NMR analyses of the bituminous coal char particles indicate that crosslinking occurs during the late stages of devolatilization, whereas the crosslinking oc'surs early in the devolatilization process for the lignite char particles.

The chemical structures of the two parent coals are quite different with regard to the amount of aromatic carbon, the number of carbons per cluster, and the size of the aromatic clusters. However, the chemical structures of the completely devolatilized chars of these two coals are remarkably similar. It is well known that lignite char reactivity (in oxygen) is much greater than that for bituminous coal chars; these NMR data support the postulate that such reactivity differences are due to differences in physical structure (apparent density, pore size distribution, etc.) rather than due to differences in intrinsic chemical reactivity.

In this report, the structures of the primary tars are compared to the parent coals, and the gas phase evolution of the tar structure is followed with time. Significant thermal decomposition of the vaporized tars from both coals occurs in the $1250 \mathrm{~K}$ gas condition; only slight thermal decomposition of tars is observed in the $1050 \mathrm{~K}$ gas 
condition. Evidence for thermal decomposition includes increases in hydrogen and carbon aromaticity and decreases in peripheral aliphatic groups, such as methyl groups and aliphatic bridge material.

\section{Task 2. The Rates and Mechanisms of Coal Char Combustion}

During this quarter, the analysis of the combustion data obtained with Blue \#1 coal (PSOC-1445D) was continued. Kinetic parameters that describe the apparent char particle burning rates were determined by combining the in situ size, temperature, and velocity measurements and the $\mathrm{m} / \mathrm{mo}_{0}$ and apparent density measurements of chars at various extents of burnoff. In previous work it was noted that when using the empirically-based, $n$-th order power-law rate expression to characterize the overall particle burning rate, the apparent reaction order that best correlated the apparent chemical reaction coefficients with temperature differed for particles burning in the 6 and 12 mole-\% oxygen environments employed in the combustion tests. The Arrhenius parameters that described the apparent chemical reaction rate coefficients differed as well. In effect, different sets of kinetic parameters were determined for each of the reactor environments employed.

In the analysis of the data obtained with Blue \#1 coal, reaction orders that best correlate the reaction rate coefficients are also found to differ for data obtained in the different oxygen level environments used in the combustion tests. However, reaction orders of 0.25 in the 6 mole-\% oxygen environment and 0.40 in the 12 mole-\% oxygen environment are found to yield apparent chemical reaction rate coefficif nts that exhibit the same temperature dependence. The apparent activation energy is determined to be about $39 \mathrm{kcal} / \mathrm{mole}$. This result suggests that the reaction order with respect to the oxygen partial pressure depends upon the oxygen partial pressure itself. The possibility of such a dependence (and even a temperature-dependent reaction order) has been discussed by other investigators.

An apparent reaction order that depends upon the oxygen partial pressure limits the utility of an n-th order power-law rate expression for describing char particle burning rates. The need to use an adsorption-desorption reaction mechanism that is adequate for all oxygen level environments is obvious when consideration is given to the fact that in typical pulverized-coal combustors, particles experience oxygen levels ranging from $21 \%$ to about $3 \%$ during the course of burnoff. In future work, kinetic parameters for an adsorption-desorption reaction mechanism will be derived for each of the coals examined in this project.

Also this quarter, for each of the ten coals examined on the PETC suite of PSOC coals, elemental carbon, hydrogen, oxygen, nitrogen, and sulfur release rates relative to the total mass release rates during char oxidation were obtained. Except for the release of sulfur, the trends in the elemental releases relative to the total mass release are the same for each of the coals. On an ash-free basis, carbon and nitrogen are released nearly in proportion to the total mass release rates and hydrogen and 
oxygen are released at rates faster than the total mass release rates. The release rates of sulfur vary from coal to coal. In general, the low rank coals release sulfur at rates that are slower than the total mass release rates and the high rank coals release sulfur at rates that exceed the total mass release rates.

Carbon, the principal component of the char, is expected to be released at a rate nearly proportional to the total mass loss rate on an ash-free basis. The release rates of hydrogen and oxygen are consistent with hydrogen and oxygen in the char occurring predominantly in peripheral groups such as $-\mathrm{COOH},-\mathrm{OH}, \mathrm{C}=\mathrm{O}$, and $-\mathrm{OCH}_{3}$ that are readily released at high temperatures. Some of the oxygen that is released relatively late in burnoff may be incorporated in aromatic clusters and aliphatic ether-structures of the form $\mathrm{C}_{\mathrm{ar}}-\mathrm{O}-\mathrm{C}_{\mathrm{ar}}, \mathrm{C}_{\mathrm{ar}}-\mathrm{O}-\mathrm{C}_{\mathrm{al}}$, and/or $\mathrm{C}_{\mathrm{al}}-\mathrm{O}-\mathrm{C}_{\mathrm{al}}$ that have been observed in coals. The release of nitrogen is consistent with the nitrogen in the char being primarily incorporated in $\mathrm{N}$-heterocyclics and $\mathrm{C}-\mathrm{N}=\mathrm{C}$ configurations distributed throughout the carbonaceous matrix, with little occurring in amido, amino, cyano, or oxidic groups (which are most likely released during devolatilization and during the early stages of burnoff).

The sulfur release rates no doubt depend upon the forms of sulfur (pyritic, sulfatic, or organic) in the coal. The pyritic and sulfatic sulfur may be preferentially released during devolatilization and early burnoff. Early release of pyritic sulfur is supported by data obtained with Illinois \#6 coal. The organic sulfur is incorporated in peripheral end-groups and linkages of the form -SH, -SR, R'-S-R, and -S-S- and in $S$ heterocyclics such as thiophenes, benzothiophenes, thioxanthenes, etc. NMR analyses indicate that in comparison to high rank coals, low rank coals have more bridge- and aliphatic-carbons, carbons that are preferentially attacked during oxidation. If a higher fraction of the sulfur in low rank coals is in heterocyclics (than in peripheral end-groups and linkages), then one would expect sulfur release rates in low rank coals to be slower than the total mass release rates. This could explain the observation that sulfur release in low rank coals is somewhat slower than the total mass release rate. Chemical analyses to determine the ratio of sulfur in peripheral end-groups and linkages to the sulfur in heterocyclics are needed to determine if this is indeed the case.

The sulfur in Illinois \#6, a bituminous coal, is released nearly in proportion to the total mass release rate, suggesting that the sulfur is incorporated primarily in aromatic clusters and aliphatic ether-structures. With the other bituminous coals examined, sulfur may be incorporated primarily in aromatic clusters and aliphatic ether-structures as well, with the sulfur incorporated in peripheral end-groups and linkages giving rise to overall sulfur release rates that are higher than the total mass release rates.

\section{Task 3. The Fate of Mineral Matter}

During this quarter a series of experiments was completed in the CCL aimed at further delineating the role of pyrite oxidation in the formation of iron-rich fumes during 
pulverized coal combustion. Analyses of the results of these experiments is presently underway.

Also during this quarter, and in close collaboration with researchers from Consolidaiion Coal Company (Consol), extensive testing was completed in the Sandia Multifuels Combustor. In these tests, ily ash and ash deposit samples were collected under a variety of combustion conditions for thirteen coals. Ash deposits were collected from air-cooled probes simulating water walls and tubes in cross flow at three particle residence times (stages of burnout) for each coal. In addition to the collected deposits, photographs were taken of deposit buildup, in situ measurements were obtained of particle size distributions in the flow upstream of the deposit surface, and heat transfer efficiencies were measured for simulated water walls and tubes in cross flow. The solid samples have been shipped to Consol for analysis at their research laboratory in Library, PA. Raw coal analyses for most of the coals were also completed and are documented in this report.

In addition, during this quarter consider'ble work was done on the development and evaluation of the Sandia ADLVIC ash deposition model. In previous quarterly reports results of preliminary predictions using ADLVIC were presented. In this report, the principal ingredients of ADLVIC are summarized and the status of the model development and predictive capabilities are described. The description of mineral matter in coal as a composite of thirteen species is described, together with methods of estimating the proportions of each. Model equations are presented which describe ash deposition, for each of these thirteen species, as the sum of four simultaneous processes: inertial deposition, thermophoresis, condensation, and chemical reaction. The first two of these processes are discussed in detail; the influence of several assumptions, e.g. turbulence levels, position on the deposit surface, and location in the boiler, are examined. Empirical equations correlating particle capture efficiency with particle residence time are also presented.

Finally, during this quarter arrangements were finalized with Central Illinois Public Service Company (CIPS) to collaborate on full-scale tests of deposition in three of their twelve boilers. These experiments involve sampling by CIPS of ash deposits under controlled and documented conditions in two $600 \mathrm{MW}$ pulverized coal boilers and one 185-250 MW pulverized coal boiler. Experiments will focus on the sensitivity of deposit composition to changes in coal type, operating condition, and location within the boiler. The test results and coal and deposit samples will be provided to Sandia for evaluation in collaboration with the CIPS engineers. ADLVIC will be used to provide blind predictions of some of the CIPS results. The test data will provide baseline data for validating predictions of the ADLVIC model and their applicability to commercial-scale systems. These collaborative tests constitute a considerable costsharing on the part of CIPS and are being undertaken with considerable enthusiasm by the CIPS engineers.

\section{Future Work}

Additional char and tar samples from different coals and different reactor conditions are currently being analyzed by NMR spectroscopy and GC/MS techniques. Analyses of char samples obtained in the Coal Devolatilization Laboratory from PSOC-1508D 
(Pocahontas lv bituminous coal) are currently in progress. It is anticipated that samples of the chars from five coals sampled in the Coal Combustion Laboratory (CCL) in the $0 \%$ post-flame oxygen condition will also be analyzed during the next quarter. The flash distillation model and crosslinking models $b$ ye already been incorporated into the Chemical Percolation Devolatilization (CPD) model. Improvernents to the CPD model will be made during the next quarter, including a description of the selection of chemical structure parameters and comparison with available NMR data on the chemical structure of coal chars.

Also during the next quarter, analysis of the combustion data from CCL experiments to determine kinetic parameters for the chars of several other coals will begin. In addition, analysis of the data obtained with the chars that were produced under different devolatilization conditions will commence. Comparisons will be made between the burning rates of the chars produced from the same coals.

Finally, during the next quarter experimental testing of the last few coals and coal blends being used in the collaborative study with Consol will be completed using the Sandia Multifuel Combustor. In addition, devlopment and improvement of the ADLVIC deposition model will condtinue. Boiler geometries, coal samples and analyses from CIPS will be used to make predictions of ash deposit characteristics in the CIPS boilers. Construction of deposit sampling probes ind other experimental tools should be completed by CIPS and the first deposit samples from the CIPS/Sandia tests should be ready for analysis by the end of the quarter. 
PROJECT TITLE:

ORGANIZATION:

CONTRACT:

REPORTING PERIOD:

REPORTED BY:
COAL COMBUSTION SCIENCE

TASK 1: COAL DEVOLATILIZATION

Sandia National Laboratories, Livermore

FWP 0709

July 1 - September 30, 1990

T. H. Fletcher and D. R. Hardesty

Plione: FTS 234-2584 and 234-2321

\section{OBJECTIVE FOR TASK 1}

The objective for Task 1 is io characterize the physical and chemical processes that constitute the early devolatilization phase of coal combustion as a function of coal type, heating rate, particle size and temperature, and gas-phase temperature and oxygen concentrations.

These objectives are met by conducting basic research in three Subtask areas as follows:

\section{Subtask 1.1 Pyrolysis Product Compositions and Heating Values}

The goal of this subtask is to consider and implement schemes that will permit measurement of tar yields and gas compositions in the existing apparatus. Plans include, analysis for major species such as $\mathrm{CH}_{4}, \mathrm{CO}, \mathrm{CO}_{2}, \mathrm{C}_{2} \mathrm{H}_{6}, \mathrm{C}_{2} \mathrm{H}_{4}$, and $\mathrm{H}_{2} \mathrm{O}$ using standard gas chromatographic and/or Fourier transform infrared (FTIR) spectroscopic techniques. In addition, it may be possible to use an on-line mass spectrometer for tar analysis and for identification of species containing nitrogen. The heating values of a few of the chars from devolatilization experiments will be measured and compared with published correlations that are principally based on raw coals. Optical experiments will also be performed using the pyrometry system in an attempt to lower the tempcrature detection threshold below the current $850 \mathrm{~K}$ for a $100 \mu \mathrm{m}$ particle.

\section{Subtask 1.2 Chemical Structure of Coal During Devolatilization}

In a collaboration with the Nuclear Magnetic Resonance (NMR) Laboratory at the University of Utah through the Advanced Combustion Engineering Research Center (ACERC), research includes investigation of the chemical structure of the parent coals as well as the chemical structure of the tar vapors and char partisles produced in rapid heating devolatilization experiments. Initial data collected in FY89 for two coals (PSOC-1493D and 1508D) will be analyzed and supplemented with NMR 
measurements for additional samples derived from these two coals. Investigations of chemical structure will continue in FY90 on other coals, including low rank coals (e.g., PSOC-1507D North Dakota Zap lignite and PSOC-1445D New Mexico Blue subbituminous coal) and bituminous coal (e.g., PSOC-1451D HVA bituminous coal). The focus of the NMR analyses will be the quantitative identification of functional groups in a manner that permits comparison with current devolatilization models, such as the chemical percolation devolatilization (CPD) model. The goal is to provide a devolatilization model simple enough to use in large coal combustor simulations, while describing the devolatilization process and product distribution in some detail. Development of the CPD model will continue as more data are generated, including meaningful ways to model molecular weight distribution and transport effects.

\section{Subtask 1.3 Transition from Coal Devolatilization to Char Combustion}

The transition from pulverized coal devolatilization to char combustion will be studied by (a) operating the Coal Devolatilization Laboratory (CDL) with $0-10 \%$ oxygen, and (b) operating the Coal Combustion Laboratory (CCL) with $0 \%$ post-flame oxygen. The solids sampling system in the CCL will be modified to separate char particles from tars and aerosols. Particles will be examined for elemental composition (C, H, N, $O$, and S), physical structure (using optical and electron microscopy), apparent density, diameter, and internal surface area. The extent of mass release will be determined from tracer elements in the ash ( $\mathrm{Si}, \mathrm{Al}$, and $\mathrm{Ti}$ ) in a manner similar to previous studies. In addition, the chars collected from the different gas environments will be reinjected into the CCL, and apparent burning rates will be determined. The results of the experiments studying the transition from coal devolatilization to char oxidation will be combined with theoretical studies involving existing devolatilization and char combustion models.

\section{SUMMARY OF TECHNICAL PROGRESS DURING THIS QUARTER}

Research this quarter was performed mainly under Subtask 1.2 on the experimental characterization of chemical structures in coal chars and tars. A paper regarding the NMR analyses of char and tar samples from an Illinois No. 6 coal was presented at the International Combustion Symposium in Orléans, France. In addition, major progress was achieved in the development of the chemical percolation devolatilization (CPD) model late in the quarter. The results from the modeling work will be presented in the next quarterly report.

\section{Subtask 1.1 Pyrolysis Product Compositions and Heating Values}

Research in this subtask during this quarter centered on determining the feasibility of measuring light gas concentrations in the Coal Devolatilization Laboratory (CDL). An FTIR with a $20 \mathrm{~m}$ cell was used to analyze light gases sampled in the CDL. The estimated concentrations of $\mathrm{CO}, \mathrm{CH}_{4}$, and $\mathrm{CO}_{2}$ in the sample were $\sim 5 \mathrm{ppm}$. Samples of light gas from a Pittsburgh No. $8 \mathrm{coal}$ (PSOC 1451D, 75-106 $\mu \mathrm{m}$ ) were collected in 
the $1250 \mathrm{~K}$ gas condition at a residence time of $225 \mathrm{~ms}$. The FTIR analysis showed the presence of these species with good resolution. Based on this preliminary experiment, it is estimated that stable gas concentrations as low as $0.5 \mathrm{ppm}$ can be measured in samples obtained from the CDL. This concentration corresponds to the amount of light gas evolved at extents of mass release of $\sim 5 \%$. Future experiments are planned to make the measurements quantitative.

\section{Subtask 1.2 Chemical Structure of Coal During Devolatilization}

Results of nuclear magnetic resonance (NMR) analyses of char and tar samples collected in the CDL are presented here. These results were obtained in collaboration with Professors Ron Pugmire and Dave Grant at the University of Utah, and have been incorporated into a paper that has been accepted for publication in Fuel.

\section{Introduction}

Coal pyrolysis is the initial step in most coal conversion processes, accounting for up to $70 \%$ of the weight loss of the coal. It is also the process that is most dependent on the organic properties of the coal. Pyrolysis is also important because of its influence on subsequent liquefaction or gasification conversion processes. To study the thermal decomposition in which coal is transformed into volatiles and char, investigators have focused on how various parameters change with extent of decomposition. These parameters have included: the extent of mass release; functional group composition; reactivity; solvent swelling ratio; tar molecular weight distribution; extract yields; and many others. Major efforts have centered around identifying the rates and the temperature regimes of pulverized coal devolatilization as a function of heating rate, final temperature, and coal type.

Particle temperature measurements during devolatilization at rapid heating conditions (Solomon, et al., 1986; Fletcher, 1989b) have eliminated many uncertainties caused by estimations of particle temperatures in early studies. Models of devolatilization have advanced beyond one-step Arrhenius kinetics to descriptions of the bonding structure in the coal, metaplast, and tar (Solomon, et al., 1988; Niksa and Kerstein, 1986; Grant, et al., 1989). Other models include detailed empirical correlations to estimate yields of tar products from elemental composition of the parent coal (Ko, et al., 1988), as well as mechanisms to describe the evolution of the physical structure of char particles (Oh, et al., 1989). Most of these models presume a mechanism for generation of metaplast during pyrolysis, followed by release of lighter fractions of th metaplast as tar vapor, where tar is commonly defined as pyrolysis products that conoense at room temperature and pressure. Light gas release is generally modeled indepenudently from solid-phase reactions (Solomon, et al., 1988), although a recent chemical percolation devolatilization (CPD) model was proposed where light gas release is partially coupled to the char formation rate (Grant, et al., 1989; Fletcher, et al., 1990a).

Quantitative experimental investigations of the evolution of the cinemical structure of solid and condensible pyrolysis products (char and tar) are critical to the 
understanding of coal devolatilization mechanisms. In particular, it is important to analyze tar and char samples that have been collected simulcaneously under a known set of conditions; i.e., matched tar/char pairs. Fletcher and co-workers (1990b) presented NMR data on matched tar/char samples produced from an Illinois No. 6 coal. Additional ${ }^{13} \mathrm{C}$ and ${ }^{1} \mathrm{H}$ NMR data are presented here for the matched tar/char pair3 derived fiom Illinois No. 6 coal (PSOC-1493D), along with new NMR data derived from a Beulah Zap lignite (PSOC-1507D). These data, together with information on the total mass release and elemental analysis for each char, are used to evaluate the evolution of the tar and char structures as a function of residence time and temperature.

\section{Experimental Procedure}

\section{a. Pyrolysis Experiments}

Char and tar samples were collected as a function of residence time in the transparent-wall, entrained-flow reactor in Sandia's Coal Devolatilization Laboratory at two separate gas temperature conditions ( $1050 \mathrm{~K}$ and $1250 \mathrm{~K}$ ). The experimental details regarding the particle temperature measurements and sample collection system were previously published (Fletcher, 1989a; Fletcher, 1989b; Fletcher, et al., 1990b). Particle temperature histories were measured with an infrared sizingpyrometry system. Heating rates at these conditions are approximately $10^{4} \mathrm{~K} / \mathrm{sec}$. Char and tar samples wire collected using a helium quench probe followed by an online aerodynamic separation of tar from char particles. The elements $\mathrm{Ti}, \mathrm{Si}$ and $\mathrm{Al}$ were used as tracers to determine the extent of mass release from the char particles as described previously (Fletcher, 1989b). Following collection, the tar and char samples were stored at temperatures less than $0^{\circ} \mathrm{C}$ until final preparation for NMR analysis.

\section{b. NMR Analyses}

The ${ }^{13} \mathrm{C}$ NMR data on the coal and char particles were obtained by a variation of the method described by Solum, et al. (1989). Cross-polarization magic-angle spinning (CP/MAS) spectra for coals and chars were obtained on a Bruker CXP-100 spectromeler with a ${ }^{13} \mathrm{C}$ frequency of $25.15 \mathrm{MHz}$ and a spectral width of $12 \mathrm{kHz}$. The radio frequency fields were $\gamma_{C} B_{1 C}=\gamma_{H} B_{1 H} \approx 48 \mathrm{kHz}$. Spinning speeds were approximately $4.0 \mathrm{kHz}$. Delay times between acquisitions were 0.5 to $1.0 \mathrm{~s}$. Contact times in dipolar dephasing measurements were between 0.8 to $2.5 \mathrm{~ms}$ depending on the maximum aromatic signal from the variable contact (VC) measurement, using 2.0 ms when signal to noise level permitted. The coal and char samples were run as received with $\lrcorner$ degassing.

The total magnetization was obtained by a variable contact time experiment in which the data were fit to a model employing a Gaussian $\left(T_{G C H}\right)$ and a Lorentzian $\left(T_{L C H}\right)$ time constant and a single, alue for the spin relaxation time $\left(T_{1} \rho^{H}\right)$. The time constarts, $T_{G C H}$ and $T_{L C H}$ and $T_{1} \rho^{H}$, along with magnetization values $M_{G C H}$ and 


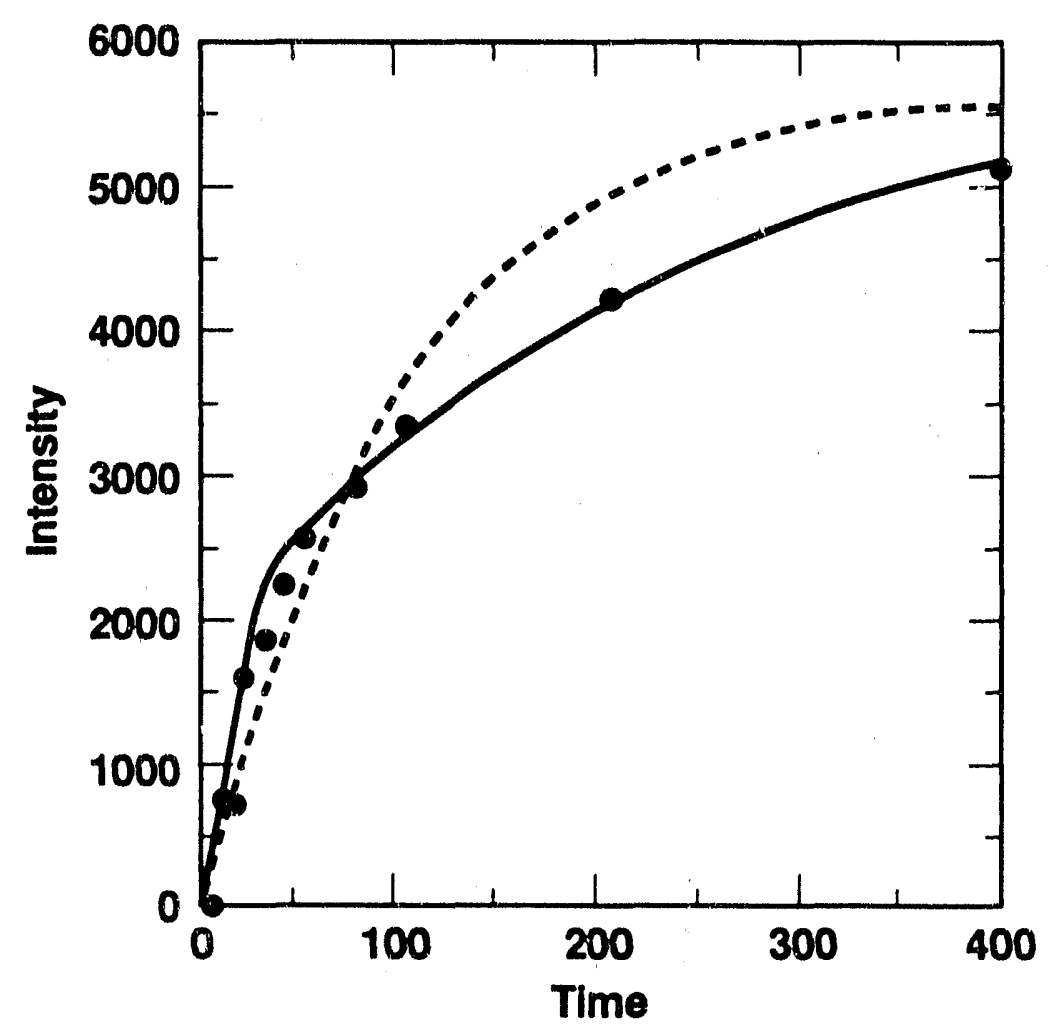

Figure 1.1 Short time ( $\mu \mathrm{s})$ behavior in a variable contact time measurement for the aromatic region of PSOC-1507D Beulah Zap lignite. Fit of data (circles) with the simple VC model using one $T_{C H}$ (dashed line) and with $T_{G C H}$ and $T_{L C H}$ accounting for two stage cross polarizaiton for carbons with directly attached protons (solid line).

$M_{L C H}$, were measured using a standard $\mathrm{CP}$ sequence while varying the contact time, $\tau_{c p}$. The carbon magnetization was fit to the following five parameter equation:

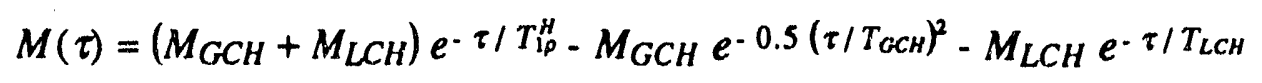

where $\left(M_{G C H}+M_{L C H}\right)$ represents the total magnetization in the sample independent of relaxation effects. The above equation was used separately for the aromatic and aliphatic regions of the spectra, and the carbon aromaticity $f_{a}$ was calculated from these values after including sideband intensity for the aromatic region. The second cross-polarization time constant, $T_{G C H}$, is included to take into account the first stage of the two stage cross-polarization from carbons with directly bonded protons (Müller, et al., 1974; Wu, et al., 1988). The second time constant $T_{L C H}$ is then an average of the time constants for nonprotonated carbons and the second stage for carbons with directly bonded protons. Curve fits of variable contact time data from PSCC-1507D aromatic region are shown in Fig. 1.1 for both the simple model (Solum, et al., 1989) 
representing a single stage cross-polarization model and the two stage cross polarization model given by Eq. (1). Between 17 and 25 different contact times from $5 \mu \mathrm{s}$ to $25 \mathrm{~ms}$ were used in variable contact time measurements.

Dipolar dephasing data were employed to separate the aromatic Gaussian $(\mathrm{C}-\mathrm{H})$ component from the Lorentzian (non-protonated) component of the carbon magnetization. The dipolar dephasing pulse sequence has been described previously (Alemany, et al., 1983), and the version used here has $180^{\circ}$ refocusing pulses in both the carbon and proton channels. There were 23 interrupted decoupling delays in this analyses, ranging from 2 to $200 \mu$ s for the aromatic region. The decay of the carbon magnetization was fit to the following four parameter equation (Sethi, et al., 1988):

$$
M(\tau)=M_{O L} e^{-\tau / T_{L}}-M_{O G} e^{-0.5\left(\tau / T_{G}\right)^{2}}
$$

In Eq. 1.2, $T_{L}$ and $M O L$ are the Lorentzian decay constant and initial magnetization, respectively, for the weakly coupled spins. The variables $T_{G}$ and $M O G$ are the Gaussian decay constant and initial magnetization, respectively, for the strongly coupled spins. The sum of $M_{O G}$ and $M_{O L}$ has been normalized to unity.

Segmental motion in the aliphatic region of the ${ }^{13} \mathrm{C} \mathrm{CP/MAS} \mathrm{spectrum} \mathrm{of} \mathrm{coals} \mathrm{creates}$ some uncertainty in the relative contributions of $\mathrm{CH}_{3}$ and $\mathrm{CH}_{2} / \mathrm{CH}$ groups (Vassola, et al., 1987; Soderquist, et al., 1987), as measured in the dipolar dephasing experiments. The methyl contribution was therefore approximated from the integrated intensities of the 0-22 (alkyl and aryl methyl groups) and 50-60 (methoxy group) ppm regions of the spectrum.

Using parameters from the above ${ }^{13} \mathrm{C}$ NMR analyses, twelve structural parameters relating to the carbon skeletal structure may be obtained. The average aromatic cluster size and the number of attachments on an aromatic cluster may also be estimatcd. This procedure for data analysis, including the cluster size estimation model, has been described by Solum and coworkers (1989).

The high mineral content of the Zap lignite and associated char samples caused a low signal to noise level in the NMR analyses. This signal to noise difficulty was reduced by demineralizing the lignite samples; all solid-state NMR data presented here for the lignite and associated chars are from the demineralized samples. Demineralization was achieved by leaching the samples successively in $\mathrm{HCl}, \mathrm{HF}$, and then $\mathrm{HCl}$ again (all at $50-60^{\circ} \mathrm{C}$ ), with warm water rinses between acid leaching steps. It is thought that the organic skeletal structure is not significantly altered by the acid leaching procedure. The bituminous coal and chars were not demineralized, since adequate signal to noise levels were achieved with the native samples.

The ${ }^{1} \mathrm{H}$ and ${ }^{13} \mathrm{C}$ NMR data for each tar sample were obtained with a Varian VXR-500 spectrometer. Tars were removed from the tar filter and dissolved in $1 \mathrm{ml}$ samples of deuterated (98\%) dimethyl sulfoxide (DMSO). The ${ }^{13} \mathrm{C}$ NMR data on tars were obtained by using a $30^{\circ}$ carbon pulse with an acquisition time of $1.2 \mathrm{~s}$ and a $0.5 \mathrm{~s}$ pulse 
delay. These conditions provide semi-quantitative data that slightly underestimate the carbon aromaticity. Small amounts of particulate matter were observed in the tar/DMSO solutions, but no serious degradation of spectral resolution was observed due to the presence of colloidal material.

\section{Results and Discussion}

\section{a. Evolution of Char Structure}

The elemental analyses of the Illinois No. 6 coal and Beulah Zap lignite are given in Table 1.1. The carbon skeletal parameters determined from the ${ }^{13} \mathrm{C}$ NMR analyses of the coals and related pyrolysis chars obtained at the $1250 \mathrm{~K}$ gas condition are given in Tables 1.2 and 1.3. Representative chemical structures identified in the ${ }^{13} \mathrm{C}$ NMR analyses of coal and char samples are illustrated in Fig. 1.2. The measured variations in several of these parameters are shown in Fig. 1.3 as a function of residence time during devolatilization in the $1250 \mathrm{~K}$ gas condition. The data shown at $0 \mathrm{~ms}$ residence time are for the parent coal; analyses of two separate samples of lignite indicate the experimental error involved in each chemical structure parameter. For clarity, only the carbon aromaticities (fraction of carbon contained in aromatic structures) with the carbonyl subtracted $\left(f_{a}^{\prime}\right.$, not $\left.f_{a}\right)$ will be discussed in this section.

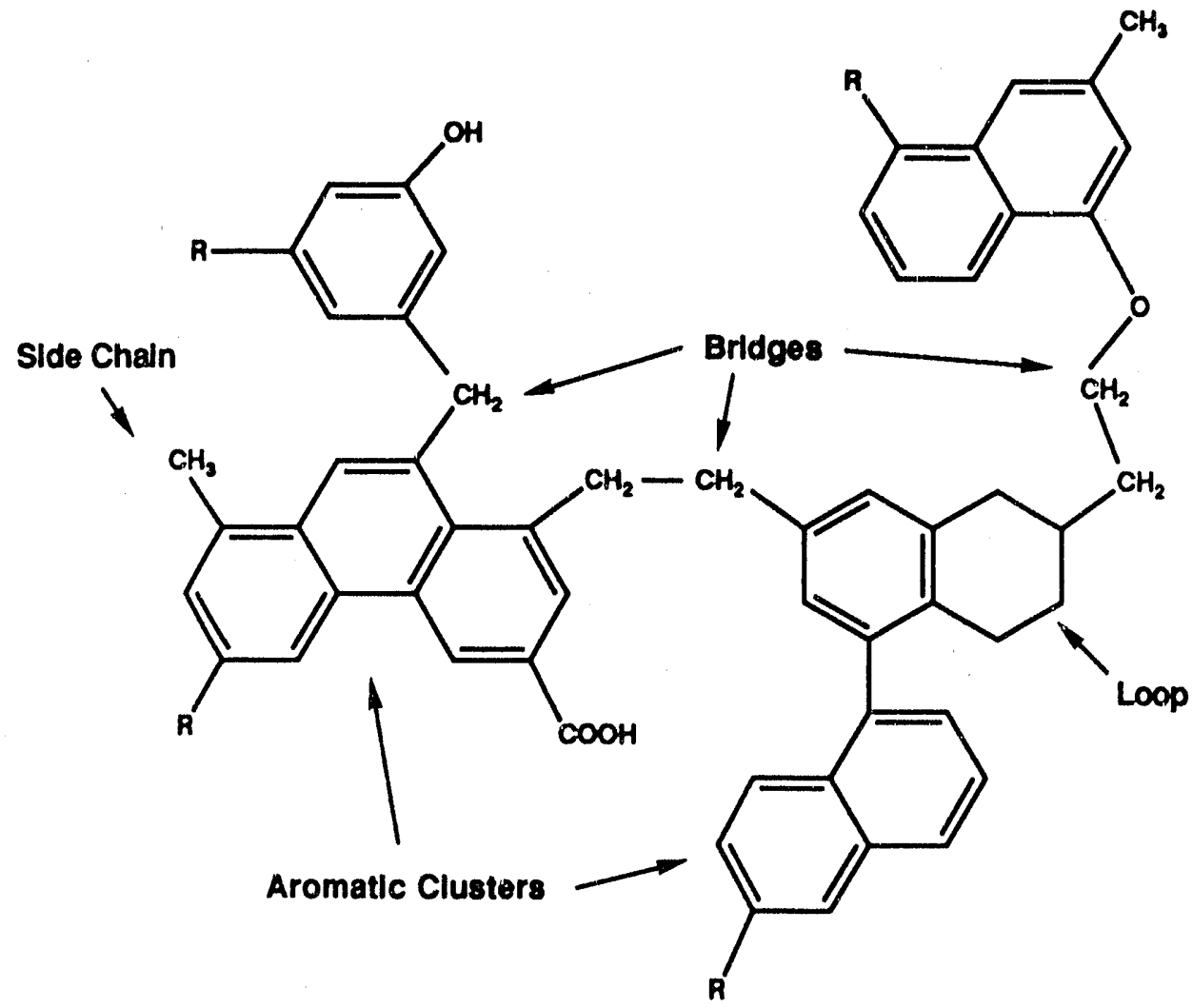

Figure 1.2 Representative chemical structures identified in ${ }^{13} \mathrm{C}$ NMR analyses of coal and coal chars. 
Table 1.1

Analysis of Parent Coals

\begin{tabular}{lcc}
\hline & $\begin{array}{c}\text { PSOC-1493D } \\
\text { Illinois No. 6 } \\
\text { hvb bituminous } \\
\text { coal }\end{array}$ & $\begin{array}{c}\text { PSOC-1507D } \\
\text { North Dakota } \\
\text { Beulah Zap } \\
\text { lignite }\end{array}$ \\
\hline Size Fraction $(\mu \mathrm{m})$ & $106-125$ & $75-106$ \\
Carbon (wt.\% daf) & 74.1 & 66.6 \\
Hydrogen & 5.0 & 4.3 \\
Oxygen & 13.2 & 25.2 \\
Nitrogen & 1.4 & 1.1 \\
Sulfur & 6.3 & 2.9 \\
Ash (wt.\% moist. free) & 11.3 & 18.7 \\
\hline
\end{tabular}

The ultimate volatiles yield at the $1250 \mathrm{~K}$ gas condition was $51 \%$ on a dry ash free (daf) basis for the Illinois No. 6 coal, and 53.7\% for the Zap lignite. As reported previously (Fletcher, et al., 1990b), approximately $40 \%$ of the volatiles from Illinois No. 6 are released by $43 \mathrm{~ms}$, and $75 \%$ of the total mass release occurs by $65 \mathrm{~ms}$. Tar is released at residence times from ranging from 30 to $65 \mathrm{~ms}$, based on model predictions (Fletcher, et al., 1990a) and comparison with similar data (Serio, et al., 1987). During this tar release period, the percentage of aromatic carbon for the bituminous coal char has changed by less than 5\% (see Fig. 1.3), suggesting that the carbon aromaticity of the initial tar is similar to that of the coal.

The number of aromatic carbons per cluster in the bituminous coal char at $223 \mathrm{~ms}$ reaches a final value of 15 (a $40 \%$ increase), a modest $40 \%$ increase in cluster size when compared to anthracite coals and graphitized samples where the number of aromatic carbons per cluster may be in the range of 50 to 350 (Sethi, et al., 1988; Orendt, et al., 1990). The number of aliphatic carbons per cluster in the bituminous coal char remains relatively constant until the late stages of devolatilization, and then decreases. The number of aliphatic carbons per cluster in the bituminous coal char at $223 \mathrm{~ms}$ is almost a factor of two lower than in the parent coal, but has changed by less than the experimental error at the point where $75 \%$ of the volatiles have been released (65 ms).

Side chain attachments to aromatic clusters (see Fig. 1.2) consist of alkyl groups and oxygen functional groups (e.g., phenols and/or alkyl and aryl ethers). Other types of 
Table 1.2

Carbon Structural Parameters Determined from ${ }^{13}$ C NMR Spectroscopy

for PSOC-1493D Illinois No. 6 Coal and Char Samples

(1250 K gas condition)

\begin{tabular}{|c|c|c|c|c|c|c|}
\hline Residence Time (ms) & 0 & 43 & 65 & 89 & 128 & 223 \\
\hline Mass Release (\% daf) & 0 & 22 & 38 & 47 & 51 & 51 \\
\hline Aromatic carbon, $f_{a}=f_{a}{ }^{\prime}+f_{a} C$ & .71 & .72 & .74 & .79 & .81 & .86 \\
\hline Carbonyl, $f_{a} C$ & .04 & .05 & .04 & .05 & .03 & .02 \\
\hline Aromatic carbon, carbonyl subtracted, $f_{a}{ }^{\prime}$ & .67 & .67 & .70 & .74 & .78 & .84 \\
\hline Protonated aromatic carbon, $f_{a}^{H}$ & .27 & .29 & .27 & .34 & .33 & .32 \\
\hline Non-protonated aromatic C, $f_{a}^{N}=f_{a} P+f_{a} S+f_{a}^{B}$ & .40 & .38 & .43 & .40 & .45 & .52 \\
\hline Aromatic carbon with $\mathrm{O}$ attachment, $f_{a}^{\widetilde{P}}$ & .08 & .09 & .07 & .07 & .05 & .05 \\
\hline Aromatic carbon with alkyl attachment, $f_{a}^{S}$ & .17 & .19 & .16 & .19 & .18 & .22 \\
\hline Aromatic bridgehead and inner carbon, $f_{d}^{B}$ & .15 & .10 & .20 & .14 & .22 & .25 \\
\hline Aliphatic carbon, $f_{a l}$ & .29 & .28 & .26 & 21 & 19 & .14 \\
\hline Aliphatic $\mathrm{CH}$ and $\mathrm{CH}_{2}, f_{a l}{ }^{H}$ & 18 & .19 & .17 & .15 & .14 & .10 \\
\hline Aliphatic $\mathrm{CH}_{3}$ and non-protonated carbon, $f_{a l}{ }^{*}$ & .11 & .09 & .09 & .06 & .05 & .04 \\
\hline Aliphatics with oxygen attachment, $f_{a l} O$ & .07 & .07 & .05 & .08 & .07 & .07 \\
\hline Proton spin-relaxation time, $T_{1} \rho^{\mathrm{Har}}(\mathrm{ms})$ & 4.0 & 2.6 & 2.7 & 4.4 & 6.1 & 8.3 \\
\hline Total carbons per cluster & 16 & 14 & 19 & 13 & 17 & 18 \\
\hline Aromatic carbons per cluster, $C$ & 11 & 10 & 14 & 10 & 14 & 15 \\
\hline Aliphatic carbons per cluster & 4.8 & 4.2 & 5.2 & 2.8 & 3.4 & 2.5 \\
\hline Total attachments per cluster, $\sigma+1$ & 4.1 & 4.2 & 4.6 & 3.5 & 4.1 & 4.8 \\
\hline Bridges and lcups per cluster, $B_{C}$ & 2.3 & 2.8 & 2.8 & 2.7 & 3.2 & 4.1 \\
\hline Side chains per cluster & 1.8 & 1.4 & 1.8 & 0.8 & 0.9 & 0.7 \\
\hline Fraction of intact bridges per cluster, $p$ & .56 & .68 & .61 & .77 & .78 & .85 \\
\hline Average cluster molecular weight & 270 & 230 & 330 & 210 & 280 & 260 \\
\hline
\end{tabular}

Note: Error estimates for each parameter are given in Table 1.3. 
Table 1.3

Carbon Structural Parameters Determined from ${ }^{13}$ C NMR Spectroscopy

for PSOC-1507D Beulah Zap Lignite and Char Samples

(1250 K gas condition)

\begin{tabular}{|c|c|c|c|c|c|c|}
\hline & & & & & & $\begin{array}{c}\text { Error } \\
\text { Estimate }\end{array}$ \\
\hline Residence Time (ms) & 0 & 0 & 74 & 99 & 233 & \pm 5 \\
\hline Mass Release (\% daf) & 0 & 0 & 18 & 30 & 54 & \pm 3 \\
\hline Aromatic carbon, $f_{a}=f_{a}{ }^{\prime}+f_{a} C$ & 65 & .65 & .75 & .84 & .89 & \pm .03 \\
\hline Carbonyl, $f_{a} C$ & .08 & .08 & .07 & .04 & .04 & \pm .02 \\
\hline Aromatic carbon, carbonyl subtracted, $f_{a}{ }^{\prime}$ & .57 & .57 & .68 & .80 & .85 & \pm .04 \\
\hline Protonated aromatic carbon, $f_{a}^{H}$ & .19 & .20 & .21 & .30 & .31 & \pm .03 \\
\hline Non-protonated aromatic C, $f_{a}^{N}=f_{a}{ }^{P}+f_{a} S+f_{a}^{B}$ & .38 & .37 & .47 & .50 & .54 & \pm .03 \\
\hline Aromatic carbon with $\mathrm{O}$ attachment, $f_{a} P$ & .07 & .08 & .08 & .07 & .07 & \pm .02 \\
\hline Aromatic carbon with alkyl attachment, $f_{a} S$ & .14 & .14 & .14 & .18 & .21 & \pm .03 \\
\hline Aromatic bridgehead and inner carbon, $f_{a}^{B}$ & .17 & .15 & .25 & .25 & .26 & \pm .04 \\
\hline Aliphatic carbon, $f_{a l}$ & .35 & .35 & .25 & .16 & .11 & \pm .02 \\
\hline Aliphatic $\mathrm{CH}$ and $\mathrm{CH}_{2}, f_{a l}{ }^{\mathrm{H}}$ & .24 & .26 & .16 & .12 & .08 & \pm .02 \\
\hline Aliphatic $\mathrm{CH}_{3}$ and non-protonated carbon, $f_{a l}{ }^{*}$ & .11 & .09 & .09 & .04 & .03 & \pm .03 \\
\hline Aliphatics with oxygen attachment, $f_{a l} O$ & .11 & .10 & .09 & .10 & .06 & \pm .02 \\
\hline Proton spin-relaxation time, $T_{1} \rho^{\mathrm{Har}}(\mathrm{ms})$ & 7.6 & 7.5 & 3.3 & 3.6 & 6.2 & \pm 2 \\
\hline Total carbons per cluster & 23 & 21 & 25 & 18 & 17 & \pm 3 \\
\hline Aromatic carbons per cluster, $C$ & 14 & 13 & 18 & 15 & 15 & \pm 3 \\
\hline Aliphatic carbons per cluster & 8.5 & 8.0 & 6.6 & 3.0 & 1.9 & \pm 2 \\
\hline Total attachments per cluster, $\sigma+1$ & 5.2 & 5.0 & 5.8 & 4.7 & 4.9 & \pm 1 \\
\hline Bridges and loops per cluster, $B_{C}$ & 2.4 & 3.0 & 3.4 & 4.0 & 4.4 & \pm 1 \\
\hline Side chains per cluster & 2.8 & 2.0 & 2.4 & 0.7 & 0.5 & \pm 1 \\
\hline Fraction of intact bridges per cluster, $p$ & .48 & .59 & .59 & .84 & .89 & \pm .05 \\
\hline Average cluster molecular weight & 440 & 410 & 450 & 300 & 260 & \pm 30 \\
\hline
\end{tabular}




\section{a. Illinois No. 6 Coal Chars}

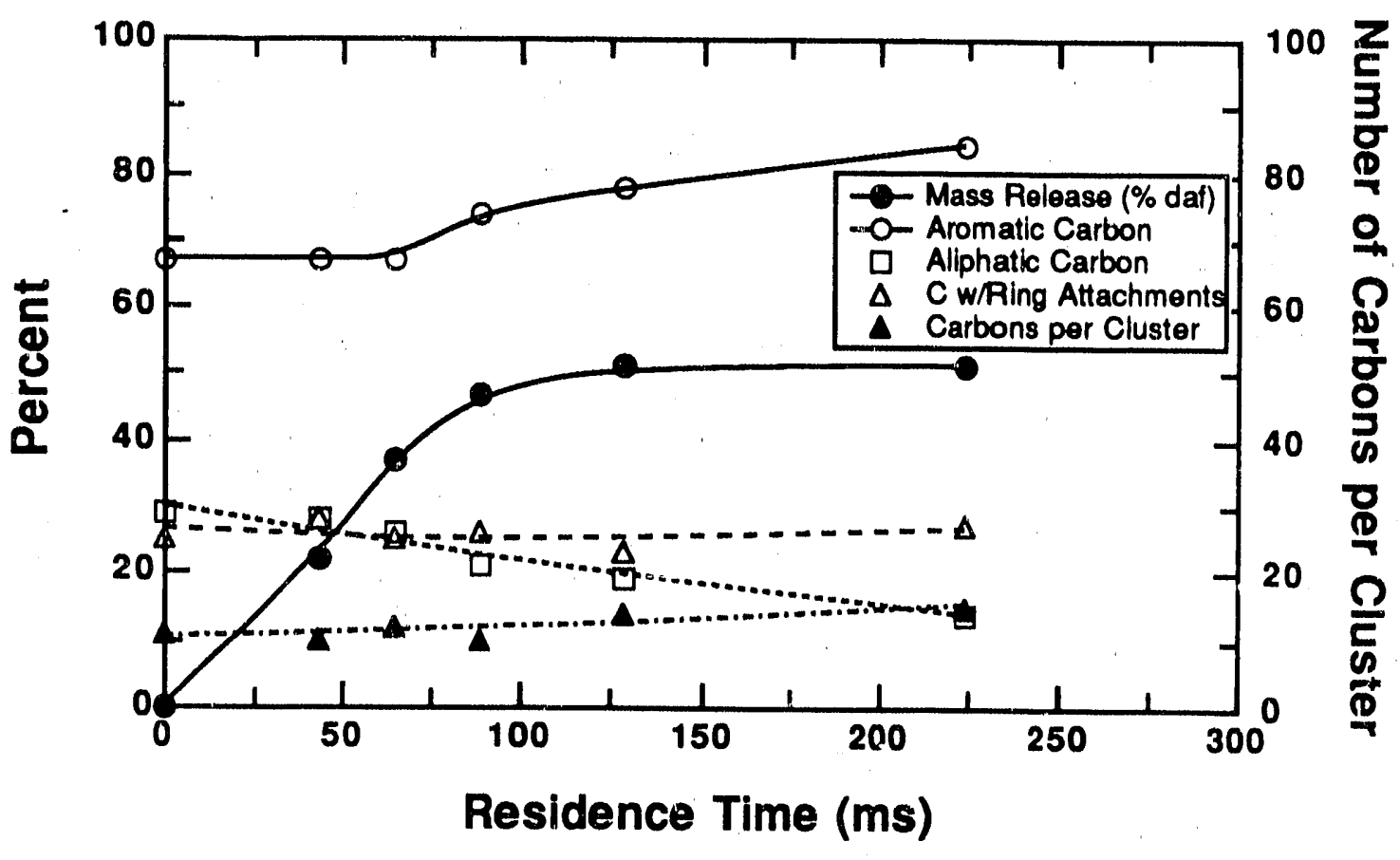

\section{b. Beulah Zap Lignite Chars}

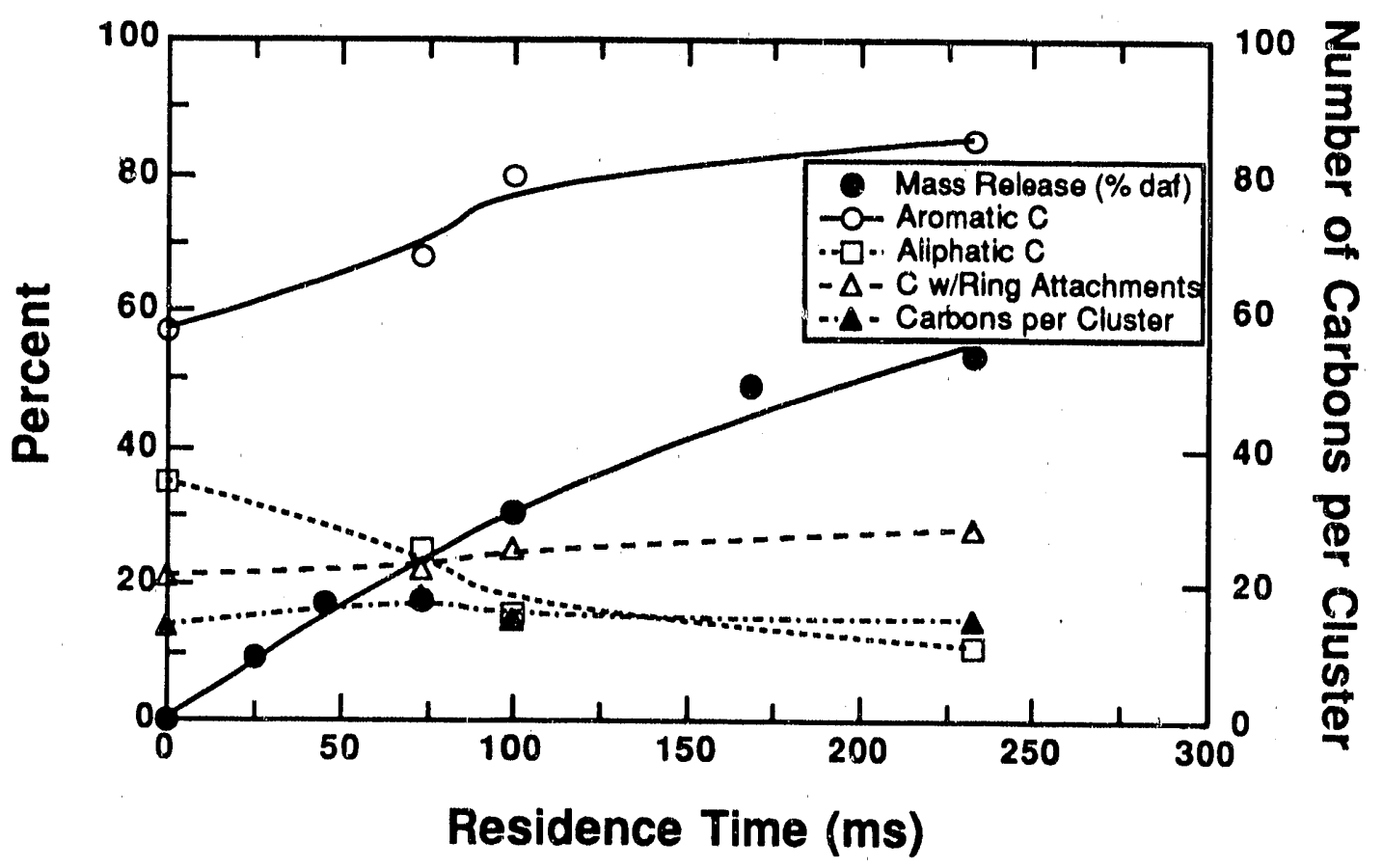

Figure 1.3 Char structure parameters and mass release profiles for (a) Illinois No. 6 coal and (b) Beulah Zap lignite, as a function of residence time at the $1250 \mathrm{~K}$ gas temperature condition. 
attachments are bridges and loops between aromatic clusters (see Fig. 1.2). The bond strengths of the aromatic clusters are much greater than the bond strengths of the labile bridges and loops. During devolatilization these labile bridges break, generating finite-size fragments containing one or more aromatic clusters. The light fragments are released as tar, while the heavier fragments stay in the char as metaplast and eventually reattach to the infinite char matrix. Broken bridge fragments are eventually released as light gas. In this analysis, it is assumed that the fractured bridge fragments may be distinguished from intact bridges by the presence of methyl groups. Hence, the number of side chains per cluster can be estimated (see Tables 1.2 and 1.3) together with the number of intact bridges and loops per cluster. It is important to note that aliphatic carbons still remain at the end of the pyrolysis process and represent the presence of stable aliphatic bridge material and/or side chains that have not been expelled at the pyrolysis temperatures employed. Within the experimental error (estimated at \pm 3 ), the total number of carbons per cluster (aromatic plus aliphatic) has not changed in the Illinois No. 6 coal and char samples. Furthermore, the total number of attachments per cluster in the bituminous coal chars remains essentially constant as a function of residence time, even though the number of aliphatic carbons in the $223 \mathrm{~ms}$ sample decreases by a factor of two from the parent coal. This means that no new attachment sites are generated during pyrolysis; any reattachment of metaplast occurs at existing side chain sites.

The number of bridges and loops (i.e., bridges between aromatic rings and aliphatic loops on aromatic rings, such as tetralin) per cluster does not change significantly in the bituminous coal chars until the end of the mass release period, as shown in Fig. 1.4. The increase in the number of bridges and loops per cluster is an indication of the extent of crosslinking that occurs between neighboring aromatic clusters. The total number of attachments per aromatic cluster $(\sigma+1)$, however, does not change significantly, indicating that bridge material is released at a rate proportional to the formation of crosslinking bridges. These stable char bridges likely are formed at the site of the original bridge. These data at rapid heating conditions clearly indicate that the average molecular structure of the Illinois No. 6 coal does not undergo major changes in functional group distribution until after most of the tar is released, at which time reactions occur in the char/metaplast that are associated with gas release.

As shown in Fig. 1.3 and Tables 1.2 and 1.3, the chemical structure of the Zap lignite changes in a manner similar to the changes exhibited by the lllinois No. 6 coal. However, the crosslinking behavior of the Zap chars is different from that observed in Illinois No. 6. The number of bridges and loops is slightly higher in the lignite and increases in a monotonic progression with the extent of mass release (Fig. 1.4). These data reflect the early crosslinking that is observed in solvent swelling measurements of lignites as compared to the high volatile bituminous coals (Solomon, et al., 1990a; Solum, et al., 1990). A careful examination of the relationship between mass release and carbon aromaticity for the lignite (Fig. 1.3) clearly indicates differences from those observed for Illinois No. 6. Approximately 20 to $25 \%$ of the total mass release for the lignite occurs over the time period where $75 \%$ of the mass release was noted for the bituminous coal. On the other hand, the carbon aromaticity 


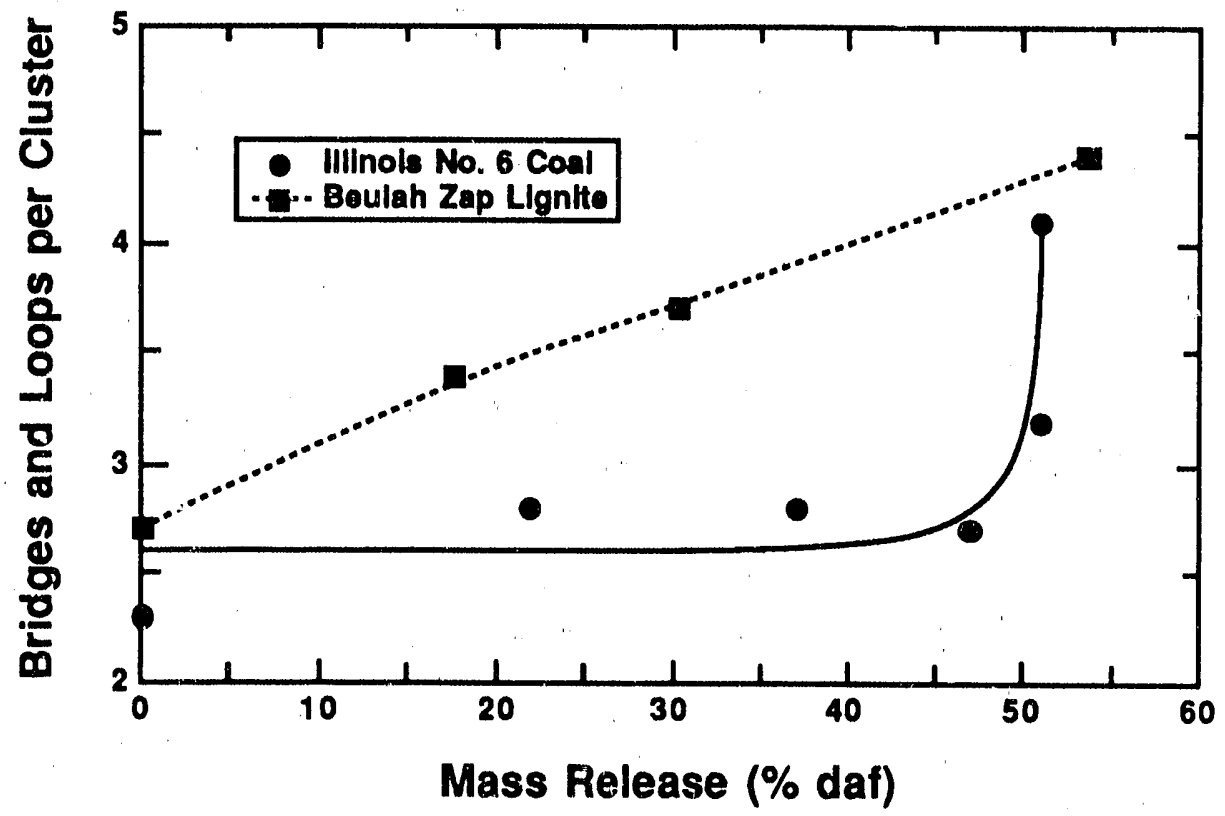

Figure 1.4 The number of bridges and loops per cluster vs. the extent of mass release due to devolatilization for chars collected at different residence times in the $1250 \mathrm{~K}$ gas temperature condition.

in the lignite char changes in the early stage of pyrolysis as compared to the bituminous coal chars, indicating that the structural relationship between the initial lignite tars and chars is quite different from those observed in the Illinois No. 6 samples. The carbon aromaticities for both sets of chars ultimately reach comparable values, but the parent lignite has a lower carbon aromaticity value $\left(f_{a}{ }^{\prime}=0.57\right)$ than the parent bituminous coal $\left(f_{a}{ }^{\prime}=0.67\right)$. Hence, some of the restructuring of the aromatic species occurs earlier in the lignite than in the Illinois No. 6 coal.

The number of aromatic carbons per cluster in the lignite chars shows no significant change with residence time, within experimental error. However, the total number of carbons per cluster decreases as the result of the release of aliphatic carbons, as indicated by the number of aliphatic carbons per cluster in Table 1.3. The high number of aliphatic carbons per cluster in the Zap lignite, relative to Illinois No. 6 coal, correlates with the higher gas release of the lignite during pyrolysis. The number of ring attachments per cluster for the lignite chars increases by approximately $25 \%$ while the number of aliphatic carbons decreases by $65 \%$. These data suggest that the pyrolysis process eliminates functional groups from the aromatic clusters, with a net loss of aliphatic carbons. At the same time, however, additional crosslinking sites are formed. 


\section{a. Illinois No. 6 Coal Chars}

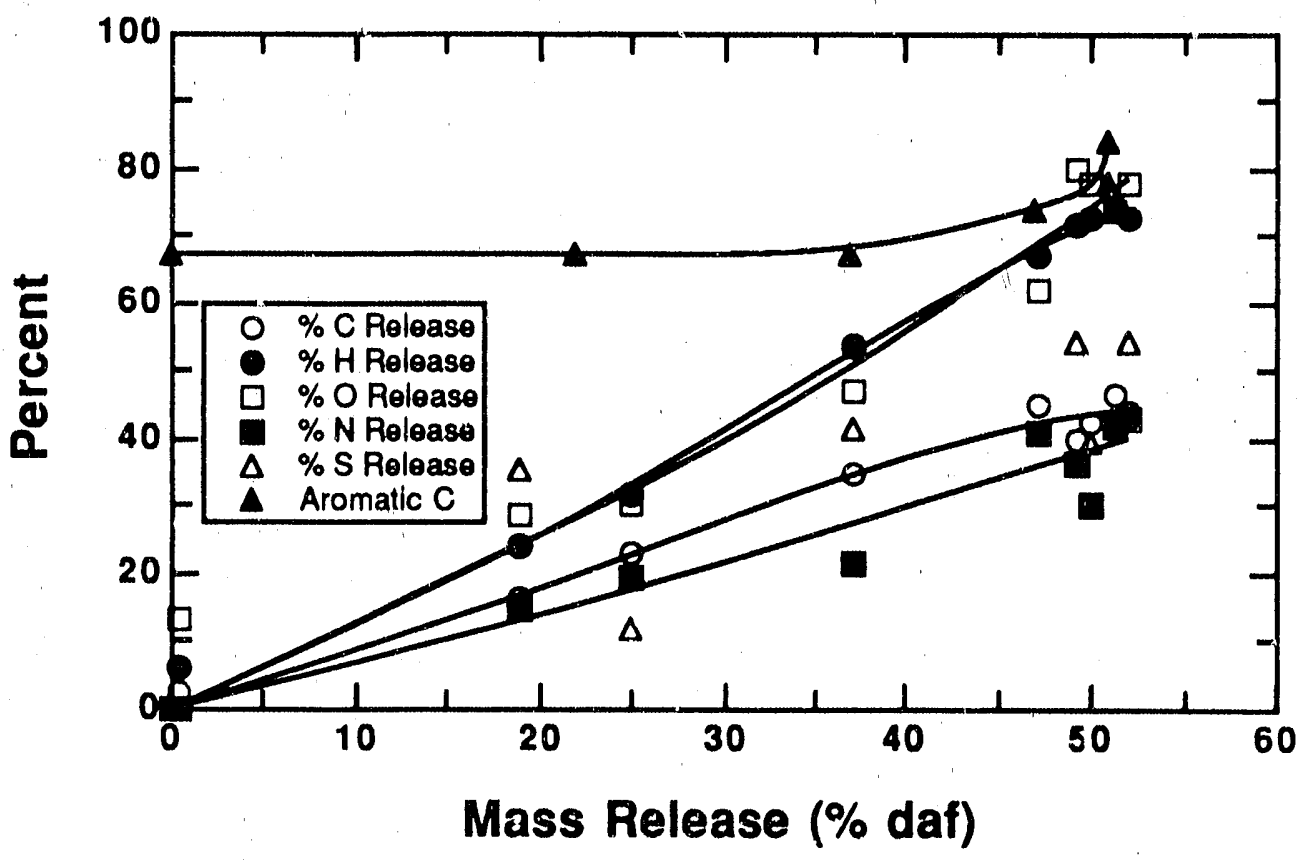

\section{b. Beulah Zap Lignite Chars}

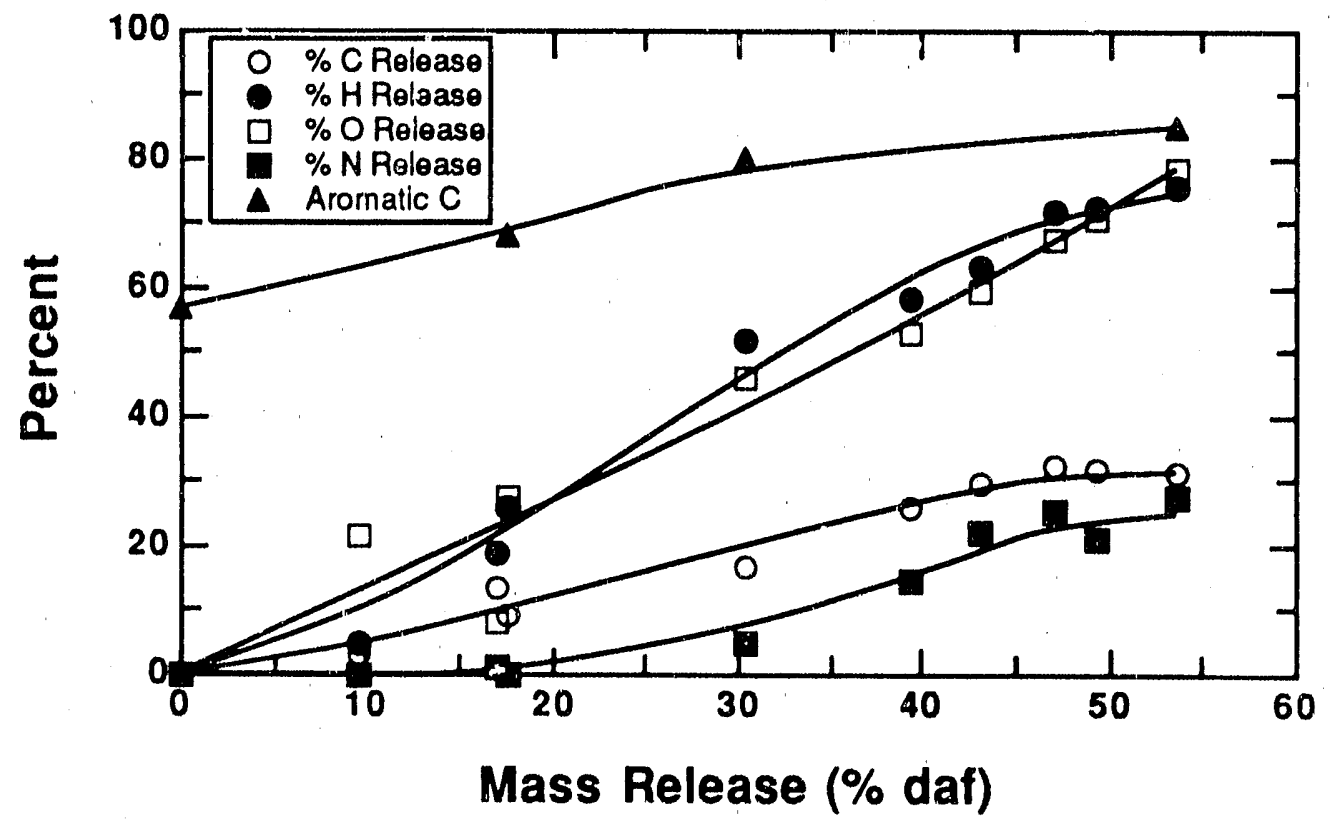

Figure 1.5 Fractional elemental mass release of $\mathrm{C}, \mathrm{H}, \mathrm{N}, \mathrm{O}$, and $\mathrm{S}$ relative to the total mass release during devolatilization for the Illinois No. 6 coal and Beulah Zap lignite. Carbon aromaticity is also shown. Solid lines represent curve fits to the data. 
The relationships between the fractional elemental miss release of $\mathrm{C}, \mathrm{H}, \mathrm{O}, \mathrm{N}$, and $\mathrm{S}$ relative to the total mass release for the Illinois No. 6 coal and the Zap lignite at the $1250 \mathrm{~K}$ gas temperature environment are shown in Fi; 1.5. The carbon aromaticities for the $1250 \mathrm{~K}$ samples are also included for comparison. For the Illinois No. 6 coal, hydrogen and oxygen are released at a higher rate than carbon in the early and intermediate stages of mass release $(0$ to $\sim 45 \%)$, corresponding to the release of light hydrocarbons, $\mathrm{CH}_{4}, \mathrm{H}_{2} \mathrm{O}$ and $\mathrm{CO}_{2}$ (Solomon, et al., 1990b) at the same time tar is released. The sulfur and nitrogen release also correspond to the carbon release, although there is some scatter due to the small s\&mples used for elemental analysis. During the late stages of mass release ( 45 to $51 \%$ ), corresponding primarily to release of side chains as light gases, the loss of carbon seems to reach a plateau at a value of $40 \%$, while rapid hydrogen and oxygeiı release continues. The increase in carbon aromaticity, rapid release of hydrogen and oxygen, and plateau in carbon release are indicative of dehydrogenation of aliphatic ring structures. Possible gases evolving from the char during the laier stages of devolatilization are $\mathrm{H}_{2}, \mathrm{CO}, \mathrm{CO}_{2}$, and $\mathrm{C}_{2} \mathrm{H}_{4}$ (Suuberg, et al., 1978).

For the lignite, the oxygen, carbon, and hydrogen release are comparable in the early stage of mass release $(0-10 \%)$, where light gases are evolved. A slight rise in hydrogen release is noted at approximately $15 \%$ mass release, which occurs at the point where tar release begins. The rates of oxygen and hydrogen release are consistently higher than the release rale of carbon through all stages of devolatilization. The carbon aromaticity increases rapidly in the early to mid-point ranges of the mass release and then begin to level off during the latter stage of pyrolysis. The elemental mass release and atomaticity data for the lignite in the latter stage of pyrolysis is associated with loss of peripheral oxygen containing groups on the aromatic cluster, as opposed to the apparent ring dehydrogenation noted in Illinois No. 6 coal. It appears that major changes in functional group distribution and restructuring of the aromatic rings occurs in the lignite at an earlier stage in the pyrolysis process than was noted for Illinois No. 6 coal.

Finally, while many of the initial structural parameters for the Zap lignite and the Illinois No. 6 coal are different, the data in Tables 1.2 and 1.3 indicate a similarity between the carbon skeletal structures of the pyrolysis chars that evolve from these two coals. For example, the total number of carbons per cluster and the estimated average cluster molecular weight for the samples of each coal at $223 \mathrm{~ms}$ are equivalent, even though the values for the parent coals are markedly different. This apparent similarity in chemical structure in the final chars, however, does not explain the large differences in char reactivity (to oxygen) observed in lignite and bituminous coals. These differences in char reactivity are most likely caused by differences in the internal surface areas and pore size distributions in the chars; based on the data reported here, reactivity differences due to chemical structure should be of secondary importance.

The proton spin relaxation time constant $T_{1} \rho^{H a r}$ is a complex function of the motion within the lattice and the effects of free electrons that are present. This parameter 
may therefore be related to the concentration of metaplast in the coal char. The value of $T_{1}$ Har in the rotating frame passes through a minimum in the chars and then rises to values similar to or higher than those observed in the parent coals. Similar behavior has been noted in other chars prepared at both rapid $\left(\sim 10^{4} \mathrm{~K} / \mathrm{sec}\right)$ and slow $(\sim 0.5 \mathrm{~K} / \mathrm{sec})$ heating conditions (Solum, et al., 1990). The relationship between $T_{1} \rho^{\text {Har }}$ and the free electrons present in coals and chars has been discussed by Jurkiewicz, et al. (1990); the variations in the value of $T_{1} \rho^{H a r}$ and the relationship the the amount of metaplast present in the char warrant further study.

\section{b. Evolution of Tar Structure}

The tars released from devolatilizing coals undergo further reaction if the gas temperature is high enough. Previously renorted ${ }^{1} \mathrm{H}$ NMR analyses of the Illinois No. 6 tars collected at the $1250 \mathrm{~K}$ ga's condition (Fletcher, et al,, 1990b) show that the chemical structure of these tars changes in the gas phase as a function of residence time in a region subsequent to significant tar release. The tars :ollected at the $1050 \mathrm{~K}$ gas condition exhibit less extreme changes in chemical structure. This section describes the results of both ${ }^{1} \mathrm{H}$ and ${ }^{13} \mathrm{C}$ NMR analysis of the tars from both the bituminous coal and the lignite, collected as a function of residence time in the two gas conditions.

Aromatic Structure. Perhaps the best indication of the extent of pyrolytic transformation of evolved tars is the changes in the carbon and hydrogen aromaticity. The carbon and hydrogen aromaticities of tars collected at the two gas temperature conditions, measured by standard ${ }^{13} \mathrm{C}$ and ${ }^{1} \mathrm{H}$ NMR spectroscopic techniques, are shown as a function of residence time in Figs. 1.6 and 1.7 for tars from the Illinois No. 6 coal and Zap lignite, respectively. The fraction of coal released as volatile material is also shown for reference. The data points shown in these figures at zero residence time correspond to the aromaticities derived from solid-state ${ }^{13} \mathrm{C} \mathrm{NMR}$ analyses of the parent coal. For the Illinois No. 6 tar samples at $1250 \mathrm{~K}$, the carbon aromaticity rises rapidly during the period of initial mass release and then continues to rise gradually to a final value of 0.97 . The hydrogen aromaticity of the tars follows a similar pattern to that of the carbon aromaticity values. This continual rise in the aromaticity of the tar is in dramatic contrast to that observed for the char residue, where the carbon aromaticity $\left(f_{a}{ }^{\prime}\right)$ remains largely unchanged until the last stages of pyrolysis. The carbon and hydrogen aromaticities of tars from long residence times in the $1050 \mathrm{~K}$ gas condition are considerably lower than those seen in the $1250 \mathrm{~K}$ gas condition. The hydrogen aromaticities actually double in tars at long residence times in the $1250 \mathrm{~K}$ gas condition. These data imply that gas phase secondary reactions occur in the evolved tars in the $1250 \mathrm{~K}$ gas environment but not in the $1050 \mathrm{~K}$ gas environment.

The final volatiles yields from the Zap lignite at the two temperatures are nearly identical (see Fig. 1.7), with a slower rate of mass release at the lower temperature (as was also noted for the Illinois No. 6 coal). At the lower temperature, both the hydrogen and carbon aromaticities rise gradually, while the aromaticity values for the 
a. $1250 \mathrm{~K}$ Gas Condition (Illinois No. 6 Coal)

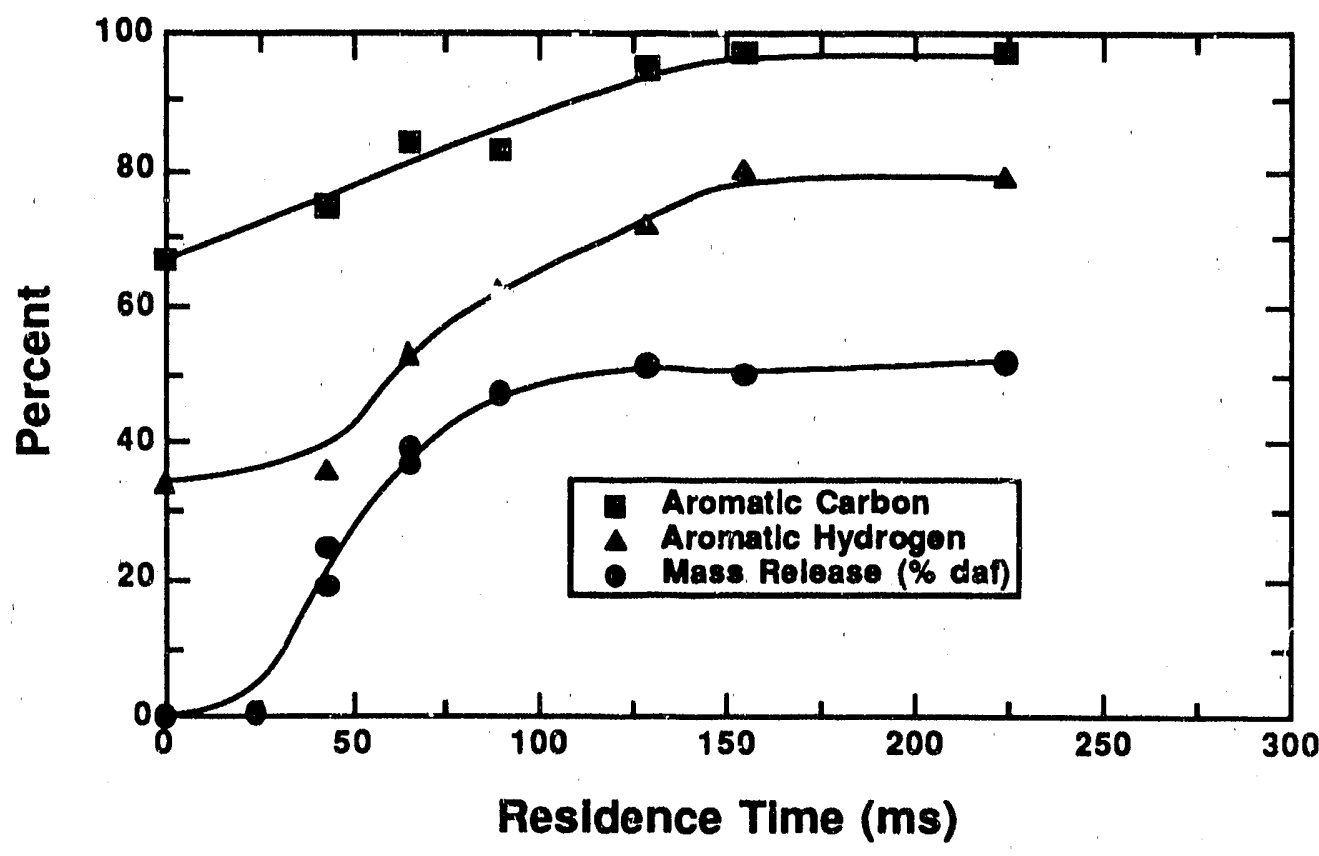

b. $1050 \mathrm{~K}$ Gas Condition (Illinois No. 6 Coal)

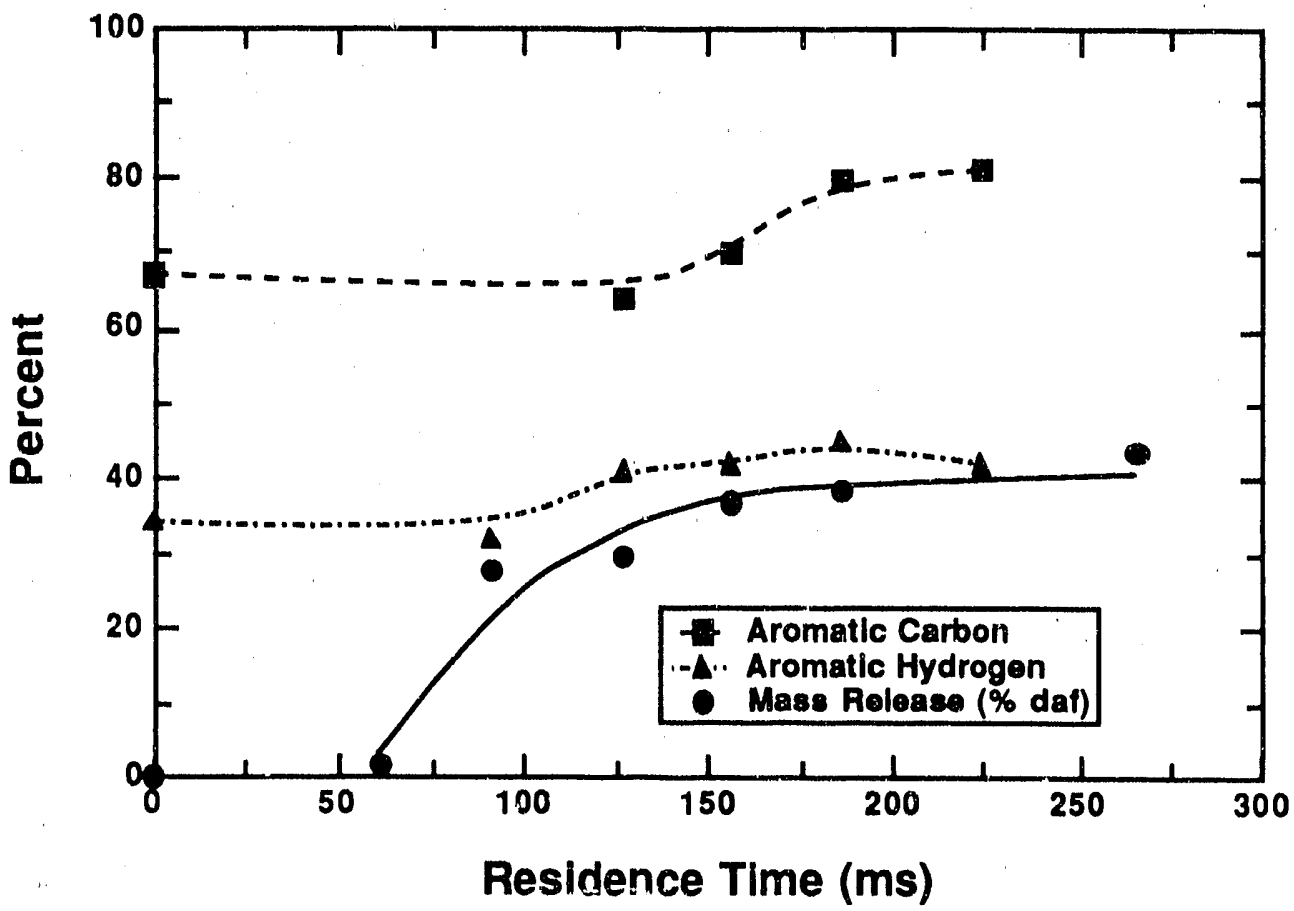

Figure 1.6 Percentages of hydrogen and carbon contained in aromatic groups in Illinois No. 6 coal tars vs. residence time in the $1250 \mathrm{~K}$ and $1050 \mathrm{~K}$ gas conditions. The hydrogen and carbon aromaticities at $0 \mathrm{~ms}$ are derived from NMR analyses of the parent coal. 
a. $1250 \mathrm{~K}$ Gas Condition (Beulah Zap Lignite)

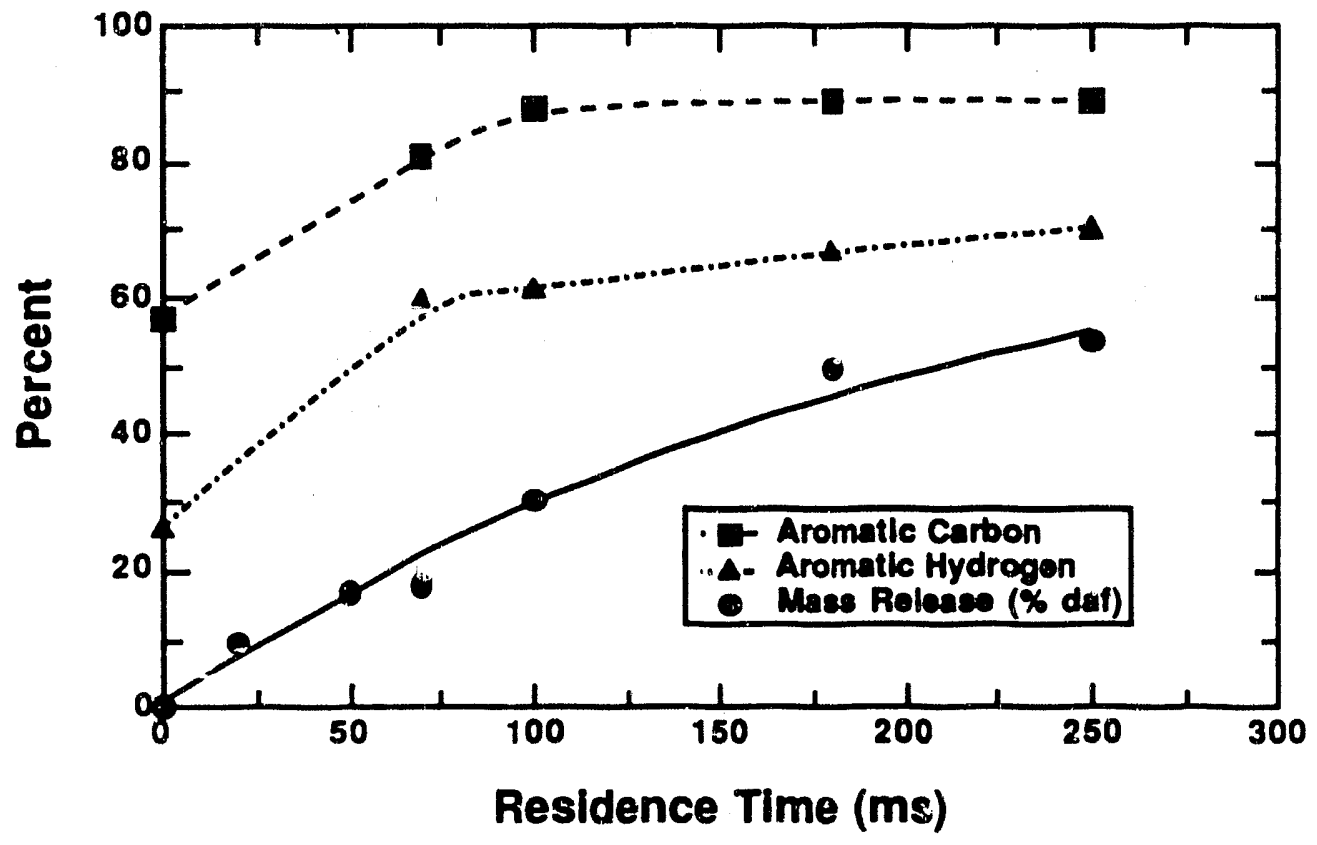

b. 1050 K Gas Condition (Beulah Zap Lignite)

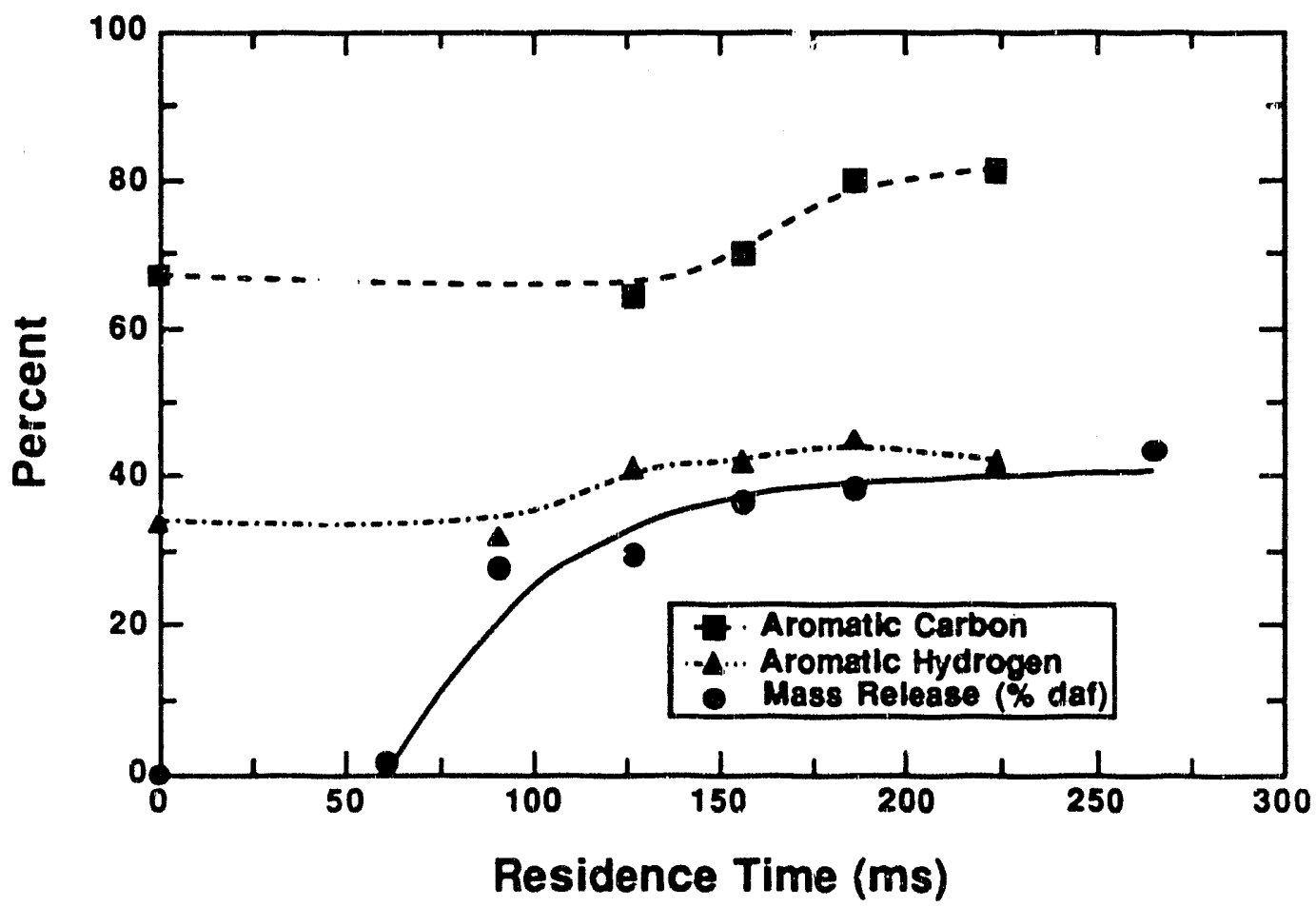

Figure 1.7 Percentages of hydrogen and carbon contained in aromatic groups in Beulah Zap lignite tars vs. residence time in the $1250 \mathrm{~K}$ and $1050 \mathrm{~K}$ gas conditions. The hydrogen and carbon aromaticities at $0 \mathrm{~ms}$ are derived from NMR analyses of the parent coal. 
high temperature experiments exhibit a rapid initial increase similar to that observed in the Illinois No. 6 tars. However, the final carbon and hydrogen aromaticity values of the lignite tars are approximately $10 \%$ (absolute scale) lower than those of the hituminous coal tars at both temperature conditions. 'This observation suggests that the fundamental differences in the structures of the parent coals are still manifest in the final pyrolysis products. Some of the differences between the components of these tars have been noted in the pyrolysis mass spectroscopy data of Lo et al. (1990), as presented in the previous quarterly report (Fletcher and Hardesty, 1990).

The percentage of hydrogen in the tar attached to 1-ring, 2-ring, and 3-ring or greater condensed aromatic species can be estimated from the ${ }^{1} \mathrm{H}$ NMR data, as shown in Figs. 1.8 and 1.9 for the tars collected at the two different gas temperature conditions. These data reveal some of the more subtle changes that occur in the tars in the gas phase. The percentage of hydrogen in aromatic structures with three or more rings increases in the Illinois No. 6 tars as a function of residence time at the $1250 \mathrm{~K}$ gas condition (Fig. 1.8), seemingly at the expense of the hydrogen in 1-ring aromatic structures, which decreases as a function of residence time. Tars collected at a residence time of $223 \mathrm{~ms}$ contain twice as much hydrogen in aromatic structures with three or more rings than the initial tars evolved during the $40-70 \mathrm{~ms}$ residence time period. The hydrogen in 2-ring aromatic structures also increases substantially at this temperature condition. In contrast, the data obtained from tars collected at the $1050 \mathrm{~K}$ gas condition, although somewhat scattered, do not show any such trend.

The hydrogen aromatic ring data (Fig. 1.9) for Zap exhibit patterns similar to those observed in the bituminous coal tars. However, the decrease in the concentration of one-ring aromatic compounds in tars collected from the lignite at long residencs times in the $1250 \mathrm{~K}$ gas condition is not quite as great as observed in the bituminous coal. However, the pyrolysis mass specuroscopy data for the lignite tars (Lo, et al., 1990; Fletcher and Hardesty, 1990) show decreases in 1-ring compounds and increases in multi-ring compounds as a function of residence time in the $1250 \mathrm{~K}$ gas condition. The implication is that gas phase secondary reactions of coal tar may be somewhat indeperident of coal type.

The evolution of condensed polynuclear aromatic species can occur by two different processes: 1) dehydrogenation reactions such as the conversion of tetralin type species to napthalenes, etc.; and 2) ring condensation reactions such as those associated with the formation of soot precursors where aliphatic side chains serve as sites for polymerization and subsequent dehydrogenation to form condensed polynuclear aromatic species.

Aliphatic structure. The aliphatic hydrogen attached to carbons at the $\alpha-, \beta-$, and $\gamma-$ positions (relative to an aromatic group as defined in Fig. 1.10) and measured by ${ }^{1} \mathrm{H}$ NMR was classified into methyl groups $\left(\mathrm{CH}_{3}\right)$ and the cumbination of $\mathrm{CH}$ and $\mathrm{CH}_{2}$ groups. For tars from the Illinois No. 6 coal in the $1250 \mathrm{~K}$ gas condition, the hydrogen in the $\beta$ - and $\gamma$-positions decreases from $19 \%$ to $4 \%$ during the period of mass release, 


\section{a. 12 's0 í Gas Condition (IIlinois No. 6 Coal)}

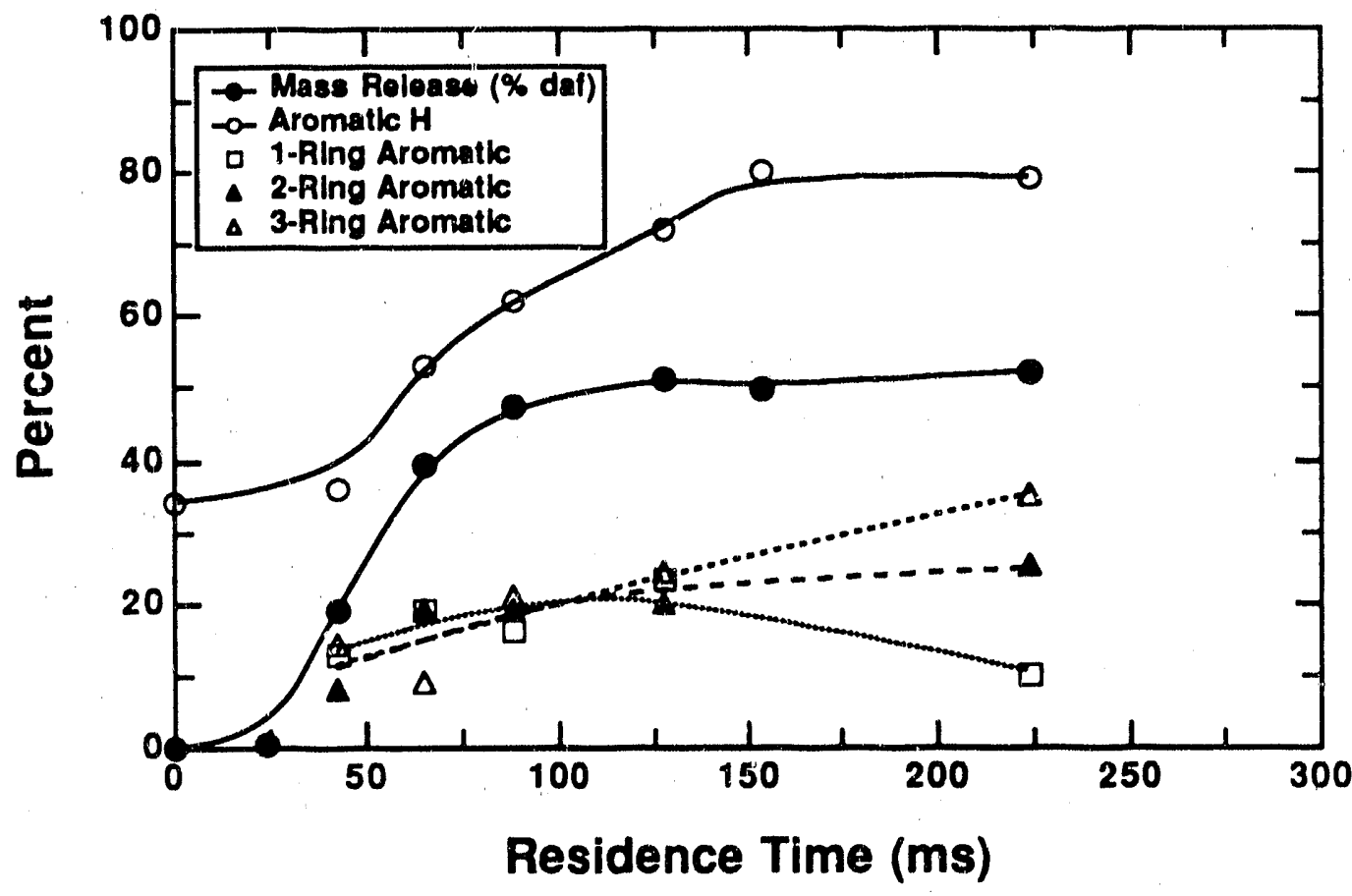

b. $1050 \mathrm{~K}$ Gas Condition (IIlinois No. 6 Coal)

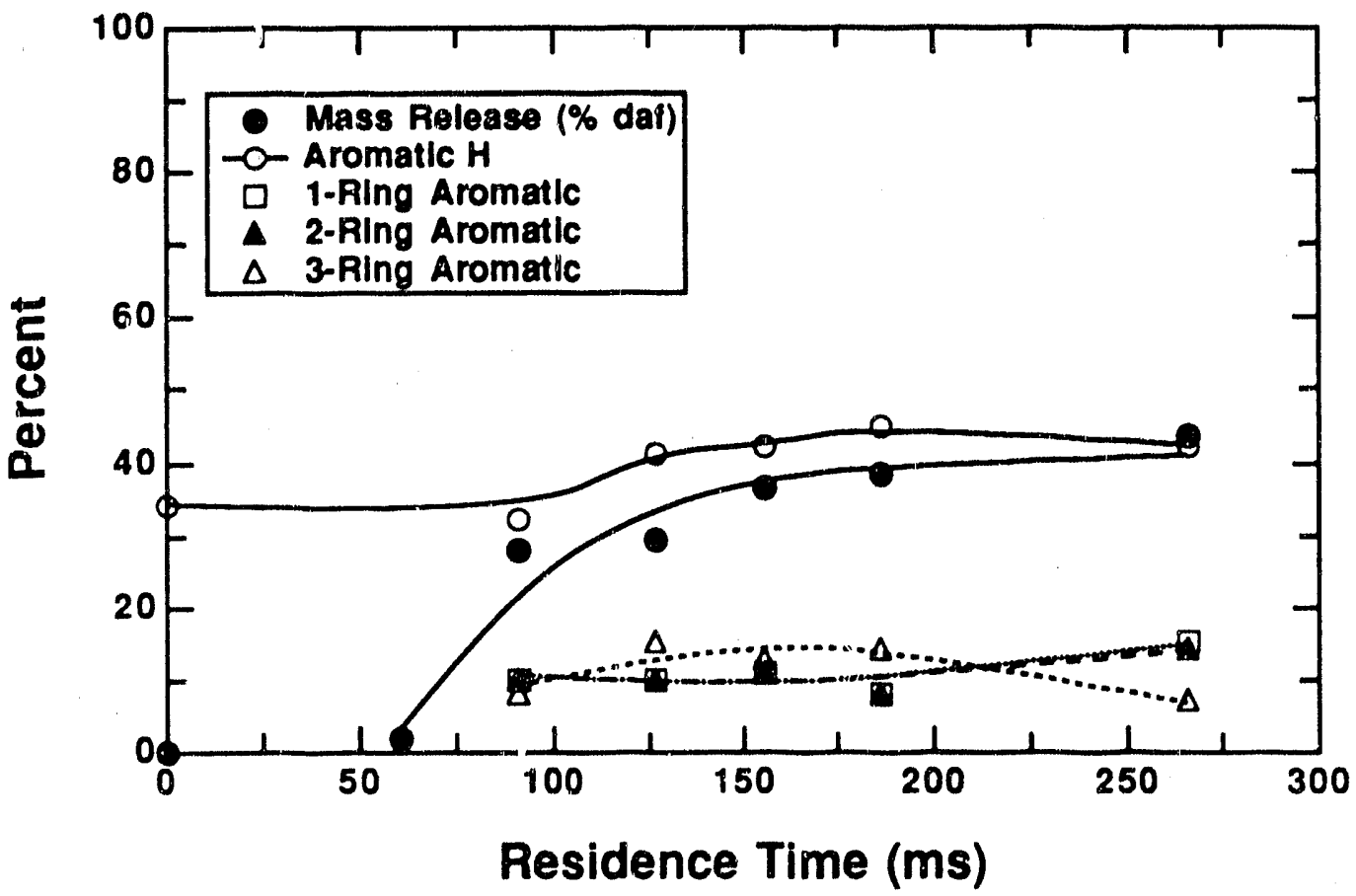

Figure 1.8 Percentage of hydrogen contained in aromatic structures in Illinois No. 6 coal tars consisting of one, two, and three or more rings vs. residence time in the $1250 \mathrm{~K}$ and $1050 \mathrm{~K}$ gas conditions. 


\section{a. 1250 K Gas Condition (Beulah Zap Lignite)}

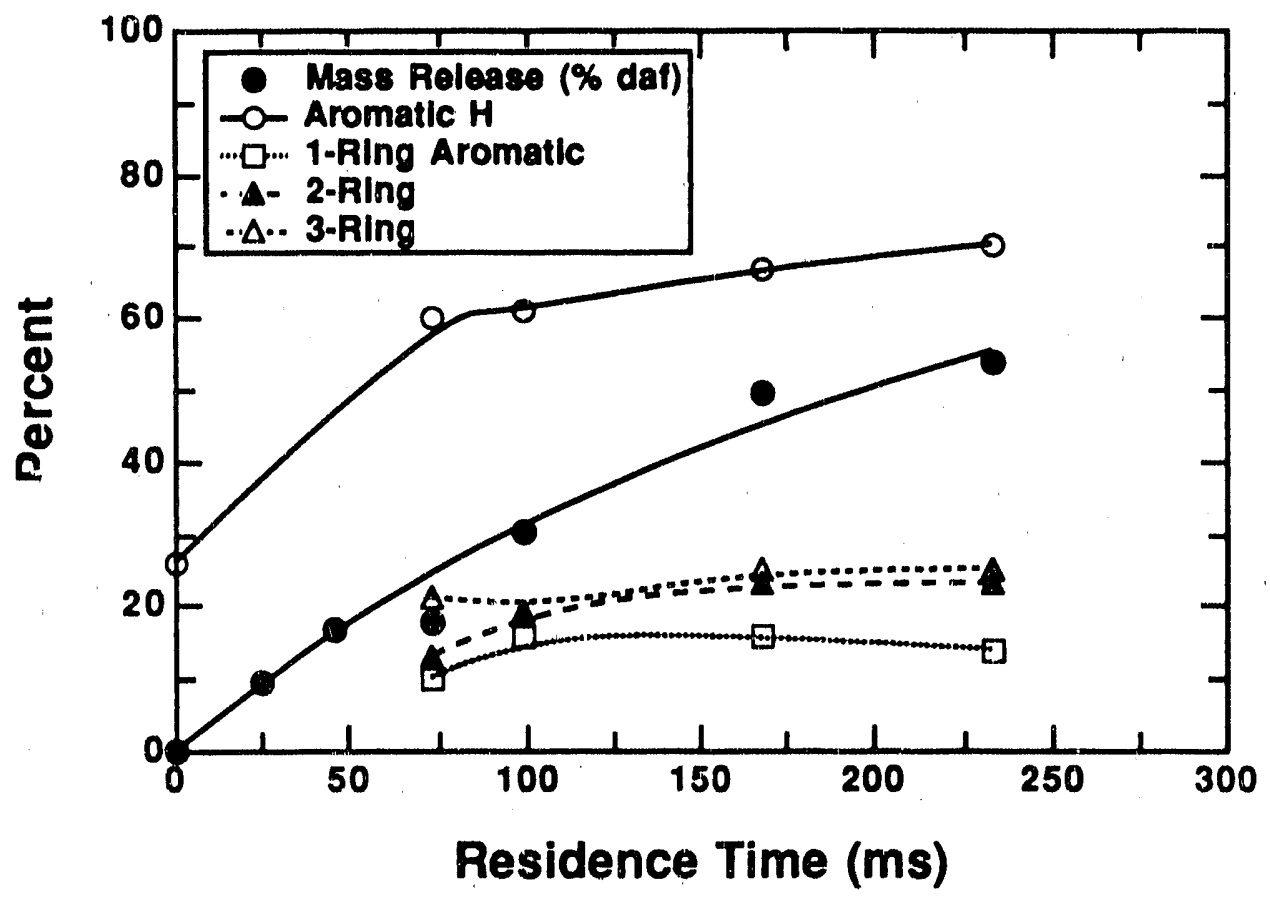

b. $1050 \mathrm{~K}$ Gas Condition (Beulah Zap Lignite)

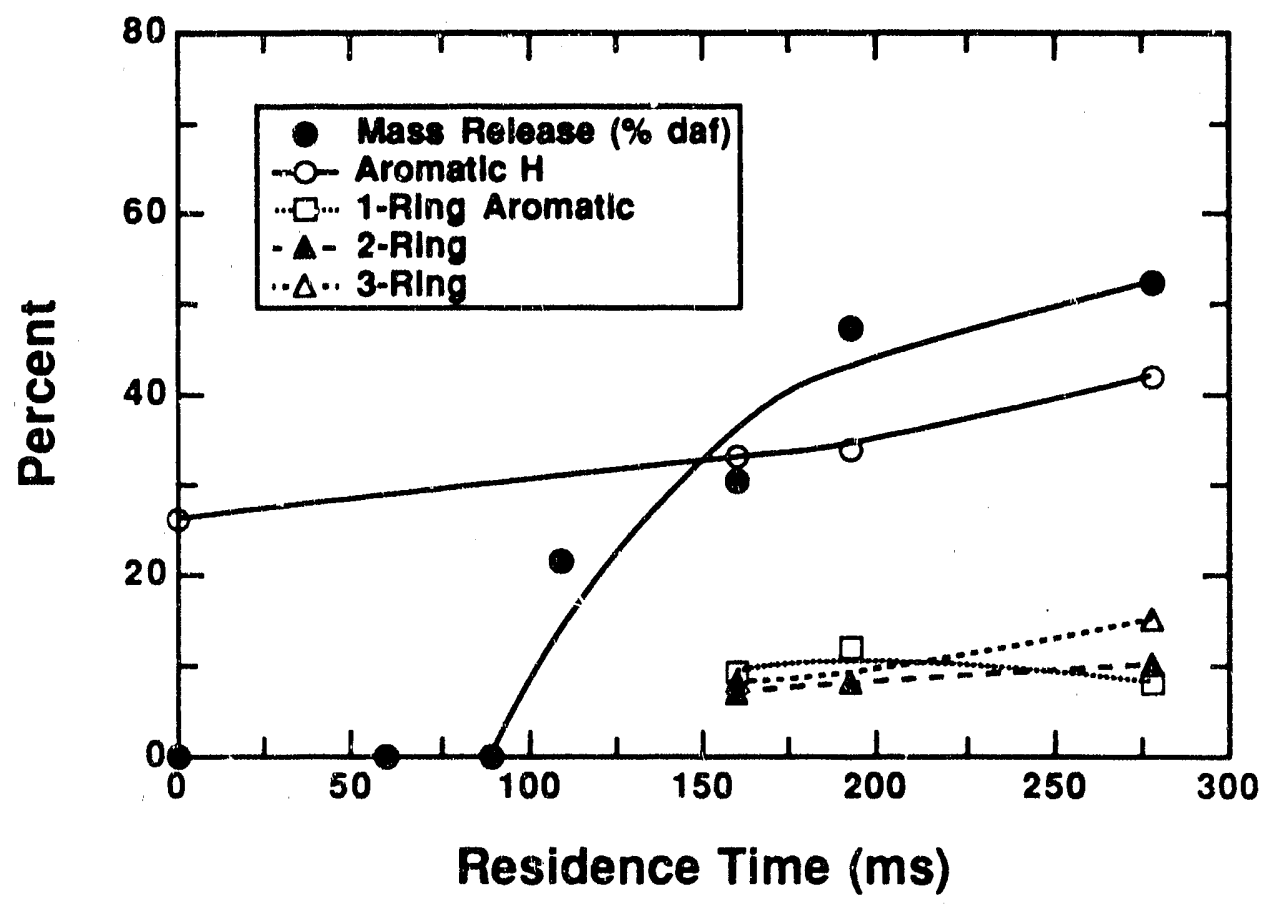

Figure 1.9 Percentage of hydrogen contained in aromatic structures in the tars from Beulah Zap lignite consisting of one, two, and three or more rings vs. residence time at the $1250 \mathrm{~K}$ and $1050 \mathrm{~K}$ gas conditions. 


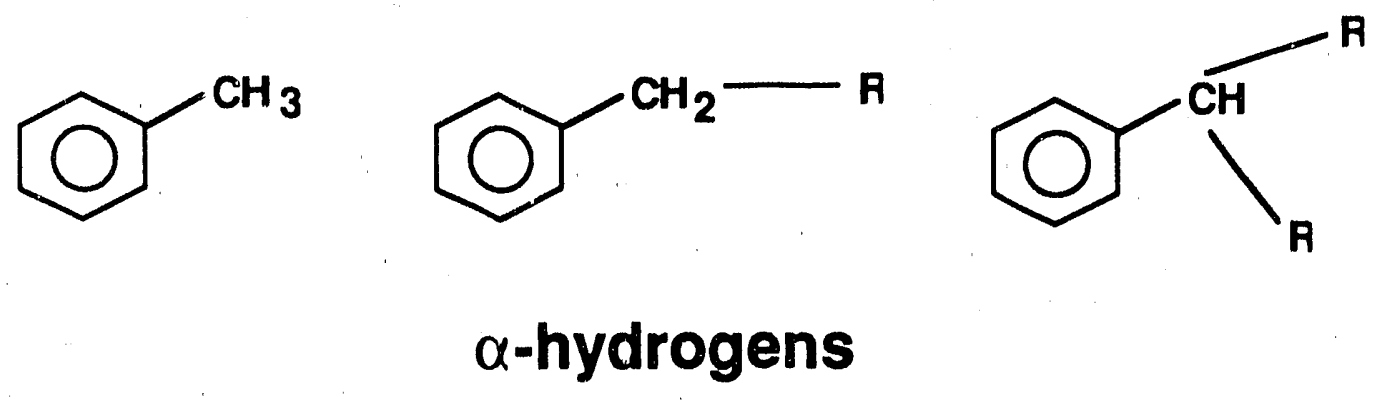

$\widehat{O} \mathrm{C}-\left(\mathrm{CH}_{2}\right) \mathrm{n}-\mathrm{P}-\mathrm{CH}_{3}$<smiles>CCCCc1ccccc1</smiles>

$\beta$ hydrogens

$\gamma$ hydrogens<smiles>[R]c1ccccc1</smiles>

1-Ring<smiles>[R]c1ccc2ccccc2c1</smiles>

2-Ring<smiles>[R]c1ccc2cc3ccccc3cc2c1</smiles>

3-Ring

Figure 1.10 Representative chemical structures detected by ${ }^{1} \mathrm{H}$ NMR spectroscopy. 


\section{a. 1250 K Gas Condition (IIlinois No. 6 Coal)}

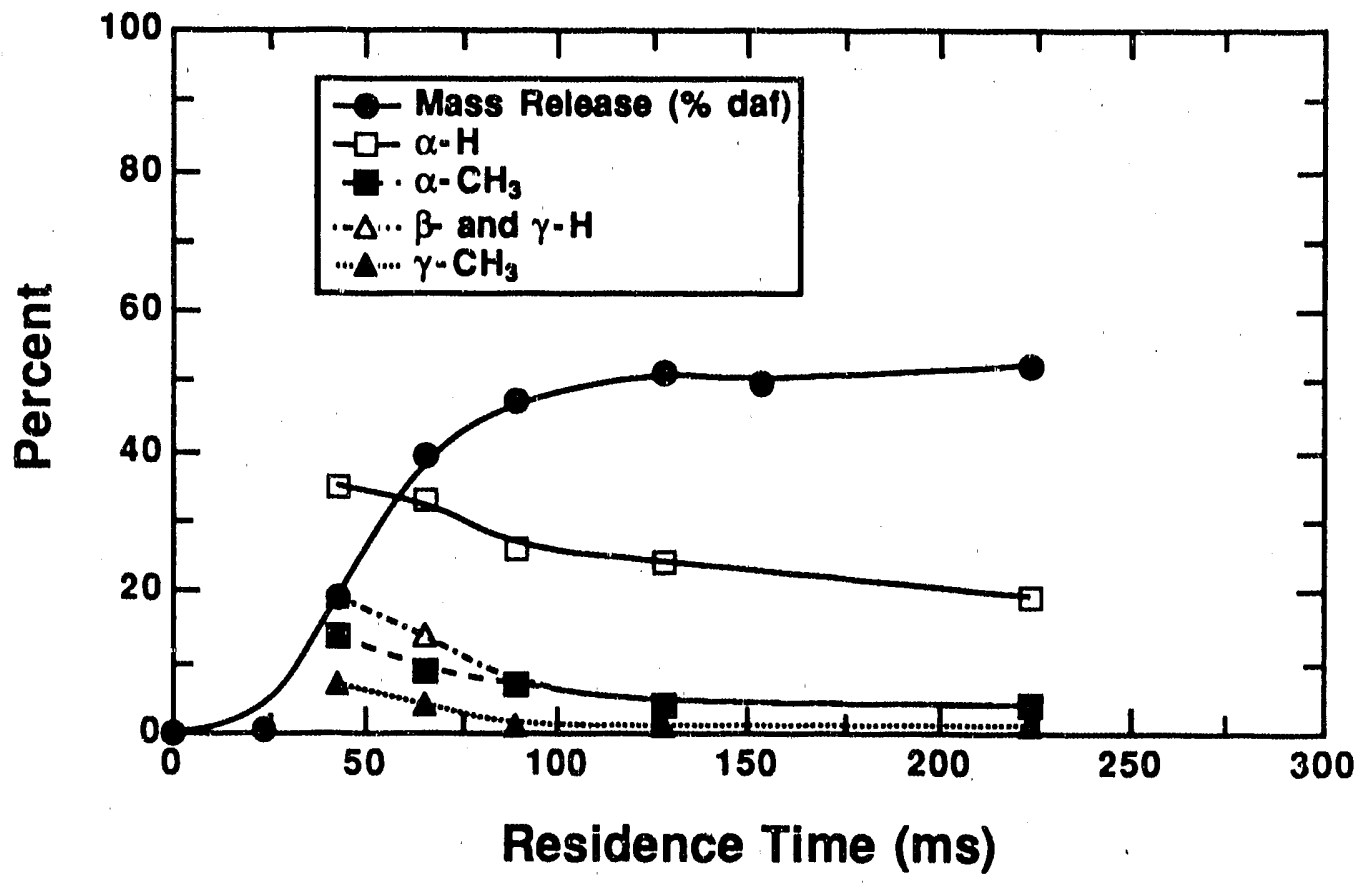

b. 1050 K Gas Condition (Illinois No. 6 Coal)

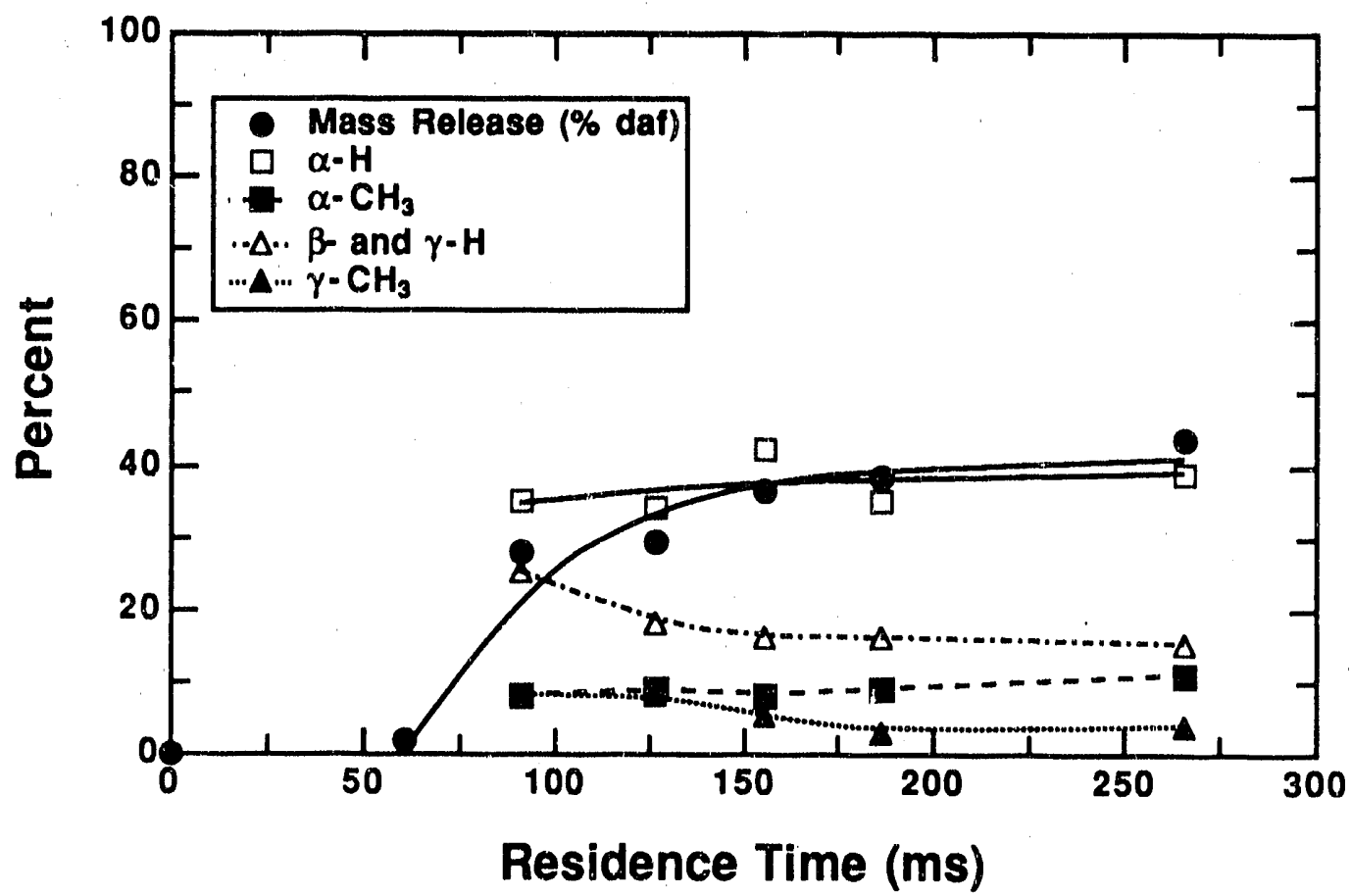

Figure 1.11 Percentage of hydrogen contained in aliphatic structures in Illinois No. 6 coal tars, with hydrogen in the $\alpha, \beta$, or $\gamma$ position relative to the aromatic ring, vs. residence time in the $1250 \mathrm{~K}$ and $1050 \mathrm{~K}$ gas conditions. 
as shown in Fig. 1.11a. These data indicate preferential release, at $1250 \mathrm{~K}$, of $\beta$ - and $\gamma$-hydrogen relative to $\alpha$-hydrogen, and suggest that $\mathrm{CH}_{3}$ or remote $\mathrm{CH}$ and $\mathrm{CH}_{2}$ groups are released preferentially to the $\alpha-\mathrm{CH}$ and $\mathrm{CH}_{2}$ groups. The release of aliphatic chain ends is more energetically favored than breakage of fairly stable aliphatic bridges and loops between aromatic structures. The number of hydrogens associated with $\gamma-\mathrm{CH}_{3}$ groups decreases quite rapidly in the gas phase to only approximately $1 \%$ of the total hydrogen present in the tar. The decrease in $\alpha$-methyl hydrogen concentration by a factor of four indicates a low concentration of methyl groups attached to aromatic rings at the final stage of pyrolysis. On the other hand, the total hydrogen present at the $\alpha$-position only drops approximately $50 \%$ and a relatively large fraction of the total protons observed in the final tar are present on functional groups (i.e., $\mathrm{CH}, \mathrm{CH}_{2}$ and $\mathrm{CH}_{3}$ ) adjacent to the aromatic rings. The low concentration of $\alpha-\mathrm{CH}_{3}$ and $\beta$ - and $\gamma$-groups requires the presence of three- to fourfold more $\mathrm{CH}$ and $\mathrm{CH}_{2}$ groups than methyl groups at the $\alpha$-position. The $\mathrm{CH}$ and $\mathrm{CH}_{2}$ groups are probably present in the form of bridges between aromatic rings or loops (hydroaromatic structures). These data are consistent with the processes associated with formation of condensed polynuclear aromatic species discussed previously.

The bituminous coal tars from the $1050 \mathrm{~K}$ gas condition exhibit different behavior as a function of residence time than the tars from the $1250 \mathrm{~K}$ condition. The concentration of $\beta$ - and $\gamma$-hydrogens decrease by only $50 \%$ in the gas phase. The concentration of $\gamma-\mathrm{CH}_{3}$ groups drops by a factor of two, but the amount of $\alpha-\mathrm{CH}_{3}$ groups present actually increases slightly. This observation, together with the overall increase in $\alpha$-hydrogen, indicates that the cracking of $\beta$ - and $\gamma$-groups from the aromatic rings leaves an increasing amount of $\alpha-\mathrm{CH}_{3}$ groups intact. Furthermore the overall increase in $\alpha$-hydrogen demonstrates that structures such as ethylene bridges and loops (two $\alpha$-carbons per bridge) are not substantially disrupted in the gas phase reactions at $1050 \mathrm{~K}$.

In the Zap lignite tars obtained at $1250 \mathrm{~K}$, the relative percentage of $\alpha-\mathrm{CH}_{3}, \beta$ - and $\gamma$ hydrogen, and $\gamma-\mathrm{CH}_{3}$ are comparable to those observed in Illinois No. 6 coal tars at equivalent residence times (see Fig. 1.12). However, a net decrease is not observed in the relative amount of $\alpha$-hydrogen present. Hence, the substantial mass release that occurs following the initial release of tar appears to be rich in $\mathrm{CH}$ and/or $\mathrm{CH}_{2}$ groups present as ethylene bridges or in hydroaromatic species. In the tars obtained at $1050 \mathrm{~K}$, the $\beta$ - and $\gamma$-hydrogen content decreases by nearly $40 \%$ while the $\gamma$ - $\mathrm{CH}_{3}$ and $\alpha-\mathrm{CH}_{3}$ groups are essentially invariant. Furthermore, the $\alpha$-hydrogen containing groups increase slightly. The loss of material associated with relatively long chain functional groups (i.e., chains with three or more carbons) without a concomitant loss of $\gamma-\mathrm{CH}_{3}, \alpha-\mathrm{CH}_{3}$, and $\alpha$-hydrogens suggests the differential loss of substances such as paraffins and/or biomarkers that are released at the lower temperature (Meuzelaar, et al., 1989; Yun, et al., 1989) whereas, at higher temperatures, they may become incorporated into the metaplast before the material can be released into the gas phase. Similar experiments carried out at intermediate temperatures (e.g., $1150 \mathrm{~K}$ ) are $\mathrm{p}$ nned in the future and may shed some light on these observations. 


\section{a. $1250 \mathrm{~K}$ Gas Condition (Beulah Zap Lignite)}
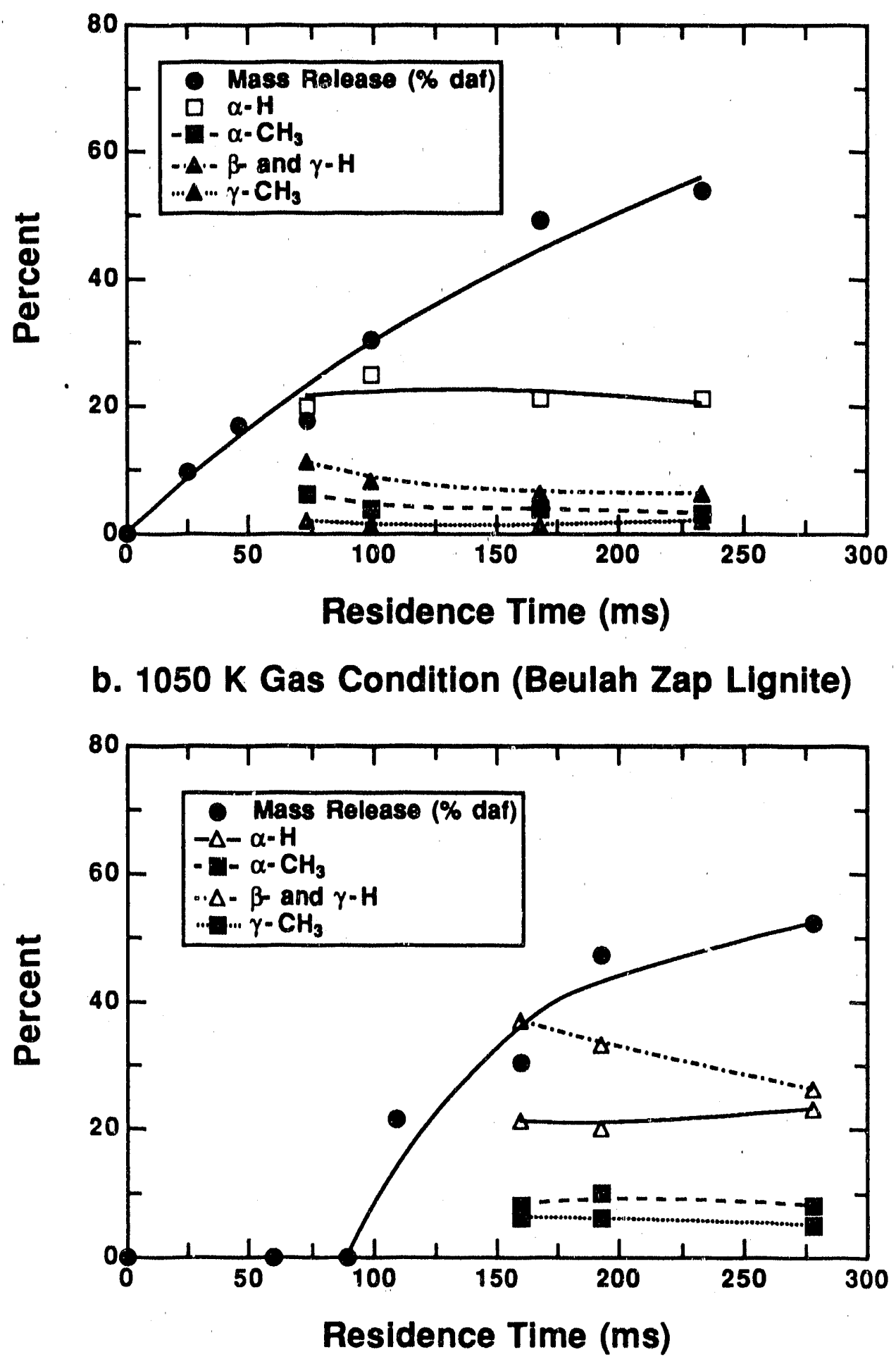

Figure 1.12 Percentage of hydrogen contained in aliphatic structures in Beulah Zap lignite tars, with hydrogen in the $\alpha, \beta$, or $\gamma$ position relative to the aromatic ring, vs. residence time in the $1250 \mathrm{~K}$ and $1050 \mathrm{~K}$ gas conditions. 


\section{Conclusions}

\section{a. Char Structure}

Based on the NMR analysis of the chars formed during devolatilization (at the $1250 \mathrm{~K}$ gas condition) from Illinois No. 6 coal and Zap lignite, the following conclusions are reached:

1) NMR data can be used to track lattice parameters associated with average cluster size and cross linking reactions. Under rapid heating conditions the NMR data demonstrates that the Zap lignite undergoes early cross linking behavior, while Illinois No. 6 coal exhibits a slower overall rate of cross linking.

2) Under rapid heating conditions $\left(10^{4} \mathrm{~K} / \mathrm{sec}\right)$, the data exhibit: a) little evidence of cluster size growth in the macromolecular structure; b) crosslinking at the same time that aliphatic carbons are released; c) little evidence for graphitization under the temperature and residence time conditions of these experiments.

3) In the Illinois No. 6 coal, most of the mass release has occurred before significant changes in carbon aromaticity has occurred. In chars from Zap lignite, the changes in carbon aromaticity occur much earlier than for the bituminous coal.

4) The carbon skeletal structure of the final chars from the bituminous coal and lignite are quite similar, even though the structures of the initial coals are quite different.

\section{b. Tar Structure}

Based on the ${ }^{1} \mathrm{H}$ and ${ }^{13} \mathrm{C}$ NMR analysis of the $1250 \mathrm{~K}$ and $1050 \mathrm{~K}$ tars from Illinois No. 6 coal and Zap lignite, the following conclusions are reached:

1) The pyrolysis temperature has a major effect on the tar structure. The proton and carbon aromaticities of the Zap and Illinois No. 6 tars are different for samples collectec' at comparable extents of mass release at the two gas temperatures.

2) The carbon aromaticity of the Illinois No. 6 tars at $1250 \mathrm{~K}$ are higher than the values for the corresponding chars collected at the same residence time. On the other hand, the carbon aromaticities found in the Zap lignite tars are comparable to those observed in the chars.

3) The proton NMR data suggest that in the $1250 \mathrm{~K}$ gas condition, hydrogens associated with 2- and 3-ring aromatic compounds increase, while that of 1-ring compounds decrease for the Illinois No. 6 tars. Similar but less compelling evidence is noted for the Zap tars. These data may suggest the conversion of hydroaromatic species to condensed polynuclear aromatic species and/or ring polymerization. 
4) The $\alpha$-hydrogen content is lower in the Zap tars than that found in Illinois No. 6 tars. The $\alpha$-hydrogen in Illinois No. 6 tars decreases with residence time at the $1250 \mathrm{~K}$ condition but not at the $1050 \mathrm{~K}$ condition. This observation suggests that relatively stable $\mathrm{CH}$ and/or $\mathrm{CH}_{2}$ bridges exist at the $1050 \mathrm{~K}$ gas condition. However, at $1250 \mathrm{~K}$ substantial bond rupture may be occurring.

5) The $\alpha$-methyl groups are released early in both coals at $1250 \mathrm{~K}$ but do not vary significantly at $1050 \mathrm{~K}$.

6) The $\gamma$-methyl groups in both tars are the most susceptible to cracking reactions in the gas phase, but the extent of release of the $\beta$ - and $\gamma$-hydrogens is based on gas temperature conditions and residence time.

The NMR data presented here for char and tar samples from the CDL have led to greater understanding of the pyrolysis process. The chemical percolation devolatilization (CPD) model (Grant, et al., 1989; Fletcher, et al, 1990a; Fletcher and Hardesty, 1990) currently uses such information on the chemical structure of coal as input parameters. Additional comparisons of CPD model predictions and the NMR data presented here will be performed during the next quarter. 


\section{Subtask 1.3 Transition from Coal Devolatilization to Char Combustion}

Char and tar/soot samples from the pyrolysis experiments performed in the Coal Combustion Laboratory (CCL) during the last quarter were sent to the NMR Laboratory at the University of Utah. In particular, the char and tar/soot samples obtained in the CCL for five different coals (PSOC-1445D, 1451D, 1493D, 1507D, and $1508 \mathrm{D}$ ) in the $0 \%$ post-flarne oxygen condition will be analyzed by NMR spectroscopy. The characterization of the chemical structure of these chars will help determine the extent of graphitization occurring at increased particle temperatures as a function of coal type. The data on the high temperature chars will also help determine the feasibility and usefulness of NMR characterizations $c^{\circ}$ samples from other char combustion experiments in the CCL.

\section{PLANS FOR NEXT QUARTER}

Additional char and tar samples from different coals and different reactor conditions are currently being analyzed by NMR spectroscopy and GC/MS techniques. Analyses of char samples obtained in the Coal Devolatilization Laboratory from PSOC-1508D (Pocahontas lv bituminous coal) are currently in progress. It is anticipated that samples of the chars from five coals sampled in the Coal Combustion Laboratory (CCL) in the $0 \%$ post-flame oxygen condition will also be analyzed during the next quarter. The flash distillation model and crosslinking models have already been incorporated into the Chemical Percolation Devolatilization (CPD) model. Improvements to the CPD model will be made during the next quarter, including a description of the selection of chemical structure parameters and comparison with available NMR data on the chemical structure of coal chars.

\section{ACKNOWLEDGMENTS}

The NMR measurements were performed by Mark Solum at the University of Utah and by Scott Critchfield at Brigham Young University, in collaboration with Professors Ronald Pugmire and David Grant. Their work was supported through the Advanced Combustion Engineering Research Center at Brigham Young University and the University of Utah which is supported by the NSF, 23 industrial firms and DOE/PETC. Additional support was provided through the Consortium for Fossil Fuel Liquefaction Science by DOE/PETC. 


\section{REFERENCES FOR TASK 1 SECTION}

Alemany. L. B., Grant, D. M., Alger, T. D., and Pugmire, R. J., J. Am. Chem. Soc., 105, 6697 (1983).

Fletcher, T. H., Comb. Sci. \& Tech., 63, 89 (1989a).

Fletcher, T., H., Comb. \& Flame, 78, 223 (1989b).

Fletcher, T. H. and Hardesty, D. R., "Coal Combustion Science: Task 1, Coal Devolatilization," DOE/PETC Quarterly Progress Report for April to June, 1990, edited by D. R. Hardesty, Sandia Report No. SAND90-8245, available NTIS (1990).

Fletcher, T. H., Kerstein, A. R., Pugmire, R. J., and Grant, D. M., Energy \& Fuels, 4, 54 (1990a).

Fletcher, T. H., Solum, M. S., Grant, D. M., Critchfield, S. and Pugmire, R. J., 23rd Symp. (Int.) on Comb., (in press, 1990b).

Grant, D. M., Pugmire, R. J., Fletcher, T. H., and Kerstein, A. R., Energy \& Fuels, 3, 175 (1989).

Jurkiewicz, A., Wind, R. A., Neevel, G. E., Fuel, 69, 830 (1990).

Ko, G. H., Sanchez, D. M., Peters, W. A., and Howard, J. A., 22nd Symp. (Int) on Comb., The Combustion Institute, 115, (1988).

Lo, R., Pugmire, R. J., Fletcher, T. H., and Meuzelaar, H. L. C, ACS Div. of Fuel Chem. Preprints, 35:3 697 (1990).

Meuzelaar, H. L. C., Yun, Y., Simmleit, N., and Schulten, H. R., ACS Div. of Fuel Chem. Preprints, 34:3, 693 (1989).

Müller, L., Kumar, A., Baumann, T. and Ernst, R. R., Phys. Rev. Lett., 32, 1402 (1974).

Niksa, S. and Kerstein, A. R., Comb. \& Flame, 66, 95 (1986).

Oh. M. S., Peters, W. A., and Howard, J. B., AIChE Journal, 35:5, 775 (1989)

Orendt, A. M., Solum, M. S., Sethi, N. K., Hughes, C. D., Pugmire, R. J., and Grant, D. M., "13C NMR Techniques for Structural Studies of Coal and Coal Chars," in Advances in Coal Spectroscopy, H. L. C. Meuzelaar, Ed., Plenum Press, (in press, 1990). 
Serio, M. A., Hamblen, D. G., Markham, J. R., and Solomon, P. R., Energy \& Fuels, 1, 138 (1987).

Sethi, N. K., Pugmire, R. J., Facelli, J. C., and Grant, D. M., Anal. Chem., 60, 1574 (1988).

Soderquist, A., Burton, D. J., Pugmire, R. J., Beeler, A. J., Grant, D. M., Durand, B., and Huk, A. Y., Energy \& Fuels, 1, 50 (1987).

Solomon, P. R., Serio, M. A., Carangelo, R. M., and Markham, J. R., Fuel, 65, 182 (1986).

Solomon, P. R., Hamblen, D. G., Carangelo, R. M., Serio, M. A., and Deshpande, G. V., Energy \& Fuels, 2, 405 (1988).

Solomon, P. R., Serio, M. A., Despande, G. V., and Kroo, E., Energy \& Fuels, 4, 42 (1990a).

Somon, P. R., Serio, M. A., Carangelo, R. M., Bassilakis, R., Gravel, D., Baillargeon, M., Baudais, F., and Vail, G., Energy \& Fuels, 4, 319 (1990b)

Solum, M. S., Pugmire, R. J., and Grant, D. M., Energy \& Fuels, 3, 187 (1989).

Solum, M. S., Gan, Z., Pugmire, R. J., Grant, D. M., and Solomon, P. R., (manuscript in preparation, 1990).

Suuberg, E. M., Peters, W. A., and Howard, J. B., 17th Symp. (Int.) on Comb., The Combustion Institute, 117 (1978).

Vassalo, A. M., Wilson, M. A., Vollin, P., Oades, J. M., Waters, A. G., and Malcolm, R. L., Anal. Chem., 59, 558 (1987).

Wu, X, Zhong, S., and Wu, X., Phys. Rev. B., 37, 9827 (1988).

Yun, Y., Maswadeh, W., Meuzelaar, H. L. C., Simmleit, N., and Schulten, H. R., ACS Div. of Fuel Chem. Preprints, 34:4, 1308 (1989). 


\section{PUBLICATIONS, PAPERS, AND PRESENTATIONS FOR TASK 1}

Fletcher, T. H., Solum, M. S., Grant, D. M., Critchfield, S., and Pugmire, R. J., "SolidState ${ }^{13} \mathrm{C}$ and ${ }^{1} \mathrm{H}$ NMR Studies of the Evolution of the Chemical Structure of Coal Char and Tar During Devolatilization," Twenty-Third Symposium (International) on Combustion (1990).

Pugmire, R. J., Fletcher, T. H., Solum, M. S., Critchfield, S., and Grant, D. M., "Structural Evolution of Matched Tar/Char Pairs in Rapid Pyrolysis Experiments," presented at the poster session for the Twenty-Third Symposium (International) on Combustion, Orléans, France (July 22-27, 1990).

Lo, R., Pugmire, R. J., Fletcher, T. H., and Meuzelaar, H. L. C., "Mass Spectrometric Studies of the Chemical Composition of Coal Tars Produced in a Laminar Flow Reactor," prepr. ACS Div. of Fuel Chem., 35(3), 697 (1990).

Pugmire, R. J., Solum, M. S., Grant, D. M., Critchfield, S., and Fletcher, T. H., "Structural Evolution of Matched Tar/Char Pairs in Rapid Pyrolysis Experiments," presented at the International Conference on Coal Structure and Reactivity, Queens College, Cambridge, UK (September 5-7, 1990); accepted for publication in Fuel (1990).

Baxter, L. L., Mitchell, R. E., and Fletcher., T. H., "Experimental Determination of Mineral Matter Release During Coal Devolatilization,". proceedings of the Seventh Annual International Pittsburgh Coal Conference, Pittsburgh, Pennsylvania, p. 62 (1990).

Solomon, P. R., Fletcher, T. H., and Pugmire, R. J., "Progress in Coal Pyrolysis," proceedings of the Seventh Annual International Pittsburgh Coal Conference, Pittsburgh, Pennsylvania, p. 3 (1990).

Fletcher, T. H., "Rates and Mechanisms of Pulverized Coal Devolatilization at Rapid Heating Rates," presented at the DOE/PETC Advanced Research and Technology Development, Direct Utilization and Instrumentation and Diagnostics Contractors' Review Meeting, Pittsburgh, Pennsylvania (September 16-18, 1990). 


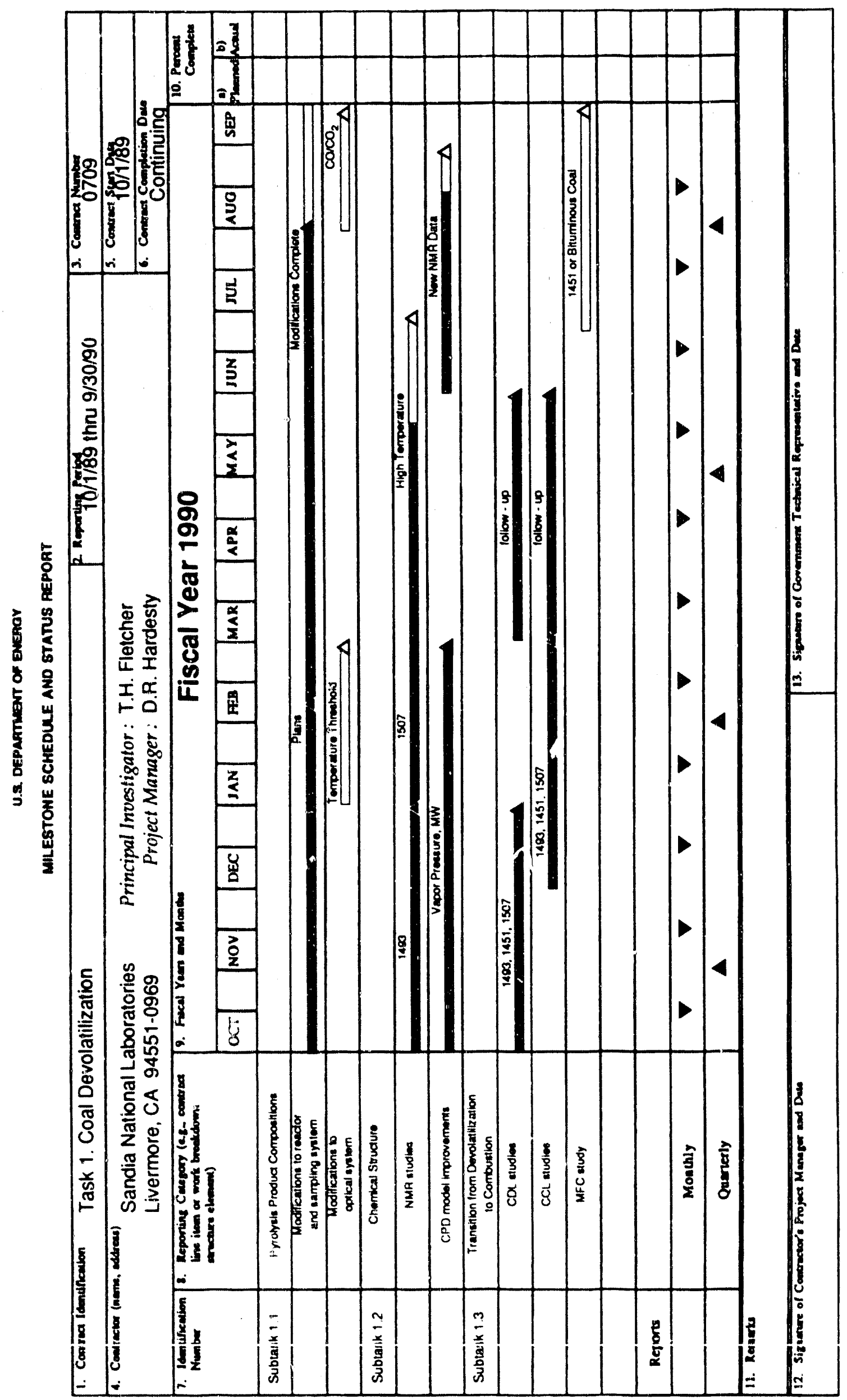


PROJECT 'TITLE:

ORGANIZATION:

CONTRACT NC .

REPORTING PERIOD: July 1 - September 30, 1990

REPORTED BY:

FTPA 0709
COAL COMBUSTION SCIENCE

TASK 2: THE RATES AND MECHANISMS OF COAL CHAR COMBUSTION

\author{
Sandia National Laboratories, Livermore
}

\author{
R. E. MITCHELL and D. R. HARDESTY
}

Phone: FTS 234-2449 and 234-2321

\section{OBJECTIVE FOR TASK 2}

The objective of this study is to characterize the physical and chemical processes involved during coal char combustion as a function of coal type, particle size and temperature, and gas temperature and composition. The experimental endeavor provides the data required to develop a predictive model of the char combustion process. Specific objectives are being met by conducting basic research in three subtask areas as follows:

\section{Subtask 2.1 Determination of Apparent Char Particle Burning Rates}

The apparent, or overall char-particle burning rate, $q$, can be expressed as:

$$
q=k_{s} P_{s}^{n}
$$

where $k_{s}$ is the apparent surface chemical reaction rate coefficient and $n$ is the apparent reaction order with respect to the oxygen partial pressure at the particle surface, $P_{s}$. The goal of this subtask is to determine the apparent reaction order and the Arrhenius parameters that describe $k_{s}$ for the chars of selected U. S. coals. In situ measurements of the sizes, temperatures, and velocities of individual particles and off-line analyses for apparent densities and relative mass losses of partially reacted char samples extracted from controlled gaseous environments are used to meet this objective. An adsorption-desorption kinetic mechanism will also be considered in the analysis of the data. Such a mechanism has a more fundamental basis than the $\mathrm{n}$-th order power-law expression given above and will allow accurate predictive capability over a wider range of combustion conditions than is possible with the power-law expression.

In addition, included in this subtask are experiments to investigate char formation effects on reactivity and the reactivity of chars near burnout. 


\section{Subtask 2.2 Determination of the Intrinsic Chemical Reactivity of Chars}

The intrinsic reactivity, $q_{i}$, can be expressed as:

$$
q_{i}=\eta k_{s, i} C_{s}^{m}
$$

where $\eta$ is the effectiveness factor, $k_{s, i}$ is the intrinsic chemical reaction rate constant, and $m$ is the true reaction order with respect to the oxygen concentration at the particle surface, $C_{s}$. The objective of this subtask is to determine the true reaction order and the Arrhenius rate parameters that describe $k_{s, i}$. Analyses of partially reacted coal chars for specific surface areas, apparent densities, and porosities are required. Combined with size, temperature, and mass loss measurements, these properties allow the evaluation of the effectiveness factor, the true reaction order, and the Arrhenius rate parameters for $k_{s, i}$. Efforts in this subtask also include the development of an adequate rate expression and evaluation of rate constants for the intrinsic chemical reactivity when an adsorption-desorption reaction mechanism is employed.

Also included in this subtask is the investigation of the relation between chemical structure and reactivity for coal chars.

\section{Subtask 2.3 Determination of Nitrogen and Sulfur Release Rates}

The rates at which nitrogen and sulfur are released during char oxidation as a function of coal type will be determined. This requires determination of the elemental compositions of partially reacted coal chars. The sulfur release rates will be considered with reference to the forms of sulfur encountered in the parent coals.

The results of this project will provide a data base on the reactivities of the chars of selected U. S. coals and on the release rates of $\mathbb{N}$ and $S$ from the char under typical pulverized-coal combustor conditions. The char oxidation models developed during the course of this investigation will be concise enough for use in coal flame simulation codes. The models will allow the accurate prediction of particle size, temperature, and mass during the char oxidation process.

\section{SUMMARY OF TECHNICAL PROGRESS DURING THIS QUARTER}

During this quarter, the analysis of the combustion data obtained with Blue \#1 coal (PSOC-1445D) was continued. Kinetic parameters that describe the apparent char particle burning rates were determined by combining the in situ size, temperature, and velocity measurements and the $m / m_{0}$ and apparent density measurements of chars at various extents of burnoff. In previous work it was noted that when using the empirically-based, $n$-th order power-law rate expression to characterize the overall particle burning rate (Eq. 2.1), the apparent reaction order that best correlated the 
apparent chemical reaction coefficients with temperature differed for particles burning in the 6 and 12 mole-\% oxygen environments employed in the combustion tests. The Arrhenius parameters that described the apparent chemical reaction rate coefficients differed as well. In effect, different sets of kinetic parameters were determined for each of the reactor environments employed.

In the analysis of the data obtained with Blue \#1 coal, reaction orders that best correlate the reaction rate coefficients are also found to differ for data obtained in the different oxygen level environments used in the combustion tests. However, reaction orders of 0.25 in the 6 mole-\% oxygen environment and 0.40 in the 12 mole-\% oxygen environment are found to yield apparent chemical reaction rate coefficients that exhibit the same temperature dependence. The apparent activation energy is determined to be about $39 \mathrm{kcal} / \mathrm{mole}$. This result suggests that the reaction order with respect to the oxygen partial pressure depends upon the oxygen partial pressure itself. The possibility of such a dependence (and even a temperature-dependent reaction order) has been discussed by other investigators.

An apparent reaction order that depends upon the oxygen partial pressure limits the utility of an $n$-th order power-law rate expression for describing char particle burning rates. The need to use an adsorption-desorption reaction mechanism that is adequate for all oxygen level environments is obvious when consideration is given to the fact that in typical pulverized-coal combustors, particles experience oxygen levels ranging from $21 \%$ to about $3 \%$ during the course of burnoff. In future work, kinetic parameters for an adsorption-desorption reaction mechanism will be derived for each of the coals examined in this project.

Also this quarter, for each of the ten coals examined on the PETC suite of PSOC coals, elemental carbon, hydrogen, oxygen, nitrogen, and sulfur release rates relative to the total mass release rates during char oxidation were obtained. Except for the release of sulfur, the trends in the elemental releases relative to the total mass release are the same for each of the coals. On an ash-free basis, carbon and nitrogen are released almost in proportion to the total mass release rates and hydrogen and oxygen are released at rates faster than the total mass release rates. The release rates of sulfur vary from coal to coal. In general, the low rank coals release sulfur at rates that are slower than the total mass release rates and the high rank coals release sulfur at rates that exceed the total mass release rates.

Carbon, the principal component of the char, is expected to be released at a rate nearly proportional to the total mass loss rate on an ash-free basis. The release rates of hydrogen and oxygen are consistent with hydrogen and oxygen in the char occurring predominantly in peripheral groups such as $-\mathrm{COOH},-\mathrm{OH}, \mathrm{C}=\mathrm{O}$, and $-\mathrm{OCH}_{3}$ that are readily released at high temperatures. Some of the oxygen that is released relatively late in burnoff may be incorporated in aromatic clusters and aliphatic ether-structures of the form $\mathrm{C}_{\mathrm{ar}} \mathrm{O}-\mathrm{C}_{\mathrm{ar}}, \mathrm{C}_{\mathrm{ar}}-\mathrm{O}-\mathrm{C}_{\mathrm{al}}$, and/or $\mathrm{C}_{\mathrm{al}}-\mathrm{O}-\mathrm{C}_{\mathrm{al}}$ that have been observed in coals. The release of nitrogen is consistent with the nitrogen in the char being primarily incorporated in $\mathrm{N}$-heterocyclics and $\mathrm{C}-\mathrm{N}=\mathrm{C}$ configurations distributed throughout the 
carbonaceous matrix, with little occurring in amido, amino, cyano, or oxidic groups (which are most likely released during devolatilization and during the early stages of burnoff).

The sulfur release rates no doubt depend upon the forms of sulfur (pyritic sulfatic, or organic) in the coal. The pyritic and sulfatic sulfur may be preferentially released during devolatilization and early burnoff. Early release of pyritic sulfur is supported by data obtained with Illinois \#6 coal. The organic sulfur is incorporated in peripheral end-groups and linkages of the form -SH, -SR, R'-S-R, and -S-S- and in $S$ heterocyclics such as thiophenes, benzothiophenes, thioxanthenes, etc. NMR analyses indicate that in comparison to high rank coals, low rank coals have more bridge- and aliphatic-carbons, carbons that are preferentially attacked during oxidation. If a higher fraction of the sulfur in low rank coals is in heterocyclics (than in peripheral end-groups and linkages), then one would expect sulfur release rates in low rank coals to be slower than the total mass release rates. This could explain the observation that sulfur release in low rank coals is somewhat slower than the total mass release rate. Chemical analyses to determine the ratio of sulfur in peripheral end-groups and linkages to the sulfur in heterocyclics are needed to determine if this is indeed the case.

The sulfur in Illinois \#6, a bituminous coal, is released nearly in proportion to the total mass release rate, suggesting that the sulfur is incorporated primarily in aromatic clusters and aliphatic ether-structures. With the other bituminous coals examined, sulfur may be incorporated primarily in aromatic clusters and aliphatic ether-structures as well, with the sulfur incorporated in peripheral end-groups and linkages giving rise to overall sulfur release rates that are higher than the total mass release rates.

Specific highlights of this quarter's research activities are discussed below.

\section{Subtask 2.1. Determination of Apparent Char Particle Burning Rates}

\section{Kinetic Parameters for Blue \#1 Coal Char}

The analysis of the combustion data obtained with Blue \#1 coal (PSOC-1445D) was continued this quarter. In the combustion tests, raw coal particles were injected into flow reactor environments containing 6 and 12 mole-\% oxygen in the temperature range 1750 to $1550 \mathrm{~K}$. In situ size, temperature, and velocity measurements were obtained at heights above the reactor inlet of $12.7,19.1$, and $25.4 \mathrm{~cm}$. Char particles were extracted from the flow reactor at these same heights and at a height of $6.4 \mathrm{~cm}$ above the reactor inlet as well. The char particles collected at the $6.4 \mathrm{~cm}$ height were obtained just subsequent to devolatilization and hence, provide estimates of the mass loss due to devolatilization and the apparent density of the initial char formed. The degree of swelling that occurred during heatup and devolatilization can be estimated from these measurements. Raw coal particles in the 75 to $106 \mu \mathrm{m}$ and 106 to $125 \mu \mathrm{m}$ size ranges were injected when char samples were being collected, however only the 106 to $125 \mu \mathrm{m}$ size range was used when the in situ measurements were made. 
Values of $m / m_{0}$ and apparent density of chars collected at the various measurement heights in the laminar flow reactor are presented in Table 2.1. As noted in the last Quarterly Progress Report (Mitchell, 1990b), mass loss data may differ slightly from that previously presented (Mitchell, 1988a) since the values presented here are mean values, as determined from values of $\mathrm{m} / \mathrm{m}_{0}$ obtained using $\mathrm{Si}, \mathrm{Al}$, and total ash as tracers, as well as from the ratio of the weight of coal fed to the weight of char collected at the measurement height. Based on the values of $\mathrm{m} / \mathrm{m}_{0}$ and apparent density at the $6.4 \mathrm{~cm}$ height in the reactor, it is estimated that as much as $18 \%$ swelling occurred during particle heatup and devolatilization.

Statistical analyses of the in situ data obtained at the selected measurement heights are presented in Appendix A, Tables A.2.1 to A.2.6. Only particles having calculated emissivities in the range 0.6 to 0.8 were considered. As indicated in previous quarterly reports, particles having calculated emissivities outside this range are believed to be irregularly-shaped and hence, not accurately sized by the particlesizing pyrorneter. (The procedure employed to determine particle diameter from the measured signal levels assumes that the emitting body is spherical. An incorrect assessment of particle size leads to an incorrect assessment of particle emissivity.) The range of particle sizes indicated in the tables is in adequate agreement with the size range of particles injected into the reactor when the degree of swelling indicated by the $\mathrm{m} / \mathrm{mo}_{0}$ and apparent density measurements at the $6.4 \mathrm{~cm}$ reactor height is taken into account.

With further regard to particle emissivities, in the previous Quarterly Progress Report (Mitchell, 1990b), the importance of examining particles that fall into different emissivity ranges when determining overall burning rates from the energy equation was emphasized. Data analysis this quarter indicates that only particles having emissivities in the range 0.6 to 0.8 yield kinetic parameters that lead to calculated mass loss profiles that agree with the measurements. This further supports the contention that particles having calculated emissivities that fall outside this range are irregularly-shaped. It is expected that char particle emissivities decrease as complete burnoff is approached, but calculations (Mitchell, 1989a) indicate that the decrease is quite gradual. Not until burnoff exceeds about $90 \%$ does the emissivity of the ash in the particle have a significant impact on the effective emissivity of the char.

As reported earlier (Mitchell, 1988a), in the gaseous environments employed, most of the Blue \#1 coal char particles burn at rates too close to their diffusion-controlled limits to allow reliable information on their chemical reactivity to be obtained using average values of particle sizes and temperatures (as outlined in Mitchell, 1987b). However, owing to the variations in particle temperatures and burning rates as a consequence of particle-to-particle variations in ash contents, some of the particles burn at rates limited by the combined effects of pore diffusion and the intrinsic chemical reactivity of the particle material. Thus, examination of such particles (those burning at rates ranging from $25 \%$ to $85 \%$ of the diffusion-limited rates) allows the 
Table 2.1

\section{Fractional Mass Remaining and Apparent Density of the Chars of Blue \#1 Coal \\ Initial particle size range: $75-106 \mu \mathrm{m}$}

\section{6 mole-\% Oxygen}

Sampling height, $\mathrm{cm}$

Approximate residence time, $\mathrm{ms}$ Fractional mass remaining, $\mathrm{m} / \mathrm{m}_{\mathbf{O}}$ Fractional burnoff, daf

$\begin{array}{lllll}0.0 & 6.4 & 12.7 & 19.1 & 25.4 \\ 0 & 47 & 72 & 95 & 117 \\ 1.0 & 0.38 & 0.28 & 0.14 & 0.08 \\ 0.0 & 0.65 & 0.75 & 0.90 & 0.96 \\ 1.12 & 0.26 & 0.25 & 0.21 & 0.24\end{array}$

Apparent density, g/cc

\section{2 mole-\% Oxygen}

Sampling height, $\mathrm{cm}$

Approximate residence time, $\mathrm{ms}$ Fractional mass remaining, $\mathrm{m} / \mathrm{m}_{\mathbf{O}}$ Fractional burnoff, daf

$\begin{array}{lllll}0.0 & 6.4 & 12.7 & 19.1 & 25.4 \\ 0 & 47 & 72 & 95 & 117 \\ 1.0 & 0.32 & 0.14 & 0.10 & 0.06 \\ 0.0 & 0.71 & 0.90 & 0.94 & 0.99 \\ 1.12 & 0.30 & 0.27 & 0.29 & 0.36\end{array}$

\section{Initial particle size range: $106-125 \mu \mathrm{m}$}

\section{6 mole-\% Oxygen}

Sampling height, $\mathrm{cm}$

$\begin{array}{lllll}0.0 & 6.4 & 12.7 & 19.1 & 25.4\end{array}$

$\begin{array}{llllll}\text { Approximate residence time, } \mathrm{ms} & 0 & 47 & 72 & 95 & 117\end{array}$

Fractional mass remaining, $\mathrm{m} / \mathrm{m}_{\mathrm{O}} \quad \begin{array}{llllll}1.0 & 0.49 & 0.35 & 0.30 & 0.27\end{array}$

$\begin{array}{llllll}\text { Fractional burnoff, daf } & 0.0 & 0.53 & 0.68 & 0.73 & 0.77\end{array}$

$\begin{array}{llllll}\text { Apparent density, g/cc } & 1.12 & 0.35 & 0.34 & 0.32 & 0.29\end{array}$

12 mole-\% Oxygen

Sampling height, $\mathrm{cm}$

Approximate residence time, ms

Fractional mass remaining, $\mathrm{m} / \mathrm{m}_{\mathrm{O}}$

0.0

6.4

12.7

19.1

25.4

Fractional burnoff, daf

Apparent density, g/cc

$0 \quad 47$

0.26

$\begin{array}{ll}95 & 117\end{array}$

1.0

0.49

$0.13 \quad 0.06$

0.0

0.53

0.78

0.91

0.99

1.12

0.35

0.32

$0.30 \quad 0.55$ 
determination of apparent chemical reaction rate coefficients.

The in situ size, temperature, and velocity measurements are combined with the $\mathrm{m} / \mathrm{m}_{0}$ and apparent density measurements to determined overall particle burning rates for individual particles. Since particles do not attain a state of thermal equilibrium with the surrounding gas in the flow reactor, the thermal inertia of each particle is accounted for in order to accurately assess its overall burning rate from the size and temperature measurements. Estimation of the thermal inertia of each particle as it burns in the laminar flow reactor is obtained by modeling the burning process.

The mass, momentum, and energy balance equations used to describe single particles burning in specified flow reactor environments have been previously presented (Mitchell, 1988b). The burning mode model used to characterize the relations between particle mass, apparent density, and diameter (when account is made for the ash content of the particle) was presented in the last Quarterly Progress Report (Mitchell, 1990b). In order to determine the thermal inertia of each particle at each of the measurement heights, the balance equations are integrated numerically from a starting height, where the particle size, temperature, velocity, $\mathrm{m}_{\mathrm{m}} / \mathrm{m}_{0}$, and apparent density are specified, to the various measurement heights. For data taken at the 19.1 and $25.4 \mathrm{~cm}$ heights in the reactor, the measurements at the $12.7 \mathrm{~cm}$ height are used as starting values. For data taken at the $12.7 \mathrm{~cm}$ height, measurements of $\mathrm{m} / \mathrm{mo}_{0}$ and the apparent density of particles collected at the $6.4 \mathrm{~cm}$ height are used as starting values for the mass balance equation and starting values for the energy equation are estimated by assuming that at the $6.4 \mathrm{~cm}$ height, gas and particles are in thermal equilibrium. During the numerical integrations, the measured gas temperature, velocity, and oxygen partial pressure profiles along the reactor centerline are imposed.

When determining the apparent order with respect to the oxygen partial pressure at the particle surface $(n)$ and apparent chemical reaction rate coefficients $\left(k_{s}\right)$ for individual particles, only particles having values of $\chi$ (the ratio of the overall particle burning rate to the maximum, diffusion-limited rate) between 0.25 and 0.85 are used. In addition, only values of $k_{s}$ determined from data at the 19.1 and $25.4 \mathrm{~cm}$ heights above the reactor inlet are used in the least squares fits to determine $A_{a}$ and $E_{a}$ since the values derived from data at the $12.7 \mathrm{~cm}$ height are affected by errors in the starting values used in the numerical integrations.

As was the case with other coal chars that have been examined in the Coal Char Combustion Laboratory (Mitchell, 1989b), the apparent reaction order that best correlates the apparent chemical reaction rate coefficients with temperature differs for particles burning in the 6 and 12 mole-\% oxygen environments. The values of $A_{a}$ and $E_{a}$ obtained differ as well. This suggests that the reaction order depends upon the oxygen partial pressure. The possibility of the reaction order depending upon the oxygen partial pressure (and even upon temperature) has been discussed by Laurendeau (1978). In the analysis of the data for the Blue \#1 coal char particles, apparent reaction orders for burning in 6 and 12 mole-\% oxygen are determined that 
yield the same temperature dependence for the rate coefficients in the two oxygen level environments.

Figure 2.1 shows apparent chemical reaction rate coefficients determined for Blue \#1 coal char particles burning in the gaseous environments employed in the combustion tests. Reaction orders of 0.25 and 0.40 in the 6 and 12 mole-\% oxygen environments, respectively, yield apparent chemical reaction rate coefficients that exhibit the same temperature dependence in each oi the oxygen level environments employed. The apparent activation energy is about $39 \mathrm{kcal} / \mathrm{mole}$, a value in the range that suggests Zone II type burning (i.e., particle burning rates that are limited by the combined effects of pore diffusion and the intrinsic chemical reactivity of the particle material). The reaction product is assumed to be solely $\mathrm{CO}$. Little $\mathrm{CO}_{2}$ formation is expected at the temperatures (greater than $1650 \mathrm{~K}$ ) attained by the particles.

Figure 2.2 shows the measured mass loss profiles in the 6 and 12 mole-\% oxygen environments when particles in the 106 to $125 \mu \mathrm{m}$ size range were injected into the flow reactor. The lines are the results of calculations using the rate parameters determined. Calculations are for a particle having a diameter of $115 \mu \mathrm{m}$ (a size representative of the size fraction employed) and the measured $m / \mathrm{m}_{0}$ and apparent densities at the $6.4 \mathrm{~cm}$ height in the reactor. Agreement between measurements and calculations is quite good for particles in both of the oxygen level environments used. Figure 2.3 shows similar comparisons between measurements and calculations when particles in the 75 to $106 \mu \mathrm{m}$ size range were employed. In this figure, calculations are for a particle having a diameter of $90 \mu \mathrm{m}$ and the measured $\mathrm{m} / \mathrm{mo}_{0}$ and apparent densities at the $6.4 \mathrm{~cm}$ height in the reactor. Again agreement between measurements and calculations is good in both $\mathrm{O}_{2}$-level environments.

The reaction orders determined for the 6 and 12 mole-\% oxygen environments are not in the expected order. Based on the Langmuir-Hinshelwood analysis, which takes into account adsorption of oxygen and desorption of products, if the reaction is first order, the reaction is adsorption dominated. If it is zero order, then the reaction is desorption dominated. In gुeneral, first order kinetics (i.e. adsorption control) is promoted by lower reactant concentrations and higher temperatures. The results for the Blue \#1 coal char indicate a higher order for the higher oxygen concentration, just opposite the expected trend. This may be a consequence of the higher particle temperatures in the 12 mole-\% oxygen environment. More likely, it is a consequence of the inadequacy of the power-law rate expression for describing char oxidation. In fact, n-th order power-law kinetics for char oxidation has no theoretical or experimental justification. As noted by Laurendeau, experimental data for any gas. solid reaction can be fitted (to a power-law expression) to determine Arrhenius parameters and reaction order to describe the rate, but the resulting expression is not rigorous and only holds over limited temperature and pressure ranges.

The necessity of having to use different values for the apparent reaction order in different oxygen level environments in order to obtain Arrhenius parameters for the rate coefficients that are adequate for all $\mathrm{O}_{2}$-level environments demonstrates a 


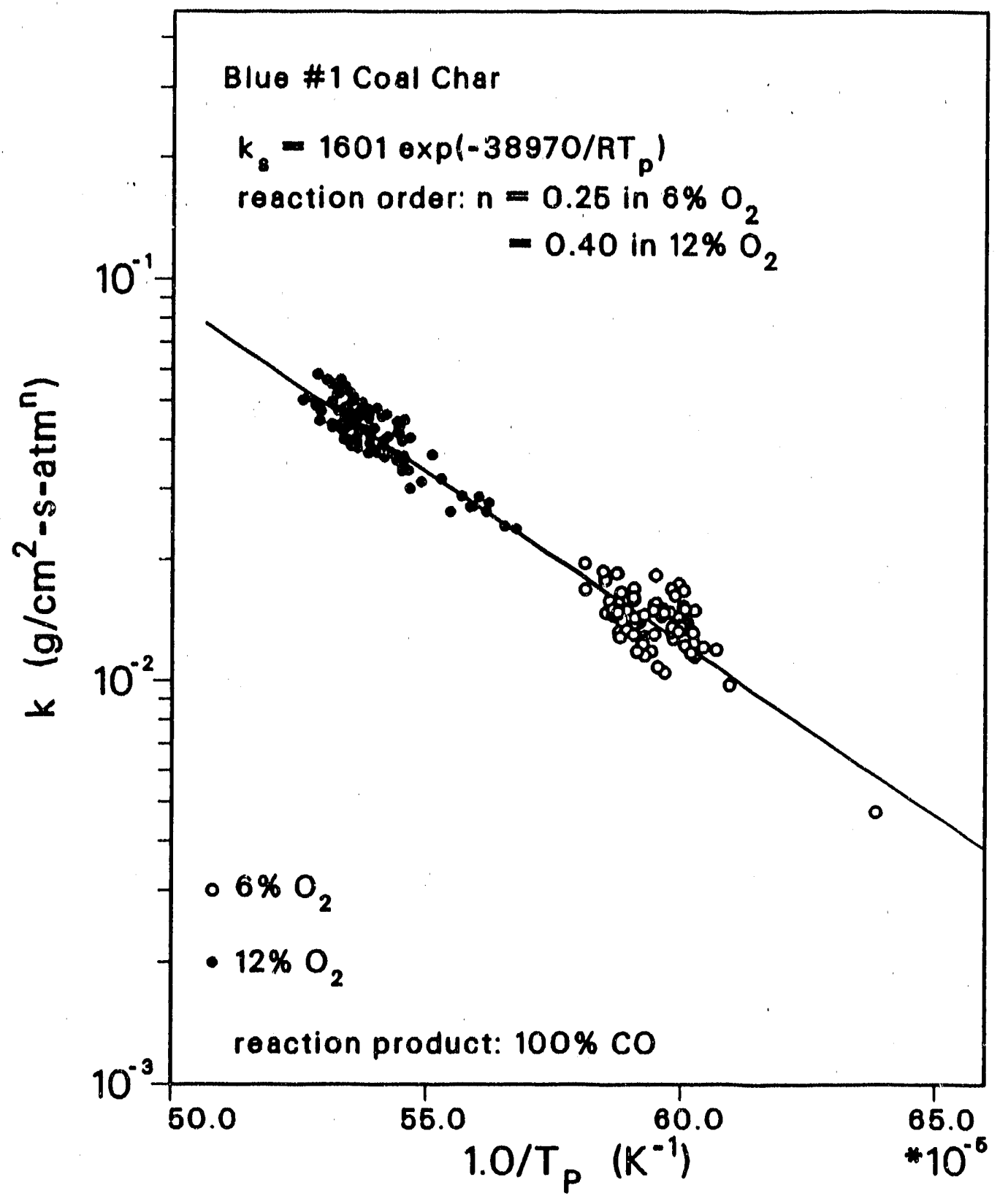

Figure 2.1 Apparent chemical reaction rate coefficients for Blue \#1 coal char particles burning in 6 and 12 mole-\% oxygen. 


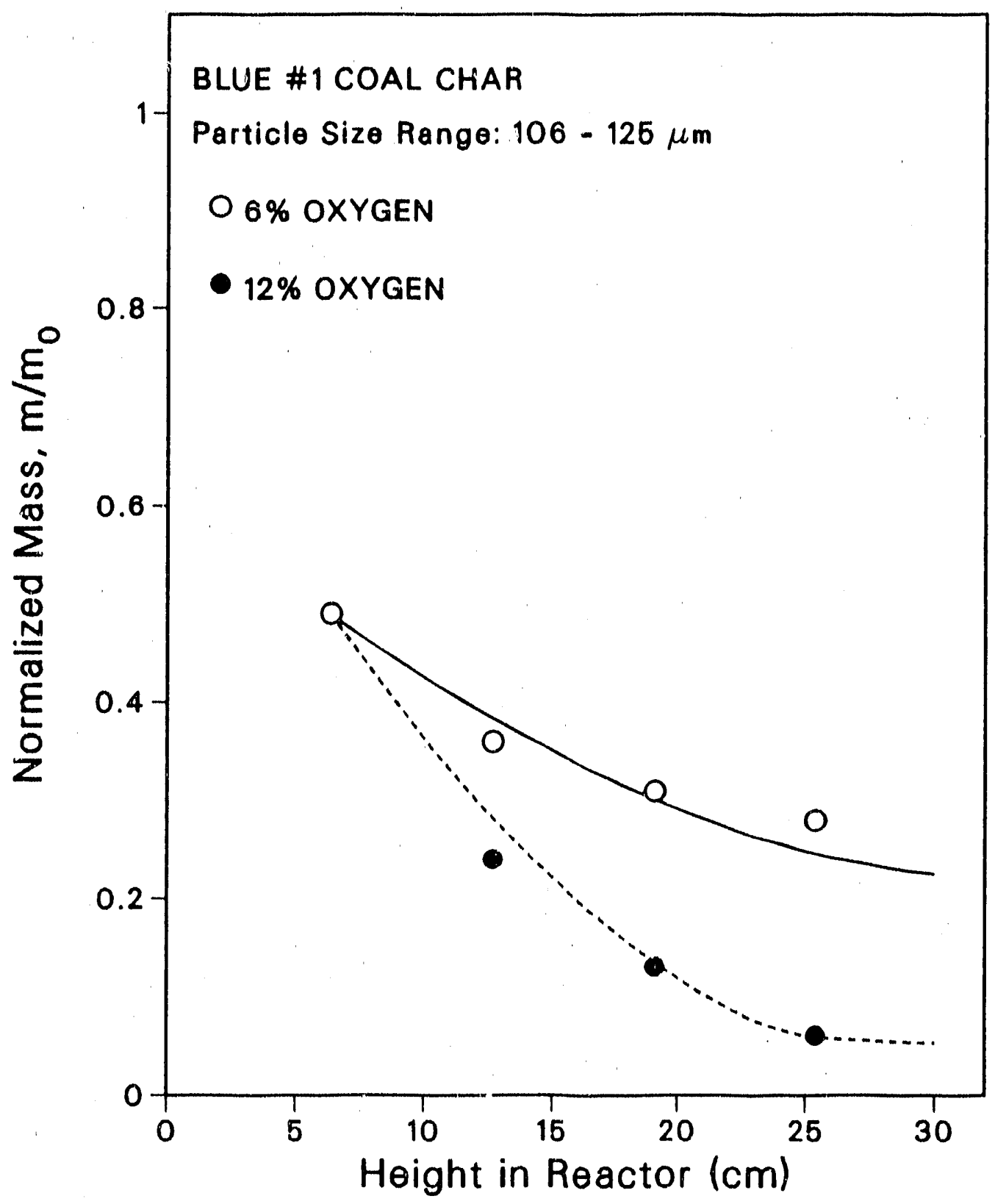

Figure 2.2 Calculated and measured mass loss profiles for particles in the 106 to $125 \mu \mathrm{m}$ size range burning in the 6 and 12 mole-\% oxygen environments. 


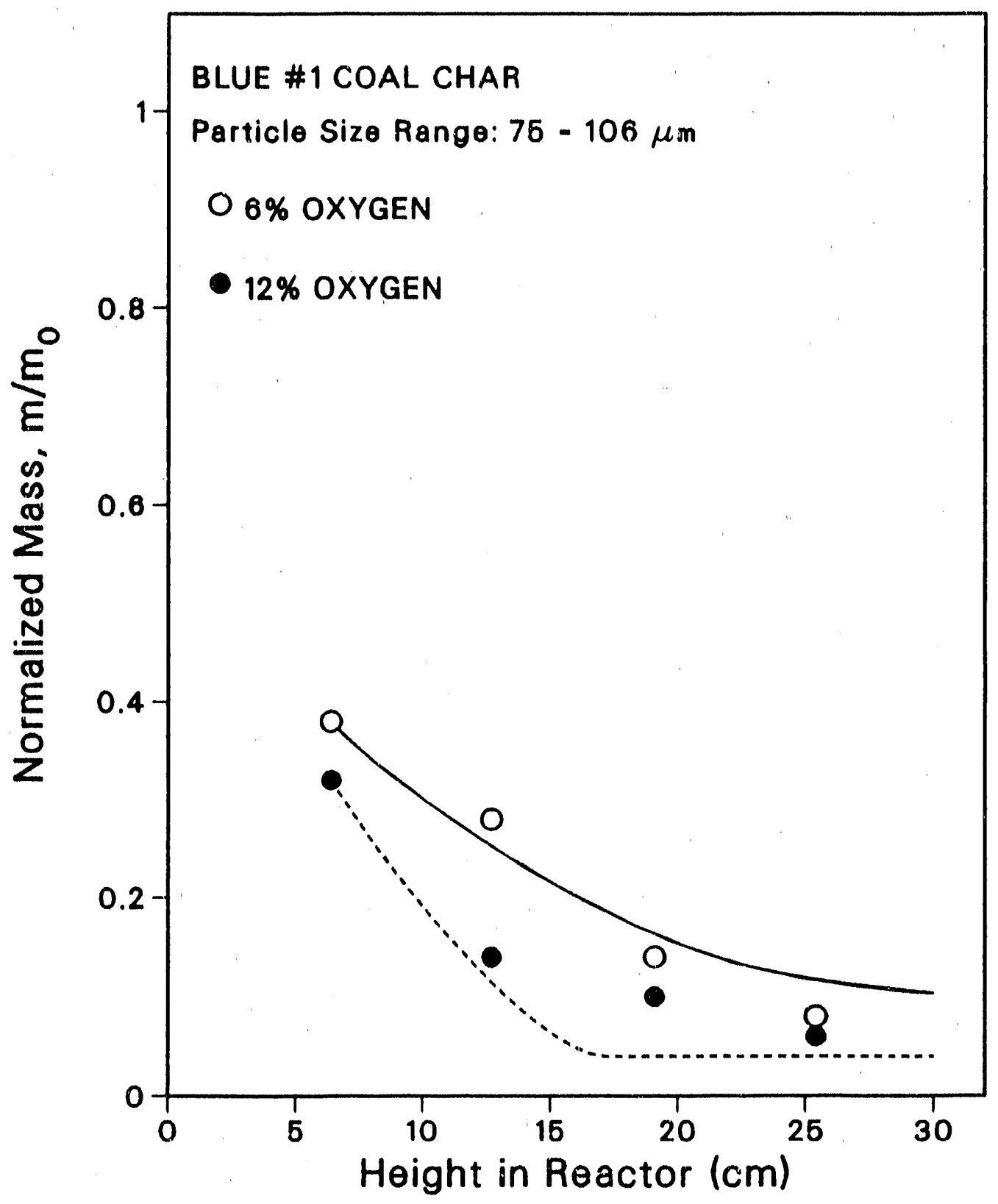

Figure 2.3 Calculated and measured mass loss profiles for particles in the 75 to $106 \mu \mathrm{m}$ size range burning in the 6 and 12 mole-\% oxygen environments. 
shortcoming of the $\mathrm{n}$-th order power-law rate expression for describing char particle burning rates. The need to use an adsorption-desorption mechanism that is adequate for all oxygen level environments is obvious when consideration is given to the fact that in typical pulverized-coal combustors, particles experience oxygen levels ranging from $21 \%$ to about $3 \%$ during the course of burnoff.

Despite the inadequacy of the power-law rate expression, the analyses of the combustion data obtained with the other coals will proceed along the lines presented here. Apparent reaction orders for each oxygen level will be determined that yield the same temperature dependence for the apparent chemical reaction rate coefficients in the gaseous environments employed in the combustion tests. The kinetic parameters obtained will receive more widespread use in the near-term, than parameters obtained for an adsorption-desorption reaction mechanism. In future work, the adsorptiondesorption mechanism previously presented (Mitchell, 1990a) will be used in the analyses of the combustion data.

\section{Subtask 2.2 Determination of the Intrinsic Chemical Reactivity of Chars}

No work pertinent to this subtask was performed this quarter. The samples of partially reacted chars of each $c$,al that were extracted from the 6 and 12 mole-\% oxygen environments at the selected measurement heights are stored in sealed containers. The specific surface areas of the samples will be determined using either $\mathrm{N}_{2}$ or $\mathrm{CO}_{2}$ as adsorbents (or both), pending the outcome of data reductions to determine if $\mathrm{N}_{2}$-BET surface areas are sufficient to yield the correct temperature dependence of the intrinsic chemical reactivity of coal chars.

\section{Subtask 2.3 Determination of Nitrogen and Sulfur Release Rates}

\section{Elemental C, H, O, N, and S Releases for Blue \#1 Coal Char}

Blue \#1 coal (PSOC-1445D) and each of its partially reacted chars extracted from the 6 and 12 mole-\% oxygen environments were subjected to organic elemental analysis for carbon, hydrogen, oxygen, nitrogen, and sulfur contents. The elemental analyses were performed by the Coors Analytical Laboratory in Golden Colorado. A colorometric combustion technique was used for carbon and hydrogen determinations, a pyrolysis technique for oxygen, a Fisher Sulfur Analyzer for sulfur, and a Carlo/Erba Nitrogen Analyzer for nitrogen. Each of the techniques was performed using a LECO instrument. The samples were dried before the analyses. Table 2.2 shows results obtained for the raw coal and its partially reacted chars. The values presented are the results of independent determinations and have not been normalized to sum to $100 \%$. Based on analyses of several raw coal samples, typical standard deviations for $\mathrm{C}, \mathrm{H}$, $\mathrm{O}, \mathrm{N}, \mathrm{S}$, and ash are about \pm 0.025 relative- $\%$.

Comparison of the results for the 106 to $125 \mu \mathrm{m}$ size fraction of the raw coal $(0.0 \mathrm{~cm}$ height) in the 6 and 12 mole-\% oxygen environments gives an indication of the 
Table $\mathbf{2 , 2}$

Organic Elemental Analysis and Percent Ash of Blue \#1 Coal and its Partially Reacted Chars

Initial particle size range, $75-106 \mu \mathrm{m}$

6 mole-\% Oxygen Environment

$\begin{array}{cccrccc}\text { Hgt (cm) } & \% \text {-C } & \% \text {-H } & \%-\mathrm{O} & \% \text {-N } & \% S & \% \text {-Ash } \\ & & & & & & \\ 0.0 & 74.24 & 5.19 & 14.92 & 1.85 & 0.66 & 3.16 \\ 6.4 & 85.04 & 0.62 & 4.32 & 1.39 & 0.89 & 8.30 \\ 12.7 & 82.20 & 0.74 & 3.48 & 1.21 & 1.04 & 11.63 \\ 19.1 & 72.30 & 0.95 & 4.30 & 1.09 & 1.17 & 21.24 \\ 25.4 & 58.60 & 0.64 & 4.53 & 0.83 & 1.43 & 34.44\end{array}$

12 mole-\% Oxygen Environment

$\begin{array}{cccrccc}\text { Hgt (cm) } & \% \text {-C } & \%-H & \%-\mathrm{O} & \%-\mathrm{N} & \% \mathrm{~S} & \% \text {-Ash } \\ & & & & & & \\ 0.0 & 74.24 & 5.19 & 14.92 & 1.85 & 0.66 & 3.16 \\ 6.4 & 84.46 & 0.64 & 1.87 & 1.25 & 1.06 & 9.46 \\ 12.7 & 76.68 & 0.32 & 2.99 & 0.86 & 0.62 & 19.88 \\ 19.1 & 60.85 & 0.41 & 4.76 & 0.74 & 1.56 & 32.62 \\ 25.4 & 45.48 & 0.69 & 5.35 & 0.76 & 1.49 & 48.08\end{array}$

Initial particle size range, $106 \cdot 125 \mu \mathrm{m}$

6 mole-\% Oxygen Environment

$\begin{array}{cccrrrr}\text { Hgt (cm) } & \%-\mathrm{C} & \%-\mathrm{H} & \%-\mathrm{O} & \%-\mathrm{N} & \% \mathrm{~S} & \% \text {-Ash } \\ & & & & & & \\ 0.0 & 74.49 & 5.25 & 13.80 & 1.36 & 0.68 & 3.53 \\ 6.4 & 77.18 & 2.26 & 6.02 & 1.48 & 0.56 & 10.12 \\ 12.7 & 85.60 & 0.58 & 0.35 & 1.38 & 0.19 & 10.49 \\ 19.1 & 82.06 & 0.55 & 0.48 & 1.07 & 0.31 & 9.06 \\ 25.4 & 79.89 & 0.80 & 2.07 & 1.08 & 0.49 & 12.45\end{array}$

12 mole-\% Oxygen Environment

$\begin{array}{cccrccc}\text { Hgt }(\mathrm{cm}) & \%-\mathrm{C} & \%-\mathrm{H} & \%-\mathrm{O} & \% \cdot \mathrm{N} & \% \mathrm{~S} & \%-\text { Ash } \\ & & & & & & \\ 0.0 & 74.42 & 5.33 & 14.76 & 1.29 & 0.69 & 3.38 \\ 6.4 & 80.53 & 2.16 & 7.70 & 1.41 & 0.80 & 7.38 \\ 12.7 & 82.55 & 0.45 & 1.88 & 0.97 & 1.06 & 13.49 \\ 19.1 & 71.98 & 0.95 & 7.61 & 1.07 & 1.19 & 19.33 \\ 19.1 & 58.93 & 0.81 & 5.57 & 0.70 & 1.29 & 31.12 \\ 25.4 & 36.36 & 0.39 & 4.65 & 0.36 & 1.30 & 55.17\end{array}$


variability of different samples of the raw coal. Comparison of the results for the 75 to $106 \mu \mathrm{m}$ and 106 to $125 \mu \mathrm{m}$ size fractions of the raw coal gives an indication of the differences between the size fractions. No significant differences in the elemental compositions or in the ash levels are noted for the different size fractions used in the combustion tests.

Two char samples were extracted from the flow reactor at the $19.1 \mathrm{~cm}$ height when coal particles in the 106 to $125 \mu \mathrm{m}$ size range were injected into the 12 mole-\% oxygen environment. Based on these data and our experience with sample-to-sample variations in the raw coal analyses, the true values at the $19.1 \mathrm{~cm}$ height are predicted witi 95\% confidence to lie in the following intervals (\%): C, $65 \pm 15 ; \mathrm{H}, 0.88 \pm 0.2$; $\mathrm{O}, 6.6 \pm 1.5 ; \mathrm{N}, 0.89 \pm 0.2 ; \mathrm{S}, 1.2 \pm 0.3 ;$ and ash, 25.2 \pm 5.7 . Calculations for all the coal and char samples examined yield similar results with regard to $95 \%$ confidence intervals.

The data presented in the table can be used to determine the release of the various elements relative to the total mass release during char oxidation. The fraction of the initial amount of element $i$ remaining in the char, $f_{i}$, is determined using the following equation:

$$
f_{i}=\left(\frac{x_{i}}{x_{i, 0}}\right)\left(\frac{m}{m_{0}}\right)
$$

where $x_{i}$ and $x_{i, 0}$ are the fractions of element $i$ in the partially reacted char and in the raw coal, respectively, and $\mathrm{m} / \mathrm{m}_{0}$ is the fraction of the initial mass remaining at the measurement height. As indicated above, the value of $\mathrm{m} / \mathrm{m}_{0}$ employed is the mean value obtained from independent determinations of $\mathrm{m} / \mathrm{mo}_{\mathrm{o}}$ using $\mathrm{Si}, \mathrm{Al}$, and total ash as tracers and the ratio of the weight of coal injected to the weight of char collected at the measurement height. The fraction of the element $i$ released prior to the sampling height is $\left(1-f_{i}\right)$ and the fraction of the initial mass released prior to the sampling height is $\left(1-m / m_{0}\right)$.

To allow comparison of elemental releases among different coals, the $\mathrm{m} / \mathrm{mo}_{0}$ values are expressed on an ash-free basis as follows:

$$
\left(\frac{m}{m_{0}}\right)_{c f}=\left(\frac{m}{m_{0}}\right) \frac{\left(1-X_{a}\right)}{\left(1-X_{a, 0}\right)}
$$

The quantity $\left(\mathrm{m} / \mathrm{mo}_{0}\right)_{\text {af }}$ represents the fraction of the initial amount of combustible material remaining in the char at the measurement height.

Figure 2.4 shows the percent elemental releases of carbon, hydrogen, oxygen, nitrogen, and sulfur relative to the total mass release for Blue \#1 coal char particles in the 6 and 12 mole- $\%$ oxygen environments. The $45^{\circ}$ line in each subplot represents the total mass release. Points below the line indicate release rates slower than the 

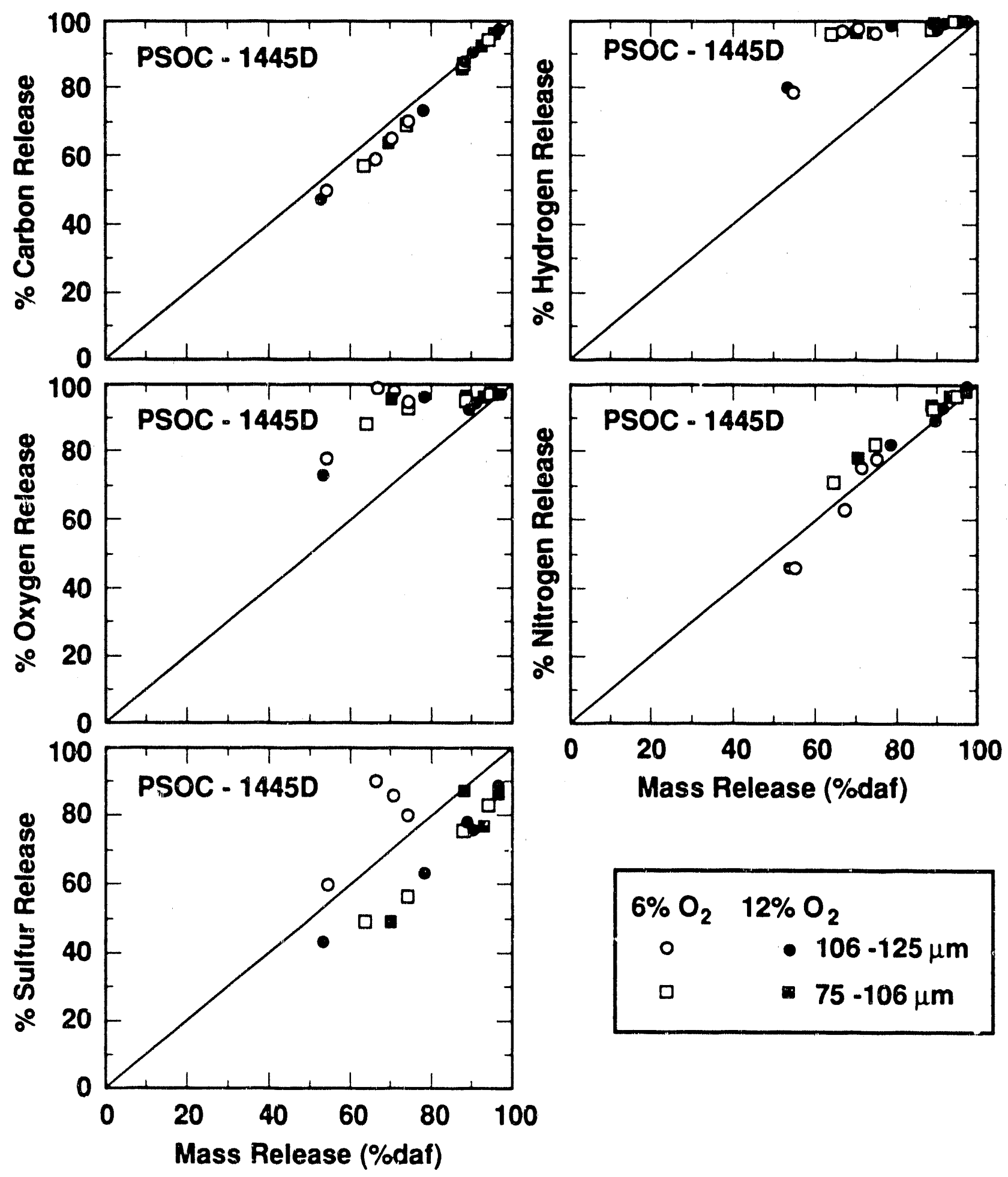

Figure 2.4 Elemental releases of carbon, hydrogen, oxygen, nitrogen, and sulfur relative to the total mass release for Blue \#1 coal char particles in the 6 and 12 mole-\% oxygen environments. 
total mass release rate and points above the line indicate release rates faster than the total mass release rate.

t or Blue \#1 coal particles injected into the gaseous environments employed, about $51 \%$ of the mass is lost during devolatilization, the remaining $49 \%$ being released during char oxidation. During burnoff, both carbon and nitrogen are released almost in direct proportion to the total mass loss rate, during the early to relatively late stages, carbon somewhat slower and nitrogen somewhat faster. About $80 \%$ of both the hydrogen and oxygen in the coal are released during devolatilization at the temperatures and heating rates the particles experienced in the flow reactor environments employed. During char oxidation, the hydrogen and oxygen are each released at rates faster than the total mass release rate.

With the smaller size fraction of particles used in the combustion tests, the release rates of sulfur are slower than the total mass release rates. However with the larger size fraction, the sulfur release rates are faster than the total mass release rates in the 6 mole-\% oxygen environment and slower than the total mass release rates in the 12 mole-\% oxygen environment. This may reflect some dependence of the sulfur release rates (relative to the total mass release rates) on temperature. Particle burning rates are considerably higher in the 12 mole-\% oxygen environment and particle temperatures are correspondingly higher in comparison to conditions in the 6 mole-\% oxygen environment. The larger particles lose more heat via radiation and consequently are at lower temperatures than the smaller particles. Thus, the larger particles in the 6 mole-\% oxygen environment are at the lowest temperatures.

\section{Elemental Releases for Other Coal Chars}

Data analogous to that presented in Table 2.2 for Blue \#1 coal and its partially reacted chars have been obtained for all the PETC coals examined in this project. The coals are listed in Table 2.3 in increasing rank (and decreasing volatile matter content within each rank). The volatile matter and ash contents (as reported by Penn State) are included in the table. Table 2.4 gives the relative anounts of the different forms of sulfur in the coals and the total sulfur contents of the coals on a dry basis.

The elemental $\mathrm{C}, \mathrm{H}, \mathrm{O}, \mathrm{N}$, and $\mathrm{S}$ releases relative to the total mass releases are presented in Figs. 2.5 to 2.9. Figure 2.5a shows the release of carbon for the lower rank lignites and subbituminous coals and Figure $2.5 \mathrm{~b}$ shows results for the higher rank bituminous coals. Similar plots are shown for the releases of hydrogen (Figs. 2.6a and 2.6b), oxygen (Figs. 2.7a and 2.7b), nitrogen (Figs. 2.8a and 2.8b), and sulfur (Figs. 2.9a and $2.9 \mathrm{~b}$ ) relative to the total mass releases.

Except for the release of sulfur, the trends in the elemental releases relative to the total mass release during burnoff are the same as those observed with the chars of Blue \# 1 coal. Carbon and nitrogen are released at rates almost in proportion to the total mass release rates and hydrogen and oxygen are released at rates faster than the total mass release rates. With respect to sulfur, in general, the lower rank lignites 
Table 2.3

\section{Coals Examined}

\begin{tabular}{lcccrr}
\multicolumn{1}{c}{ Name } & $\begin{array}{c}\text { State of } \\
\text { Origin }\end{array}$ & PSOC \# & Rank & $\begin{array}{c}\% \text {-VM } \\
\text { dry }\end{array}$ & $\begin{array}{c}\text { \%-ash } \\
\text { dry }\end{array}$ \\
Lower Wilcox & TX & 1443 & lignite & 44.2 & 21.4 \\
Beulah Zap & ND & 1507 & lignite & 40.8 & 12.5 \\
Smith Roland & WY & 1520 & subbituminous & 54.7 & 12.4 \\
Dietz & MT & 1488 & subbituminous & 41.9 & 5.4 \\
Blue \#1 & NM & 1445 & subbituminous & 40.3 & 4.6 \\
Hiawatha & UT & 1502 & hvc-bituminous & 40.8 & 9.0 \\
Illinois \#6 & II & 1493 & hvb-bituminous & 37.9 & 15.2 \\
Pittsburgh \#8 & PA & 1451 & hva-bituminous & 34.4 & 13.7 \\
Lower Kittanning & PA & 1516 & lv-bituminous & 17.7 & 10.3 \\
Pocahontas \#3 & WV & 1508 & lv-bituminous & 15.7 & 7.4
\end{tabular}

Table 2.4

Sulfur Forms in the Coals Examined

\begin{tabular}{lcccc}
\multicolumn{1}{c}{ Coal } & \multicolumn{3}{c}{ Sulfur forms, \%-dry } & Total S \\
& pyritic & sulfatic & organic & \%-dry \\
& & & & \\
Lower Wilcox & 0.09 & 0.01 & 0.64 & 0.74 \\
Beulah Zap & 0.02 & 0.01 & 1.40 & 1.43 \\
Smith Roland & 0.05 & 0.01 & 1.15 & 1.21 \\
Dietz & 0.02 & 0.00 & 0.48 & 0.50 \\
Blue \#1 & 0.16 & 0.01 & 0.55 & 0.72 \\
Hiawatha & 0.15 & 0.00 & 0.36 & 0.51 \\
Illinois \#6 & 2.61 & 0.04 & 2.33 & 4.98 \\
Pittsburgh \#8 & 0.82 & 0.01 & 0.53 & 1.36 \\
Lower Kittanning & 0.61 & 0.01 & 0.78 & 1.40 \\
Pocahontas \#3 & 0.14 & 0.00 & 0.50 & 0.64
\end{tabular}




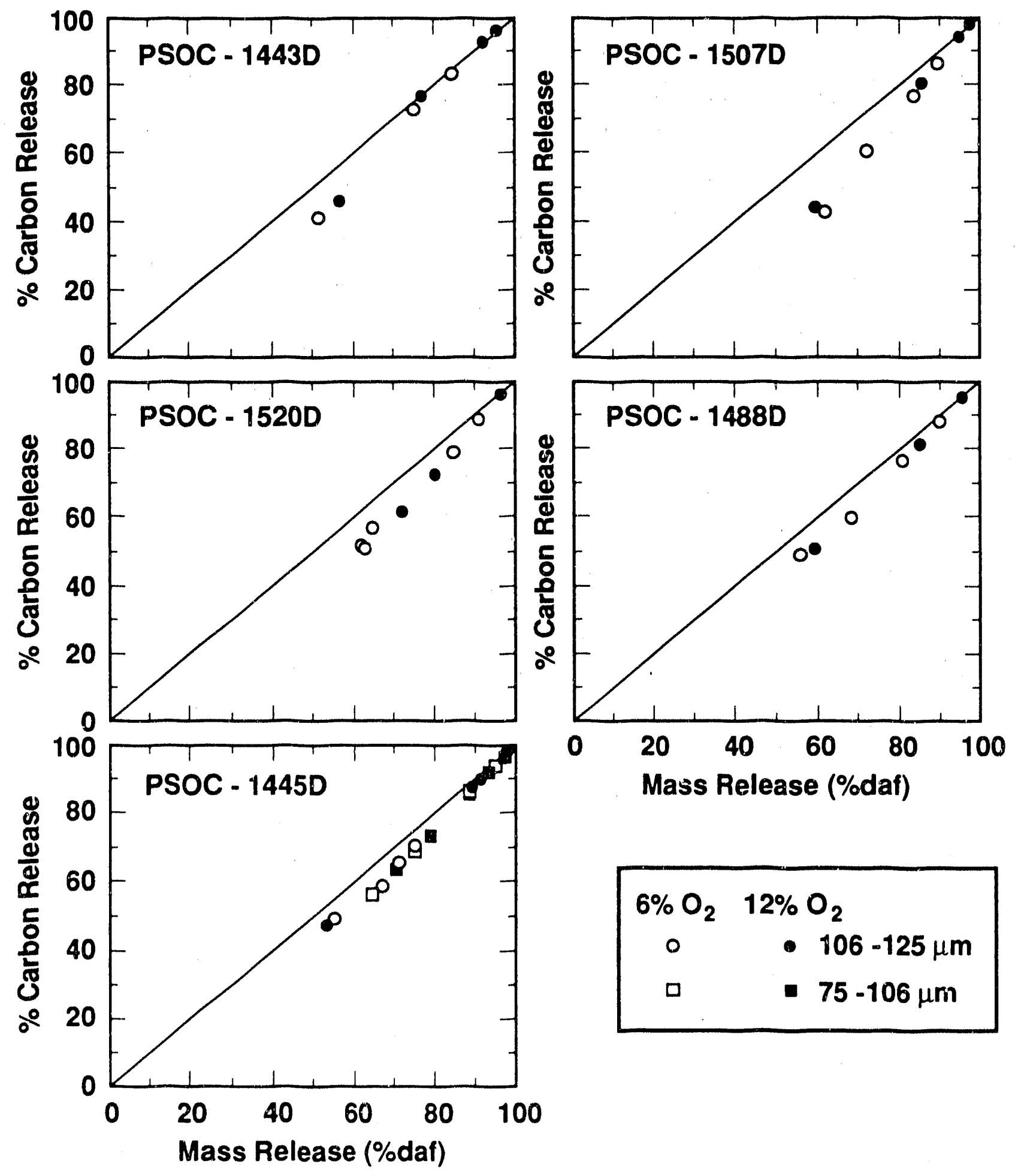

Figure 2.5a Release of elemental carbon relative to the total mass release for the lignites and subbituminous coals examined. Refer to Table 2.3 for the coal name and rank associated with the PSOC-number. 

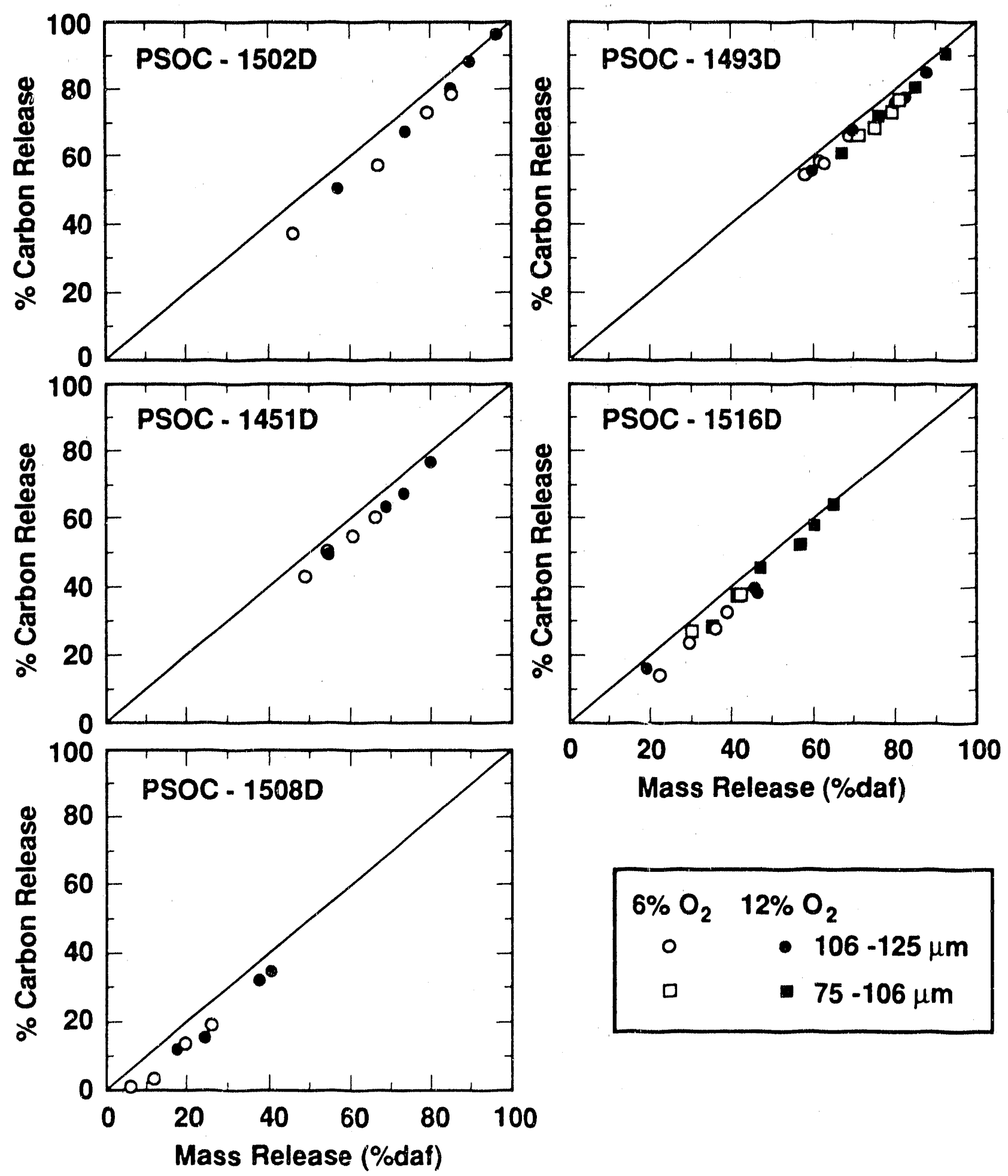

Figure 2.5b Release of elemental carbon relative to the total mass release for the bituminous coals examined. Refer to Table 2.3 for the coal name and rank associated with the PSOC-number. 


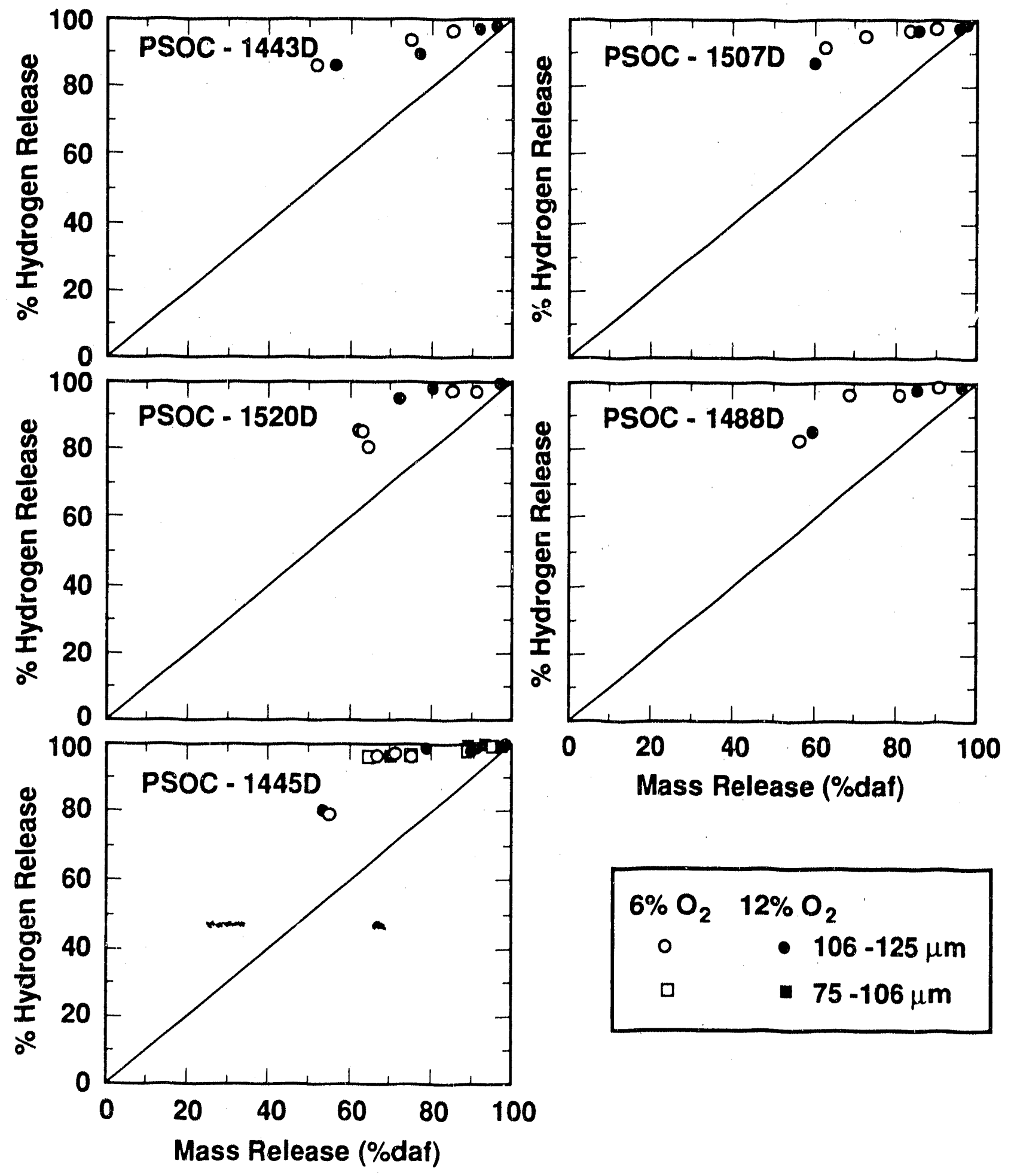

Figure 2.6a Release of elemental hydrogen relative to the total mass release for the lignites and subbituminous coals examined. Refer to Table 2.3 for the coal name and rank associated with the PSOC-number. 

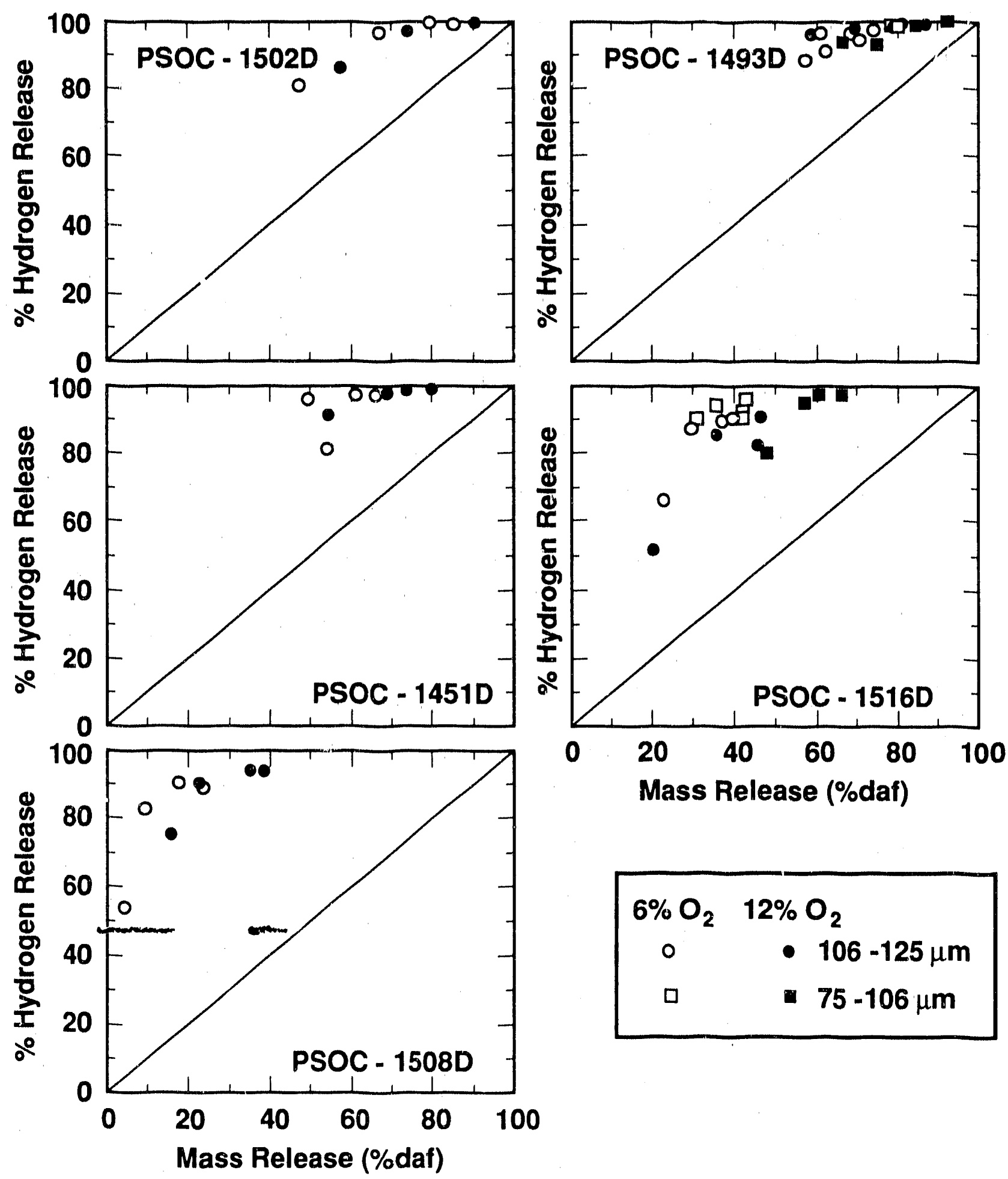

Figure 2.6b Release of elemental hydrogen relative to the total mass release for the bituminous coals examined. Refer to Table 2.3 for the coal name and rank associated with the PSOC-number. 

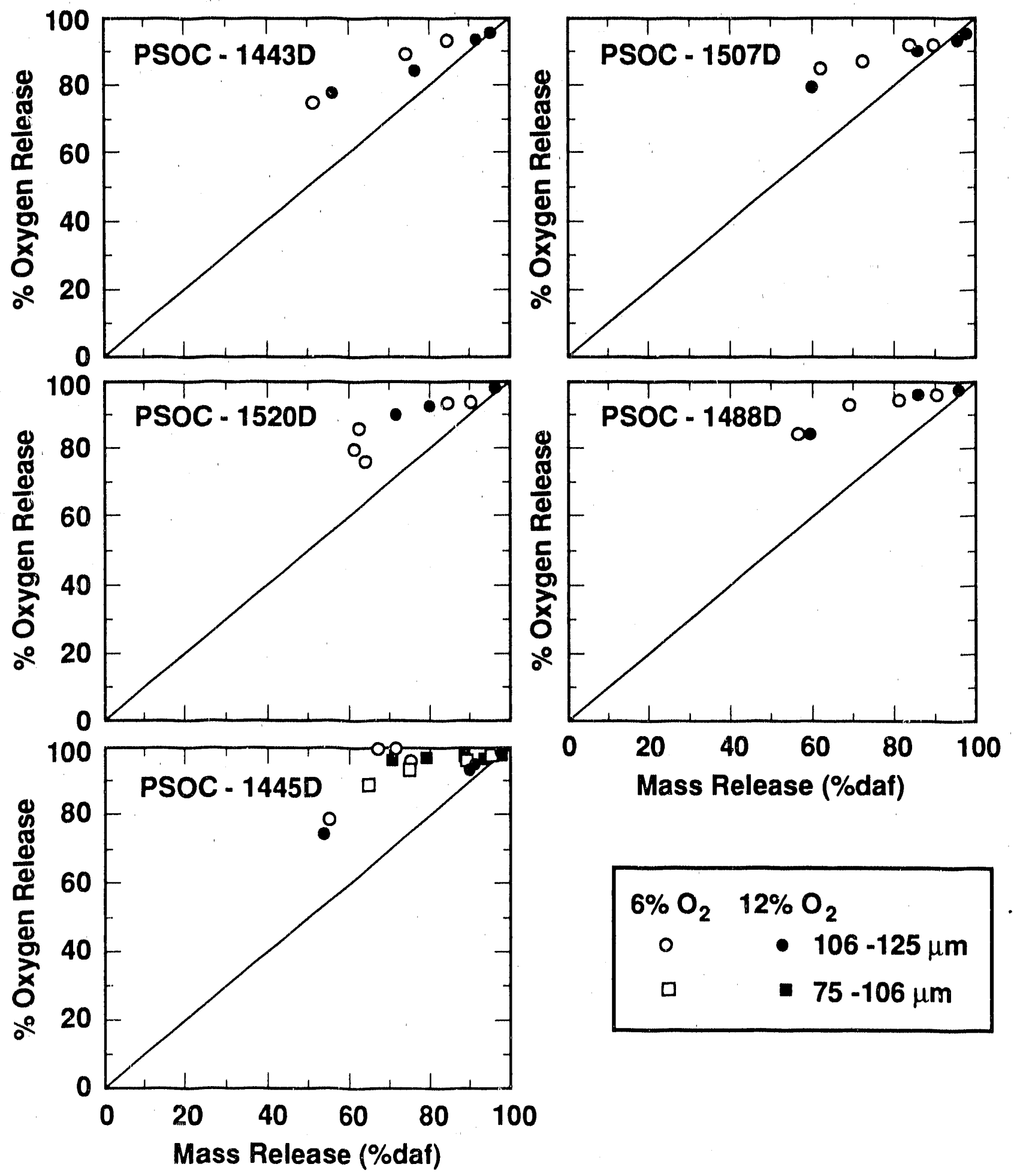

Figure 2.7a Release of elemental oxygen relative to the total mass release for the lignites and subbituminous coals examined. Refer to Table 2.3 for the coal name and rank associated with the PSOC-number. 


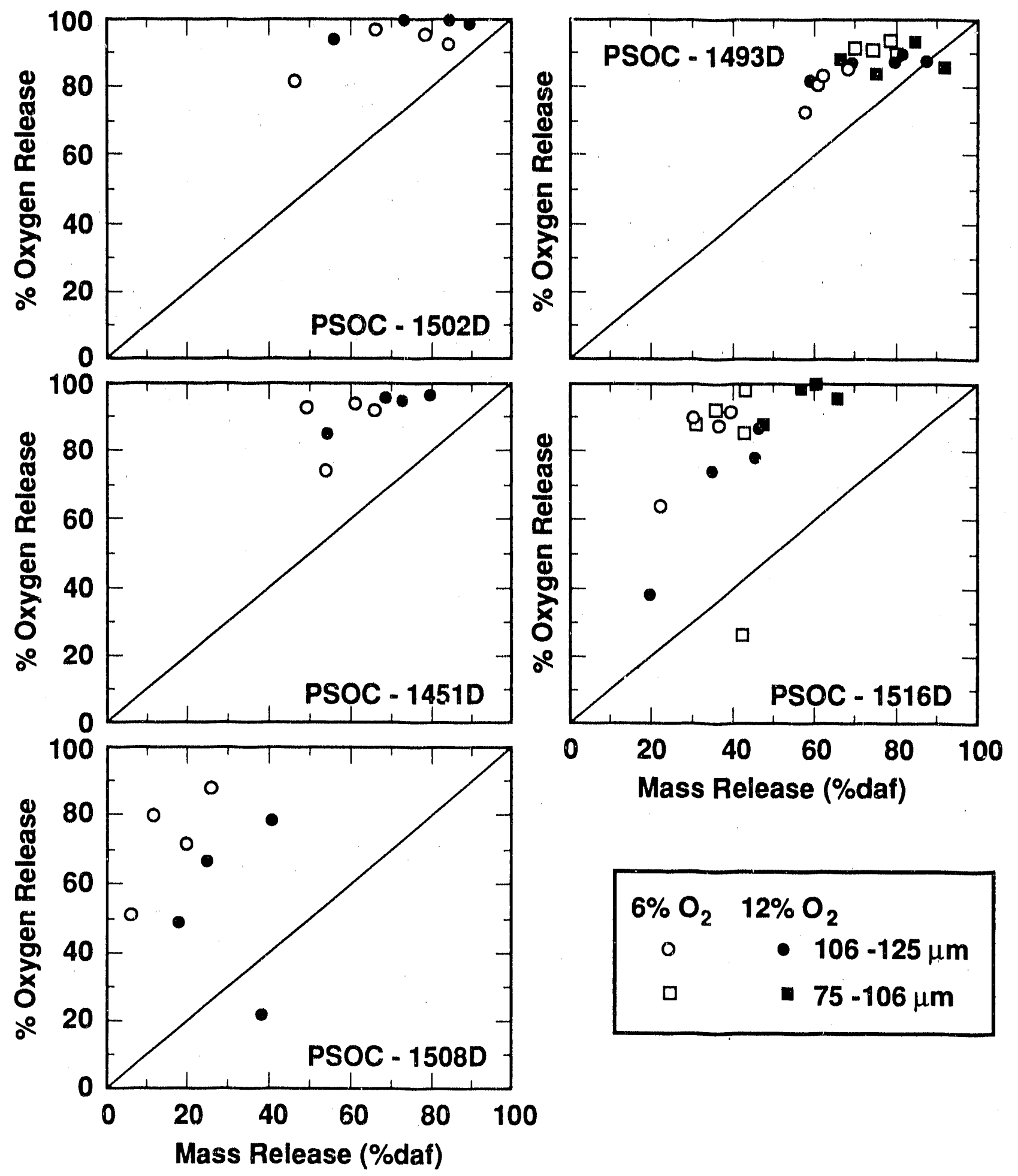

Figure 2.7b Release of elemental oxygen relative to the total mass release for the bituminous coals examined. Refer to Table 2.3 for the coal narne and rank associated with the PSOC-number. 

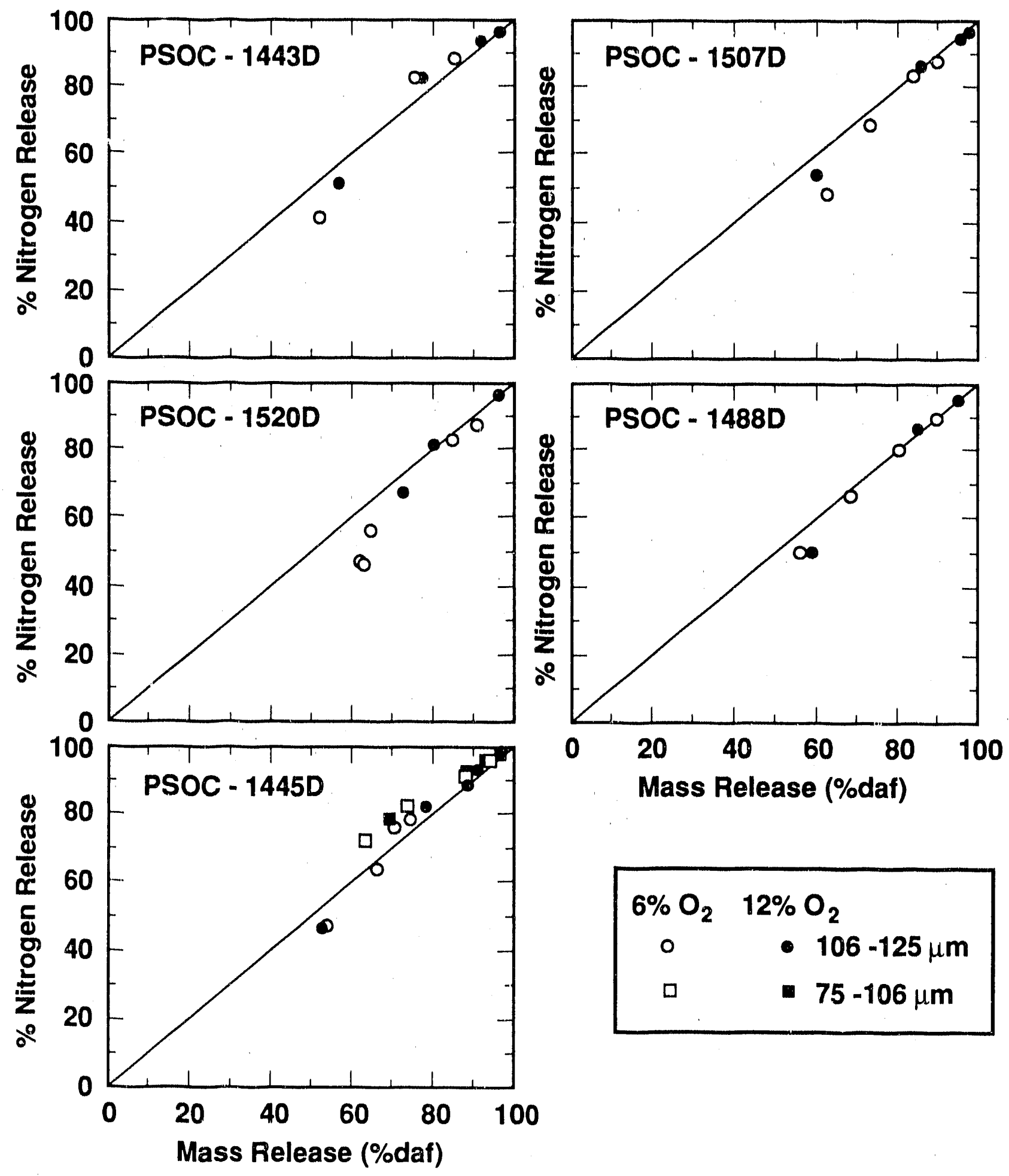

Fi gure 2.8a Release of elemental nitrogen relative to the total mass release for the lignites and subbituminous coals examined. Refer to Table 2.3 for the coal name and rank associated with the PSOC-number. 


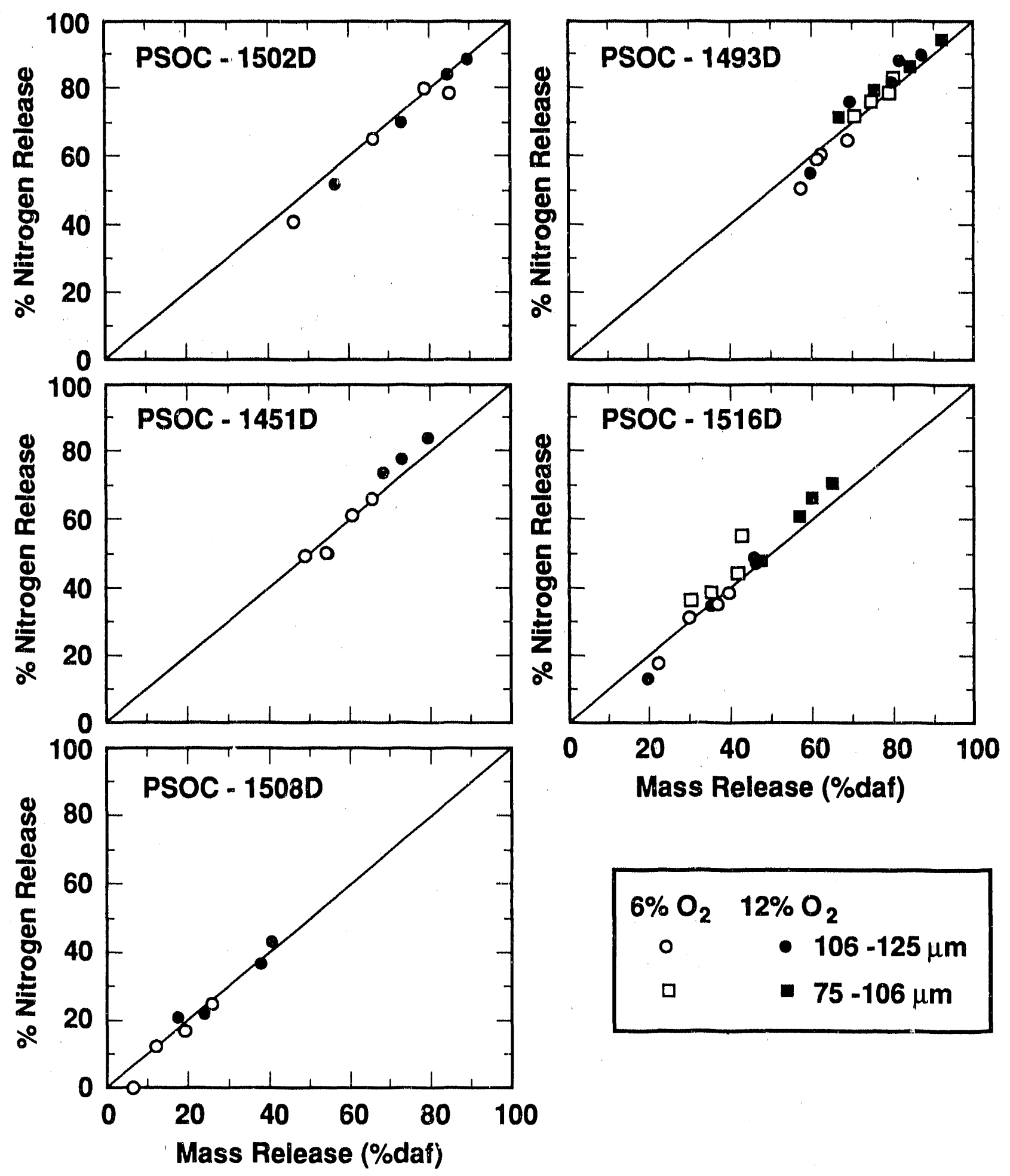

Figure 2.8b Release of elemental nitrogen relative to the total mass release fur the bituminous coals examined. Refer to Table 2.3 for the coal name and rank associated with the PSOC-number. 

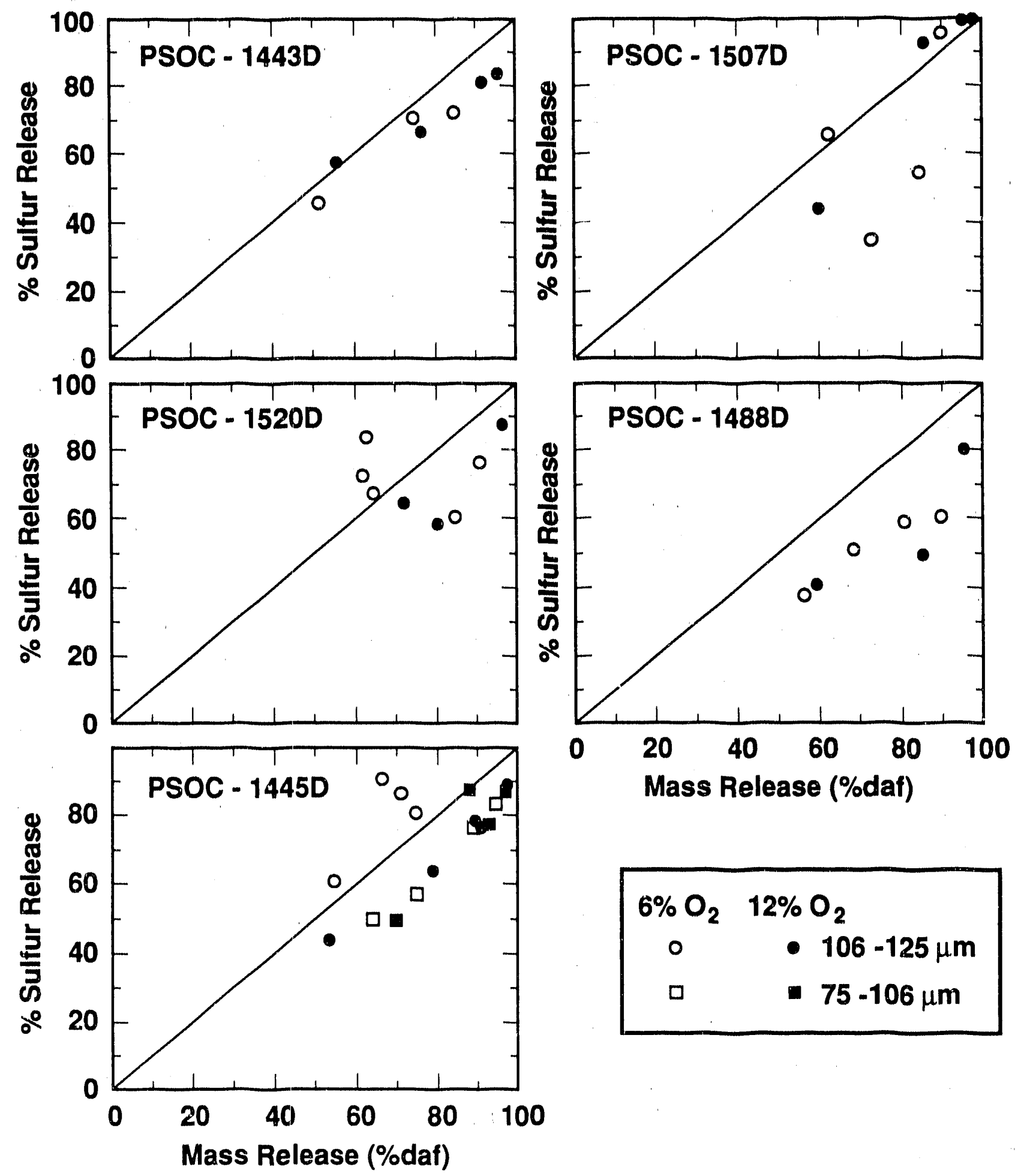

$6 \% \mathrm{O}_{2} \quad 12 \% \mathrm{O}_{2}$

○ $\quad 106-125 \mu \mathrm{m}$

ㅁ $75-106 \mu \mathrm{m}$

Figure 2.9a Release of elemental sulfur relative to the total mass release for the lignites and subbituminous coals examined. Refer to Table 2.3 for the coal name and rank associated with the PSOC-number. 

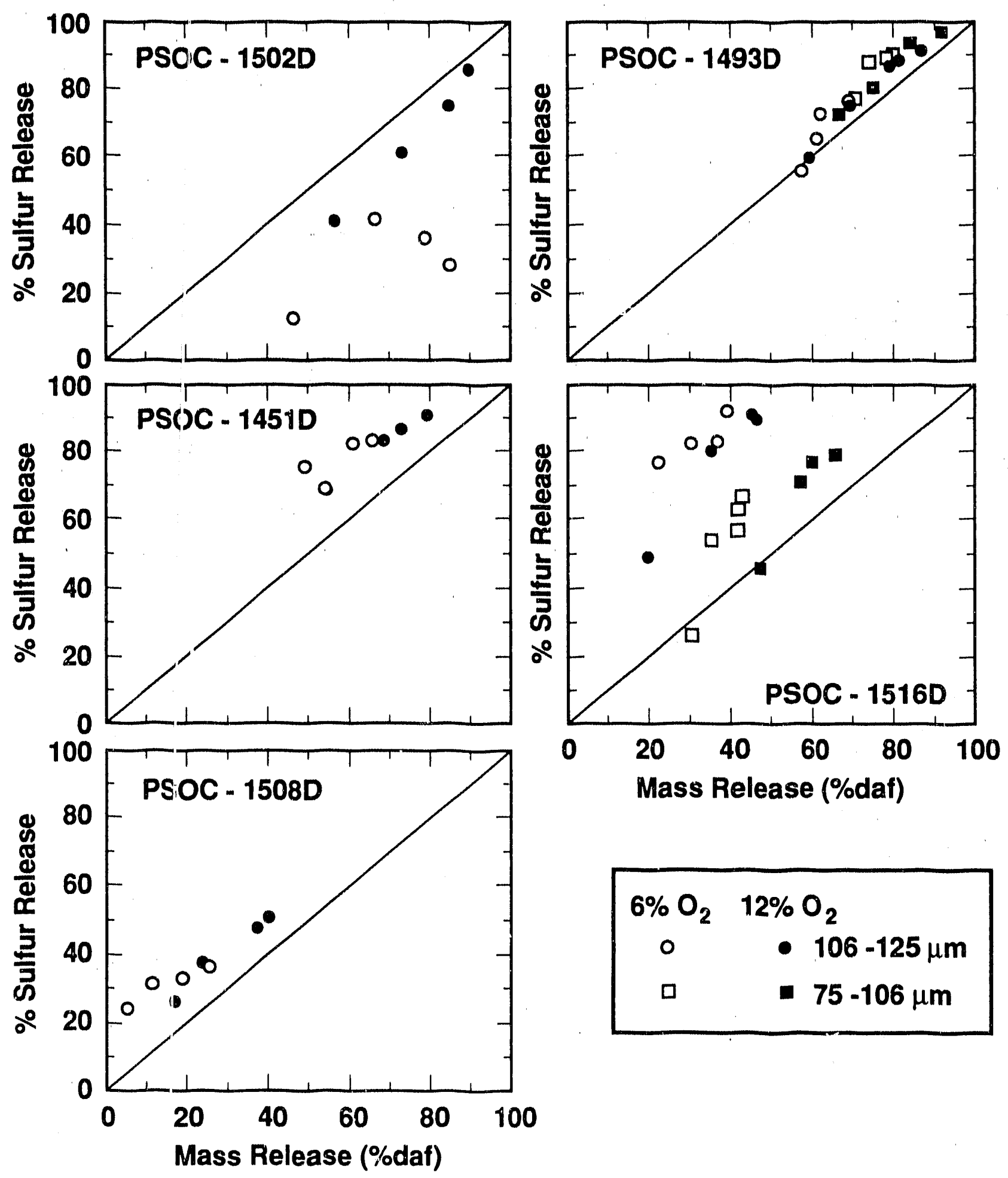

Figure $2.9 \mathrm{~b}$ Release of elemental sulfur relative to the total mass release for the bituminous coals examined. Refer to Table 2.3 for the coal name and rank associated with the PSOC-number. 
and subbituminous coals exhibit sulfur release rates slower than the total mass release rates and the higher rank bituminous coals exhibit sulfur release rates faster than the total mass release rates.

\section{Interpretations and Conclusions Conccining Elemental Release Rates during Burnoff}

During the course of char oxidation, carbon is released almost in direct proportion to the total mass release rate on an ash-free basis. This is expected since carbon is the principal component of the char. Hydrogen and oxygen are each released at rates faster than the total mass release rate during bumoff. Such releases are consistent with hydrogen and oxygen in the char occurring generally in peripheral groups such as $-\mathrm{COOH},-\mathrm{OH}, \mathrm{C}=\mathrm{O}$, and $-\mathrm{OCH}_{3}$ that are readily released at high temperatures. Some of the oxygen that is released relatively late in burnoff may be incorporated in aromatic and aliphatic ether-structures of the form $\mathrm{C}_{\mathrm{ar}}-\mathrm{O}-\mathrm{C}_{\mathrm{ar}}, \mathrm{C}_{\mathrm{ar}}-\mathrm{O}-\mathrm{C}_{\mathrm{al}}$, and/or $\mathrm{C}_{\mathrm{al}}$ O- $\mathrm{C}_{\mathrm{al}}$ that have been observed in coals (Berkowitz, 1985).

The release of nitrogen is consistent with nitrogen in the char being primarily incorporated in $\mathrm{N}$-heterocyclics and $\mathrm{C}-\mathrm{N}=\mathrm{C}$ configurations distributed throughout the carbonaceous matrix, with little occurring in amido, amino, cyano, or oxidic groups. Such nitrogen-containing functional groups are most likely released during devolatilization and during the early stages of burnoff. As noted with the release of nitrogen during heatup and devolatilization (Fletcher, 1989), for all the conls examined, nitrogen release during char oxidation is almost proportional to carbon release (at a slightly higher rate during oxidation as opposed to a slightly lower rate during devolatilization). This is more evident when the nitrogen release is plotted versus the carbon release, as shown in Fig. 2.10. Nitrogen releare proportional to carbon release supports the contention that nitrogen in coal chars is primarily bound in $\mathrm{N}$-heterocyclics and $\mathrm{C}-\mathrm{N}=\mathrm{C}$ configurations rather than in loosely bound amino, amido, or cyano groups.

Sulfur release rates no doubt depend upon the relative amounts of the different forms of sulfur (pyritic, sulfatic, or organic) in the coal. Illinois \#6 coal, which contains almost equal amounts of pyritic and organic forms of sulfur, releases sulfur almost in proportion to the total mass release rate during the middle to late stages of burnoff. This suggests that the pyritic sulfur is released preferentially to the organic sulfur (during devolatilization and early burnoff), for onf would expect that only sulfur incorporated in aromatic clusters and aliphatic ether-structures to be released in proportion to the carbon release rate.

The organic sulfur is incorporated in peripheral end-groups and linkages of the form $-S H,-S R, R^{\prime}-S-R$, and $-S-S-$ and in S-heterocyclics such as thiophenes, benzothiophenes, thioxanthenes, etc. (Berkowitz, 1985). As already mentioned, in general, the lower rank lignites and subbituminous coals exhibit sulfur release rates slower than the total mass release rates and the higher rank bituminous coals exhibit 


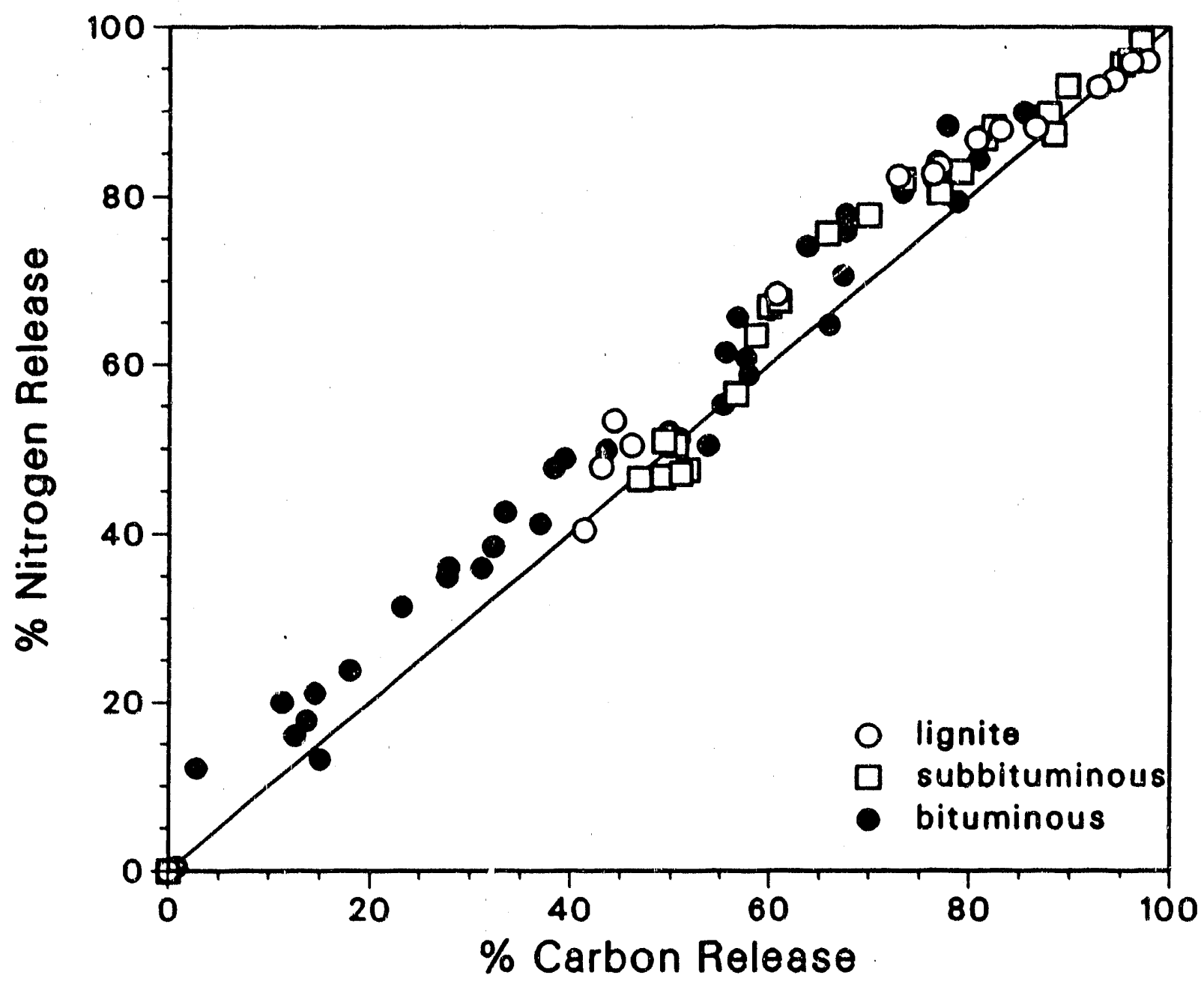

Figure 2.10 Release of elen.antal nitrogen relative to the release of elemental carbon for all the coals examined. 
sulfur release rates faster than the total mass release rates. NMR analyses indicate that in comparison to high rank coals, low rank coals have more bridge- and aliphaticcarbons, carbons that are preferentially attacked during oxidation. If a higher fraction of the sulfur in low rank coals is in heterocyclics (than in peripheral end-groups and linkages), then one would expect for sulfur release rates in low rank coals to be slower than the total mass release rates. This could explain the observed sulfur release rates relative to the total mass release rates for the low rank coals (and for Hiawatha (PSOC-1502), a hvc-bituminous coal that exhibits similar sulfur release relative to the total mass release). Chemical analysis to determine the ratio of sulfur in peripheral end-groups and linkages to the sulfur in heterocyclics are needed to determine if this is indeed the case.

Sulfur in Illinois \#6, a bituminous coal, is released almost in proportion to the total mass release rate, suggesting that the sulfur is incorporated primarily in aromatic clusters and aliphatic ether-structures. With the other bituminous coals examined, sulfur may be incorporated primarily in aromatic clusters and aliphatic ether-structures as well, with the sulfur incorporated in peripheral end-groups and linkages giving rise to overall sulfur release rates that are higher than the total mass release rates.

Illinois \#6 has the highest sulfur content of the coals examined and in comparison to the other coals, the release of sulfur is more or less orderly. This suggests that the scatter observed in the release of sulfur may be associated, in part, with the low sulfur contents of the coals and the small sample sizes analyzed.

These results indicate that the composition of the off-gas during coal char oxidation varies with burnoff. As a good, first approximation, it may be assumed that the hydrogen, oxygen, and pyritic and ulfatic sulfur in the coal leave during devolatilization and that the carbon, nitrogen, and organic sulfur leave the char at rites proportional to the total mass release rates.

\section{COAL CHAR DATA PACKAGES}

The data packages for each of the coals examined were updated to include the results of the organic elemental analyses of the raw coals used in the combustion tests and of their char samples collected in the 6 and 12 mole-\% oxygen environments. Presently, for each coal the packages contain: (1) the in situ size, temperature, and velocity measurements; (2) the $m / m_{0}$ and apparent density measurements at each sampling height; (3) the correlations for apparent density and burnoff; (4) proximate analyses of the raw coals and their partially reacted chars; and (5) $\mathrm{C}, \mathrm{H}, \mathrm{O}, \mathrm{N}$, and S elemental releases plotted as a function of burnoff on an ash-free basis. The package for Blue \#1 coal also contains the apparent chemical reaction rate coefficients and reaction orders and predicted and measured mass loss profiles in the 6 and 12 mole-\% oxygen environments. Additional information will be added to the package for each coal as the data for each are analyzed. 


\section{PLANS FOR NEXT QUARTER}

During the next quarter, analysis of the combustion data to determine kinetic parameters for the chars of several other coals tested will begin. As was indicated above, despite the inadequacy of the power-law rate expression, data analyses will proceed along the lines taken with Blue \#1 coal -- apparent reaction orders for each oxygen level will be determined that yield the same temperature dependence for the apparent chemical reaction rate coefficients in the gaseous environments employed in the combustion tests. In future work, an adsorption-desorption reaction mechanism that is adequate for all oxygen-level environments will be used in the analyses of the combustion data.

In addition, during the next quarter analysis of the data obtained with the chars that were produced under different devolatilization conditions will commence. Comparisons will be made between the burning rates of the chars produced from the same coals.

\section{REFERENCES FOR TASK 2 SECTION}

Berkowitz, N., Coal Science and Technology 7. The Chemistry of Coal, Elsevier, New York (1985).

Fletcher, T. H., "The Rates and Mechanisms of Coal Char Combustion," in Coal Combustion Science Quarterly Progress Report, January - March 1989, ed., D. R. Hardesty, Sandia National Laboratories SAND89-8241 (July 1989).

Laurendeau, N. M., Prog. Energy. Combust. Sci. 4, 221-270, (1978).

Mitchell, R. E., "The Rates and Mechanisms of Coal Char Combustion," in Coal Combustion Science Quarterly Progress Report, January - March 1987, ed., D. R. Hardesty (May 1987a).

Mitchell, R. E., "Experimentally Determined Overall Burning Rates of Coal Chars," Combustion Science and Technology 53, 2-3, 165 ,1987b)

Mitchell, R. E., "The Rates and Mechanisms of Coal Char Combustion," in Coal Combustion Science Quarterly Progress Report, April - June 1988, ed., D. R. Hardesty, Sandia National Laboratories SAND88-8260 (November 1988a).

Mitchell, R. E., "On the Products of the Heterogeneous Oxidation Reaction at the Surfaces of Burning Coal-Char Particles", Twenty-Second Symposium (International) on Combustion, The Combustion Institute, Pittsburgh, p. 69 (1988b). 
Mitchell, R. E., "The Rates and Mechanisms of Coal Char Combustion," in Coal Combustion Science Quarterly Progress Report, January - March 1989, ed., D. R. Hardesty, Sandia National Laboratories SAND89-82.41 (July 1989a).

Mitchell, R. E., "The Rates and Mechanisms of Coal Char Combustion," in Coal Combustion Science Quarierly Progress Report, April - June 1989, ed., D. R. Hardesty, Sandia National Laboratories SAND89-8250 (October 1989b).

Mitchell, R. E., "The Rates and Mechanisms of Coal Char Combustion," in Coal Combustion Science Quarterly Progress Report, January - March 1990, ed., D. R. Hardesty, Sandia National Laboratories SAND90-8223 (May 1990a).

Mitchell, R. E., "The Rates and Mechanisms of Coal Char Combustion," in Coal Combustion Science Quarterly Progress Report, April - June 1990, ed., D. R. Hardesty, Sandia National Laboratories SAND90-XXXX (November 1990b).

\section{NOMENCLATURE FOR TASK 2 SECTION}

$A_{a} \quad$ apparent pre-exponential factor, $\mathrm{gC} \mathrm{cm}^{-2} \mathrm{~s}^{-1} \mathrm{~atm}^{-\mathrm{n}}$

$C_{s} \quad$ oxygen concentration at the particle surface, mole $\mathrm{cm}^{-3}$

$E_{a} \quad$ apparent activation energy, cal mole-1

$f_{i}$ fraction of the initial amount of element i remaining in the char

$k_{s} \quad$ apparent chemical reaction rate coefficient, $\mathrm{gC} \mathrm{cm}^{-2} \mathrm{~s}^{-1} \mathrm{~atm}-\mathrm{n}$

$k_{s, i} \quad$ intrinsic chemical reaction rate constant, $\left(\text { mole } \mathrm{O}_{2}\right)^{(1-\mathrm{m})}\left(\mathrm{cm}^{3} \text { fluid }\right)^{\mathrm{m}} \mathrm{s}^{-1}$ (cm $^{2}$ surface)-1

$m \quad$ true reaction order (Eq. (2.2) or mass of coal char, $g$

mo mass of raw coal, $\mathrm{g}$

$n \quad$ apparent reaction order

$P_{s} \quad$ oxygen partial pressure at the particle surface, atm

$q$ overall particle burning rate per unit external surface area, $\mathrm{gC} \mathrm{cm}^{-2} \mathrm{~s}^{-1}$

$q_{i} \quad$ intrinsic chemical reaction rate, $\left(\right.$ mole $\left.\mathrm{O}_{2}\right) \mathrm{s}^{-1}\left(\mathrm{~cm}^{2} \text {-surface }\right)^{-1}$

$T_{p} \quad$ particle temperature, $\mathrm{K}$

$\mathrm{x}_{i} \quad$ weight fraction of element $\mathrm{i}$ in the char

$\mathrm{x}_{i, 0} \quad$ weight fraction of element $\mathrm{i}$ in the raw coal

$X_{a} \quad$ weight fraction of ash in the char

$X_{a, 0} \quad$ weight fraction of ash in the raw coal

Greek

$\eta \quad$ effectiveness factor: the ratio of the actual reaction rate to that which would occur if the entire particle were exposed to the same oxygen concentration and temperature as that existing at the outer surface of the particle

$\rho_{p} \quad$ apparent density of the particle, $\mathrm{g} \mathrm{cm}^{-3}$ 


\section{VISITING STUDENT}

In August, Mr Lucien Johnson, a junior at Howard University in Mechanical Engineering, completed his two and one-half month summer visit to Sandia. During his visit, he helped perform experiments in the coal char combustion laboratory. His help was greatly appreciated.

\section{PUBLICATIONS, PAPERS AND PRESENTATIONS FOR TASK 2}

Two papers were presented at the Twenty-Third International Symposium on Combustion in Orleans, France, July $22-27,1990$. The papers are entitled "The Effect of CO Conversion in the Boundary Layers St rrounding Pulverized-Coal Char Particles" and "Variations in the Temperatures of Coal-Char Particles during Combustion: A Consequence of Particle-to-Particle Variations in Ash-Content."

A presentation entitled "Modeling Coal Char Combustion" was presented at a "MiniSymposium" at the Danish Gas Center in Horsholm, Denmark, July 31, 1990. The presentation summarized the theoretical models used in this DOE effort to describe the burning characteristics of ccai chiar particles in typical pulverized-coal combustors.

A presentation entitled "Coal Char Combustion" was presented at the 1990 DOE Review of Fossil Energy Advanced Research in Bethesda, MD, August 22, 1990. The presentation reviewed the objectives and accomplishments of this research effort on coal char combustion.

A presentation entitled "Rates and Mechanisms of Pulverized Coal Chars" was presented at the Advanced Research and Technology Development, Direct Utilization and Instrumentation and Diagnostics Contractors' Review Meeting in Pittsburgh, PA, September 16-18, 1990. The talk summarized recent advances in understanding the combustion characteristics of pulverized coal chars. 


\title{
APPENDIX FOR TASK 2 SECTION
}

\section{STATISTICAL ANALYSIS OF SIZE, TEMPERATURE, AND VELOCITY DATA OBTAINED WITH BLUE \#1 COAL}

\author{
Table 2.A.1. 6 mole-\% Oxygen Environment, $12.7 \mathrm{~cm}$ height \\ Table 2.A.2. 6 mole-\% Oxygen Environment, $19.1 \mathrm{~cm}$ height \\ Table 2.A.3. 6 mole-\% Oxygen Environment, $25: 4 \mathrm{~cm}$ height \\ Table 2.A.4. 12 mole-\% Oxygen Environment, $12.7 \mathrm{~cm}$ height \\ Table 2.A.5. 12 mole-\% Oxygen Environment, $19.1 \mathrm{~cm}$ height \\ Table 2.A.6. 12 mole-\% Oxygen Environment, $25.4 \mathrm{~cm}$ height
}


TABLE 2.A.1

COAL TYPE: BLUE \#1 COAL, 106 - 125 micron OXYGEN CONTENT OF GAS: 6.0 mole-\% GAS TEMPERATURE: $1642 \mathrm{~K}$ SAMPLING HEIGHT: $12.7 \mathrm{~cm}$

$\begin{array}{cccccccc}\begin{array}{c}\text { SIZE } \\ \text { (micron) }\end{array} & \text { NUM } & \begin{array}{c}\text { TEMP } \\ (\mathrm{K})\end{array} & \begin{array}{c}\mathrm{rms}(\mathrm{T}) \\ (\mathrm{K})\end{array} & \begin{array}{c}\text { VEL } \\ (\mathrm{m} / \mathrm{s})\end{array} & \begin{array}{c}\mathrm{rms}(\mathrm{V}) \\ (\mathrm{m} / \mathrm{s})\end{array} & \text { EMISS } & \mathrm{rms}(\mathrm{E}) \\ & & & & & & \\ 50 . & 0 & 0 & 0 & 0.00 & 0.00 & 0.00 & 0.00 \\ 60 . & 0 & 0 & 0 & 0.00 & 0.00 & 0.00 & 0.00 \\ 70 . & 0 & 0 & 0 & 0.00 & 0.00 & 0.00 & 0.00 \\ 80 . & 0 & 0 & 0 & 0.00 & 0.00 & 0.00 & 0.06 \\ 90 . & 0 & 0 & 0 & 0.00 & 0.00 & 0.00 & 0.00 \\ 100 . & 0 & 0 & 0 & 0.00 & 0.00 & 0.00 & 0.00 \\ 110 . & 2 & 1732 & 20 & 2.59 & 0.02 & 0.75 & 0.05 \\ 120 . & 6 & 1736 & 11 & 2.62 & 0.02 & 0.74 & 0.05 \\ 130 . & 17 & 1737 & 13 & 2.61 & 0.02 & 0.71 & 0.06 \\ 140 . & 9 & 1733 & 13 & 2.62 & 0.02 & 0.68 & 0.05 \\ 150 . & 13 & 1724 & 8 & 2.62 & 0.02 & 0.71 & 0.05 \\ 160 . & 5 & 1730 & 6 & 2.63 & 0.02 & 0.64 & 0.04 \\ 170 . & 1 & 1716 & 0 & 2.55 & 0.00 & 0.74 & 0.00 \\ 180 . & 3 & 1697 & 32 & 2.60 & 0.04 & 0.65 & 0.00 \\ 190 . & 1 & 1721 & 0 & 2.63 & 0.00 & 0.61 & 0.00 \\ 200 . & 0 & 0 & 0 & 0.00 & 0.00 & 0.00 & 0.00 \\ 210 . & 0 & 0 & 0 & 0.00 & 0.00 & 0.00 & 0.00 \\ 220 . & 0 & 0 & 0 & 0.00 & 0.00 & 0.00 & 0.00 \\ 230 . & 0 & 0 & 0 & 0.00 & 0.00 & 0.00 & 0.00 \\ 240 . & 0 & 0 & 0 & 0.00 & 0.00 & 0.00 & 0.00\end{array}$


TABLE 2.A.2

COAL TYPE: BLUE \#1 COAL, 106 - 125 micron

OXYGEN CONTENT OF GAS: 6.0 mole-\%

GAS TEMPERATURE: $1593 \mathrm{~K}$

SAMPLING HEIGHT: $19.1 \mathrm{~cm}$

\begin{tabular}{|c|c|c|c|c|c|c|c|}
\hline $\begin{array}{c}\text { SIZE } \\
\text { (micron) }\end{array}$ & NUM & $\begin{array}{c}\text { TEMP } \\
(\mathrm{K})\end{array}$ & $\begin{array}{c}\operatorname{rms}(\mathrm{T}) \\
(\mathrm{K})\end{array}$ & $\begin{array}{l}\text { VEL } \\
(\mathrm{m} / \mathrm{s})\end{array}$ & $\begin{array}{c}\mathrm{rms}(\mathrm{V}) \\
(\mathrm{m} / \mathrm{s})\end{array}$ & EMISS & $\operatorname{rms}(E$ \\
\hline 50. & 0 & 0 & 0 & 0.00 & 0.00 & 0.00 & 0.00 \\
\hline 60. & 0 & 0 & 0 & 0.00 & 0.00 & 0.00 & 0.00 \\
\hline 70. & 0 & 0 & 0 & 0.00 & .0 .00 & 0.00 & 0.00 \\
\hline 80. & 0 & 0 & 0 & 0.00 & 0.00 & 0.00 & 0.00 \\
\hline 90. & 0 & 0 & 0 & 0.00 & 0.00 & 0.00 & 0.00 \\
\hline 100. & 0 & 0 & 0 & 0.00 & 0.00 & 0.00 & 0.00 \\
\hline 110. & 6 & 1711 & 6 & 2.81 & 0.01 & 0.74 & 0.05 \\
\hline 120. & 13 & 1714 & 18 & 2.78 & 0.03 & 0.73 & 0.05 \\
\hline 130. & 23 & 1707 & 9 & 2.77 & 0.05 & 0.69 & 0.05 \\
\hline 140. & 21 & 1693 & 14 & 2.77 & 0.07 & 0.68 & 0.06 \\
\hline 150. & 12 & 1694 & 7 & 2.77 & 0.02 & 0.69 & 0.06 \\
\hline 160. & 6 & 1690 & 10 & 2.77 & 0.02 & 0.66 & 0.05 \\
\hline 170. & 3 & 1685 & 4 & 2.78 & 0.01 & 0.67 & 0.01 \\
\hline 180. & 2 & 1685 & 1 & 2.80 & 0.00 & 0.76 & 0.00 \\
\hline 190. & 0 & 0 & 0 & 0.00 & 0.00 & 0.00 & 0.00 \\
\hline 200 . & 0 & 0 & 0 & 0.00 & 0.00 & 0.00 & 0.00 \\
\hline 210. & 0 & 0 & 0 & 0.00 & 0.00 & 0.00 & 0.00 \\
\hline 220 . & 0 & 0 & 0 & 0.00 & 0.00 & 0.00 & 0.00 \\
\hline 230 . & 0 & 0 & 0 & 0.00 & 0.00 & 0.00 & 0.00 \\
\hline 240 . & 0 & 0 & 0 & 0.00 & 0.00 & 0.00 & 0.00 \\
\hline
\end{tabular}

NUMBER OF PARTICLES $=86$

PARTICLES SCREENED BASED ON EMISSIVITIES FROM 0.60 TO 0.80 
TABLE 2.A.3

COAL TYPE: BLUE \#1 COAL, 106 - 125 micron OXYGEN CONTENT OF GAS: 6.0 mole-\%

GAS TEMPERATURE: $1536 . \mathrm{K}$

SAMPLING HEIGHT: $25.4 \mathrm{~cm}$

$\begin{array}{cccccccc}\begin{array}{c}\text { SIZE } \\ \text { (micron) }\end{array} & \text { NUM } & \begin{array}{c}\text { TEMP } \\ (\mathrm{K})\end{array} & \begin{array}{c}\mathrm{rms}(\mathrm{T}) \\ (\mathrm{K})\end{array} & \begin{array}{c}\text { VEL } \\ (\mathrm{m} / \mathrm{s})\end{array} & \begin{array}{c}\mathrm{rms}(\mathrm{V}) \\ (\mathrm{m} / \mathrm{s})\end{array} & \text { EMISS } & \text { rms(E) } \\ 50 . & 0 & 0 & 0 & 0.00 & 0.00 & 0.00 & 0.00 \\ 60 . & 0 & 0 & 0 & 0.00 & 0.00 & 0.00 & 0.00 \\ 70 . & 0 & 0 & 0 & 0.00 & 0.00 & 0.00 & 0.00 \\ 80 . & 0 & 0 & 0 & 0.00 & 0.00 & 0.00 & 0.00 \\ 90 . & 1 & 1693 & 0 & 3.07 & 0.00 & 0.61 & 0.00 \\ 100 . & 1 & 1692 & 0 & 3.00 & 0.00 & 0.79 & 0.00 \\ 110 . & 4 & 1675 & 6 & 3.02 & 0.04 & 0.77 & 0.02 \\ 120 . & 25 & 1677 & 10 & 3.00 & 0.04 & 0.70 & 0.05 \\ 130 . & 21 & 1673 & 8 & 3.00 & 0.04 & 0.71 & 0.05 \\ 140 . & 20 & 1662 & 23 & 2.98 & 0.05 & 0.66 & 0.04 \\ 150 . & 3 & 1657 & 3 & 2.96 & 0.00 & 0.71 & 0.04 \\ 160 . & 8 & 1664 & 17 & 2.95 & 0.06 & 0.70 & 0.07 \\ 170 . & 0 & 0 & 0 & 0.00 & 0.00 & 0.00 & 0.00 \\ 180 . & 0 & 0 & 0 & 0.00 & 0.00 & 0.00 & 0.00 \\ 190 . & 0 & 0 & 0 & 0.00 & 0.00 & 0.00 & 0.00 \\ 200 . & 0 & 0 & 0 & 0.00 & 0.00 & 0.00 & 0.00 \\ 210 . & 0 & 0 & 0 & 0.00 & 0.00 & 0.00 & 0.00 \\ 220 . & 0 & 0 & 0 & 0.00 & 0.00 & 0.00 & 0.00 \\ 230 . & 0 & 0 & 0 & 0.00 & 0.00 & 0.00 & 0.00 \\ 240 . & 0 & 0 & 0 & 0.00 & 0.00 & 0.00 & 0.00\end{array}$

NUMBER OF PARTICLES $=83$

PARTICLES SCREENED BASED ON EMISSIVITIES FROM 0.60 TO 0.80 
TABLE 2.A.4

COAL TYPE: BLUE \#1 COAL, 106 - 125 micron OXYGEN CONTENT OF GAS: 12.0 mole-\%

GAS TEMPERATURE: $1645 \mathrm{~K}$

SAMPLING HEIGHT: $12.7 \mathrm{~cm}$

$\begin{array}{cccccccc}\begin{array}{c}\text { SIZE } \\ \text { (micron) }\end{array} & \text { NUM } & \begin{array}{c}\text { TEMP } \\ (\mathrm{K})\end{array} & \begin{array}{c}\mathrm{rms}(\mathrm{T}) \\ (\mathrm{K})\end{array} & \begin{array}{c}\text { VEL } \\ (\mathrm{m} / \mathrm{s})\end{array} & \begin{array}{c}\mathrm{rms}(\mathrm{V}) \\ (\mathrm{m} / \mathrm{s})\end{array} & \text { EMISS } & \mathrm{rms}(\mathrm{E}) \\ 50 . & 0 & 0 & 0 & 0.00 & 0.00 & 0.00 & 0.00 \\ 60 . & 0 & 0 & 0 & 0.00 & 0.00 & 0.00 & 0.00 \\ 70 . & 0 & 0 & 0 & 0.00 & 0.00 & 0.00 & 0.00 \\ 80 . & 0 & 0 & 0 & 0.00 & 0.00 & 0.00 & 0.00 \\ 90 . & 0 & 0 & 0 & 0.00 & 0.00 & 0.00 & 0.00 \\ 100 . & 4 & 1904 & 8 & 2.64 & 0.04 & 0.72 & 0.07 \\ 110 . & 7 & 1896 & 8 & 2.63 & 0.02 & 0.69 & 0.04 \\ 120 . & 19 & 1879 & 10 & 2.61 & 0.02 & 0.73 & 0.04 \\ 130 . & 19 & 1883 & 11 & 2.61 & 0.03 & 0.69 & 0.04 \\ 140 . & 14 & 1867 & 18 & 2.62 & 0.03 & 0.70 & 0.06 \\ 150 . & 10 & 1868 & 9 & 2.60 & 0.04 & 0.68 & 0.05 \\ 160 . & 14 & 1866 & 10 & 2.60 & 0.03 & 0.71 & 0.06 \\ 170 . & 7 & 1870 & 11 & 2.60 & 0.03 & 0.68 & 0.05 \\ 180 . & 1 & 1863 & 0 & 2.60 & 0.00 & 0.73 & 0.00 \\ 190 . & 2 & 1875 & 10 & 2.59 & 0.02 & 0.63 & 0.02 \\ 200 . & 0 & 0 & 0 & 0.00 & 0.00 & 0.00 & 0.00 \\ 210 . & 0 & 0 & 0 & 0.00 & 0.00 & 0.00 & 0.00 \\ 220 . & 0 & 0 & 0 & 0.00 & 0.00 & 0.00 & 0.00 \\ 230 . & 0 & 0 & 0 & 0.00 & 0.00 & 0.00 & 0.00 \\ 240 . & 0 & 0 & 0 & 0.00 & 0.00 & 0.00 & 0.00\end{array}$

NUMBER OF PARTICLES $=97$

PARTICLES SCREENED BASED ON EMISSIVITIES FROM 0.60 TO 0.80 
TABLE 2.A.5

COAL TYPE: BLUE \#1 COAL, 106 - 125 micron

OXYGEN CONTENT OF GAS: 12.0 mole- $\%$

GAS TEMPERATURE: $1591 \mathrm{~K}$

SAMPLING HEIGHT: $19.1 \mathrm{~cm}$

\begin{tabular}{|c|c|c|c|c|c|c|c|}
\hline$\underset{\text { (micron) }}{\text { SIZE }}$ & NUM & $\begin{array}{c}\text { TEMP } \\
(\mathrm{K})\end{array}$ & $\begin{array}{c}\operatorname{rms}(\mathrm{T}) \\
(\mathrm{K})\end{array}$ & $\begin{array}{l}\text { VEL } \\
(\mathrm{m} / \mathrm{s})\end{array}$ & $\begin{array}{c}\mathrm{rms}(\mathrm{V}) \\
(\mathrm{m} / \mathrm{s})\end{array}$ & EMISS & $\mathrm{rms}(\mathrm{E})$ \\
\hline 50. & 0 & 0 & 0 & 0.00 & 0.00 & 0.00 & 0.00 \\
\hline 60. & 0 & 0 & 0 & 0.00 & 0.00 & 0.00 & 0.00 \\
\hline 70. & 0 & 0 & 0 & 0.00 & 0.00 & 0.00 & 0.00 \\
\hline 80. & 1 & 1892 & 0 & 2.60 & 0.00 & 0.79 & 0.00 \\
\hline 90. & 0 & 0 & 0 & 0.00 & 0.00 & 0.00 & 0.00 \\
\hline 100. & 14 & 1870 & 18 & 2.75 & 0.07 & 0.68 & 0.05 \\
\hline 110. & 18 & 1872 & 7 & 2.76 & 0.04 & 0.74 & 0.05 \\
\hline 120. & 22 & 1864 & 16 & 2.77 & 0.05 & 0.69 & 0.06 \\
\hline 130. & 18 & 1852 & 41 & 2.74 & 0.09 & 0.70 & 0.05 \\
\hline 140. & 10 & 1848 & 21 & 2.73 & 0.06 & 0.69 & 0.06 \\
\hline 150. & 5 & 1799 & 129 & 2.70 & 0.07 & 0.66 & 0.06 \\
\hline 160. & 2 & 1841 & 11 & 2.77 & 0.04 & 0.65 & 0.01 \\
\hline 170. & 0 & 0 & 0 & 0.00 & 0.00 & 0.00 & 0.00 \\
\hline 180. & 0 & 0 & 0 & 0.00 & 0.00 & 0.00 & 0.00 \\
\hline 190. & 0 & 0 & 0 & 0.00 & 0.00 & 0.00 & 0.00 \\
\hline 200. & 0 & 0 & 0 & 0.00 & 0.00 & 0.00 & 0.00 \\
\hline 210. & 0 & 0 & 0 & 0.00 & 0.00 & 0.00 & 0.00 \\
\hline 220. & 0 & 0 & 0 & 0.00 & 0.00 & 0.00 & 0.00 \\
\hline 230. & 0 & 0 & 0 & 0.00 & 0.00 & 0.00 & 0.00 \\
\hline 240. & 0 & 0 & 0 & 0.00 & 0.00 & 0.00 & 0.00 \\
\hline
\end{tabular}

NUMBER OF PARTICLES $=90$

PARTICLES SCREENED BASED ON EMISSIVITIES FROM 0.60 TO 0.80 
TABLE 2.A.6

COAL TYPE: BLUE \#1 COAL, 106 - 125 micron

OXYGEN CONTENT OF GAS: 12.0 mole-\%

GAS TEMPERATURE: $1532 \mathrm{~K}$

SAMPLING HEIGHT: $25.4 \mathrm{~cm}$

$\begin{array}{cccccccc}\begin{array}{c}\text { SIZE } \\ \text { (micron) }\end{array} & \text { NUM } & \begin{array}{c}\text { TEMP } \\ (\mathrm{K})\end{array} & \begin{array}{c}\mathrm{rms}(\mathrm{T}) \\ (\mathrm{K})\end{array} & \begin{array}{c}\text { VEL } \\ (\mathrm{m} / \mathrm{s})\end{array} & \begin{array}{c}\mathrm{rms}(\mathrm{V}) \\ (\mathrm{m} / \mathrm{s})\end{array} & \text { EMISS } & \mathrm{rms}(\mathrm{E}) \\ 50 . & 0 & 0 & 0 & 0.00 & 0.00 & 0.00 & 0.00 \\ 60 . & 0 & 0 & 0 & 0.00 & 0.00 & 0.00 & 0.00 \\ 70 . & 0 & 0 & 0 & 0.00 & 0.00 & 0.00 & 0.00 \\ 80 . & 0 & 0 & 0 & 0.00 & 0.00 & 0.00 & 0.00 \\ 90 . & 1 & 1785 & 0 & 3.00 & 0.00 & 0.66 & 0.00 \\ 100 . & 7 & 1840 & 28 & 2.96 & 0.05 & 0.64 & 0.04 \\ 110 . & 8 & 1819 & 30 & 2.91 & 0.05 & 0.70 & 0.06 \\ 120 . & 11 & 1773 & 104 & 2.92 & 0.04 & 0.64 & 0.04 \\ 130 . & 3 & 1830 & 6 & 2.96 & 0.00 & 0.62 & 0.00 \\ 140 . & 0 & 0 & 0 & 0.00 & 0.00 & 0.00 & 0.00 \\ 150 . & 0 & 0 & 0 & 0.00 & 0.00 & 0.00 & 0.00 \\ 160 . & 0 & 0 & 0 & 0.00 & 0.00 & 0.00 & 0.00 \\ 170 . & 0 & 0 & 0 & 0.00 & 0.00 & 0.00 & 0.00 \\ 180 . & 0 & 0 & 0 & 0.00 & 0.00 & 0.00 & 0.00 \\ 190 . & 0 & 0 & 0 & 0.00 & 0.00 & 0.00 & 0.00 \\ 200 . & 0 & 0 & 0 & 0.00 & 0.00 & 0.00 & 0.00 \\ 210 . & 0 & 0 & 0 & 0.00 & 0.00 & 0.00 & 0.00 \\ 220 . & 0 & 0 & 0 & 0.00 & 0.00 & 0.00 & 0.00 \\ 230 . & 0 & 0 & 0 & 0.00 & 0.00 & 0.00 & 0.00 \\ 240 . & 0 & 0 & 0 & 0.00 & 0.00 & 0.00 & 0.00\end{array}$

NUMBER OF PARTICLES $=30$

PARTICLES SCREENED BASED ON EMISSIVITIES FROM 0.60 TO 0.80 


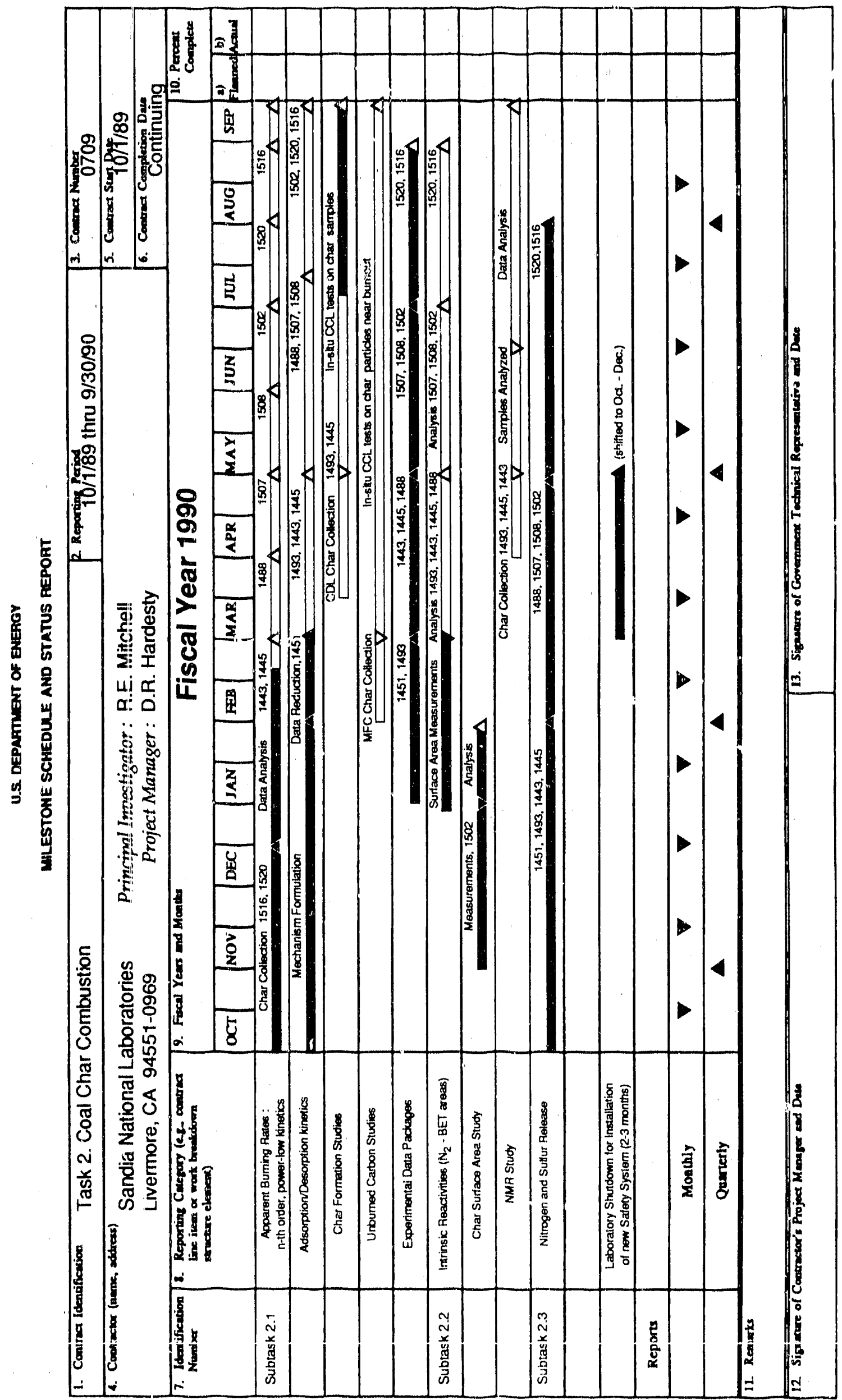


PROJECT TITLE:

ORGANIZATION:

CONTRACT:

REPORTING PERIOD:

REPORTED BY:
COAL COMBUSTION SCIENCE

TASK 3: THE FATE OF MINERAL MATTER

Sindia National Laboratories, Livermore

FWP 0709

July 1, 1990 - September 30, 1990

L. L. Baxter and D. R. Hardesty

Phone: FTS 234-2862 and 234-2321

\section{OBJECTIVES FOR TASK 3}

The long-term objective of this task is to gain quantitative understanding of the rates and mechanisms of selected aspects of mineral matter evolution, transport and deposition under conditions relevant tr pulverized coal combustion. These selected aspects of mineral matter evolution include: (1) release of n norganic material from coal particles during reactions of the organic and inorganic portions of the particle and by vaporization; (2) changes in mineral matter composition during combustion; (3) size distributions of fly ash formed du ag coal combustion; and (4) depcsition of mineral matter on surfaces. These aspects of mineral matter evolution will be studied as a function of coal and mineral type, total ash loading, rate of organic and inorganic reaction, local gas conditions, and time.

The focus of research during FY90 is on (i) the release of inorganic material during coal devolatilization, (ii) the evolution of particle and fly ash size distributions, and (iii) theoretical and experimental studies of ash depovition. Three subtasks are defined to address these issues.

\section{Subtask 3.1 Release of Inorganic Material During Coal Devolatilization and Char Oxidation}

The goal of this subtask is to test the hypothesis that some inorganic species are released from coal particles during coal devolatilization and char oxidation. Particular focus is on mechanisms of release other than ash vaporization. Material release effected by coal devolatilization involves the small-grained and organically-associ ated minerals, man \% of which are str ngly implicated in depos.t formation in commercia siale boilers. Mireral release associated with inorganic reactivity is associated includes thermally unstable or chemically reactive material such as pyrits: and calcite, both of which play significant roles in deposit 'ormation and properties. This subtask uses data collected in each of the three coal reactors at Sandia ard tests several rariks of coal at several rates of devolatilization. 


\section{Subtask 3.2 The Evolution of Particle and Fly ash Size Distributions}

The goal of this subtask is to determine the extent of char pulverized coal combustion. This is accomplished by measiaring the particle size distributions of the char and fly ash and relating these through a mathematical model. The model indicates the number of fly ash particles generated per original char particle, both for the overall fuel and as a function of size. These results are collecied as a function of coal rank and of ash loading.

\section{Subtask 3.3 Theoretical and Experimental Studies of Ash Deposition}

Theoretical and experimental investigations of ash deposition are being conducted to determine the elemental composition of deposits as a function of coal type boiler operating conditions, and coal type. The effect of deposit formation on heat transfer efficiency through sinnulated boiler tubes and waterwalls is also being studied. The mechanisms of deposit formation are being combined into an engineering model that predicts elemental deposit composition.

\section{SUMMARY OF TECHNICAL PROGRESS DURING THIS QUARTER}

\section{Subtask 3.1 Release of Inorganic Material During Coal Devolatilization and Char Oxidation}

During this quarter experiments focusing on the role of pyrite oxidation in iron fume formation were completed. In these experiments, three samples of Illinois \#6 coal (PSOC-1493D) were exposed to room temperature air for up to one week and then used as feedstock for experiments in the Char Combustion Laboratory (CCL). These experiments were performed with the same coal (albeit oxidized or weathered), in the same facility, and under the same conditions as previously reported. In the earlier experiments it was observed that large amounts of iron fume are formed. Solid samples have been submitted to the same analysis procedures as used in the previous experiments. A complete report of the results of this work will be given in the next quarterly report, after analysis of the samples is completed.

\section{Subtask 3.2 The Evolution of Particle and Fly Ash Size Distributions}

During this quartc baseline experiments were conducted in the Multifuel Combustor $\left(M^{\mp} \mathrm{C}\right)$ on a suite of coals. A combination of in situ measurements, solid sampling, and photography was used to collect data on: (1) particle size distributions between 0.5 and $100 \mu \mathrm{m} ;(2)$ fly ash composition and particle burnout, and; (3) particle velocities. During these experiments data for Subtask 3.3 were alsc collected, inclidirig: (1) rate of growth, morphology, and composition of deposits on both a tube in cross rlow and a simulated wa er wall, and; (2) heat transfer efficiencies on water walls and tubes in cross flow. These data were obtained as a function ol particle residence time $(0-2.5 \mathrm{~s})$, coal type (lignites to bituminous), and coal blending (three blends and their corstituents). Four coals have been added to the original suire of 15 coals (total of 19). Three of thesi additional coals are derived from a coal blend, $30 \%$ Illinois $\# 6 / 70 \%$ Rochelle (Powder 
River Basur. , currently being tested at a midwestern utility. The fourth is a Pittsburgh seam coal being tested at Consol; it will be used for comparison of data obtained in the Sanuia and Consol experiments.

An updated table of the coals being tested is presented as Table 3.1, including an indication of the status of the testing for each coal. These tests should be completed within the next quarter.

Table 3.1

Summary of the 19 Coals and Blends of Coals, Including Ranks, Used in Support of Subtasks 3.2 and 3.3.

\begin{tabular}{|c|c|c|c|c|c|}
\hline \multicolumn{6}{|c|}{$\begin{array}{c}\text { Fuels Selectec for Fly Ash Formation and Ash Deposition Experiments in the } \\
\text { Multifuel Combustor }\end{array}$} \\
\hline Coal or Blend $\S$ & Rank & Status $\dagger$ & Coal or Blend $\S$ & Rank & Status $\dagger$ \\
\hline Pittsburgh Seam & $\begin{array}{l}\text { hvA } \\
\text { Bituminous }\end{array}$ & $p$ & $\begin{array}{l}\text { Illinois \#6(2)/ } \\
\text { Rochelle Blend }\end{array}$ & $\begin{array}{l}\text { hvC } \\
\text { Bituminous }\end{array}$ & $p$ \\
\hline Pittsburgh \#8 (1) & $\begin{array}{l}\text { hvA } \\
\text { Bituminous }\end{array}$ & c & Kentucky \#9* & $\begin{array}{l}\text { hvC } \\
\text { Bituminous }\end{array}$ & c \\
\hline Pitısburgh \#8 (2) & $\begin{array}{l}\text { hvA } \\
\text { Bituminous }\end{array}$ & c & Blind Canyon & $\begin{array}{l}\text { hvC } \\
\text { Bituminous }\end{array}$ & $\mathrm{p}$ \\
\hline Eastern Blend & $\begin{array}{l}\text { hvA } \\
\text { Bituminous }\end{array}$ & c & Decker & $\begin{array}{l}\text { hvC } \\
\text { Bituminous }\end{array}$ & c \\
\hline Upper Freeport * & $\begin{array}{l}\text { hvA } \\
\text { Bituminous }\end{array}$ & $\mathrm{u}$ & Wyodak & Subbitum. B & c \\
\hline Eastern Kentucky & $\begin{array}{l}\text { hvA } \\
\text { Bituminous }\end{array}$ & c & Eagle Butte * & Subbitum. C & $\mathrm{c}$ \\
\hline $\begin{array}{l}\text { Pitt\#8/Decker } \\
\text { Blend }\end{array}$ & $\begin{array}{l}\text { hvA } \\
\text { Bituminous }\end{array}$ & c & Rochelle & Subbiturn. C & $\mathrm{p}$ \\
\hline Kentucky \#11* & $\begin{array}{l}\text { hvB } \\
\text { Bituminous }\end{array}$ & $c$ & $\begin{array}{l}\text { San Miguel } \\
\text { Lignite* }\end{array}$ & s abbitum. C & u \\
\hline Illinois \#6 (1) * & $\begin{array}{l}\text { hvC } \\
\text { Bituminous }\end{array}$ & c & Beulah Lignite * & Lignite A & c \\
\hline Illinois \#6 (2) & $\begin{array}{l}\text { hvC } \\
\text { Biturninous }\end{array}$ & $\mathrm{p}$ & & & \\
\hline
\end{tabular}

$\S$ Numbers in parenthesis () indicate samples from the same seam but different mines.

+ Status of testing is indicated as complete (c), underway (u), or planned (p).

* Coals marked by an asterisk are supplied (with analyses) by Foster Wheeler/Physical Sciences Technology. All others supplied by Consol.

Most of the analyses of these coals are complete; these analyses are summarized in the Appendix as Tables 3.A.1 - 3.A.10. These include: proximate, ultimate, heating value, ash chemistry, forms of sulfur, acid soluble fractions, ash fusion temperatures (reducing and oxidizing), and particle size distribution analyses. The analyses of the coals in the table are the test available data. In some cases the reported data are for a different 
sample of coal than was burned in the MFC. Some of the coals contain significant fractions of large particles: more than are representative of pulverized coal boiler feedstocks. These coals were sieved to produce more typical size distributions. Analyses of the sieved fractions are underway and will be reported in the future.

\section{Subtask 3.3 Theoretical and Experimental Studies of Ash Deposition}

Previous reports [Baxter, 1990g; Baxtcr, 1990d] document comparisons of predicted results and measurements of ash deposit composition from an engineering model of ash deposition on heat transfer surfaces. A discussion of the mathematical and physical bases of this model is presented in this report. The model predicts the Ash Deposit Local Viscosity, Index of refraction, and Composition and is designated ADLVIC. The viscosities and index of refraction (emissivity) predictions are based on correlations with respect to the elemental composition of the deposit. The model is sensitive to boiler operating conditions, coal ash composition, and the location of the deposit within the boiler.

The model is in a preliminary stage of development at this time. Calibrations of the model with respect to low rank coals are yet to be completed. Nevertheless, the framework of the model is established for all ranks of coal and it is our intertion to derive the as yet undetermined parameters of the model from the experiments described above under Subtask 3.2. The following discussion describes the model and some of the analysis that has been performed during the course of its development.

\section{Description of Coal Mineral Matter}

Within the framework of ADLVIC, mineral matter in coal is described as consisting of thirteen constituents. These include: pyritic iron, other iron, free silica, silicates, calcium carbonate, atomically-dispersed calcium, atomically-dispersed sodium, atomicallydispersed magnesium, atomically-dispersed potassium, atomically-dispersed titanium, sulfur, carbon, and other. The last category, 'other', includes all material not included in the former twelve categories. The behavior of each of these species is tracked as a function of time as the coal particles are convected through the combustor or boiler and as the mineral matter is transformed into fly ash. The occurrence and importance of each of these species, including means of estimating their initial concentrations, are briefly discussed below.

\section{a. Pyritic Iron and Other Forms of Iron}

Pyritic iron is the predominate form of iron in most eastern coals. It typically is among the largest of the mineral grains, with average diameters varying from 5 to $10 \mu \mathrm{m}$. It occurs both as discrete grains within coal particles and as isolated or excluded grains. Its transformations during combustion have been documented [Srinivasachar and Boni, 1989; Taneja and Jones, 1994; Cole et al., 1987; Huggins et al., 1984]. Pyritic iron plays an important role in determining both deposit composition and properties [Bryers, 1988]. It is usually the dominant base in eastern deposits and has a pronounced impact on deposit emissivity [Goodvin, 1986] and viscosity [Raask, 1985]. Procedures available for discriminating between pyritic and other forms of iron include (in approximate order of arcuracy): (1) Mössbauer spectroscopy, (2) forms of sulfur analysis [ASTM D246?], (3) x-ray diffraction, and (4) scanning electron microscope 
(SEM) analyses. Of these, the ASTM procedure is by far the most commonly available. The fraction of pyritic iron can be determined from the ash chemistry and the ASTM analysis for pyritic sulfur as follows:

$$
\frac{\left[\mathrm{Fe}_{\text {pyriti: }}\right]}{\left[\mathrm{Fe}_{\text {total }}\right]}=\frac{1.25\left[\mathrm{~S}_{\text {pyritic }}\right]}{\left[\mathrm{Fe}_{2} \mathrm{O}_{3}\right]}
$$

where the quantities in square brackets are mass percents of pyritic sulfur and iron oxide $\left(\mathrm{Fe}_{2} \mathrm{O}_{3}\right)$ on a whole-coal basis. All quantities in Eq. 3.1 are available from routinely performed ASTM analyses of coal.

We have compared this procedure of estimating the pyritic iron content against Mössbauer data for several coals for which both were available. Data from different laboratories were used in the analysis. Laboratory-to-laboratory variations in the pyritic: iron measurements are large. It is not clear whether this is attributable to pyrite oxidation or to differences in analytical technique.

All forms of iron other than pyritic iron are treated together. Other forms of iron, such as siderite, silicate-bound iron, and iron oxides, occur in greater proportion in western coals than eastern coals. As was reported in the last quarterly report [Baxter, 1990], we have noted a tendency for pyritic iron in pulverized coal samples to oxidize to form sulfatic iron when stored for even short periods of time at room temperature in air. Increases in fractional non-pyritic iron content due either to coal cleaning or to natural variations among coals typically are associated with decreases of iron in deposits [Baxter, 1990].

\section{b. Free Silica and Silicates}

Free silica is distinguished from silicon in silicates. Free silica typically has a less than average propensity to accumulate in deposits in coal-fired boilers. Free silica concentrations can be determined from: (1) x-ray diffraction analyses, (2) silica mass balances ba ed on ash composition, or (3) SEM-based analyses. The most commonly available data are ash compositions. The fraction of free silica can be calculated by assuming that all of the aluminium $\mathrm{i}^{\mathrm{r}}$ associated with silicates and assuming an average stoichiometric ratio of silica to alumina. Raask [1985] recommends the following as an indication of free silica.

$$
\frac{\left[S i_{\text {free }}\right]}{\left[S i_{\text {total }}\right]}=1-\frac{1.5\left[\mathrm{Al}_{2} \mathrm{O}_{3}\right]}{\left[\mathrm{SiO}_{2}\right]}
$$

where the quantities in square brackets represent mass fractions on either a whole-coal or a coal-ash basis. The remaining silica is assumed to be in the form of silicates.

\section{c. Forms of Calcium}

Calcium is one of the implicated species in both corrosive and very tenacious deposits that often occur in the convective pass of boilers. Calcium is believed to deposit in coal beds primarily as calcium carbonate. However, circulating water in the western coal beds facilitates ion-exchange reactions to the extent that calcium in the as-mined coal 
often occurs primarily as organo-metallic salts, that is, as atomically dispersed calcium. Calcium can also occur in the forms of sulfates and silicates. The fractionation of calcium among these several forms cannot be estimated from standard ASTM analyses. Techniques of acid washing have been developed that allow an indication of the fraction of calciurn carbonate versus other forms of calcium.

d. Atomischy-Dispersed Species (Sodium, Magnesium, Potassium, and Titanium)

All of the alkali and alkaline earth elements potentially occur as atomically dispersed, organo-metallic salts. They are all also potentially incorporated in silicates and most can occur as chlorides, sulfates, or carbonates. These species are implictated in the formation of both corrosive and tenacious deposits, especially in the convection pass of boilers burning western-type fuels. The chemical fractionation techniques mentioned earlier are among the few means of measuring concentrations of atomically dispersed alkali or alkaline earth species.

Atomically dispersed titanium typically occurs in an organically complexed site. The relativeiy few measurements of this type of titanium that have been performed indicate that $10-15 \%$ of the total titanium is atomically dispersed in the coal [Finkelman, 1980].

\section{e. Carbon and Sulfur}

Carbon and sulfur are both subject to heterogeneous reactions between the combustion gases and ash deposits. Carbon typically reacts to form $\mathrm{CO}$ and is thereby transferred from the deposit to the gas. Gas-phase sulfur often reacts with ash deposits to form. sulfates and is thereby transferred from the combustion gas to the deposits.

\section{f. Other}

The final ash species ireated by ADLVIC is "other" and includes all material not classifiable in one of the former categories. This typically accounts for less than $5 \%$ of the total ash, and may include contributions from titanium, calcium, sodium, potassium, and magnesium. However, all of the iron, silica, and aluminium are classified in one of the other categories.

\section{Modeling Approach}

Coal particles, including ash described in terms of these mintral species, are tracked as a function of particle residence tims through the pulverized coal boiler. The gas velocity fields, temperatures, and compositions and the boiler geometry are specified as a function of position. The response of the particle to chinges in gas properties is rnonitored as a function of particle residence time. In particular, the propensity of each of these thirteen ash constituents to collect on deposition surfaces is predicted as a function of particle residence time. Note that the thirteen constituents are identified according to their original composition, even though some of them quickly transform to other species. The details of tracking these particles through the combustor are presented in the following section.

Previous reports [Baxter, 1990 a-c] document the formation of fly ash during coal combustion. Mechanisms of fume formation from coal particles associated with 
vaporization [Quann and Sarofim, 1983; Helble et al., 1987], heterogeneous reaction [Baxter and Mitchell, 1990] and convection of coal volatiles during coal devolatilization [Baxter et al., 1990] are developed to various degrees in the literature. Experiments documenting the extent of particle fragmentation as a function of coal rank, initial char particle size, and ash loading have been reported that resolve, at least partially, inconsistencies in previously reported data [Baxter, 1990a]. The focus of this discussion is on means of predicting rates of deposition from a fully described, particle-laden gas stream.

The objective of this effort is to produce an engineering model capable of quantitative prediction of deposit elemental composition, emissivity, and viscosity as a function of coal type, boiler operating conditions, and location within the boiler. This engineering model is distinguished from a scientific model and from a fouling or slagging index. The engineering model produces results based on scientific or fundamental considerations augmented with experimental correlations. Results for practical systems are predicted with sufficient accuracy and detail to be useful in operation and design of boilers. Scientific models typically address issues in more detail. They often are applicable to idealized systems and give useful insight into mechanisms but are difficult to apply to commercial-scale processes. Indices are back-of-the-envelope type calculations focusing on a subset of the relevant variables in the process (fuel analyses to the exclusion of operating conditions and location in a boiler, for example). It is our intention to continue to develop the model and to demonstrate its usefulness by continuing to collaborate with coal suppliers and utility boiler operators.

\section{Modeling of Ash Deposit Formation}

A material, or Lagrangian, reference frame is used to track coal and ash particles as they flow through the boiler. That is, equations are written from the reference frame of the particles rather than the boiler. This formulation allows incorporation of fundamental physics and chemistry but does not require establishing a large number of computational cells or ncdes. Mathematically, the model consists of a series of coupled, nonlinear, ordinary differential equations. The complexity of this model does not increase with increasing dimensionality of the problem. Three-dimensional boilers are desc ibed with essentially the same model as laboratory-scale, one- or two-dimensional reactors. The predictions that have been presented to date [Baxter, 1990d and $\mathrm{g}$ ] have been computed using a Macintosh II computer and a modest FORTRAN cc.mpiler.

Most particle properties are treated in a customary fashion for Lagrangian models. For example, heat transfer coefficients and particle reaction rates are used to predict particle properties such as temperature as a function of particle history and gas temperature. The unique aspect of ADLVIC is the treatment of the deposition process, which is the focus of this discussion.

The fou: processes in deposition that are treated in ADLVIC are: (1) inertial impaction (and particle capture), (2) thermophoresis, (3) condensation, and (4) heterogeneous reaction. All heat transfer surfaces are involved in these processes. ADLVIC currently uses flat walls in turbulent flows as an approximation to waterwalls and single tubes in cross flow as an approximation to convective pass tubes. The four processes of ash deposition are assumed to have additive influences on deposit composition. That is, the rate of accumulation of ash on the surface of a heat transfer tube is written as 


$$
\frac{d m_{i}}{d \tau}=I_{i}(t, \tau) \mathrm{G}_{i}(t, \tau)+T_{i}(t, \tau)+C_{i}(t, \tau)+R_{i}(t, \tau)
$$

In this equation, $m_{i}$ represents the mass of component $i$ in the deposit. The factor $I_{i}$ represents the rate of inertial impaction, $G_{i}$ represents the relative particle capture efficiency, $T_{i}$ represents the rate of thermophoretic deposition, $C_{i}$ represents the rate of condensation, and $R_{i}$ represents the rate of chemical reaction. The subscript $i$ refers to each of the thirteen components discussed previously. Before describing each of these terms in more detail, some explanation of the two independent variables is in order.

Two time scales are identified in Equation 3.3. The variable $t$ is a material time scale, designating particle residence time relative to the time of injection of the particles. The variable $\tau$ designates elapsed or laboratory time, i.e., time relative to an arbitrary time of day independent of the particle residence time. In a steady-state or stationary system, the only relevant time scale is $t$. Ash deposition rates, composition, and all other characteristics of the process would have the same mean values at all times at a given location. However, ash deposition clearly is a non-stationary process [Baxter et al., 1990b; Beèr et al, 1990]. Therefore, both the material and elapsed time scales must be addressed. Equation 3.3 can be thought of as an ordinar!' differential equation parameterized by the variable $t$.

Practical illustrations can be used to clarify the differences in the two time scales. Changes in deposit composition from one location to another in a boiler are indicative of variation of one or more of the terms in Eq. 3.3 with particle residence time $(t)$. For example, our experience, consistent with industrial observations, is that ash deposits formed from eastern, pyrite-bearing coals are enriched in iron. This enrichment is most pronounced when the deposits are sampled near the burners, with typical enrichments of $60 \%$. Deposits sampled midway between the burners and the furnace exit are slightly less enriched in iron. A typical enrichment of $40 \%$ may be observed in this area. Near the furnace exit, iron enrichment in the deposit drops to $10-20 \%$. This change in deposit composition with location in a boiler is a reflection of the residence time $(t)$ dependence of the inertial impaction and particle capture efficiency terms in Equation 3.3.

Changes in deposit composition as a function of deposit thickness are indicative of variation of one of the terms in Eq. 3.3 with clock time $(\tau)$. With respect to our previous example, industrial experience suggests that wail deposit composition in the radiant section of a boiler is not strongly dependent on deposit depth unless there is a change in boiler operating parameters [Levasseur et al., 1987]. That is, the deposit usually has about the same cumposition at the outer edge as on the inner surface next to the heat exchanger surface. Therefore, the dependence of the inertial impaction term on $\tau$ would be expected to be minimal in this section of the boiler. By contrast, the deposits formed in the convection pass of boilers firing both eastern and western coals typically show pronounced variation in composition between the heat exchanger surface and the outside of the deposit. These composition changes are related to the variation of terms in Eq. 3.3 with $\tau$.

The five functions in Eq. 3.3, $I, G, T, C$, and $R$ are discussed in more detail below. The first three terms are developed in some detail., since they denote the processes that 
dominate ash deposition in the furnace region of a boiler during the combustion of bituminous coals. The remaining terms are discussed more briefly. They involve experimental parameters that are currently being characterized experimentally based on the ongoing combustion tests in Sandia's MFC.

\section{a. Inertial Impaction $I(t, \tau)$}

Inertial impaction is generally the process by which the bulk of the ash deposit is transported to the heat transfer surface. Particles depositing on a surface by inertial impaction have sufficient inertia to traverse the gas stream lines and impact on the surface. The particle capture efficiency describes the propensity of these particles to stay on the surface once they impact. Both particle and surface properties play significant roles in determining the particle capture efficiency.

The controlling issue for inertial impaction is the relative magnitudes of the particle and fluid relaxation time or length scales. Specifically, inertial impaction occurs when the distance a particle travels before it fully adjusts to changes in the fluid velocity is larger than the length scale of an object, or target, submerged in the fluid. The particle Stokes number is defined as the ratio of these length scales. It is reasonable to expect, then, that particle impaction efficiencies can be correlated with suitably defined Stokes numbers for a wide range of particle and fluid properties. In this section we examine the success of such correlations by comparing their predictions with fundamentally determined impaction efficiencies for realistic flows.

The rate of inertial impaction is the product of the total mass flux of particles in the flow and the fraction of these particles - which we call the impaction efficiency - that actually strike the surface. That is,

$$
I_{i}(S t k)=q_{i} \eta_{i}
$$

where $q_{i}$ is the local particle flux, Stk is the Stokes number, and $\eta_{i}$ is the impcation efficiency. The point of evaluation of $q_{i}$, and $S t k$ and the function form of $\eta_{i}$ differ for cylinders and walls. The details of these differences and correlating expressions for $\eta_{i}$ are discussed below.

Cylinders in Cross Flow. Inertial impaction is schematically illustrated in Figure 3.1 for the case of a cylinder in cross flow. Two particles are illustrated as they approach the cylinder. Both respond to the gas flow field around the cylinder by beginning to move around the cylinder on approach. However, in both cases, the particle inertia overwhelms the speed with which the particle responds to the gas flow, and both particles impact on the cylinder. One is shown rebounding and the other sticking to the surface. Gas stream lines, including recirculation zones, are shown in light gray in this and subsequent similar figures.

This process is most important for large particles (10-15 $\mu \mathrm{m}$ or larger) and results in a coarse-grained surface, as illustrated. The rates of impaction are highest at the stagnation point on the cylinder, decreasing rather rapidly with angular position along the surface as measured from this stagnation point. At angular displacements larger than about $50^{\circ}$, the rate of inertial impaction drops to essentially zero under conditions typical 
of boiler operation. Thus, the deposits formed from inertial impaction mechanisms are often bell-shaped, as is also illustrated. (Further discussion of this aspect of inertial impaction is included below in an illustration of the application of the model.)

\section{Particle Impaction}

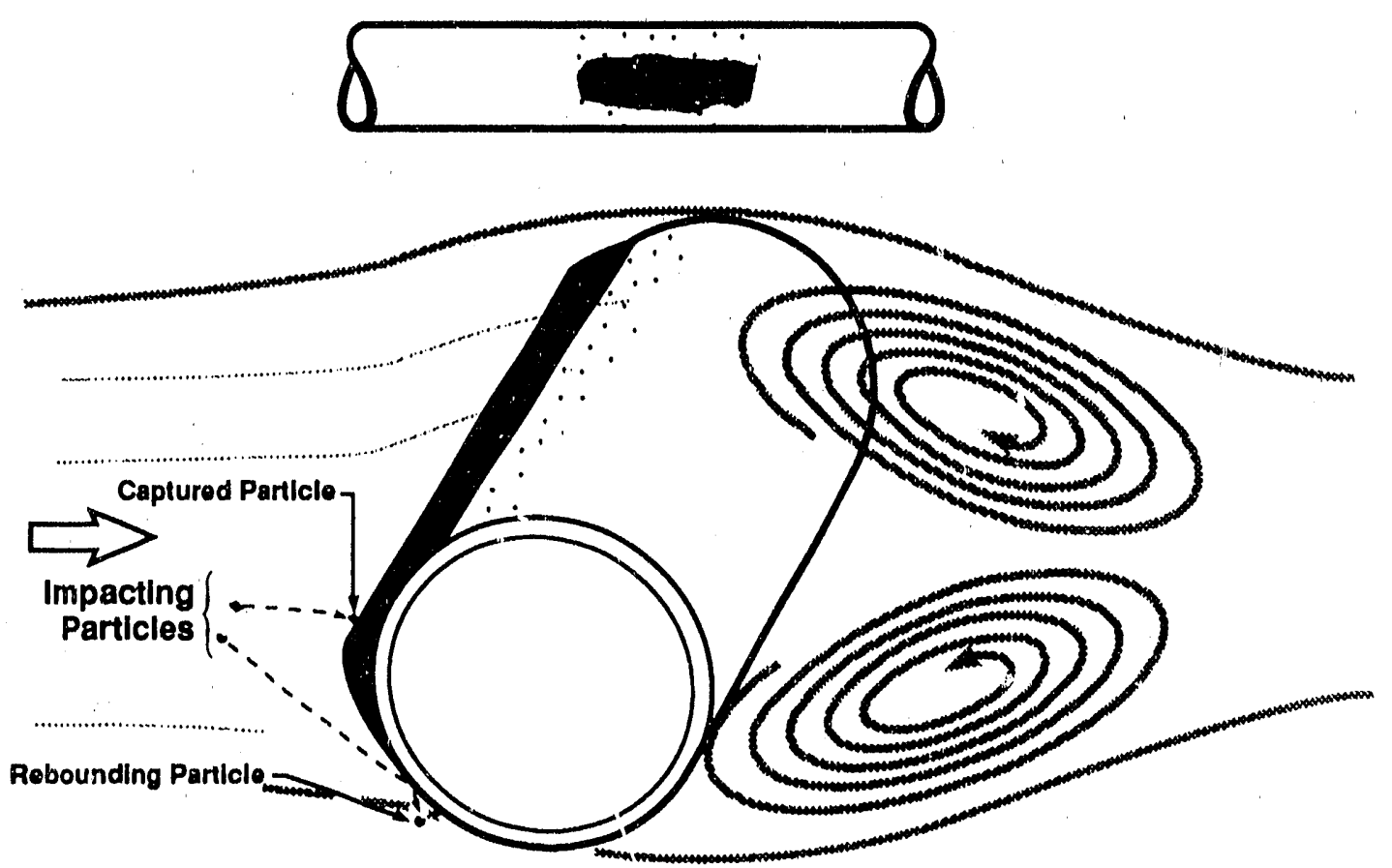

Figure 3.1 Conceptual illustration of inertial impaction mechanism on a cylinder in cross flow: The deposit is typically confined to the leading edge $\pm 50^{\circ}$ of the cylinder. Two particles are also illustrated, one which rebounds and one which sticks.

Mathematically, the rate of impaction is described in the reference frame illustrated in Figure 3.2. A cylinder is shown in cross section in a parallel, constant velocity flow field. Potential flow theory is used to describe the flow of gas around the cylinder. According to this theory, the $\mathrm{x}$ and $\mathrm{y}$ components of velocity around the cylinder are given by [Bird et al., 1960]

$$
u_{x}=u^{\infty}\left[1-\left(\frac{R}{r}\right)^{2} \cos (2 \theta)\right]
$$

and

$$
u_{y}=u^{\infty}\left(\frac{R}{r}\right)^{2} \sin (2 \theta)
$$

or, in terms of cylindrical coordinates, 


$$
u_{r}=u^{\infty}\left[1-\left(\frac{R}{r}\right)^{2}\right] \cos (\theta)
$$

arid

$$
u_{\theta}=-u^{\infty}\left[1+\left(\frac{R}{r}\right)^{2}\right] \sin (\theta)
$$

where $u^{\infty}$ is the gas free stream velocity (assumed to be aligned with the $x$ coordinate direction), $R$ is the cylinder radius, and $r$ is the radial distance to the point for which the velocity components are being calculated. Equations 3.5 through 3.8 are assumed to be correct everywhere in the flow field except within the boundary layer. Within the boundary layer, the velocity components are interpolated from tabulated results [Schlichting, 1979].

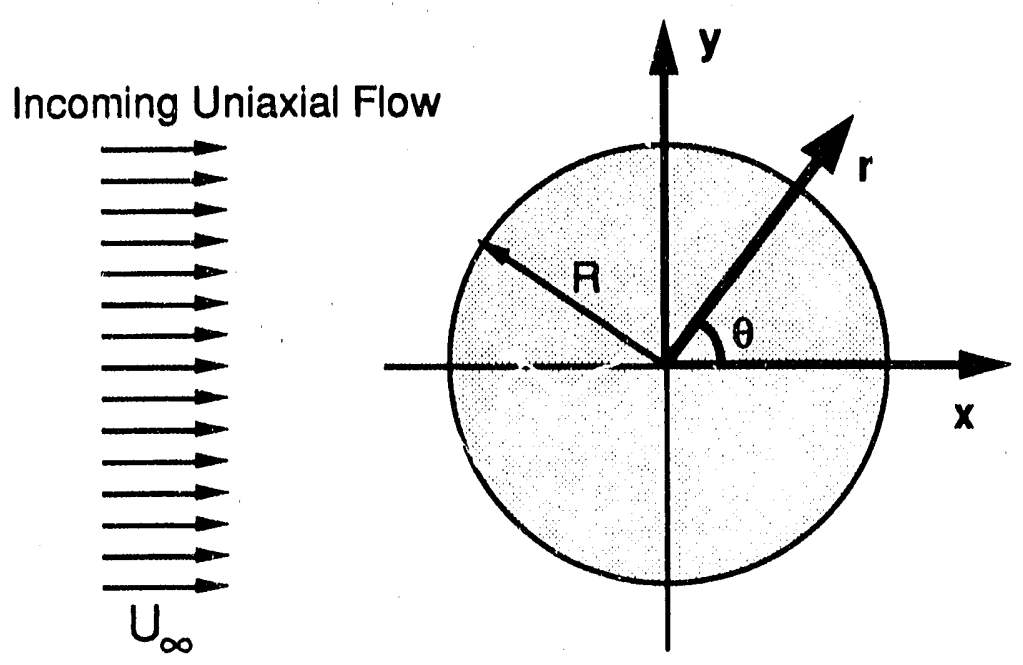

Figure 3.2 Schematic diagram of coordinate system and reference frames used in describing a tube in cross flow.

Particles are introduced to this flow field far upstream and their positions are predicted according to the particle equation of motion

$$
\frac{d u_{j ; p}}{d t}=\beta\left(u_{j ; g^{-}} u_{j ; p}\right)
$$

where particle and gas velocities are indicated by subscripts $p$ and $g$, respectively, and the index $j$ refers to both the $x$ and $y$ components of velocity. The proportionality constant $\beta$ is defined as 


$$
\beta=\frac{3 \pi f \mu_{g} d_{p}}{m_{p}}=\frac{18 f \mu_{g}}{\rho_{p} d_{p}^{2}}
$$

where $\mu_{g}$ is gas viscosity, $\rho_{p}$ is particle density, $d_{p}$ is particle diameter, and $r_{p}$ is the particle mass. The term $f$ allows for incorporation of non-Stokesian drag forces [Israel and Rosner, 1983; Beér et al., 1990]. Analytical approximations for this term are discussed by several authors. In our experience, particles of practical concern in pulverized coal combustors are well described assuming Stoke's law, i.e., $f=1$.

As an illustration of the calculations, average particle streak lines are shown in Figure 3.3 upstream of the cylinder. The particles respond to the flow field stream lines around the cylinder; depending upon the particle s:ze, density and velocity and the size of the cylinder, some fraction of the particles impact the tube. An impaction efficiency $(\eta)$ for a uniform flow of identical particles can be defined, as illustrated in the figure, in terms of the cylinder diameter and the distance between the outcrmost particle streak lines that reach the cylinder surface.
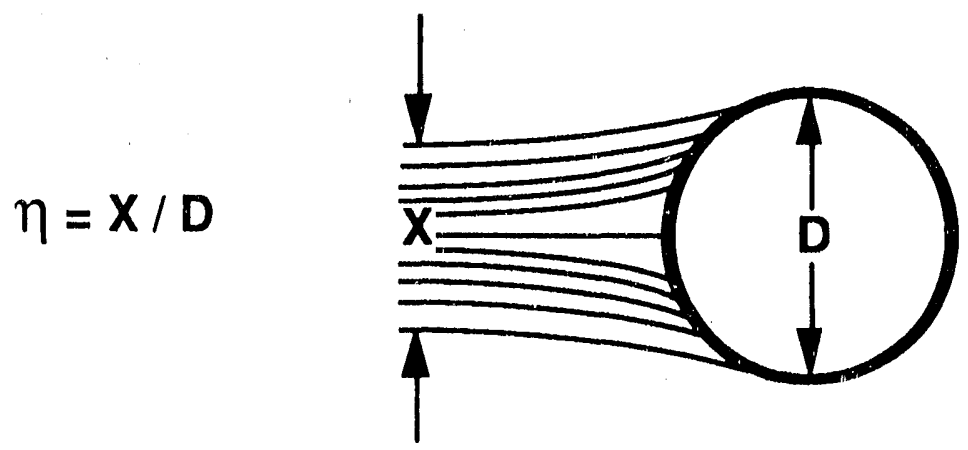

Figure 3.3 Illustration of particle steak lines and definition of particle impaction efficiency for a cylinder in cross flow.

Theoretical predictions of the impaction efficiency as a function of particle, gas, and tube properties have been published, for various levels of approximation, by numerous investigators [Sell, 1931; Langmuir and Blodget, 1946; Brun et al., 1955; I: rael and Rosner, 1983; Walsh, et al., 1987; Latoine, 1981]. In particular, we are interested in: (1) the importance of including the viscous boundary layer in performing the predictions; (2) the relative importance of thermophoresis at the large particle sizes; (3) resolving the rate of deposition as a function of position aiong the cylinder surface, and; (4) evaluating the importance of turbulent fluctuations of gas velocity on the impaction efficiency. Typical results are illustrated in Figure 3.4.

Boundary Layer (and Thermophoretic) Effects. The impact of the fluid dynamic boundary layer around the cylinder was investigated. Predicted impaction efficiencies 
are illustrated at three increasingly sophisticated levels of solution. The first solution uses only the potential flow description of the flow field (Eqs. 3.5 to 3.8). In this approximation, the fluid velocity (unrealistically) maximizes at the surface of the cylinder, becoming twice the free stream velocity at an angle of $90^{\circ}$. The second level of approximation includes the effect of the boundary layer and the third includes the effects of both the boundary layer and thermophoresis. (Modeling of thermophoresis is discussed later.) The data presented in the figure are in essential agreement with those of Brun et al. [1955] and correlated by Israel and Rosner [1983] over most of the particle size range.

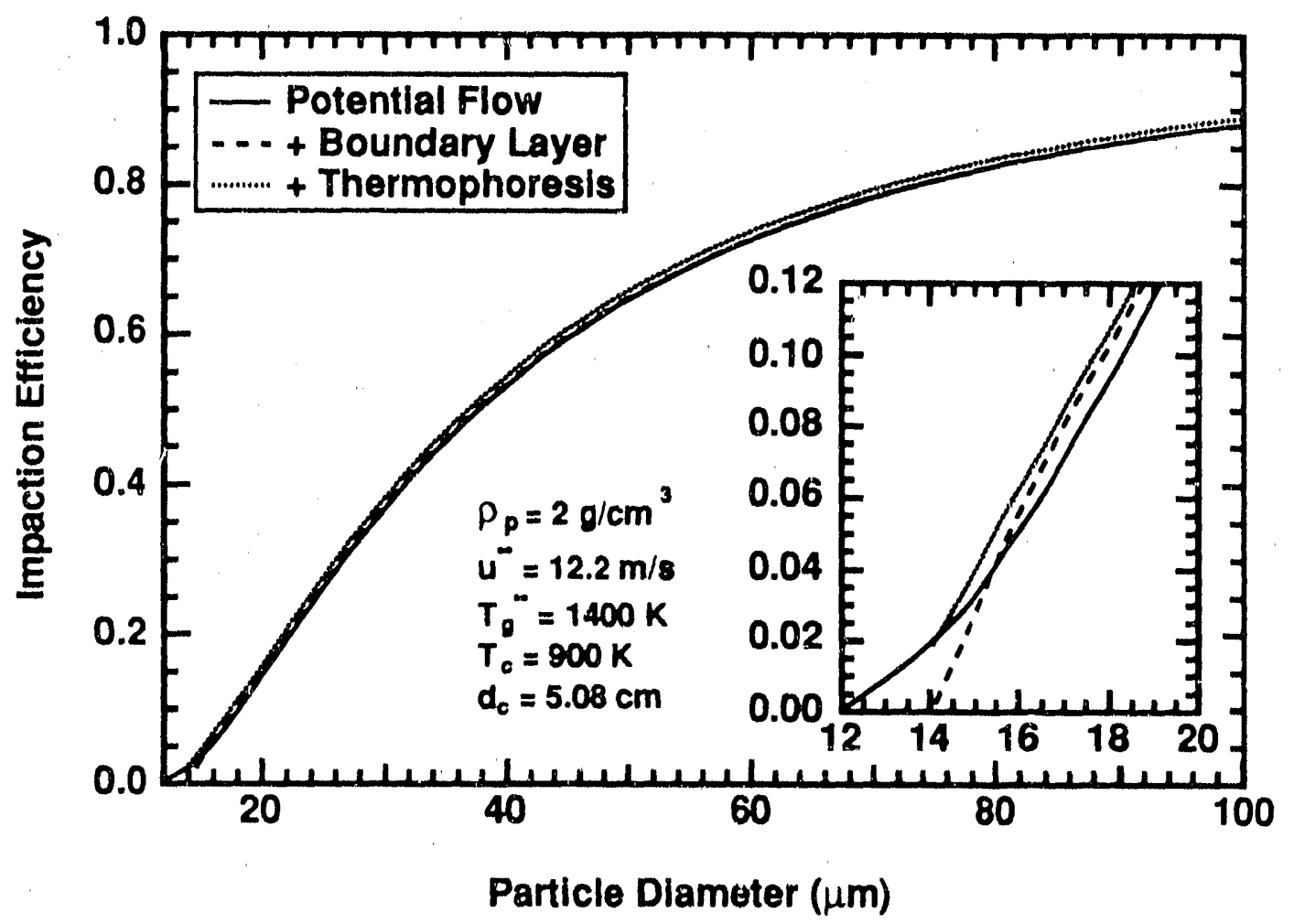

Figure 3.4 Theoretical calculation of particle impaction efficiencies as a function of particle size at three levels of sophistication.

It is clear from these predictions thai, at most particle sizes, the boundary layer has esse tially no effect on the particle impaction efficiency. This is the most important conclusion from Figure 3.4. However, the details of the figure indicate that at small particle sizes the boundary layer can cither slightly enhance or significantly retard particle impaction. For example, the impaction efficiency for parti-les less than $15 \mu \mathrm{m}$ in diameter is predicted to be many times higher (although near zero), using potential flow only, than when using the more complete solution including the effects of the boundary layer. This predicted retardation of inertial impaction results from the boundary layer stopping the particles before they reach the surface. At slightly larger particle sizes $(\approx 20 \mu \mathrm{m})$ the rate of impaction is enhanced rather than retarded. At these sizes, the boundary layer has the effect of increasing the particle residence time near the cylinder surface by decreasing its tangential velocity component. This increased 
residence time allows up to $20 \%$ more of the particles to impact on the surface than is predicted in the absence of the boundary layer.

Angular Dependence of Impaction Efficiency. Figure 3.5 illustrates predicted impaction efficiencies (expressed as a percent) per degree arc length as a function of angle along the surface for $50 \mu \mathrm{m}$ diameter particles under the conditions indicated in Figure 3.4. The practical interpretation of these data relates to the initial shape of the deposit that grows on a surface, assuming particle capture cfficiencies are independent of angle of approach, velocity, time, or position on the tube. (Capture efficiencies are discussed later). Each clurve in the figure indicates the predicted height of the deposit as a function of angular position. Four curves are presented in which the total rate of deposition is used to normalize the data. Two of these curves are representative of the deposit height as a function of angular position as measured radially from the surface. These are laheled total surface area. Two additional curves are presented that represent the height of the deposit as measured in the direction of the oncoming flow. This is equivalent to measuring the deposit height in the direction of the flow. In each case, both the potential flow and complete solutions are indicated. Note that the abscissa is labeled in terms of the angle as rneasured from the forward stagnation point, or $180^{\circ}$ minus the angle as defined in Figure 3.2.

The ordinate is the rate of impaction per degree arc, normalized by the particle flux. The figure indicates that approximately $1.75 \%$ of the rotal particle mass approaching the tube impacts within one degree of arc on the tube leading edge. This fraction decreases, slowly for the first $15^{\circ}$ then more rapidly for points beyond approximately $20^{\circ}$ from the forward stagnation point. Essentially no mass is collected at angles larger than $55^{\circ}$ from the forward stagnation point.

As particle velocity or density decreases, or as tube diameter increases, the fraction of material impacting at all angles other than 0 decreases and the curves shown in Figure 3.5 become increasingly narrow. A similar trend is seen with decreasing particle size until the particles become sufficiently small that thermophoresis is the dominant deposition mechanism. At this point, the curve begins to broaden, indicating that the deposit thickness becomes more uniform around the tube.

Experimental observations at Sandia and elsewhere indicate that deposits formed from bituminous coals often take on the shape suggested by Figure 3.5. On the other hand, some deposits, especially those from low-rank coals, grow rapidly at angular displacements of $30-45^{\circ}$ [Benson et al., 1990]. There is no simple aerodynamic explanation for these results. However, one explanation is that the deposits collected at angles greater than $35^{\circ}$ would be expected to be dominated by thermophoretic or condensed material. Therefore, the tube surface at these locations would be of different composition and expected to have a different capture efficiency than at smaller angles. Note also that the deposit shape illustrated in Figure 3.5 is valid only for the initial inertial impaction deposit. As the flow field adjusts to the growing deposit, the flow field description in Eqs. $3.5-3.8$ is no longer valid. 


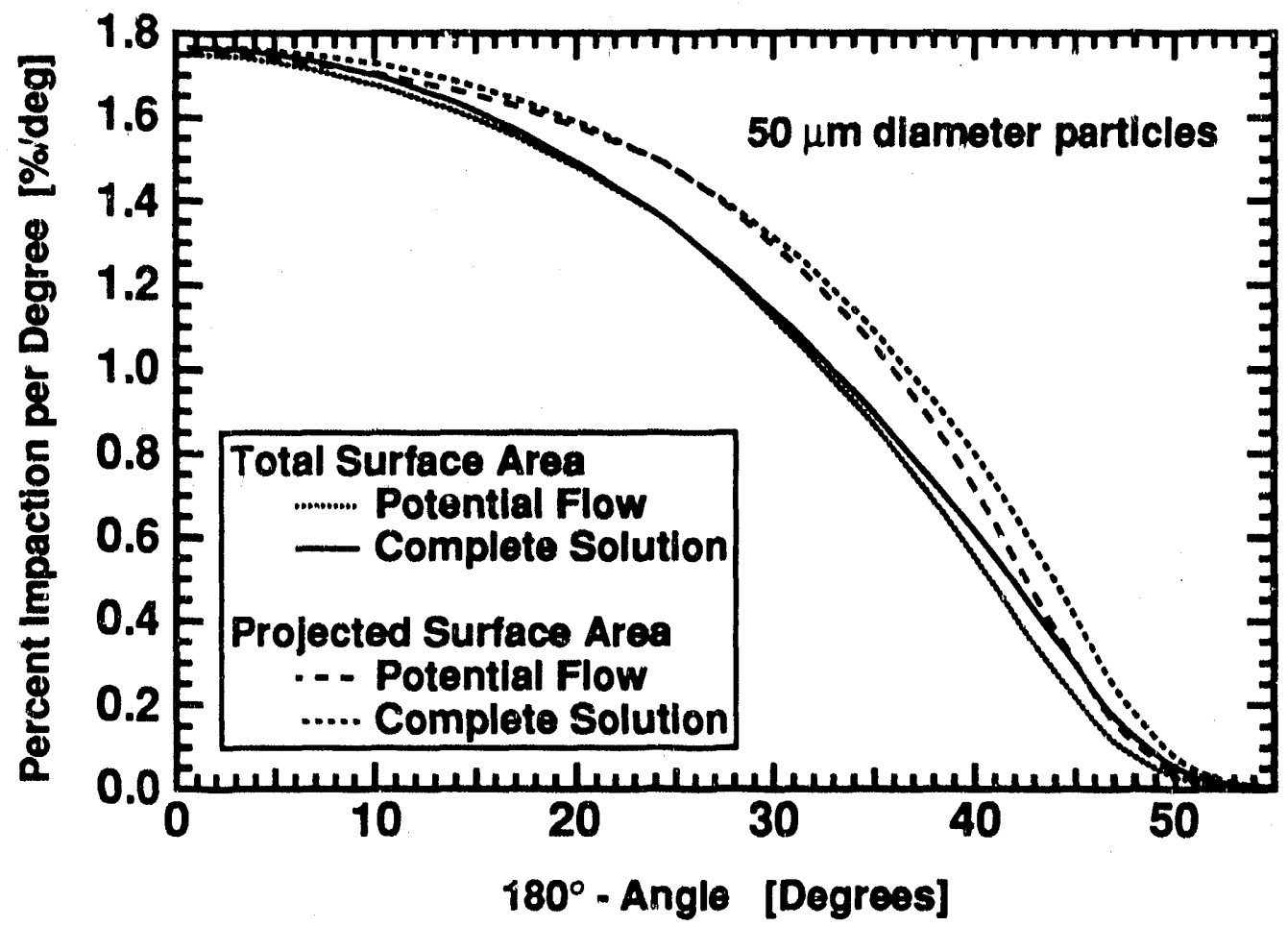

Figure 3.5 Predicted particle impaction efficiency (expressed as a percent) as a function of angular position measured from the leading edge of a cylinder in cross flow.

Effect of Turbulence. The predictions illustrated thus far have assumed that all particles experience the average gas velocity, consistent with the bulk of the literature. The impact of turbulent fluctuations in the oncoming particle velocity can be accounted for analytically as follows

$$
\eta^{t}\left(d_{p}\right)=\int_{-\infty}^{\infty} \eta\left(u_{p} ; d_{p}\right) P\left(u_{p} ; d_{p}\right) d u_{p}
$$

where $\eta^{\prime}\left(d_{p}\right)$ is the particle impaction efficiency accounting for turbulent fluctuations as a function of particle diameter, $P$ is the probability density function for particle velocity, and the remaining terms have already been defined.

The predicted variation of $\eta$ with particle Stokes number assuming several levels of turbulent intensity is illustrated in Figure 3.6 for the case of a cylinder in cross flow. In these simulations, the Stokes number, $S t k^{\mathfrak{c}}$, is defined as follows: 


$$
S t k^{c} \equiv \frac{\rho_{p} d_{p}^{2}\left\langle u_{p}\right\rangle_{p}}{9 \mu_{g} d_{c}} \Psi
$$

where $\left\langle u_{p}\right\rangle$ is the ensemble average particle (and gas) velocity in the bulk flow and $\Psi$ is a correction factor for non-Stokesian drag effects [Israel and Rosner, 1983], which is unity in most cases of practical interest in pulverized coal combustion. The remaining terms were previously defined. The gas viscosity, $\mu_{g}$, is evaluated at the temperature of the bulk gas stream. The superscript $c$ on the Stokes number indicates it relates to tubes in cross flow.

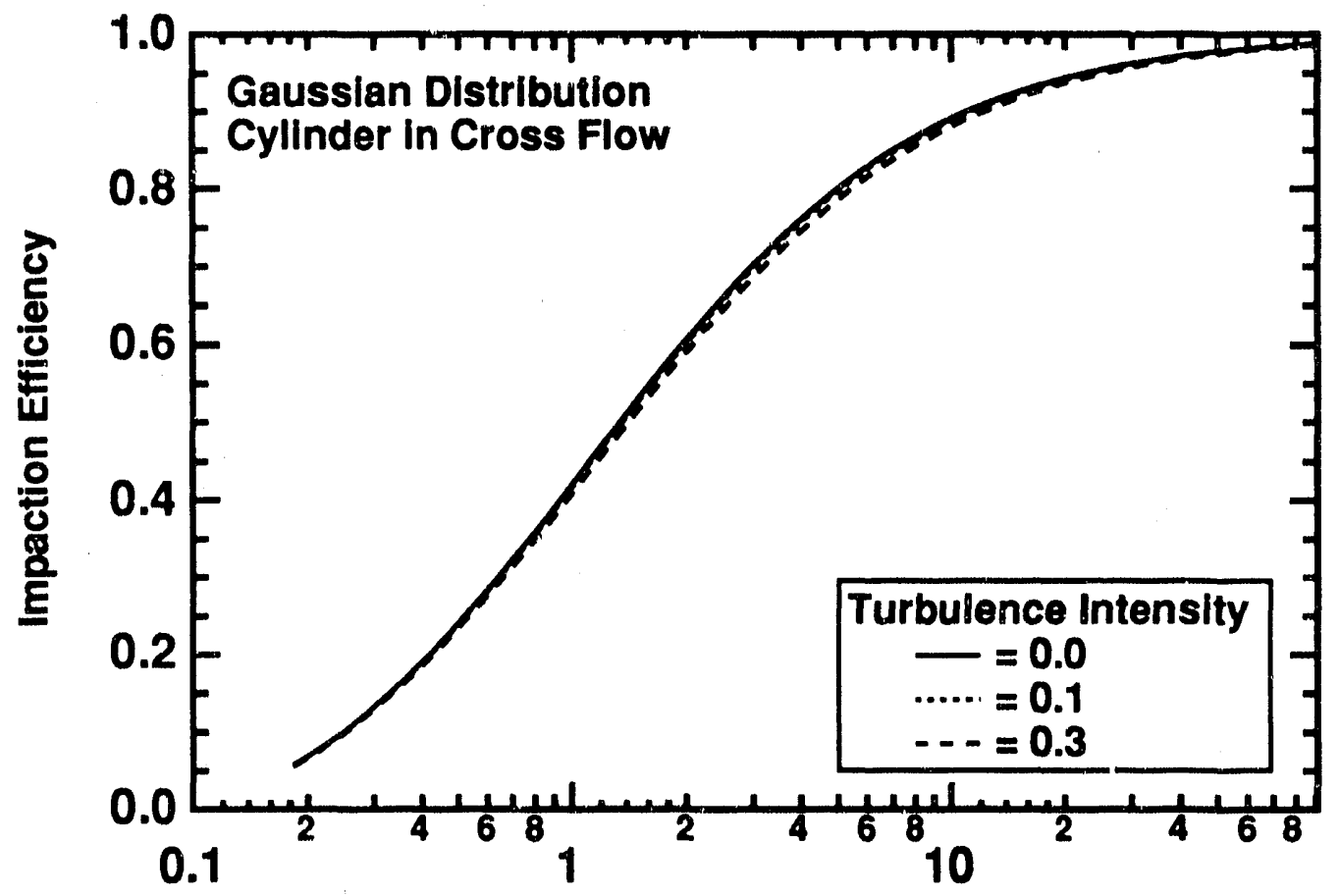

Particle Stokes Number

Figure 3.6 Sensitivity of particle impaction efficiency to turbulent fluctuations in the gas and particle velocity. A Gaussian distribution of velocity fluctuations was assumed in making these predictions.

As can be seen, the effect is very slight. Gaussian distributions in gas and particie velocity were assumed in performing these calculations. Few flows experience turbulent intensities as large as 0.3 ( 0.1 is a typical upper hound), therefore the plot covers bnth the Stokes number and turbulence intensity ranges of interest to pulverized coal combustion. If the turbulent velocity distribution is not symmetric, the effect of turbulence on the predicted impaction efficiency is only slightly more pronounced, as is shown in Figure 3.7, where the velocity fluctuations are assumed to be described by a Rayleigh distribution, given by 


$$
f(x ; \alpha)=\left\{\begin{array}{cc}
2 \alpha x \mathrm{e}^{-\alpha x^{2}} & 0<x<\infty \\
0 & x \leq 0
\end{array}\right.
$$

These results do not imply that $\eta$ is insensitive to gas or particle velocity. Rather, the mild sensitivity of the impaction efficiency to turbulence reflects increased impaction efficiencies resulting from positive fluctuations being offset by decreased impaction efficiencies associated with negative fluctuations.

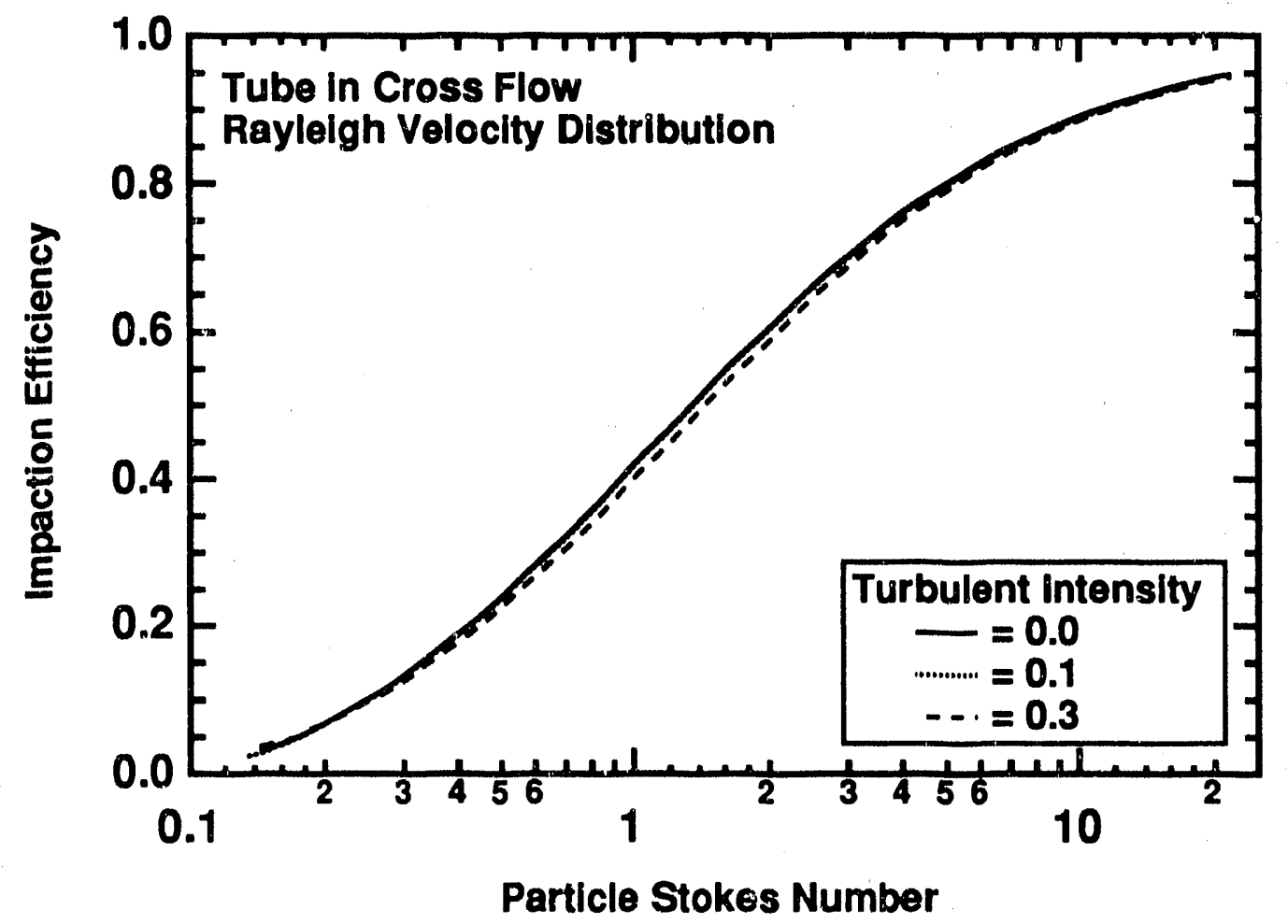

Figure 3.7 Sensitivity of particle impaction efficiency on a tube in cross flow to turbulent fluctuations in gas and particle velocity. A (skewed) Rayleigh distribution of velocities was assumed in making these predictions.

Correlating Expression. The previous discussion demonstrates the general insensitivity of the impaction efficiency to near-surface phenomena and turbulent fluctuations. The results of the predictions with the fundamental model, derived from Eqs. 3.5 - 3.8, are compared with the correlation of Israel and Rosner [1983] in Figure 3.8. Note that the Stokes number is evaluated using the properties of the free stream (as could be anticipated considering the relative unimportance of the boundary layer on the predictions). The agreement is satisfactory for the purposes of our engineering model. The slight disagreement at small Stokes numbers is consistent with the low Reynolds number results illustrated by the previous investigators [Israel and Rosner, 1983]. A slightly better agreement at low Stokes numbers was obtained by fitting the coefficients 
in the expression to our calculations. Two fits are illustrated. The first, designated ' $a$ ', corresponds to the solution including thermophoresis and the second, designated ' $b$ ', corresponds to the solution neglecting thermophoreis. The overall impaction efficiency on a cylinder in cross flow is given by the function $R(S t k)$ as follows:

$$
\eta_{i}\left(S_{t k^{c}}\right) \cong\left[1+b\left(S_{t k^{c}}-a\right)^{-1}-c\left(S_{t k^{c}}-a\right)^{-2}+d\left(S_{t k^{c}}-a\right)^{-3}\right]^{-1} \equiv R\left(S t k^{c}\right)
$$

where $a, b, c$, and $d$ are the correlating parameters. The values of the parameters are given in Table 3.2 for the three correlations illustrated in Figure 3.8. For values of $S t k^{c}$ less than 0.14 , none of the functions are accurate.

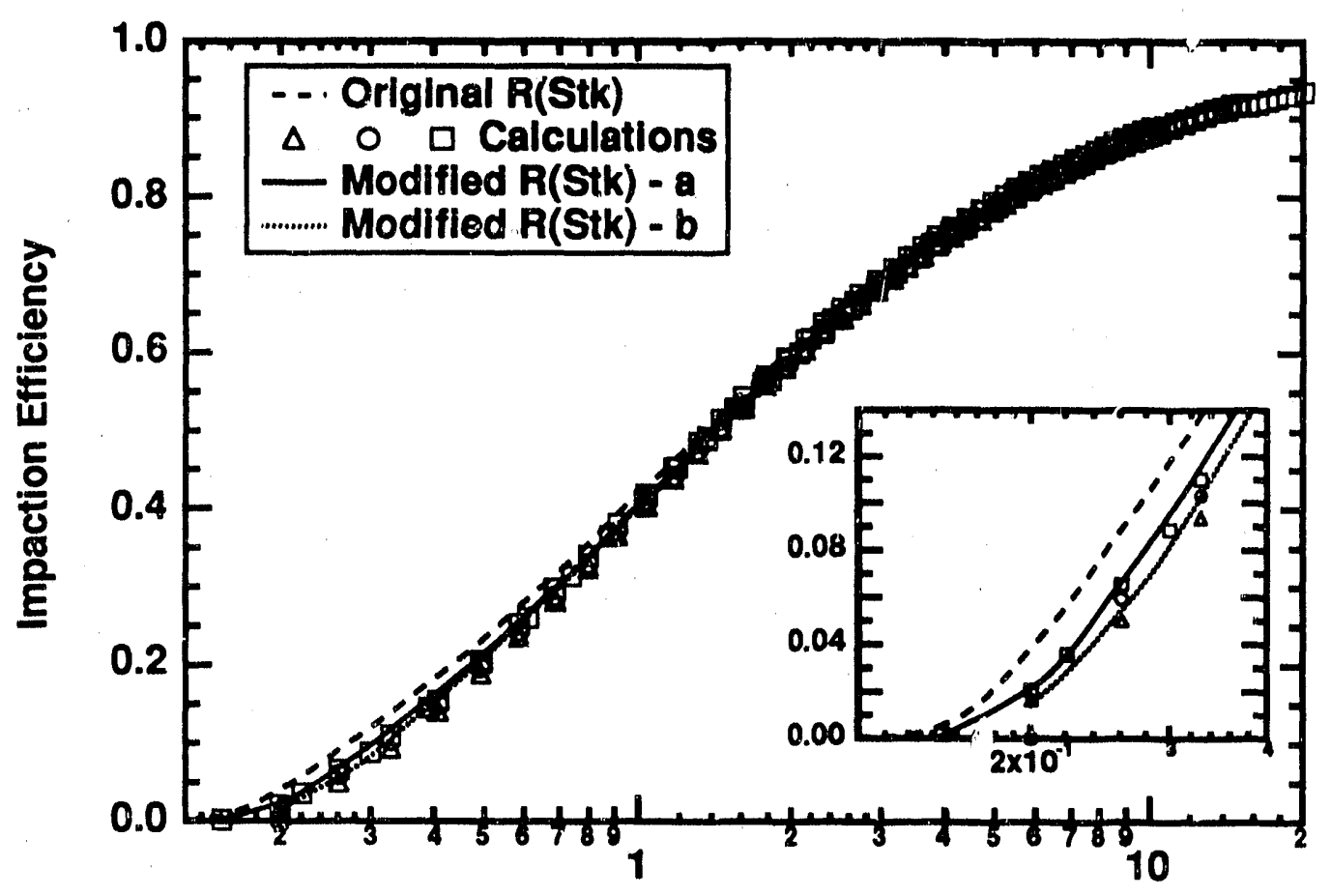

\section{Stokes Number}

Figure 3.8 Correlation of particle inupaction efficiency as a function of Stokes number. Points are from our calculations. Original function is from Israel and Rosner [1983]. Modified (and original) function parameters are presented in Table 3.2.

The term $I_{i}$ is calculated from the impaction efficiency to yield a particle impaction flux as follows:

$$
I_{i}\left(S t k^{c}\right)=q_{i} \eta_{i}
$$

where $q_{i}$ is the mass flux $\left(\mathrm{kg} / \mathrm{cm}^{2}-\mathrm{s}\right)$ of particles of type $i$ with Stokes number $S t k^{c}$ in the (undisturbed) flow approaching the cylinder. The residence time dependence is introduced through time-dependent particle sizes, particle flow sates, etc. A complete description of impaction would include the $\tau$ dependence of the impaction efficiency 
deriving from changes in the shape of the cylinder as the deposit grows. This level of complexity is not yet incorporated in ADLVIC.

Table 3.2

\section{Original and Slightly Modified Coefficients in the Correlating Expression for Particle Impaction Efficiency on Cylinders in Cross Flow}

\begin{tabular}{|l|cccc|}
\hline & $\mathrm{a}$ & $\mathrm{b}$ & $\mathrm{c}$ & $\mathrm{d}$ \\
\hline Original & 0.125 & 1.25 & -0.014 & 0.00508 \\
Modified - a & 0.1425 & 1.28 & 0.00215 & 0.00587 \\
Modified - $\mathrm{b}$ & 0.1238 & 1.34 & -0.034 & 0.0289 \\
\hline
\end{tabular}

Elat Plates. Two fluid-dynamic features that were shown to have very little influence on the predicted rate of inertial impaction for cylinders in cross flow were the laminar boundary layer and the turbulent fluctuations. This result should not be hastily generalized to other geometries. The same two fluid dynamic features have a dominant influence on the rate of inertial impaction on flat plates in parallel flow; Indeed, they become the central parameters in the definition of the Stokes number in this geometry.

Correlating Parameter and Conceptual Definitions. The definition of the particle Stokes number with respect to a wall or flat plate can be approximated as follows:

$$
S t k^{w} \equiv \frac{\rho_{p} d_{p}^{2}\left[\widehat{u_{p}}+\sigma_{u_{p}}\right]}{9 \mu_{g} \delta_{w}} \psi
$$

where $\hat{u}_{p}$ and $\sigma_{u p}$ represent the median and standard deviation of the particle velocity componerit normal to the wall at the edge of the boundary layer. This allows for flows impinging on a wall as well as parallel flows. As shown later, use of the median velocity rather than the mean results in a more accurate correlation of the impaction efficiency. The median value is the value above and below which there is a $50 \%$ probability of finding the instantaneous value. This is equivalent to the average (or expected) value only for symmetrical velocity probability distributions. The target dimension $\left(\delta_{w}\right)$ is the boundary layer thickness. The gas viscosity in this case is evaluated at the mean of the wall and free stream temperatures. The median particle velocity at the edge of the boundary layer is nonzero in cases of flows with mean components directed toward the wall and skewed velocity distributions.

An impaction efficiency for a flat plate indicates the fraction of particles at the edge of the boundary layer that will ultimately impact on the wall. The equation of motion for a particle entering a fully developed boundary layer indicates that the initial particle 
velocity must exreed a critical value for the particle to reach the wall. The Stokes number, defined in Eq. 3.15 for a wall, is the ratio of the distance the particle travels by inertia (the stopping distance) to the thickness of the boundary layer. The success of the wall Stokes number $S t k_{p} w$ as a correlating parameter for impaction efficiencies is still under investigation. It will be illustrated, however, that the impaction efficiency depends not only on the magnitude of the fluctuations, but alsn on the shape of the distribution. Current investigations are focusing on identifying a general characterization of these velixcity fluctuations.

Effect of Turbulence. Figure 3.9 illustrates the impaction efficiency as a function of particle Stokes number for a flat plate, assuming Gaussian and Rayleigh probability density functions (pdfs). The predicted impaction efficiency based on the median velocity alone would be zero (for a Gaussian profile) for all particles. This contrasts strongly with the results for the cylinder in cross flow. Whereas the fluid dynamic boundary layer around a cylinder in cross flow plays only a minor role in determining rates of inertial impaction, the boundary layer along a wall is the dominant fluid dynamic feature. Although turbulence levels have little impact on particle impaction rates as a function of particle Stokes numbers for cylinders, in many applications the turbulent fluctuations can be the only mechanism for inertial impaction on a flat wall in fully developed turbulent flow.

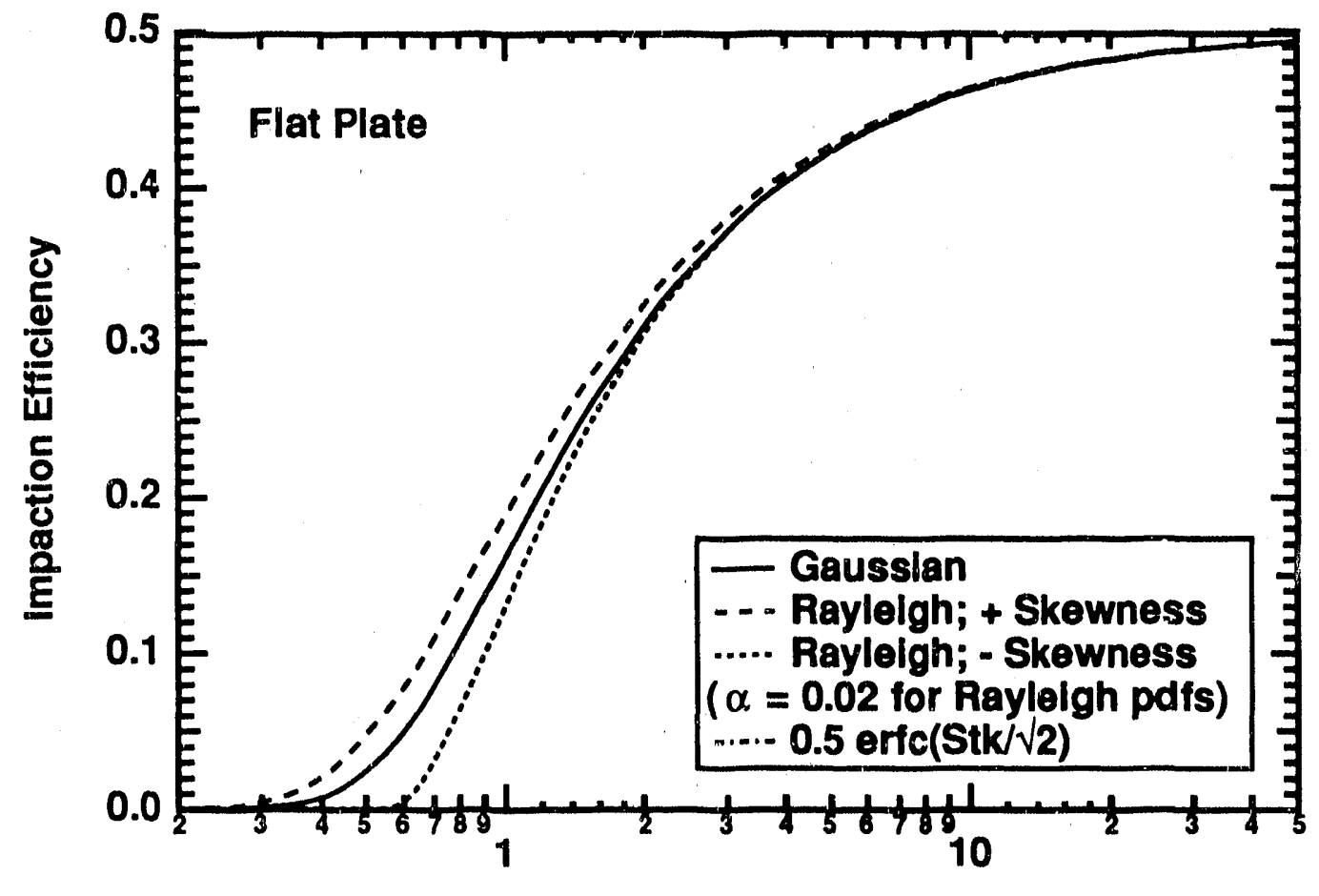

Particle Stokes Number

Figure 3.9 The predicted impaction efficiency of particles on flat plates as a function of particle Stokes number. 
The two lines for the Rayleigh pdfs illustrate the sensitivity of the parameter to the shape of the pdf. The two lines are based on the same functional form. Only the direction of skewness was changed. There is clearly a greater amount of disparity between these predictions and those previously presented for a cylinder in cross flow. The region of the figure in which there is the greatest disparity among the several predictions, i.e., Stkw $\leq 4$, is relevant to a large fraction of a typical particle flow stream. Therefore, there is significant uncertainty in the prediction of the impaction efficiency for flat plates.

Correlating Expression. The complementary error function correlating expression illustrated in Figure 3.9 (indistinguishable from the Gaussian results) is theoretically derivable based on assumed Gaussian pdfs for particle velocity. This correlation is currently used in the same manner that the function $R$ is used to correlate impaction rates on cylinders in cross flow (see Eq. 3.13). Specifically,

$$
\eta_{i}\left(S t k^{w}\right) \cong 0.5 \operatorname{erfc}\left(\frac{S t k^{w}}{\sqrt{2}}\right)
$$

This impaction efficiency is combined with the flux of particles along the wall of the boiler in the same manner as is shown in Eq. 3.15 to predict the mass flux of each species by inertial impaction.

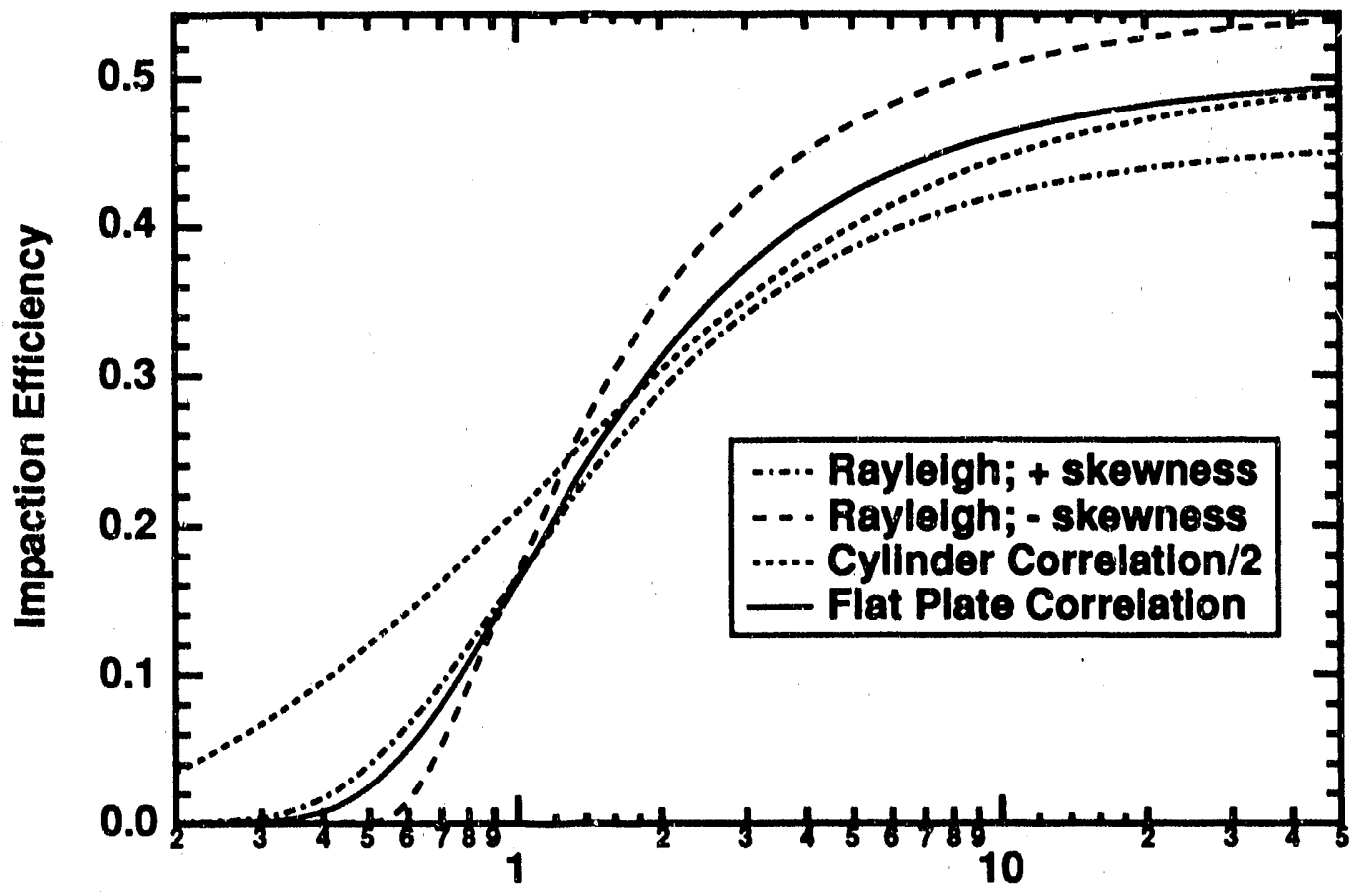

Particle Stokes Number

Figure 3.10 Illustration of the impact of using the velocity mean rather than median in the Stokes number calculation for flat plates. Also shown for comparison are the correlations for the cylinder in cross flow (divided by 2 ) and for the flat plate. 
It is important that the proper definition (that is, the one given by Eq. 3.16) of the Stokes number be used in making these predictions. Using the mean velocity instead of the median leads to less satisfactory results, as shown in Figure 3.10. These predictions are identical to those shown in Figure 3.9 except that the Stokes number is calculated using the mean velocity. Also shown is the correlation for the cylinder (divided by two) for comparison to the flat plate.

In summary, rates of inertial impaction on both flat plates and cylinders can be predicted from fundamental descriptions of fluid and particle mechanics. These descriptions are for idealized flows, ignoring features such as developing boundary layers, transient fluid mechanics, wake effects, and changes in target geometry with time. However, they provide reasonable estimates of first-order effects associated with particle velocity, diameter, and density and fluid mechanics in the vicinity of the deposition surfaces. Correlations have been shown that allow more efficient computation of the impaction rates.

\section{b. Capture Efficiency $G(t, \tau)$}

The particle capture efficiency term $(G)$ in Eq. 3.3 is essentially empirical, in contrast to the inertial impaction term. This term is defined as the ratio of the number of particles adhering to or captured by the target surface to the number of particles impacting on the surface. The term $G_{i}$ indicates a relative capture efficiency whereas $\gamma_{i}$ (used in previous reports and publications [Baxter et al., 1990]) indicates an absolute capture efficiency. The former can be greater or less than one and is only important relative to the values of the other $G_{i}$ 's. The latter is needed to predict rates of deposition and has been demonstrated to have large time $(\tau)$ variations [Baxter et al., 1990]. The relative value is essentially independent of $\tau$ in conditions representative of the radiant section of the boiler, as indicated by essentially no variation in deposit composition with depth of deposit. A knowledge of $\gamma_{i}$ for even one of the species will allow calculation of the absolute values from the relative values and, therefore, calculation of the rate of ash deposition in addition to its composition. However, absolute capture efficiencies have yet to be cetermined for ADLVIC.

Several investigators report capture efficiencies as a function of particle properties [Srinivasachar et al., 1990, for example]. In practical systems, where surface properties are changing, the variation of $\gamma$ with surface properties must also be addressed. That is, both viscid particles impacting hard surfaces and inviscid particles impacting soft surfaces experienc a high capture efficiencies. Softness of a surface is influenced by its viscosity and morphology. Powdery surfaces can be as effective in capturing particles as viscid surfaces.

The current approach in ADLVIC is to correlate empirically the capture efficiencies as a function of particle residence time in a boiler and as a function of time with respect to the last surface cleaning. The correlating function with respect to particle residence time is based on the following two assumptions: (1) the capture efficiency of a given ash species should approach some constant value in the limit of long residence times; and (2) the rate at which the capture efficiency approaches this limiting value is froportional 
to its difference from the value. These assumptions describe a first-order, linear variation of the capture efficiency with time that can be described by the following differential equation:

$$
\frac{d G_{i}}{d t}=\alpha_{i}\left(G_{i}^{\infty}-G_{i}\right)
$$

subject to the initial condition

$$
G_{i}(t=0)=G_{i}^{0}
$$

where $G_{i}$ is the particle capture efficiency, $G_{i}^{\infty}$, is the ultimate value, $\alpha$ is the proportionality constant that determines the rate at which the capture efficiency approaches its ultimate value, and $G_{i}{ }^{0}$ is its initial value. The algebraic form of Es. 3.18 and 3.19 (assuming constant $\alpha$ ) is given by

$$
G_{i}(t, \tau)=G_{i}^{\infty}(\tau)-\left(G_{i}^{\infty}(\tau)-G_{i}^{0}(\tau)\right) e^{-\alpha t}
$$

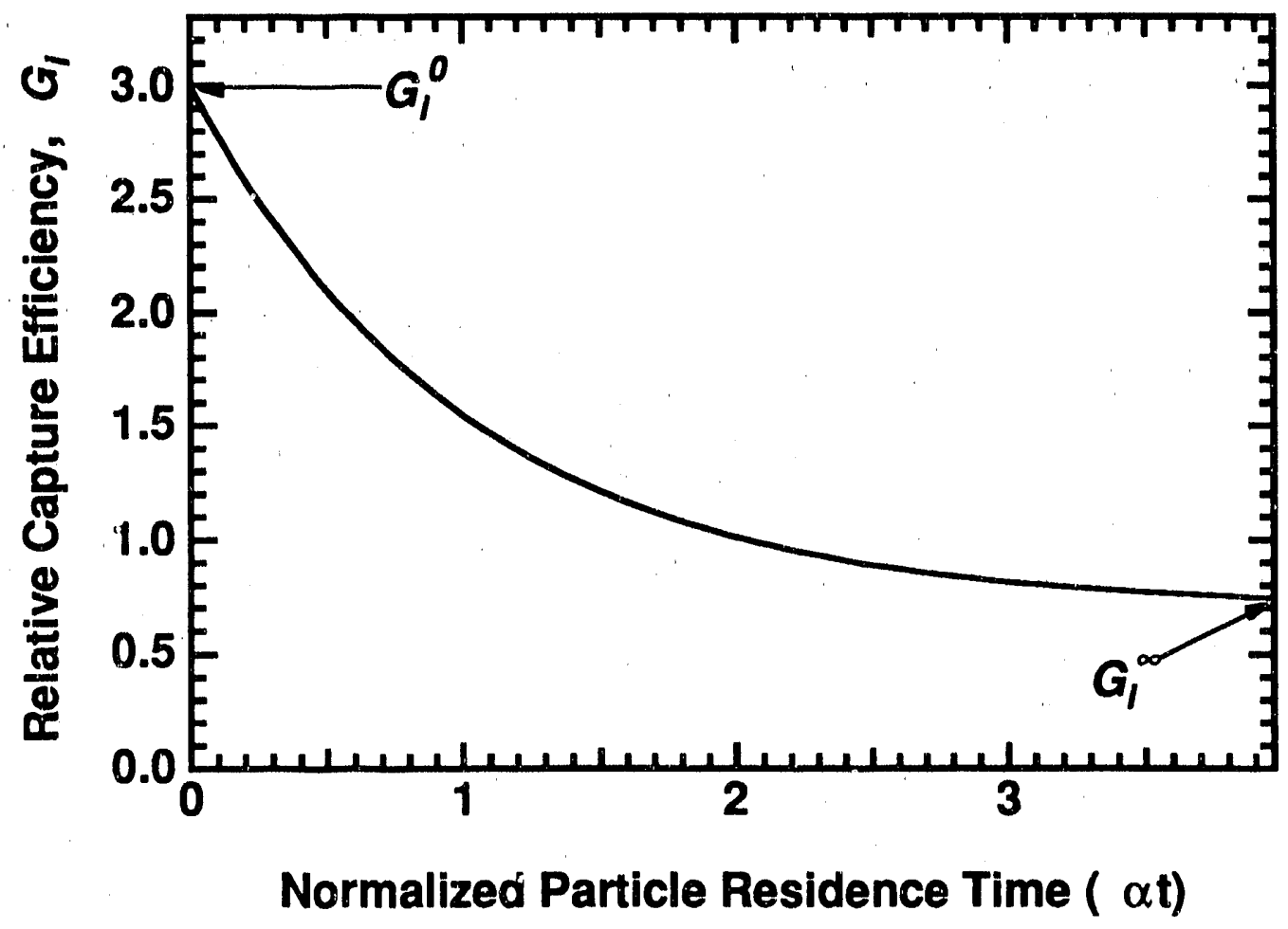

Figure 3.11 Illustration of the parameters and form of the correlating expression used to describe particle capture efficiencies for both tubes in cross flow and flat plates.

These values and a typical variation of the capture efficiency with particle residence time are illustrated in Figure 3.11. Particle residence time has been normalized with $\alpha$ 
in this figure. The three parameters $\alpha, G^{\infty}$, and $G^{0}$ are determined empirically for each of the thirteen species indicated above, but independent of coal rank, based on deposit composition data collected in the MFC. These empirical correlations combined with the more fundamental impaction data combine to form the first term of Eq. 3.3.

\section{c. Thermophoresis $T(t, \tau)$}

Thermophoresis is the process of particle transport in a gas due to local temperature gradients. Thermophoretic forces or a particle may be induced either by the temperature gradient in the gas (in which the particle is suspended) or as a consequence of a temperature gradient in the particle itself. In general, these forces act in the direction opposite to that of the temperature gradient, although they can act in the direction of the gradient under certain conditions of particle surface temperature.

An illustration of thermophoretic deposition is presented as Figure 3.11. Thermophoretic deposits are finer grained and more evenly distributed around the tube surface than deposits formed by inertial impaction, as indicated. As deposits accumulate on the tube surface, the temperature gradient in the thermal boundary layer decreases, decreasing the rate of thermophoresis.

\section{Thermophoresis}
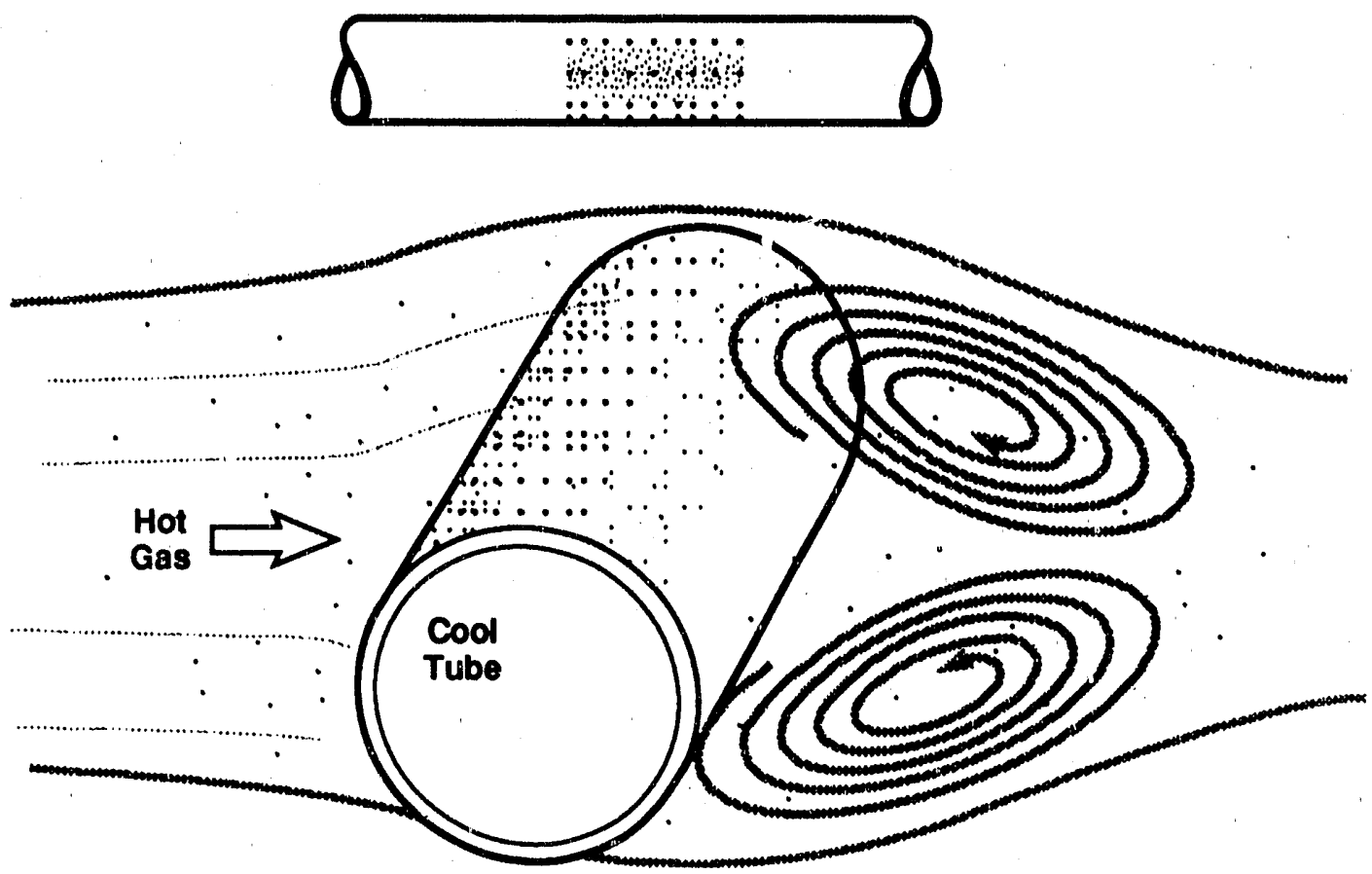

Figure 3.12 Schematic illustration of thermophoretic deposition on a tube in cross flow.

Mechanistic Descriptions. There are at least two mechanisms that give rise to this force. The first mechanism is that of the high-temperature gas molecules colliding with one 
side of the particle with more energy and at a higher collision frequency than the lowtemperature molecules on the opposing side of the particle. This creates a greater pressure on the high temperature side of the particle than on the opposing side, resulting in a force opposite the direction of the temperature gradient. For the case of an isothermal particle, this force is proportional to the particle cross sectional area and the gradient in gas temperature and is given by [Einstein, 1924; Cawood, 1936]:

$$
F_{T}=-\frac{\pi p \lambda d_{p}^{2}}{8 T_{g}} \nabla T_{g}
$$

where $F_{T}$ is the thermophoretic force, $p$ is the total pressure, $\lambda$ is the mean free path of the gas, and $T_{g}$ is the gas temperature. Note that the force is independent of both total pressure (the product of $p \lambda$ is independent of pressure) and gas thermal conductivity. The assumption that the particle is isothermal is equivalent to assuming that the particle thermal conductivity is large compared to that of the gas. This equation is valid for $d_{p} \ll \lambda$.

As particle size increases beyond the mean free path of the gas molecules, the particle temperature gradient must be considered, giving rise to a second, and often dominant, mechanism of thermophoresis. This mechanism can be described in terms of a particle with an internal temperature gradient suspended in an arbitrary gas. At the particle surface, the particle and the gas temperatures are considered equal as a function of angular position around the particle and momentum balances are performed between the two phases. The molecules approaching the surface from the direction of the hot gases have, again, both greater average momenta and more rapid average collision rates than those approaching from the direction of the cold gases. This induces a net force on the particle in the direction of the cold gases. The gases experience an equal but opposite force, establishing a convection in the direction of the hot gases. (Note that the convection of gases in this radiometric flow is in the opposite direction as the force on the particle, as opposed to viscous flow, where they are in the same direction). The force induced on the particle is given by [Hettner, 1926]:

$$
F_{T}=-\frac{3 \pi R_{g} \mu_{g}^{2} d_{p}}{2 p M} \nabla T_{p}
$$

where $R_{g}$ is the gas constant and $M$ is the molecular mass of the gas. Note that the gradient is now with respect to particle temperature rather than gas temperature.

A particle temperature gradient can be effected by reaction rates, radiative and convective heat transfer, or a gas temperature gradient. In some cases, where the particle temperature gradient is established by radiative interactions with hot walls (photophoresis), the particle and gas temperature gradients can have opposite signs [Castillo, et al., 1990]. For the purposes of our discussion, the particle temperature gradient will be assumed to be entirely due to a gas temperature gradient, in which case the thermophoretic force has been expressed as [Fuchs, 1964] 


$$
F_{T}=-\frac{9 \pi k_{g} \mu_{g}^{2} d_{p}}{2 \rho_{g} T_{g}\left(2 k_{g}+k_{p}\right)} \nabla T_{g}
$$

where $k_{i}$ is the thermal conductivity of the gas $(i=\mathrm{g})$ or particle $(i=\mathrm{p})$ and the remaining terms were defined previously.

Note the different trends in this expression for the thermophoretic force and that of Eq. 3.21. Equation 3.23 indicates a linear dependence on particle diameter, an inverse dependence on gas pressure (through the term $\rho_{g}$ ), and a slightly less than linear dependence on gas thermal conductivity (the sum in the denominator is typically dominated by $k_{p}$ ). Furthermore, the force predicted in by Eq. 3.22 vanishes as $k_{p}$ approaches infinity.

The ratio of the mean free path to the particle radius $\left(2 \lambda / d_{p}\right)$ is defined as the Knudsen number and indicates the applicability of Eq. $3.21 \mathrm{vs.} \mathrm{3.23.} \mathrm{In} \mathrm{flows} \mathrm{of} \mathrm{practical} \mathrm{interest}$ $\left(p=1 \mathrm{~atm}, T_{g}=1700 \mathrm{~K}\right.$, molecular diameter $\left.=3 \times 10^{-10} \mathrm{~m}\right)$, the gas mean free path is approximately $0.6 \mu \mathrm{m}$. This yields a particle Knudsen numbers of 6 for a $0.1 \mu \mathrm{m}$ particle and 0.6 for a $1 \mu \mathrm{m}$ particle. Therefore, the Knudsen number range of interest in this application is in the transition region from free molecular flow to viscous flow, and neither equation is expected to describe thermophoresis over the entire regime.

Expression Currently Employed. There have been many suggested functional forms for the coefficient of the gradient in Eq. 3.23, most of which involve modification of the dependencies on gas and particle thermal conductivity. A technical review of these functional forms is continuing as part of this research project. In the meantime, we have adapted a functional form that should apply over a broad range of Knudsen numbers. It is based on an integration of particle-gas momentum exchange over the surface of the particle [Jacobsen and Brock, 1965] and has been used by other investigators with some success [Im and Chung, 1983]. The thermophoretic force in this approach is given by

$$
F_{T}=-6 \pi \mu_{g} d_{p} f(K n) \nabla T_{g}
$$

where

$$
f(K n)=\frac{d_{p} C_{m} K n\left[\left(\frac{k_{g}}{k_{p}}+C_{t} K n\right)\left(1+\frac{4 a_{3} C_{m} K n}{3}\right)-\frac{4 a_{3} C_{m} K n}{3}\right]}{2\left(1+3 C_{m} K n\right)\left(1+2 \frac{k_{g}}{k_{p}}+2 C_{t} K n\right)}
$$

where the constants $C_{t m}, C_{t}, C_{m}$, and $a_{3}$ are equal to $0.461 \mathrm{~m} /(\mathrm{sK}), 3.32,1.19$, and 2 , respectively. (These constants are associated with thermal velocity, temperature jump, viscous slip, and second order slip, respectively.)

Incorporation in ADLVIC. The thermophoresic force is used in the particle force balance to predict trajectories as particles traverse thermal boundary layers. Specifically, 


$$
\frac{d\left(m_{p} u_{p}\right)}{d(t)}=\sum_{j} F_{j}=m_{p} \beta\left(u_{g}-u_{p}\right)+F_{T}
$$

where $F_{j}$ are the forces on the particles. Eq. 3.26 is solved for the smallest particles (< $15 \mu \mathrm{m}$ ) from the edge of the boundary layer to the target surface. (Deposition of larger particles is dominated by inertial impaction, which is described by use of correlated efficiencies without having to do the detailed tracking through a boundary layer.)

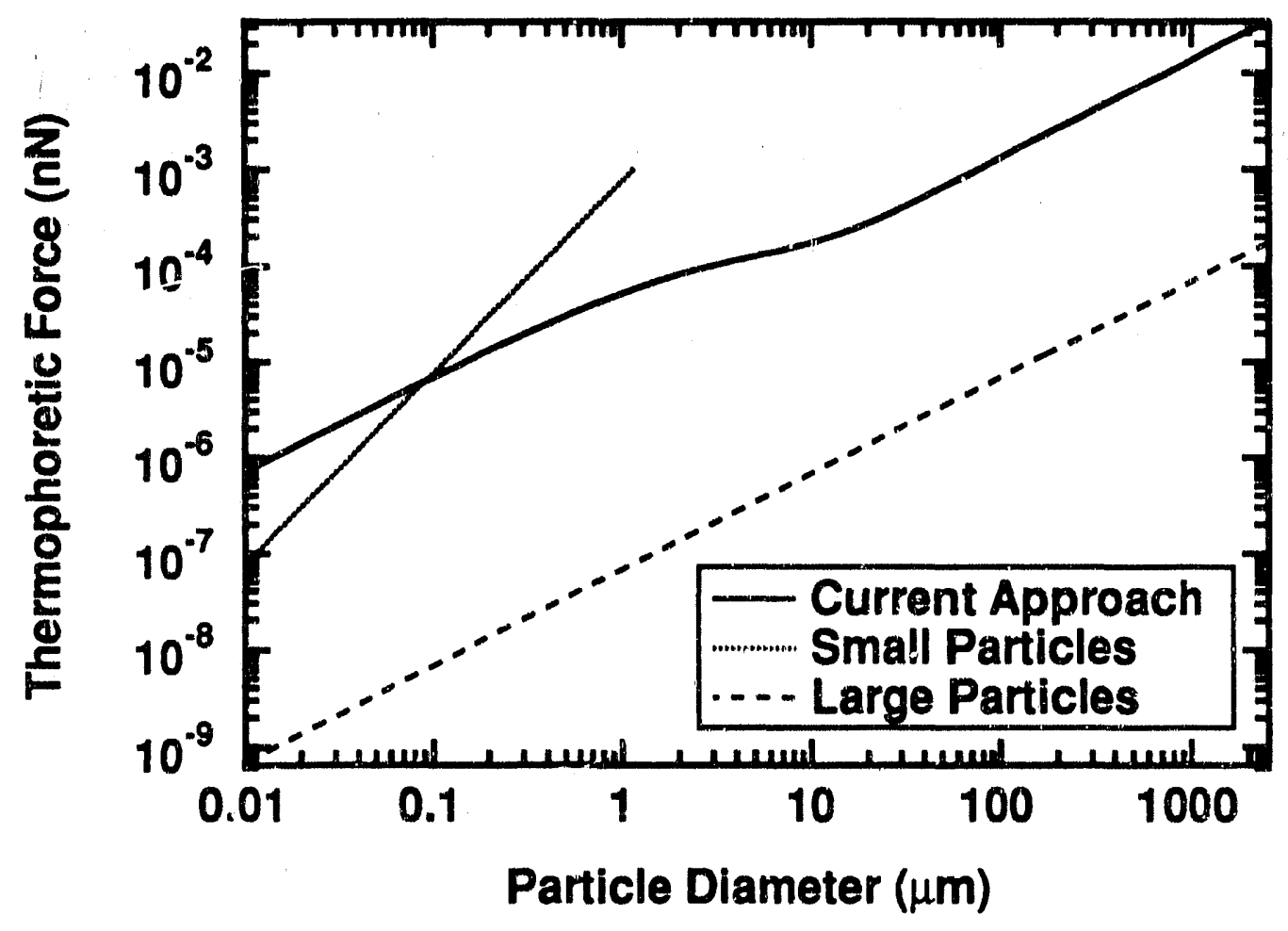

Figure 3.13 Predicted thermophoretic force as a function of particle size using several different models.

The dependence of Eq. 3.23 on particle diameter is illustrated in Figure 3.13 and compared to the results from Eqs. 3.21 (small particles) and 3.23 (large particles). The same data are illustrated as a function of Knudsen number in Figure 3.14. Eq. 3.24 shows qualitative agreement at best with Eqs. 3.21 and 3.23 at the extremes of small and large particles. The differences in the predicted forces exceed an order of magnitude over most of the relevant range of particle sizes. Both Eq. 3.23 and Eq. 3.24 have been "verified by experiment," as have several other formulations for the thermophoretic force [Byers and Calvert, 1969; Goren, 1977; Walker et al., 1979; Sehmel, 1970; Friedlander and Johnstone, 1957]. A compallinis reason to adopt one of the several 
expressions for $F_{T}$ has not been identified. Therefore, we plan to revisit the issue of thermophoresis in the future.

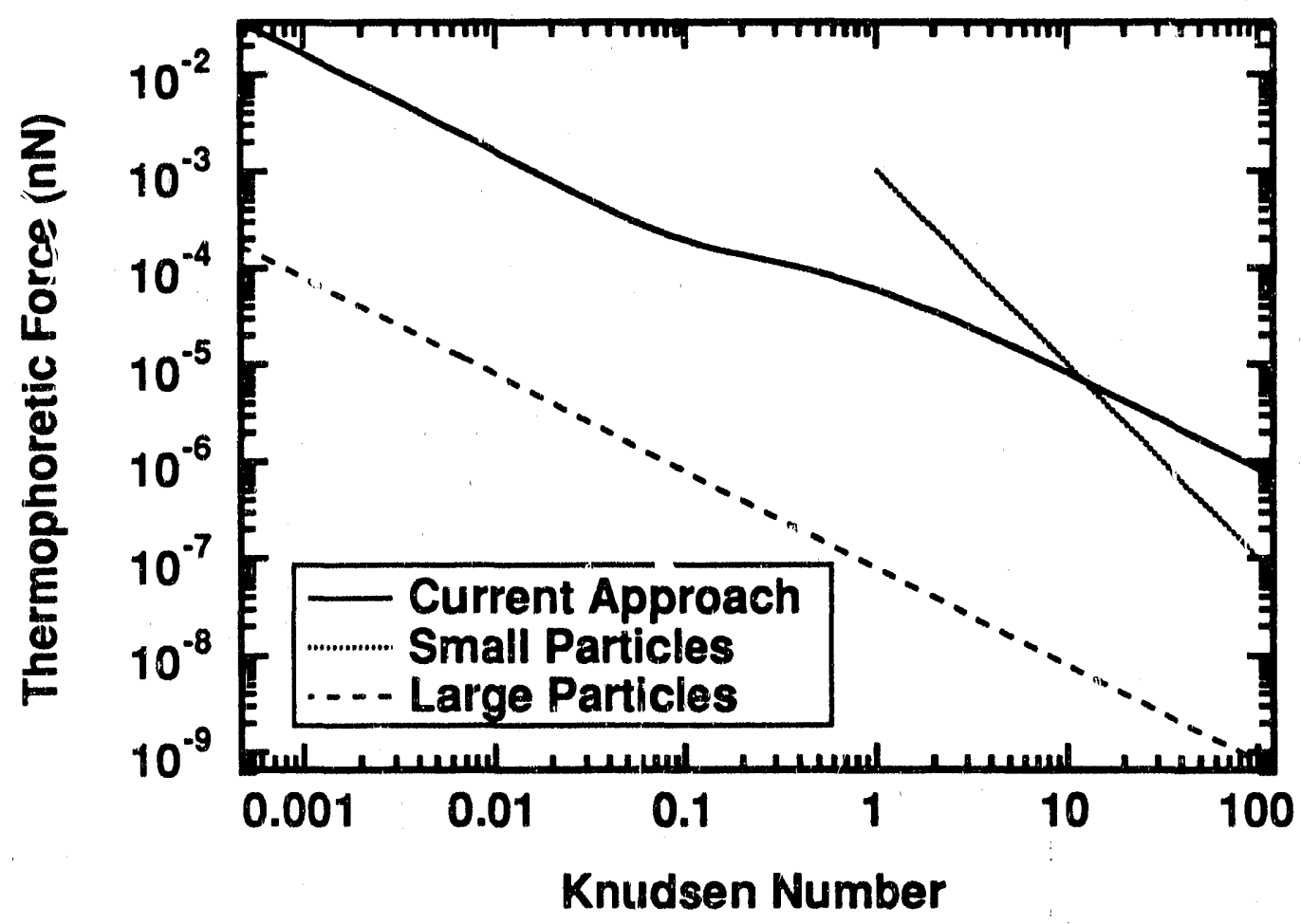

Figure 3.14 Predicted thermophoretic force as a function of Knudsen nrmber over the range of particle sizes of importance in pulverized coal combustion.

\section{d. Condensation $C(t, \tau)$}

Condensation is the mechanism by which vapors are collected on cooled heat transfer surfaces. All vapors that enter the thermal boundary layer around a heat transfer surface and subsequently are deposited on the surface are treated within the condensation term of the model. At least three mechanisms for this process are available: (1) vapors may traverse the boundary layer and heterogeneously condense on the heat transfer surface; (2) vapors may homogeneously nucleate to form a fume and subsequently deposit by thermophoresis on the surface; and (3) vapors may heterogeneously condense on other particles in the boundary layer and arrive at the heat transfer surface by thermophoresis.

An illustration of deposition by condensation on a tube in cross flow is presented in Figure 3.15. Condensation deposits have no granularity and are more uniformly deposited on the tube than either thermophoretically or inertially deposited material. The deposits are tacky and would be expected to have a major impact on the surface capture efficiency. 


\section{Condensacion}

\section{0}

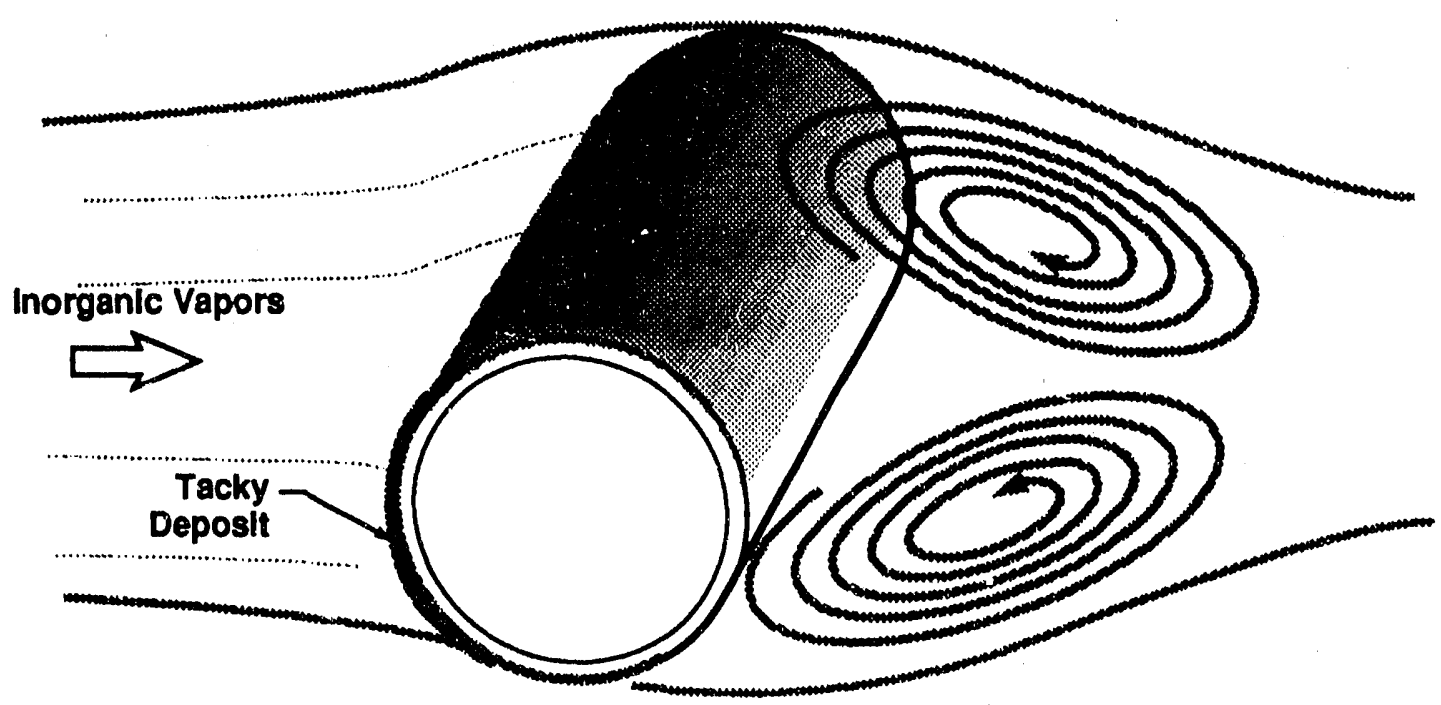

Figure 3.15 Schematic illustration of deposition by condensation on a tube in cross flow.

The precise role of condensation in deposit formation is not well estabiished. Those who have addressed the issues involved with coupled condensation and thermophoresis show that the observed rates of deposition can vary by about a factor of four depending on assuniptions regarding thermodynamics, heterogeneous condensation on particles, and particle loading [Castillo and Rosner, 1988]. Recent experiments in the MFC using low rank coals demonstrate the commonly observed formation of deposits rich in calcium, sodium, and magnesium in regions of heat transfer surfaces that are not affected strongly by inertial impaction. Possible mechanisms for the formation of these deposits include: (1) thermophoretically deposited fume material from the bulk gas phase, (2) condensation of vapors within the thermal boundary layer and subsequent thermophoretic deposition of these particles, or (3) heterogeneous condensation of vapors on the heat transfer surface. All of these mechanisms are likely contributors to the process. Our current hypothesis is that the third is more significant than has been commonly recognized.

Our current approach to modeling condensation is to treat the problem in the frozen boundary layer limit, implying no homogeneous condensation and no scavenging of vapors by small particles in the boundary layer. This is an upper limit for the condensation rate. Since thermophoretic velocities and diffusion rates are slower than the corresponding molecular rates, introduction of either nucleation of vapors or scavenging of vapors by pre-existing particles in the boundary layer decreases the total 
vapor deposition rate. This upper limit will be augmented by an empirically determined "condensation efficiency" parameter to account for the observed rates of condensation on the heat transfer surface. The value of the empirically determined parameter should lie between about 0.25 and 1.0 and will depend on the ratio of surface and gas temperatures but (presumably) not on coal type. Therefore, the condensation flux is modeled as

$$
C_{i}=\zeta_{i} \theta k_{m}\left(x_{i, b}-x_{s}\right)+x_{i, b} \sum_{i} C_{i}
$$

Where $\zeta_{i}$ is the condensation efficiency, $\theta$ is a blowing factor (which will be very near unity for this application), $k_{m}$ is a mass transfer coefficient with a value that depends in known ways on geometry, Reynolds number, and fluid properties, and $x$ represents a mole fraction of species $i$ in the bulk gas (subscript $b$ ) and at the tube surface (subscript s). The second term on the right side of the equation represents convective transport to the surface and will probably be insignificant compared to the first term. Alternative expressions for this condensation rate are available in the literature [Castillo and Kosner, 1988, for example]. Evaluation of the several possible expressions will continue in the future.

Initial experiments with low rank coals that generate large quantities of condensible material in the gas phase have been completed in the MFC. Data analysis is not yet complete, but when completed it will allow determination of the empirical parameter $\zeta$ discussed above and an indication of the validity of this approach.

\section{e. Reaction $R(t, \tau)$}

Deposits undergo heterogeneous chemical reactions that change their elemental composition. The most prominent reactions are oxidation (e.g. of carbon), sulfation (e.g. of sodium and calcium), and chemical adsorption/absorption (e.g. of alkali material into silica and silicates). The rate of conversion depends on mass transfer rates to the surface and on chemical kinetics of the heterogeneous reactions involved. Mass transfer rates can be determined using an approach similar to Eq. 3.21. A literature search has been initiated to determine the extent to which the heterogeneous reaction rates have been characterized. The incorporation of this term in the model will be completed in the future.

A schematic illustration of changes in deposit composition associated with chemical reaction is illustrated in Figure 3.16. Individual molecules are shown (in gross exaggeration) to emphasize the chemical rather than physical nature of this deposition process. In this context, condensation would be viewed as a physical process, involving a phase change but no rearrangement of molecules. 


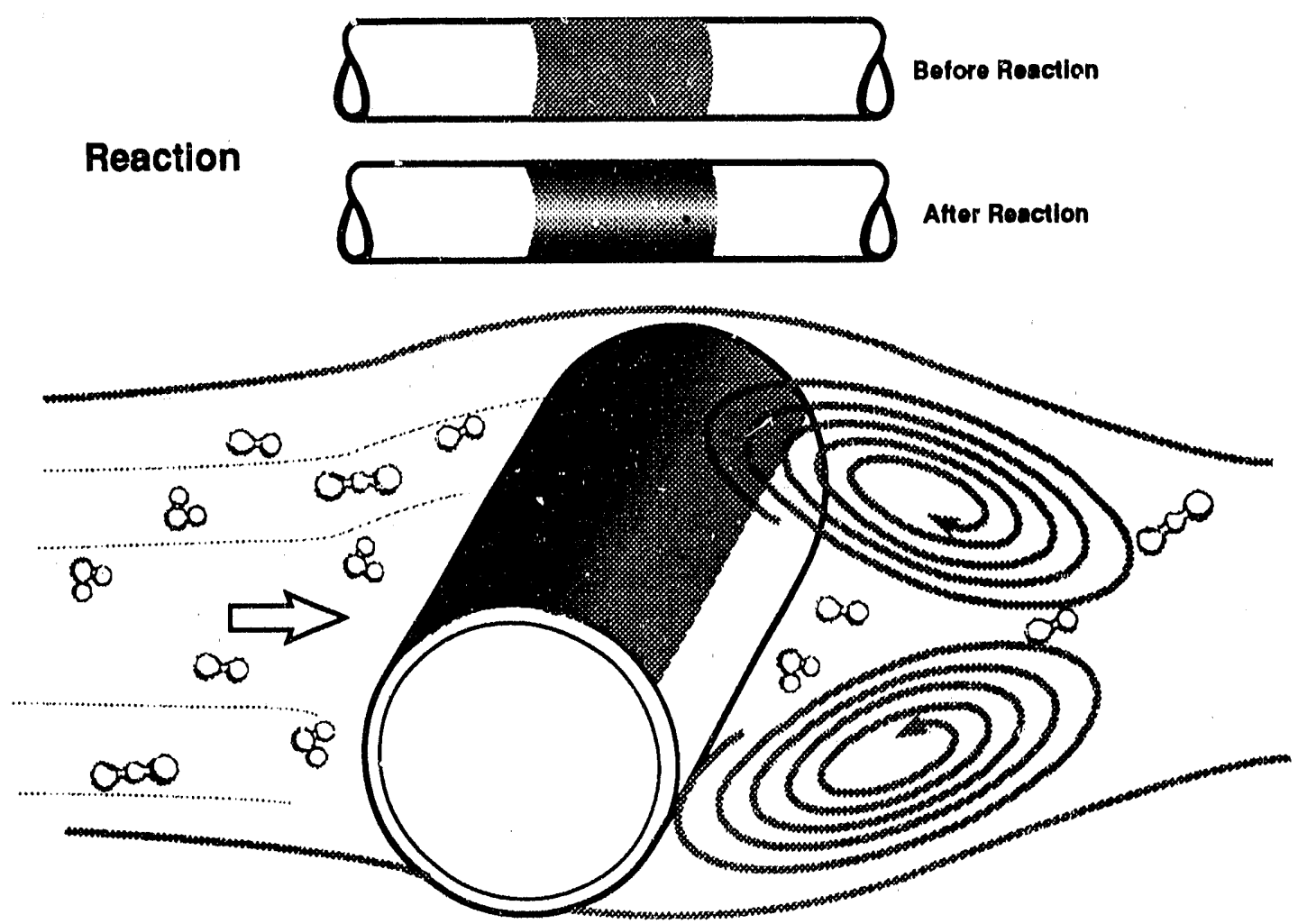

Figure 3.16 Schematic illustration of deposit composition changes induced by chemical reaction.

\section{Outline of Computational Algorithm}

The computations proceed by the following steps

1. Describe the coal, boiler, and gas conditions.

2. Compute the elemental composition of each of the thirteen species with mass balances and Eqs. 3.1 - 3.2. Define initial conditions and begin particle tracking.

3. Track the species through the boiler as a function of time, describing the propensity to deposit on either flat walls or cylinders at each time step (Eq. 3.3).

4. Calculate inertial impaction rates using Eq. 3.15 augmented with Eq. 3.14 for cylinders and 3.17 for flat plates. Multiply these by the capture efficiency (Eq. $3.20)$.

5. Calculate thermophoretic deposition for particles with Stokes numbers less than 0.15 using Eqs. 3.26 and 3.24.

6. Calculate condensation rates using Eq. 3.27. 
7. Calculate reaction rates using Eq. 3.27 and chemical kinetic expressions.

8. Repeat steps 2 through 7 for each particle size and type.

9. Sum the masses and compute the deposit compositions.

10. Calculate viscosities and emissivities using correlations based on deposit composition.

11. Write output files and stop.

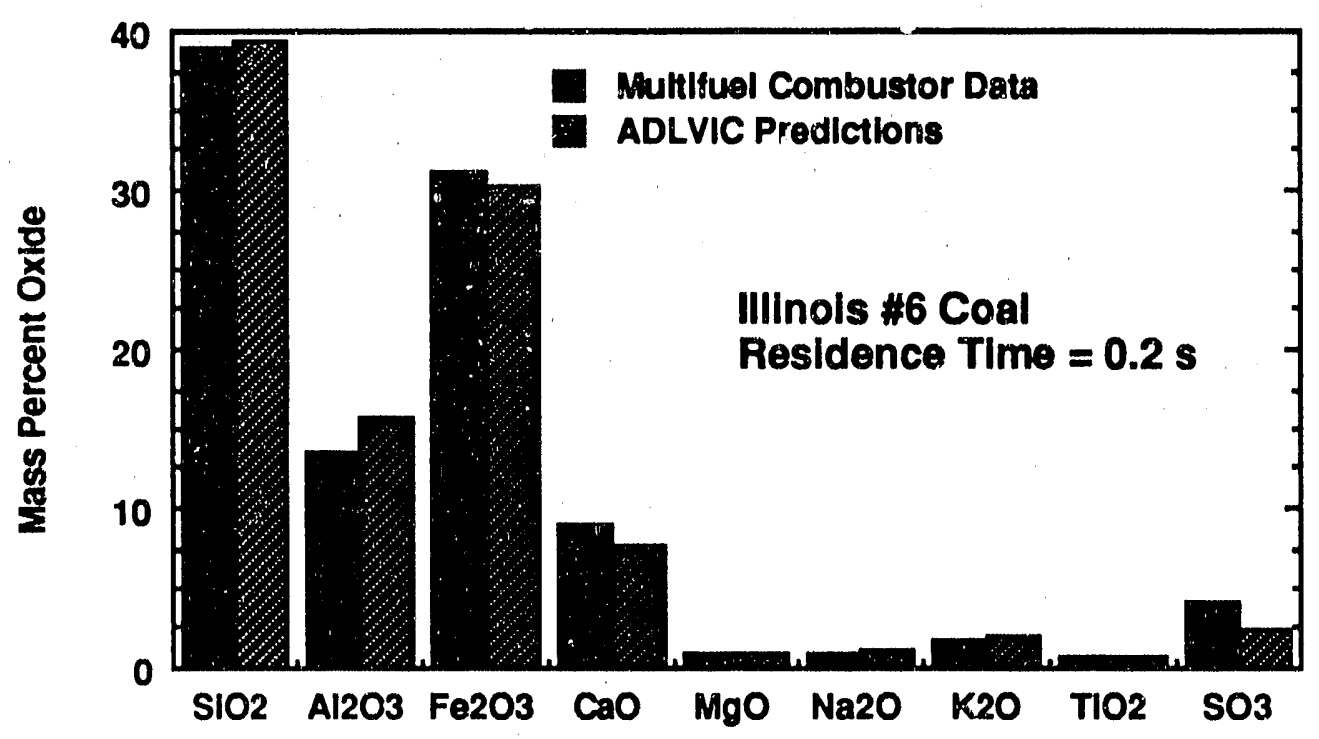

Figure 3.17 Comparisor of data and predictions of ash deposit composition for a high volatile bituminous coal.

Calculations to date are limited to bituminous coals in the furnace region. The current suite of experiments in the MFC will allow calibration of the condensation and reaction portions of the model and provide data to help evaluate the thermophoresis models. ADLVIC, in this preliminary stage of development, has application to bituminous coals in the radiant section of a boiler, where there is little propensity for material to condense. In these applications, rigorous treatment of reactions with sulfur and oxygen has not been included. Several such cases have been predicted and previously presented and discussed [Baxter, 1990d and g]. Figure 3.17 and 3.18 illustrate two typical results. These figures show the predicted and measured ash compositions of two coals used in the MFC. Agreement is well within measurement errors. 


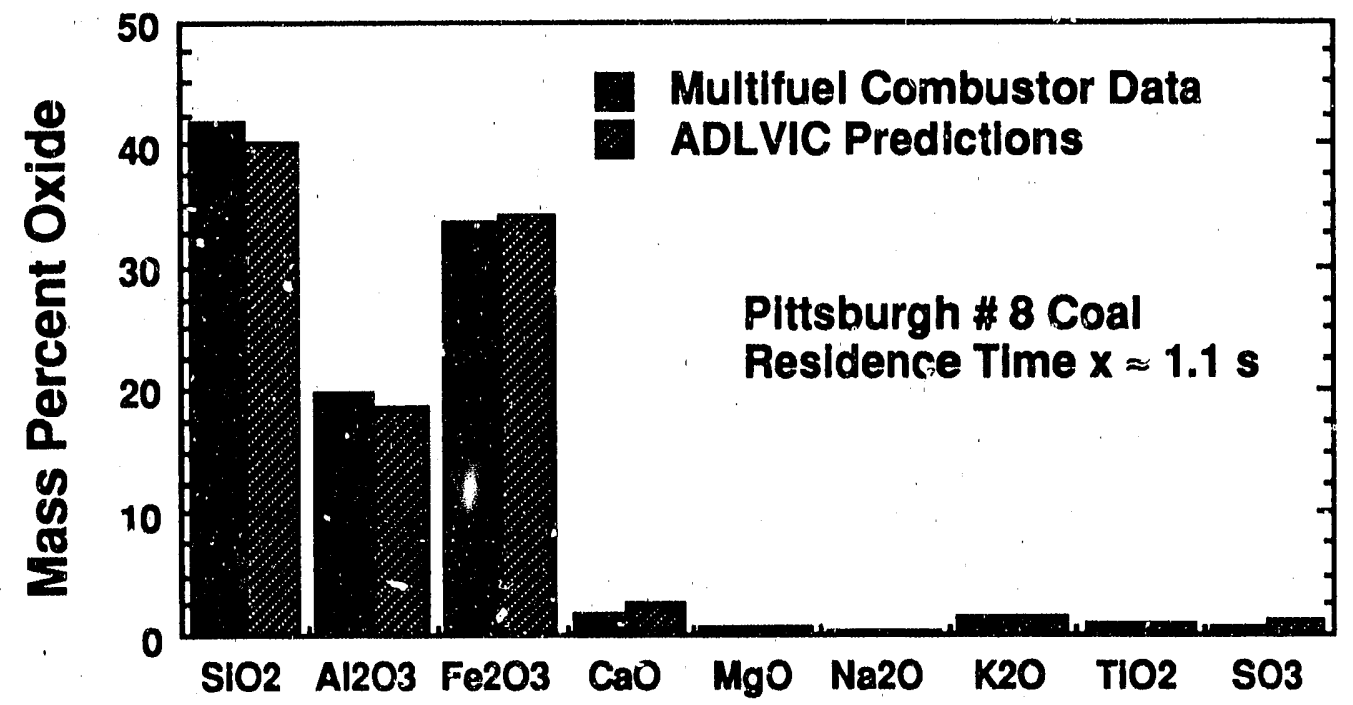

Figure 3.18 Comparisons of predictions and data for a different rank coal at a different residence time as compared to Fig. 3.17.

\section{TECHNOLOGY EXCHANGE FOR TASK 3}

\section{Collaboration with Consol}

During this quarter, engineers from Consol, including Dee Reese, Murray Abbot, and Robert Douglas, visited Sandia and assisted in performing combustion tests a $d$ in running the early version of the ADLVIC code to predict some of the results of these tests. Predictions of deposit composition were performed for several of the coals identified in Tables 3.1 and 3.2 as a function of particle residence time. Combustion tests were also completed and solid samples are currently being analyzed. Samples are being analyzed to determine: ultimate composition, proximate forms of sulfur, heating value, ash chemistry, fusion temperatures (educing and oxidizing), and particle size distribution. These analyses are being performed at Consol's analytical laboratories. Additional analyses (e.g. CCSEM) will be performed at Sandia as needed. Arrangements are currently being made for Sandia engineers to visit Consol and present the preliminary results to their staff and management.

\section{Collaboration with Central Illinois Public Services}

Also during this quarter arrangements were finalized with Richard DeSollar and Warren Lovelas of Central Illinois Public Services (CIPS) to collaborate in three utility-scale boiler tests. DeSollar, the Fuels Coordinator for (CIPS), has shown interest in and 
agreed to help evaluate our ash deposition model ADLVIC. Lovelas is the Senior Performance Engineer and has agreed to assist in these tests. DeSollar has technical responsibility for selecting and evaluating fuels, and Lovelas for predicting performance, for the approximately one dozen boilers in this utility.

The planned tests involve blind predictions, using the ADLVIC model, of deposit properties in three CIPS utility boilers, including Units \#1 and \#2 at the Newton plant and a unit at the Meredosia plant. In the plant tests ash deposits will be collected and evaluated by CIPS engineers. The agreed-upon test plans are as follows:

\section{Test 1: Effect of Operating Conditions: Tests at Newton Unit \#1.}

Two $\approx 10$ hour tests will be conducted in this $600 \mathrm{MW}$, tangentially-fired (CE) unit to test the sensitivity of deposit composition to operating conditions. One test will be run during the night, when the boiler is operated at about 20 percent of capacity. The second test will be done during the day, when the boiler is operated at 100 percent capacity. This test will be conducted using a high-sulphur Illinois \#6 coal. Sandia will predict deposit properties; the predictions will be compared with the results obtained by CIPS.

Test 2: Effect of Coal Type: Tests at Newton Unit \#2 (this unit is essentially 1dentical to the Newton Unit \#1).

CIPS is currently preparing this boiler to perform a test burn of 50,000 to 60,000 tons of a Hanna Basin coal (which is similar in properties to Powder River Basin coal). The boiler will then resume operation on an Indian low sulfur coal. Sandia will predict deposit properties for both coals and compare them with the measured results from CIPS.

\section{Test 3: Operating Strategy: Tests at Meredosia Unit.}

This unit (180-250 MW, CE tangentially fired) currently uses a high-moisture, low-ash Illinois \#2 coal. CIPS is contemplating switching to an Illinois \#6 coal with significantly higher ash. Sandia will attempt to predict current deposit properties (with the Illinois \# 2 coal) and anticipated properties (with the Illinois \#6 coal) using the ADLVIC code.

During the tests CIPS will collect and analyze numerous ash deposits. Proximate, ultimate, heating value, forms of sulfur, particle size distribution and ash chemistry analyses will be performed on raw coals. Appropriate analyses (primarily ash chemistry) will be performed on fly ash and deposits. These analyses, as well as samples of the deposits, will be provided by CIPS to Sandia. In addition CIPS will provide descriptions of the boiler geometries and the operating conditions in support of all three tests. CIPS is also prepared to supply samples of the test coals for either our analysis (e.g. by CCSEM) or for testing in the MFC; CIPS staff will also help resolve differences in predictions and measurements by replicating experiments. Conducting the tests, completing the analyses, and providing the samples will entail a considerable cost sharing on the part of CIPS. In our view, the planned tests represent a unique opportunity in terms of the type of services rendered by CIPS and in view of the nature of the data to be obtained, ie. extensive full-scale deposition data in the same utility boiler (and in similar boilers) as a function of operating conditions and coal type. 


\section{PLANS FOR THE NEXT QUARTER}

During the next quarter experimental testing of the last few coals and coal blends being used in the collaborative study with Consol will be completed. The results will be presented to management and other divisions of Consol. Work will continue to develop and to improve the ADLVIC deposition model. Boiler geometries, coal samples and analyses from CIPS will be used to make predictions of ash deposit characteristics in the CIPS boilers. Construction of deposit sampling probes and other experimental tools should be completed by CIPS and the first deposit samples from the CIPS/Sandia tests should be ready for analysis by the end of the quarter.

\section{ACKNOWLEDGMENTS}

The contributions of Krishnan Padmanabhan in performing some of the initial impaction and thermophoresis predictions is gratefully acknowledged. Krishnan Padmanabhan recently completed his undergraduate degree at Princeton University and worked as a summer employee at Sandia before initiating his graduate studies at Stanford. The assistance of Eric Harwood, James Brandt, and Ephraim Arquitola in performing experiments and maintenance of the MFC during this quarter are gratefully acknowledged. Eric Harwood is a student at Las Positas College, located in the Livermore area. James Brandt is a student at Livermore High School. Ephraim Arquitola is Senior Technical Aide at Sandia.

\section{REFERENCES FOR TASK 3 SECTION}

Baxter, L.L. "Char Fragmentation and Fly Ash Formation During Pulverized Coal Combustion," submitted to Combustion and Flame 1990a.

Baxter, I.L., "Task 3: Fate of Mineral Matter During Pulverized Coal Combustion," in "Coal Combustion Science: Quarterly Progress Report" Hardesty, D.R., ed., Sandia Report (in press), August, 1990b.

Baxter, L.L., "Task 3: Fate of Mineral Matter During Pulverized Coal Combustion," in "Coal Combustion Science: Quarterly Progress Report" Hardesty, D.R., ed., Sandia Report SAND90-8223, April, 1990c.

Baxter, L.L., "Task 3: Fate of Mineral Matter During Pulverized Coal Combustion," in "Coal Combustion Science: Quarterly Progress Report" Hardesty, D.R., ed., Sandia Report SAND90-8219, May, 1990d.

Baxter, L.L., "Task 3: Fate of Mineral Matter During Pulverized Coal Combustion," in "Coal Combustion Science: Quarterly Progress Report" Hardesty, D.R., ed., Sandia Report SAND90-8209, February, 1990e. 
Baxter, L.L., "Evolution of Inorganic Material during Coal Devolatilization," proceedings of the ASME Research Committee on Corrosion and Deposits from Combustion Gases Seminar'on Fireside Fouling Problems, Provo, Utah, April 4-6, 1990f.

Baxter, L.L., "Ash Composition Prediction as a Function of Coal Type, Operating Conditions, and Boiler Location" proceedings of the EPRI conference on the Effects of Coal Quality on Power Plants, St. Lois, Missouri, September 19-21, $1990 \mathrm{~g}$.

Baxter, L.L, R.E. Mitchell, and T.H. Fletcher, "Experimental Determination of Mineral Matter Release During Coal Devolatilization," proceedings of the Seventh Annual International Pittsburgh Coal Conference, Pittsburgh PA, September 10-14, 1990.

Baxter, L.L., and R.E. Mitchell, "The Release of Iron During the Combustion of Illinois \#6 Coal," submitted to Combustion and Flame, 1990

Beér, J.M., L.S. Monroe, L.E. Barta, and A.F. Sarofim, "From Coal Mineral Matter Properties to Fly Ash Deposition Tendencies; a Modeling Route," proceedings of the Seventh International Pittsburgh Coal Conference, Pittsburgh, Pennsylvania, (1990).

Benson, S.A., E.N. Steadman, M.L. Jones, and D.P. Kalınanovitch, "In Situ Determination of Temperature Distributions in Ash Deposits in a Pilot Scale Furnace," in Mineral Matter and Ash Deposition From Coal, Bryers, R.W. and K.S. Vorres, ed., Engineering Foundation Conferences; United Engineering Trustees, Inc., (1990).

Bird, R.B., W.E. Stewart, and E.N. Lightfoot, "Transport Phenomena," Wiley, New York, 1960.

Boni, A.A., Beér, J.M., Bryers, R.W., Flagan, R.C., Helble, J.J., Huffman, G.P., Huggins, F.E., Peterson, T.W., Sarofim, A.F., Srinivasachar, S., and Wendt, J.O.L., "Transformations of Inorganic Coal Constituents in Combustion Systems," Phase I Draft Final Report, US DOE Contract No. CE-AC22-86PC90751, March, 1990.

Brun, R.J., W. Lewis, P.J. Perkins, and J.S. Serafini, NACA Rep. No. 1215, 1955.

Byers, R.L., and S. Calvert, "Particle Deposition from Turbulent Streams by Means of Thermal Force," Industrial and Engineering Chemistry Fundamentals 8: 646-655 (1969).

Castillo, J.L., and D.E. Rosner, "A Nonequilibrium Theory of Surface Deposition from Particle-Laden, Dilute Condensible Vapor-Containing Laminar Boundary Layers," International Journal of Multiphase Flow 14: 99-120 (1988).

Castillo, J.L., D. Mackowski, and D.E. Rosner, "Photophoretic Contribution to the Transport of Absorbing Particles Across Combustion Gas Boundary Layers," Progress in Energy and Combustion Science (in press) (1990). 
Cawood, W., Transactions of the Faraday Society 32: 1068 (1936).

Cole, D.A., G.W. Simmons, R.G. Herman, K. Klier, and I. Czak6-Nagy, "Transformations of Iron Minerals During Coal Oxidation," Fuel 66:1240-1248 (1987).

Einstein, A., Zeitung der Physik 27: 1 (1924)

Finkelman, R.B., Miodes of Occurrence of Trace Elements in Coal, PhD Dissertation, University of Maryland, 1980.

Friedlander, S.K. and H.F. Johnstone, "Deposition of Suspended Particles from Turbulent Gas Streams," Industrial and Engineering Chemistry 49: 1151-1156 (1957).

Fuchs, N.A., The Mechanics of Aerosols Daisley, R.E. and M. Fuchs trans., Dover, New York (1964).

Gökoåglu, S.A., and D.E. Rosner, "Thermophoretically Augmented Mass Transfer Rates to Solid Walls Across Laminar Boundary Layers," AIAA Journal 24: 172-179 (1986).

Gökoåglu, S.A., and D.E. Rosner, "Thermophoretically Enhanced Mass Transport Rates to Solid and Transpiration-Cooled Walls Across Turbulent (Law-of-the-Wall) Boundary Layers," Ind. Eng. chem. Fundam. 24: 208-214 (1985).

Gökoglu, S.A., and D.E. Rosner, "Correlation of Thermophoretically-Modified Small Particle Diffusional Deposition Rates in Forced Convection Systems with Variable Properties, Transpiration Cooling and/or Viscous Dissipation," International Journal of Heat and Mass Transfer 27 : 639-646 (1984).

Goodwin, D.G., "Infrared Optical Constants of Coal Slags," PhD Dissertation, Department of Mechanical Engineering, Stanford University, (1986).

Goren, S.L., "Thermophoresis of Aerosol Particles in the Laminar Boundary Layer on a Flat Plate," Journal of Colloid and Interface Science 61 77-85 (1977).

Helble, J., M. Neville, and A.F. Sarofim, "Aggregate Formation from Vaporized Ash During Pulverized Coal Combustion," Proceedings of the Twenty-First Symposium (International) on Combustion, The Combustion Institute, 1987.

Hettner, G. Zeitung der Physik 37:179 (1926).

Huggins, F.E., G.P. Huffman, and M.C. Lin, "Observations of Low-Temperature Oxidation of Minerals in Bituminous Coals," International Journal of Coal Geology, 3:157-182 (1983).

Im, K.H., and P.M. Chung, "Particulate Deposition from Turbulent Parallel Streams," AIChE Journal 29:498-505 (1983) 
Israel, R., and D.E. Rosner, "Use of a Generalized Stokes Number to Determine the Aerodynamic: Capture Efficiency of Non-Stokesian Particles from a Compressible Gas Flow," Aerosol Science and Technology, 2:45-51 (1983).

Jamaluddin, A.S. and P.J. Smith, "Predicting Particulate Deposition from Turbulent Streams," in Mineral Matter and Ash Deposition From Coal, Bryers, R. W. and K.S. Vorres, ed., Engineering Foundation Conferences; United Engineering Trustees, Inc., (1990).

Laitone, J.A., “A Numerical Solution for Gas-Particle Flows at High Reynolds Numbers," Journal of Applied Mechanics, 48:465-471 (1981).

Langmuir, I. and K. Blodgett" "A Mathematical Investigation of Water Droplet Trajectories," Technical Report No. 5418, Air Material Command, Army Air Forces, Feb. 1946

Levasseur, A.A., O.K. Chow, and G.F. Lexa, "Combustion Characterization of the Kentucky No. 9 Cleaned Coals," EPRI Final Report, CS-4994, Research Project 2425-1, 1987.

Quann, R.J., and A.F. Sarofim, "Vaporization of Refractory Oxides During Puiverized Coal Combustion," Proceedings of the N'ineteenth Symposium (International) on Combustion, The Combustion Institute, 1983.

Raask, E., "Mineral Impurities in Coal Combustion," Hemisphere, New York, 1985.

Rosner, D.E., “Total Deposition Rates from 'Polydispersed' Aerosols," AIChE Journal $35: 164-167$ (1989).

Rosner, D.E., and M. Tassopoulos, "Deposition Rates from Polydispersed Particle Populations of Arbitrary'Spread," AIChE Journal 35:1497-1508 (1989).

Rosner, D.E., and R. Ganarajan, "Transport-Induced Shifts in Condensate Dew-Point and Composition in Multicomponent Systems with Chemical Reaction," Chemical Engineering Science 40: 177-186 (1985).

Schlichting, H., Boundary Layer Theory, Mc-Graw Hill Book Co., New York, p $131 ; 216,(1979)$.

Sehmel, G.A., "Particle Deposition frcm Turbulent Air Flow," Journal of Geophysical Research 75 : 1766-1781 (1970).

Sell, W., "Dust Deposition on Single Targets and Air Filters," Research Report $\$ 347$. Ver. Deutsch. Ing., Issue B. 2, August, Berlin (1931).

Srinivasachar, S. and A.A. Boni, "A Kinetic Model for Pyrite Transformations in a Combustion Environment," Fuei, 68 : 7-14 (1989). 
Srinivasachar, S., J.J. Helble, C.B. Katz, and A.A. Boni, Proceedings of the TwentyThird Conference (International) on Combustion, The Combustion Institute, Pittsburgh (in press) (1990).

Stairmand, C.J., "Dust Coilection by Impingement and Diffusion," Transactions of the Institute of Chemical Engineering, 28:130-139 (1950).

Taneja, S.P., and C.H.W. Jones, "Mössbauer Studies of Iron Bearing Minerals in Caol and Coal Ash," Fuel, 63 : 695-701 (1984).

Tassopoulos, M., J.A. C'Brien, and D.E. Tosner, "Simulation of Microstructure Mechanism Relationships in Particle Deposition," AlChE Journal 35:967-980 (1989).

Walker, K.L., G.M. Homsy, and F.T. Geyling, "Thermophoretic Deposition of Small Particles in Larninar: Tuine Flow," Journal of Colloid and Interjace Science 69: 138147 (1979).

Walsh, P.M., J.M. Beér, and A.F. Sarofim, "Estimation of Aerodynamic Effects of Erosion on a Tube by Fly Ash," EPRI Conference on Effects of Coal Quality on Power Plants, Atlanta, GA, October 13-15, 1987 
NOMENCLATURE FOR TASK 3

\begin{tabular}{|c|c|c|}
\hline Symbol & Units & Definition \\
\hline$a$ & - & constant (Eq. 3.13; Table 3.2) \\
\hline$a_{3}$ & - & second order slip coefficient (Eq. 3.24) \\
\hline$b$ & - & constant (Eq. 3.13; Table 3.2) \\
\hline$c$ & - & constant (Eq. 3.13; Table 3.2) \\
\hline$C$ & $\mathrm{~kg} / \mathrm{m}^{2} \mathrm{~s}$ & mass flux by condensation \\
\hline$C_{t m}$ & $\mathrm{~m} / \mathrm{sK}$ & thermal velocity coefficient (Eq. 3.24) \\
\hline$C_{t}$ & - & temperature jump coefficient (Eq. 3.24) \\
\hline$C_{m}$ & - & viscous slip coefficient (Eq. 3.24 ) \\
\hline$d$ & - & constant (Eq. 3.13; Table 3.2) \\
\hline$d$ & m & diameter \\
\hline$D$ & $\mathrm{~m}$ & cylinder diameter \\
\hline$f$ & $\mathrm{~s} / \mathrm{m}$ & velocity probability density function \\
\hline$f$ & - & arbitrary function \\
\hline$F$ & $\mathbf{N}$ & force \\
\hline$G$ & - & reiative capture efficiency \\
\hline$I$ & $\mathrm{~kg} / \mathrm{m}^{2} \mathrm{~s}$ & mass flux by inertial impaction \\
\hline$k$ & $\mathrm{~W} / \mathrm{m} \mathrm{K}$ & thermal conductivity \\
\hline$k_{m}$ & $\mathrm{~kg} / \mathrm{m}^{2} \mathrm{~s}$ & mass transfer coefficient \\
\hline$m$ & kg & mass \\
\hline$M$ & $\mathrm{~kg} / \mathrm{kg}-\mathrm{mol}$ & molecular weight \\
\hline$p$ & $\mathrm{~N} / \mathrm{m}^{2}$ & pressure \\
\hline$P$ & $\mathrm{~s} / \mathrm{m}$ & velocity probability density function \\
\hline$q$ & $\mathrm{~kg} / \mathrm{m}^{2} \mathrm{~s}$ & particle mass flux \\
\hline$\dot{r}$ & $\mathrm{~m}$ & radial position, cylindrical coordinate direction \\
\hline$R_{g}$ & $\mathrm{~J} / \mathrm{kg}-\mathrm{mol} \mathrm{K}$ & universal gas constant $=8314.4$ \\
\hline$R$ & $\mathrm{~m}$ & radius \\
\hline$R$ & $\mathrm{~kg} / \mathrm{m}^{2} \mathrm{~s}$ & mass flux by chemical reaction \\
\hline$R$ & - & function defined by Eq. 3.13 \\
\hline$t$ & $\mathbf{s}$ & residence time \\
\hline$T$ & $\mathrm{~kg} / \mathrm{m}^{2} \mathrm{~s}$ & mass flux by thermophoresis \\
\hline$T$ & $\mathrm{~K}$ & temperature \\
\hline$u$ & $\mathrm{~m} / \mathrm{s}$ & velocity \\
\hline$x$ & - & mole fraction (Eq. 3.26) \\
\hline$x$ & $\mathrm{~m}$ & distance, coordinate (rectilinear) direction \\
\hline$y$ & $\mathrm{~m}$ & coordinate (rectilinear) direction \\
\hline
\end{tabular}


Greek

\begin{tabular}{|c|c|c|}
\hline Symbol & Units & Definition \\
\hline$\alpha$ & $\mathrm{s}^{-1}$ & time constant (Eq. 3.19) \\
\hline$\beta$ & $\mathbf{s}^{-1}$ & proportionality constrint (Eqs. .3.8 - 3.9) \\
\hline$\gamma$ & - & absolute capti e efficiency \\
\hline$\delta$ & $\mathrm{m}$ & boundary layer thickness \\
\hline$\zeta$ & - & condensation efficiency (Eq. 3.26) \\
\hline$\eta$ & - & impaction efficiency \\
\hline$\theta$ & - & blowing factor (Eq. 3.26) \\
\hline$\theta$ & radians & $\begin{array}{l}\text { angular position, azimuthal coordinate } \\
\text { direction }\end{array}$ \\
\hline$\lambda$ & m & mean free path \\
\hline$\mu$ & $\mathrm{Ns} / \mathrm{m}^{2}$ & viscosity \\
\hline$\rho$ & $\mathrm{kg} / \mathrm{m}^{3}$ & density \\
\hline$\tau$ & $\mathbf{s}$ & elapsed time \\
\hline$\sigma$ & $\mathrm{m} / \mathrm{s}$ & standard deviation of velocity fluctuations \\
\hline$\tau$ & $\mathbf{s}$ & elapsed time \\
\hline$\Psi$ & - & correction factor for non-Stokesian drag \\
\hline
\end{tabular}

Subscripts

Symbol Definition

$b$ bulk

c cylinder

8 gas

$i \quad$ species index

$m$ mass transfer

$p$ particle

$r$ radial direction

$s$ su: ce

$T$ thermophoretic

$u_{p} \quad$ particle velocity

$w$ wall

$x \quad \mathrm{x}$-coordinate direction

$y \quad y$-coordinate direction

$\theta$ azimuthal direction

Superscripts

\begin{tabular}{cl} 
Symbol & Definition \\
\hline$c$ & cylinder \\
$t$ & turbulent \\
$w$ & wall \\
0 & initial (at time $=0$ ) \\
$\infty$ & bulk gas stream
\end{tabular}

Dimensionless Numbers

Stk Stokes number (Eqs. 3.11 and 3.15)

$K n \quad$ Knudsen number $\left(2 \lambda / d_{p}\right)$ 


\section{PUBLICATIONS, PAPERS AND PRESENTATIONS FOR 'TASK 3}

The following publications, papers and presentations were completed under Task 3 during this quarter:

Baxter, L.L., K.E. Hencken, and N.S. Harding, "Dynamic Variation of Particle Capture Efficiency During Ash Deposition in Pulverized Coal Combustion," Twenty-third Symposium (International) on Combustion, Orleans, France, July 22-27, 1990

Baxter, L.L., "Ash Deposition," presented to the University of Stuttgart July 15, 1990.

Baxter, L.L., R.E. Mitchell, and T.H. Fletcher, "Experimental Determination of Mineral Matter Release During Coal Devolatilization," proceedings of the Seventh Annual International Pittsburgh Coal Conference, Pittsburgh PA, September 10-14, 1990.

Baxter, L.L., "The Fate of Mineral Matter During Pulverized Coal Combustion" proceedings of the Advanced Research and Technology Development Direct Utilization, Instrumentation and Diagnostics Contractors Review Meeting, Pittsburgh PA, September 17-19, 1990.

Baxter, L.L., "Ash Composition Prediction as a Function of Coal Type, Operating Conditions, and Boiler Location" proceedings of the EPRI conference on the Effects of Coal Quality on Power Plants, St. Lois, Missouri, September 19-21, 1990.

Baxter, L.L., "The Fate of Mineral Matter During Pulverized Coal Combustion" presented at the DOE Fossil Energy Review,Bethesda, Maryland, August 21-23, 1990 


\section{APPENDIX FOR TASK 3}

In this appendix the information obtained from the analyses of the coals being used in Task 3 is presented. Table 3.1 (repeated below for purposes of comparison) summarizes these coals and denotes the status of the testing for each coal.

Table 3.1

Summary of the 19 Coals and Blends of Coals, Including Ranks, Used in Support of Subtasks 3.2 and 3.3.

\begin{tabular}{|c|c|c|c|c|c|}
\hline \multicolumn{6}{|c|}{$\begin{array}{l}\begin{array}{l}\text { Fuels Selected for Fly Ash Formation and Ash Deposition Experiments in the } \\
\text { Multifuel Combustor }\end{array}\end{array}$} \\
\hline Coal or Blend \& & Rank & Statust & Coal or Blend \& & Rank & Status $\dagger$ \\
\hline Pittsburgh Seam & $\begin{array}{l}\text { hvA } \\
\text { Bituminous }\end{array}$ & $\mathrm{p}$ & $\begin{array}{l}\text { Illinois \#6(2)/ } \\
\text { Rochelle Blend }\end{array}$ & $\begin{array}{l}\text { hvC } \\
\text { Bituminous }\end{array}$ & $\mathrm{p}$ \\
\hline Pittsburgh \#8 (1) & $\begin{array}{l}\text { hvA } \\
\text { Bituminous }\end{array}$ & c & Kentucky \#9* & $\begin{array}{l}\text { hvC } \\
\text { Bituminous }\end{array}$ & c \\
\hline Pittsburgh \#8 (2) & $\begin{array}{l}\text { hvA } \\
\text { Bituminous }\end{array}$ & c & Blind Canyon & $\begin{array}{l}\text { hvC } \\
\text { Bituminous }\end{array}$ & $\mathrm{p}$ \\
\hline Eastern Dlend & $\begin{array}{l}\text { hvA } \\
\text { Bituminous }\end{array}$ & c & Decker & $\begin{array}{l}\text { hvC } \\
\text { Bituminous }\end{array}$ & c \\
\hline Upper Freeport * & $\begin{array}{l}\text { hvA } \\
\text { Bituminous }\end{array}$ & $\mathbf{u}$ & Wyodak & Subbitum. B & c \\
\hline Eastern Kentucky & $\begin{array}{l}\text { hvA } \\
\text { Bituminous }\end{array}$ & c & Eagle Butte * & Subbitum. C & $\mathbf{u}$ \\
\hline $\begin{array}{l}\text { Pitt\#8/Decker } \\
\text { Blend }\end{array}$ & $\begin{array}{l}\text { hvA } \\
\text { Bituminous }\end{array}$ & $\mathrm{c}$ & Rochelle & Subbitum. C & $\mathrm{p}$ \\
\hline Kentucky \#11* & $\begin{array}{l}\text { hvB } \\
\text { Bituminous }\end{array}$ & c & $\begin{array}{l}\text { San Miguel } \\
\text { Lignite }\end{array}$ & Subbitum. C & $\mathrm{u}$ \\
\hline $\begin{array}{l}\text { Illinois \#6 (1) * } \\
\text { Illinois \#6 (2) }\end{array}$ & $\begin{array}{l}\text { hvC } \\
\text { Bituminous } \\
\text { hvC } \\
\text { Bituminous }\end{array}$ & $\mathrm{p}$ & Beulah Lignite * & Lignite A & c \\
\hline
\end{tabular}

$\S$ Numbers in parenthesis () indicate samples from the same seam but different mines.

† Status of testing is indicated as complete (c), underway (u), or planned (p).

* Coals marked by an aste isk are supplied (with analyses) by Foster Wheeler/Physical Sciences Technology. All others supplied by Consol.

The analyses include: proximate, ultimate, heating value, ash chemistry, forms of sulfur, acid soluble fractions, ash fusion temperatures (reducing and oxidizing), and particle size distribution analyses. Some of the coals contain significant fractions of large particles: more than are representative of pulverized coal boiler feedstocks. These coals were sieved to produce more typical size distrijutions. 
Table 3.A.1

Ultimate, Proximate, Heating Value, Ash Chemistry, Chlorine and Forms of Sulfur Analyses of Coals Used in Baseline Experiments in the MFC: Pittsburgh Seam, Pittsburgh \#8 (1), Pittsburgh \#8 (2), and Utah Blind Canyon Coals.

\begin{tabular}{|c|c|c|c|c|}
\hline Analyses & $\begin{array}{l}\text { Pitts. Seam } \\
\text { Hazzard }\end{array}$ & $\begin{array}{l}\text { Pitt. \#8 (1) } \\
\text { Powhatan }\end{array}$ & $\begin{array}{c}\text { Pitt. \#8 (2) } \\
\text { Bailey }\end{array}$ & $\begin{array}{l}\text { Blind } \\
\text { Canyon }\end{array}$ \\
\hline $\begin{array}{l}\text { Moisture (\% coal, wet) } \\
\text { Ultimate (\% coal, dry) } \\
\text { C } \\
\text { H } \\
\text { O } \\
\text { N } \\
\text { S } \\
\text { Ash }\end{array}$ & & $\begin{array}{r}1.02 \\
71.51 \\
5.03 \\
6.76 \\
1.24 \\
4.78 \\
10.68 \\
\end{array}$ & $\begin{array}{c}1.9 \\
78.77 \\
5.18 \\
6.43 \\
1.47 \\
1.56 \\
6.5 \\
\end{array}$ & \\
\hline $\begin{array}{l}\text { Proximate (\% coal, dry) } \\
\text { Fixed Carbon } \\
\text { Volatile Matter }\end{array}$ & & $\begin{array}{l}49.16 \\
40.16 \\
\end{array}$ & $\begin{array}{l}56.77 \\
36.73 \\
\end{array}$ & \\
\hline $\begin{array}{l}\text { Heating Value (Btu/lb) } \\
\text { As Fired (Dry) } \\
\text { Dulong }\end{array}$ & & 13004 & 14065 & \\
\hline $\begin{array}{l}\text { A sh Che mis try } \\
\text { (\% dry coal) } \\
\mathrm{SiO} 2 \\
\mathrm{Al} 2 \mathrm{O} 3 \\
\mathrm{TiO} 2 \\
\mathrm{Fe} 2 \mathrm{O} 3 \\
\mathrm{CaO} \\
\mathrm{MgO} \\
\mathrm{K} 2 \mathrm{O} \\
\mathrm{Na} 2 \mathrm{O} \\
\mathrm{SO} 3 \\
\mathrm{P} 2 \mathrm{O} 5 \\
\text { Undetermined Ash } \\
\text { Free Silica/Total Silicon } \\
\text { Pyritic Iron/Total Iron } \\
\text { Cl (bomb) } \\
\text { Cl in ash }\end{array}$ & & $\begin{array}{l}4.422 \\
2.19 \\
0.095 \\
3.1 \\
0.221 \\
0.083 \\
0.185 \\
0.043 \\
0.249 \\
0.016 \\
0.075 \\
0.416 \\
0.727\end{array}$ & $\begin{array}{l}3.059 \\
1.612 \\
0.07 \\
1.138 \\
0.211 \\
0.055 \\
0.119 \\
0.028 \\
0.17 \\
0.042 \\
-0.0033 \\
0.379 \\
0.745 \\
0.093\end{array}$ & \\
\hline $\begin{array}{l}\text { Forms of Sulfur (\% dry } \\
\text { coal) } \\
\text { Sulfatic } \\
\text { Pyritic } \\
\text { Organic }\end{array}$ & & $\begin{array}{l}0.15 \\
1.81 \\
2.82\end{array}$ & $\begin{array}{l}0.05 \\
0.68 \\
0.83\end{array}$ & \\
\hline
\end{tabular}


Table 3.A.2

Acid Soluble Alkali, Fusion Temperature (Reducing and Oxidizing), and Particle Size Distribution Analyses of Coals used in Baseline Experiments in the MFC: Pittsburgh Seam, Pittsburgh \#8 (1), Pittsburgh \#8 (2), and Utah Blind Canyon Coals.

\begin{tabular}{|c|c|c|c|c|}
\hline Analyses & Pitts. Seam & Pitt. \#8 (1) & Pitt. \#8 (2) & $\begin{array}{l}\text { Blind } \\
\text { Canyon }\end{array}$ \\
\hline $\begin{array}{l}\text { Acid Soluble Alkali (ppm) } \\
\mathrm{Na} \\
\mathrm{Mg} \\
\mathrm{Ca} \\
\mathrm{K}\end{array}$ & & & & \\
\hline $\begin{array}{l}\text { Fusion Temperatures } \\
\left({ }^{\circ} \mathrm{F} \text {, Reducing) }\right. \\
\text { Initial Deformation } \\
\text { Spherical } \\
\text { Hemispherical } \\
\text { Fl'did }\end{array}$ & & $\begin{array}{l}1917 \\
1980 \\
2154 \\
2232 \\
\end{array}$ & $\begin{array}{l}2107 \\
2250 \\
2396 \\
2468 \\
\end{array}$ & \\
\hline $\begin{array}{l}\text { Fusion Temperatures } \\
\left({ }^{\circ} \mathrm{F} \text {, Oxidizing) }\right. \\
\text { Initial Deformation } \\
\text { Spherical } \\
\text { Hemispherical } \\
\text { Fluid }\end{array}$ & & $\begin{array}{l}2438 \\
2502 \\
2518 \\
2532 \\
\end{array}$ & $\begin{array}{l}2474 \\
2521 \\
2557 \\
2597 \\
\end{array}$ & \\
\hline $\begin{array}{l}\text { Size Distribution (mass \% } \\
\text { of sample) } \\
\qquad \begin{array}{l}\mathrm{d}_{\mathrm{p}}>600 \mu \mathrm{m} \\
600 \mu \mathrm{m}>\mathrm{d}_{\mathrm{p}}>300 \mu \mathrm{m} \\
300 \mu \mathrm{m}>\mathrm{d}_{\mathrm{p}}>149 \mu \mathrm{m} \\
149 \mu \mathrm{m}>\mathrm{d}_{\mathrm{p}}>74 \mu \mathrm{m} \\
74 \mu \mathrm{m}>\mathrm{d}_{\mathrm{p}}>44 \mu \mathrm{m} \\
44 \mu \mathrm{m}>\mathrm{d}_{\mathrm{p}}\end{array}\end{array}$ & & $\begin{array}{r}0 \\
0.2 \\
0.8 \\
0.8 \\
22.1 \\
34.8 \\
42.1 \\
\end{array}$ & $\begin{array}{r}0.1 \\
0.6 \\
1.9 \\
25.6 \\
32.5 \\
39.4 \\
\end{array}$ & \\
\hline
\end{tabular}


Table 3.A.3

Ultimate, Proximate, Heating Value, Ash Chemistry, Chlorine and Forms of Sulfur Analyses of Coals used in baseline tests in the MFC: Upper Freeport, Eastern Kentucky, III \#6 (1), and Illinois \#6 (2).

\begin{tabular}{|c|c|c|c|c|}
\hline Analyses & $\begin{array}{l}\text { Upper } \\
\text { Freeport }\end{array}$ & E Kentucky & IIl \#6 (1) & Ill \#6 (2) \\
\hline $\begin{array}{l}\text { Moisture (\% coal, wet) } \\
\text { Ultimate (\% coal, dry) }\end{array}$ & 0.593 & 0.59 & 12.135 & 2.09 \\
\hline C & 65.417 & 75.24 & 68.918 & 69.72 \\
\hline $\mathrm{H}$ & 4.173 & 5.01 & 5.158 & 4.83 \\
\hline 0 & 4.492 & 7 & 9.948 & 8.64 \\
\hline $\mathrm{N}$ & 1.645 & 1.47 & 1.568 & 1.26 \\
\hline $\mathbf{S}$ & 2.000 & 0.98 & 4.353 & 3.44 \\
\hline Ash & 22.273 & 10.21 & 10.053 & 12.01 \\
\hline Proximate (\% coal, dry) & & & & \\
\hline Fixed Carbon & 53.765 & 52.98 & 48.840 & 48.94 \\
\hline Volatile Matter & 23.962 & 36.81 & 41.092 & 39.05 \\
\hline Heating Value (Btu/lb) & & & & \\
\hline $\begin{array}{l}\text { As Fired (Dry; } \\
\text { Dulong }\end{array}$ & $\begin{array}{l}11683 \\
11836 \\
\end{array}$ & 13325 & $\begin{array}{l}12266 \\
12615 \\
\end{array}$ & \\
\hline $\begin{array}{l}\text { Ash Chemistry } \\
(\% \text { dry coal) }\end{array}$ & & & & \\
\hline $\mathrm{SiO} 2$ & 11.315 & 5.888 & 4.644 & 6.252 \\
\hline $\mathrm{Al} 2 \mathrm{O} 3$ & 5.492 & 3.178 & 1.735 & 2.320 \\
\hline $\mathrm{TiO} 2$ & 0.267 & 0.199 & 0.092 & 0.114 \\
\hline $\mathrm{Fe} 2 \mathrm{O} 3$ & 3.001 & 0.509 & 2.042 & 2.018 \\
\hline $\mathrm{CaO}$ & 0.529 & 0.108 & 0.530 & 0.482 \\
\hline $\mathrm{MgO}$ & 0.305 & 0.04 & 0.071 & 0.132 \\
\hline $\mathrm{K} 2 \mathrm{O}$ & 0.672 & 0.104 & 0.205 & 0.264 \\
\hline $\mathrm{Na} 2 \mathrm{O}$ & 0.067 & 0.012 & 0.129 & 0.121 \\
\hline $\mathrm{SO} 3$ & 0.558 & 0.128 & 0.464 & 0.377 \\
\hline $\mathrm{P} 2 \mathrm{O} 5$ & 0.022 & 0.013 & 0.013 & 0.019 \\
\hline Undetermined Ash & & 0.030 & 0.111 & -0.090 \\
\hline Free Silica/Total Silicon & 0.427 & 0.364 & 0.559 & \\
\hline Pyritic Iron/Total Iron & 0.640 & 0.733 & 0.922 & \\
\hline Cl (bomb) & & 0.091 & 0.110 & 0.100 \\
\hline $\mathrm{Cl}$ in ash & & & 0.016 & \\
\hline $\begin{array}{l}\text { Forms of Sulfur (\% dry } \\
\text { coal) }\end{array}$ & & & & \\
\hline Sulfatic & 0.000 & 0.01 & 0.057 & \\
\hline Pyritic & 1.528 & 0.3 & 1.512 & \\
\hline Organic & 0.472 & 0.68 & 2.785 & \\
\hline
\end{tabular}


Table 3.A.4

Acid Soluble Alkali, Fusion Temperature (Reducing and Oxidizing), and Particle Size Distribution Analyses of Coals used in baseline tests in the MFC: Upper Freeport, Eastern Kentucky, III H6 (1), and Illinois \#6 (2).

\begin{tabular}{|l|c|c|c|c|}
\hline Analyses & $\begin{array}{c}\text { Upper } \\
\text { Freeport }\end{array}$ & E Kentucky & Ill \#6 (1) & Ill \#6 (2) \\
\hline Acid Soluble Alkali (ppm) & 343 & & 2256 & \\
$\mathrm{Na}$ & 1208 & & 1766 & \\
$\mathrm{Mg}$ & 3766 & & 5977 & \\
$\mathrm{Ca}$ & 2291 & & 2380 & \\
$\mathrm{~K}$ & & & & \\
\hline Fusion Temperatures & & & & \\
$\left({ }^{\circ}\right.$ F, Reducing) & 2167 & 2947 & 1906 & 2008 \\
Initial Deformation & 2260 & 2977 & 1961 & 2058 \\
Spherical & 2329 & 2987 & 2073 & 2214 \\
Hemispherical & 2376 & 3000 & 2172. & 2405 \\
Fluid & & & & \\
\hline Fusion Temperatures & & 2951 & 2257 & 2276 \\
$\left({ }^{\circ}\right.$ F, Oxidizing) & 2419 & 3000 & 2281 & 2345 \\
Initial Deformation & 2498 & 3000 & 2356 & 2451 \\
Spherical & 2522 & 3000 & 2504 & 2527 \\
Hemispherical & 2559 & & & \\
Fluid & & & & \\
\hline Size Distribution (mass \% & & 0 & 0.0 & 0.0 \\
of sample) & & 0.1 & 0.2 & 0.0 \\
$d_{p}>600 \mu \mathrm{m}$ & 1.7 & 2.3 & 1.7 \\
$600 \mu \mathrm{m}>\mathrm{d}_{\mathrm{p}}>300 \mu \mathrm{m}$ & & 33.3 & 16.3 & 32.1 \\
$300 \mu \mathrm{m}>\mathrm{d}_{\mathrm{p}}>149 \mu \mathrm{m}$ & & 29.7 & 29.9 & 29.9 \\
$149 \mu \mathrm{m}>\mathrm{d}_{\mathrm{p}}>74 \mu \mathrm{m}$ & & 35.3 & 56.3 & 36.3 \\
\hline $74 \mu \mathrm{m}>\mathrm{d}_{\mathrm{p}}>44 \mu \mathrm{m}$ & & & & \\
$44 \mu \mathrm{m}>\mathrm{d}_{\mathrm{p}}$ & & & & \\
\hline
\end{tabular}


Table 3.A.5

Ultimate, Proximate, Heating Value, Ash Chemistry, Chlorine and Forms of Sulfur Analyses of Coals used in baseline tests in the MFC: Kentucky \#4, Kentucky \#11, Decker, and Wyodak.

\begin{tabular}{|c|c|c|c|c|}
\hline Analyses & Ken \#9 & Ken \#11 & Decker & Wyodak \\
\hline $\begin{array}{l}\text { Moisture (\% coal, wet) } \\
\text { Ultimate (\% coal, dry) }\end{array}$ & 8.430 & 3.800 & 17.84 & 21.05 \\
\hline $\mathrm{C}$ & 66.243 & 59.374 & 72.54 & 70.51 \\
\hline $\mathrm{H}$ & 4.705 & 4.536 & 5.09 & 4.98 \\
\hline 0 & 8.773 & 8.066 & 15.63 & 16.62 \\
\hline $\mathbf{N}$ & 1.778 & 1.174 & 1.08 & 0.91 \\
\hline$S$ & 3.900 & 4.752 & 0.55 & 0.56 \\
\hline Ash & 14.600 & 22.098 & 5.11 & 6.38 \\
\hline Proximate (\% coal, dry) & & & & \\
\hline Fixed Carbon & 47.672 & 42.954 & 49.73 & 48.53 \\
\hline Volatile Matter & 37.728 & 34.948 & 45.16 & 45.09 \\
\hline Heating Value (Btu/lb) & & & & \\
\hline $\begin{array}{l}\text { As Fired (Dry) } \\
\text { Dulong }\end{array}$ & $\begin{array}{l}11907 \\
12053\end{array}$ & 10550 & 12612 & 12141 \\
\hline Ash Chemistry & & & & \\
\hline $\begin{array}{l}\text { (\% dry coal) } \\
\mathrm{SiO} 2\end{array}$ & 6.495 & 9.965 & 1.334 & 1.666 \\
\hline $\mathrm{Al} 2 \mathrm{O} 3$ & 2.984 & 4.172 & 0.885 & 0.954 \\
\hline $\mathrm{TiO} 2$ & 0.153 & 0.194 & 0.06 & 0.087 \\
\hline $\mathrm{Fe} 2 \mathrm{O} 3$ & 3.403 & 4.648 & 0.336 & 0.354 \\
\hline $\mathrm{CaO}$ & 0.439 & 0.959 & 0.759 & 1.598 \\
\hline $\mathrm{MgO}$ & 0.159 & 0.208 & 0.163 & 0.282 \\
\hline $\mathrm{K} 2 \mathrm{O}$ & 0.365 & 0.485 & 0.025 & 0.013 \\
\hline $\mathrm{Na} 2 \mathrm{O}$ & 0.142 & 0.071 & 0.365 & 0.06 \\
\hline $\mathrm{SO} 3$ & 0.636 & 1.045 & 1.014 & 1.21 \\
\hline $\mathrm{P} 2 \mathrm{O} 5$ & 0.016 & 0.040 & 0.044 & 0.063 \\
\hline Undetermined Ash & & & 0.098 & 0.093 \\
\hline Free Silica/Total Silicon & 0.457 & 0.507 & 0.218 & 0.325 \\
\hline Pyritic Iron/Total Iron & 0.617 & 0.825 & 0.928 & 0.844 \\
\hline $\mathrm{Cl}$ (bomb) & 0.066 & 0.030 & 0.04 & 0.038 \\
\hline $\mathrm{Cl}$ in ash & 0.026 & 0.020 & & \\
\hline $\begin{array}{l}\text { Forms of Sulfur (\% dry } \\
\text { coal) }\end{array}$ & & & & \\
\hline Sulfatic & 0.058 & 0 & 0.02 & 0.03 \\
\hline Pyritic & 1.685 & 3.086 & 0.25 & 0.24 \\
\hline Organic & 2.157 & 1.666 & 0.28 & 0.29 \\
\hline
\end{tabular}


Table 3.A.6

Acid Soluble Alkali, Fusion Temperature (Reducing and Oxidizing), and Particle Size Distribution Analyses of Coals used in baseline tests in the MFC: Kentucky \#9, Kentucky \#11, Decker, and Wyodak.

\begin{tabular}{|c|c|c|c|c|}
\hline Analyses & Ken \#9 & Ken \#11 & Decker & Wyodak \\
\hline $\begin{array}{l}\text { Acid Soluble Alkali (ppm) } \\
\mathrm{Na} \\
\mathrm{Mg} \\
\mathrm{Ca} \\
\mathrm{K}\end{array}$ & $\begin{array}{r}694 \\
830 \\
2835 \\
2225\end{array}$ & $\begin{array}{r}400 \\
1037 \\
4981 \\
3578\end{array}$ & & \\
\hline $\begin{array}{l}\text { Fusion Temperatures } \\
\left({ }^{\circ} \mathrm{F}, \text { Reducing) }\right. \\
\text { Initial Deformation } \\
\text { Spherical } \\
\text { Hemispherical } \\
\text { Fluid }\end{array}$ & $\begin{array}{l}2178 \\
2332 \\
2373 \\
2408 \\
\end{array}$ & $\begin{array}{l}2292 \\
2318 \\
2341 \\
2359 \\
\end{array}$ & $\begin{array}{l}2120 \\
2175 \\
2188 \\
2220\end{array}$ & $\begin{array}{l}2145 \\
2192 \\
2211 \\
2254\end{array}$ \\
\hline $\begin{array}{l}\text { Fusion Temperatures } \\
\left({ }^{\circ} \mathrm{F} \text {, Oxidizing) }\right. \\
\text { Initial Deformation } \\
\text { Spherical } \\
\text { Hemispherical } \\
\text { Fluid }\end{array}$ & $\begin{array}{l}2314 \\
2418 \\
2459 \\
2504\end{array}$ & $\begin{array}{l}2313 \\
2350 \\
2389 \\
2423\end{array}$ & $\begin{array}{l}2304 \\
2453 \\
2480 \\
2527\end{array}$ & $\begin{array}{l}2141 \\
2181 \\
2208 \\
2262\end{array}$ \\
\hline $\begin{array}{l}\text { Size Distribution (mass \% } \\
\text { of sample) } \\
\mathrm{d}_{\mathrm{p}}>600 \mu \mathrm{m} \\
600 \mu \mathrm{m}>\mathrm{d}_{\mathrm{p}}>300 \mu \mathrm{m} \\
300 \mu \mathrm{m}>\mathrm{d}_{\mathrm{p}}>149 \mu \mathrm{m} \\
149 \mu \mathrm{m}>\mathrm{d}_{\mathrm{p}}>74 \mu \mathrm{m} \\
74 \mu \mathrm{m}>\mathrm{d}_{\mathrm{p}}>44 \mu \mathrm{m} \\
44 \mu \mathrm{m}>\mathrm{d}_{\mathrm{p}}\end{array}$ & $\begin{array}{c}0 \\
0.2 \\
1.6 \\
13.5 \\
29.3 \\
55.4\end{array}$ & & $\begin{array}{c}0 \\
0.3 \\
4.6 \\
23.8 \\
25.5 \\
45.8\end{array}$ & $\begin{array}{c}0 \\
0.1 \\
3.6 \\
20.7 \\
22.4 \\
53.3\end{array}$ \\
\hline
\end{tabular}


Table 3.A.7

Ultimate, Proximate, Heating Value, Ash Chemistry, Chlorine and Forms of Sulfur Analyses of Coals used in baseline tests in the MFC: Eagle Butte, Rochelle, Beulah Lignite, San Miguel (Texas) Lignite.

\begin{tabular}{|c|c|c|c|c|}
\hline Analyses & Eagle Butte & Rochelle & $\begin{array}{l}\text { Beulah } \\
\text { Lignite }\end{array}$ & $\begin{array}{l}\text { San Miguel } \\
\text { Lignite }\end{array}$ \\
\hline $\begin{array}{l}\text { Moisture (\% coal, wet) } \\
\text { Ultimate (\% coal, dry) }\end{array}$ & 25.238 & 9.26 & 28.655 & 19.820 \\
\hline C & 66.975 & 70.29 & 60.126 & 28.582 \\
\hline $\mathrm{H}$ & 4.938 & 4.84 & 4.165 & 3.434 \\
\hline $\mathrm{O}$ & 19.795 & 16.86 & 18.596 & 14.152 \\
\hline $\mathbf{N}$ & 1.335 & .93 & 1.174 & 0.518 \\
\hline S & 0.480 & .54 & 1.885 & 1.694 \\
\hline Ash & 6.477 & 6.49 & 14.054 & 51.620 \\
\hline Proximate (\% coal, dry) & & & & \\
\hline Fixed Carbon & 48.087 & 49.13 & 43.868 & 16.970 \\
\hline Volatile Matter & 45.437 & 44.38 & 42.079 & 31.410 \\
\hline Heating Value (Btu/lb) & & & & \\
\hline As Fired (Dry) & 11656 & & 9939 & 5032 \\
\hline Dulong & 11289 & & 9909 & \\
\hline $\begin{array}{l}\text { A sh Chemistry } \\
(\% \text { dry coal })\end{array}$ & & & & \\
\hline $\mathrm{SiO} 2$ & 1.824 & 1.978 & 3.039 & 33.794 \\
\hline $\mathrm{Al} 2 \mathrm{O} 3$ & 0.958 & 0.934 & 2.024 & 10.634 \\
\hline $\mathrm{TiO} 2$ & 0.056 & 0.070 & 0.057 & 0.465 \\
\hline $\mathrm{Fe} 2 \mathrm{O} 3$ & 0.399 & 0.530 & 1.740 & 0.960 \\
\hline $\mathrm{CaO}$ & 1.714 & 1.199 & 2.375 & 1.610 \\
\hline $\mathrm{MgO}$ & 0.405 & 0.312 & 0.599 & 0.238 \\
\hline $\mathrm{K} 2 \mathrm{O}$ & 0.018 & 0.031 & 0.328 & 0.981 \\
\hline $\mathrm{Na} 2 \mathrm{O}$ & 0.120 & 0.121 & 0.820 & 1.178 \\
\hline $\mathrm{SO} 3$ & 0.904 & 1.243 & 3.083 & 1.242 \\
\hline $\mathrm{P} 2 \mathrm{O} 5$ & 0.045 & 0.057 & 0.000 & 0.000 \\
\hline Undetermined Ash & & 0.015 & & \\
\hline Free Silica/Total Silicon & 0.381 & & 0.215 & 0.629 \\
\hline Pyritic Iron/Total Iron & 0.202 & & 0.143 & 0.465 \\
\hline $\mathrm{Cl}$ (bomb) & & 0.045 & & 0.054 \\
\hline $\mathrm{Cl}$ in ash & & & & 0.010 \\
\hline $\begin{array}{l}\text { Forms of Sulfur (\% dry } \\
\text { coal) }\end{array}$ & & & & \\
\hline Sulfatic & 0.000 & & 0.066 & 0.000 \\
\hline Pyritic & 0.065 & & 0.196 & 0.358 \\
\hline Organic & 0.415 & & 1.623 & 1.336 \\
\hline
\end{tabular}


Table 3.A.8

Acid Soluble Alkali, Fusion Temperature (Reducing and Oxidizing), and Particle Size Distribution Analyses of Coals used in baseline tests in the MFC: Eagle Butte, Rochelle, Beulah Lignite, San Miguel (Texas) Lignite.

\begin{tabular}{|c|c|c|c|c|}
\hline Analyses & Eagle Butte & Rochelle & $\begin{array}{l}\text { Beulah } \\
\text { Lignite }\end{array}$ & $\begin{array}{l}\text { San Miguel } \\
\text { Lignite }\end{array}$ \\
\hline $\begin{array}{l}\text { Acid Soluble Alkali (ppm) } \\
\mathrm{Na} \\
\mathrm{Mg} \\
\mathrm{Ca} \\
\mathrm{K}\end{array}$ & $\begin{array}{r}822 \\
1891 \\
72501 \\
751\end{array}$ & & $\begin{array}{r}73571 \\
33211 \\
14036 \\
152\end{array}$ & $\begin{array}{r}8788 \\
11568 \\
76288 \\
5862 \\
\end{array}$ \\
\hline $\begin{array}{l}\text { Fusion Temperatures } \\
\left({ }^{\circ} \mathrm{F} \text {, Reducing) }\right. \\
\text { Initial Deformation } \\
\text { Spherical } \\
\text { Hemispherical } \\
\text { Fluid }\end{array}$ & $\begin{array}{l}2227 \\
2252 \\
2258 \\
2261\end{array}$ & $\begin{array}{l}2038 \\
2095 \\
2110 \\
2152\end{array}$ & $\begin{array}{l}1998 \\
2124 \\
2154 \\
2162 \\
\end{array}$ & $\begin{array}{l}2347 \\
2439 \\
2509 \\
2621 \\
\end{array}$ \\
\hline $\begin{array}{l}\text { Fusion Temperatures } \\
\left({ }^{\circ} \mathrm{F} \text {, Oxidizing) }\right. \\
\text { Initial Deformation } \\
\text { Spherical } \\
\text { Hemispherical } \\
\text { Fluid }\end{array}$ & $\begin{array}{l}2176 \\
2207 \\
2218 \\
2223 \\
\end{array}$ & $\begin{array}{l}2127 \\
2176 \\
2205 \\
2244\end{array}$ & $\begin{array}{l}2273 \\
2335 \\
2361 \\
2365 \\
\end{array}$ & $\begin{array}{l}2354 \\
2420 \\
2502 \\
2651 \\
\end{array}$ \\
\hline $\begin{array}{l}\text { Size Distribution (mass \% } \\
\text { of sample) } \\
\mathrm{d}_{\mathrm{p}}>600 \mu \mathrm{m} \\
600 \mu \mathrm{m}>\mathrm{d}_{\mathrm{p}}>300 \mu \mathrm{m} \\
300 \mu \mathrm{m}>\mathrm{d}_{\mathrm{p}}>149 \mu \mathrm{m} \\
149 \mu \mathrm{m}>\mathrm{d}_{\mathrm{p}}>74 \mu \mathrm{m} \\
74 \mu \mathrm{m}>\mathrm{d}_{\mathrm{p}}>44 \mu \mathrm{m} \\
44 \mu \mathrm{m}>\mathrm{d}_{\mathrm{p}}\end{array}$ & & $\begin{array}{r}0.0 \\
0.0 \\
1.5 \\
30.3 \\
30.3 \\
37.9\end{array}$ & $\begin{array}{r}0.3 \\
4.4 \\
12.7 \\
19.1 \\
14.6 \\
48.9\end{array}$ & \\
\hline
\end{tabular}


Table 3.A.9

Ultimate, Proximate, Heating Value, Ash Chemistry, Chlorine and Forms of Sulfur Analyses of Coals used in baseline tests in the MFC: Eastern Blend, PittsburghDecker Blend, Rochelle-Illinois \#6 Blend.

\begin{tabular}{|c|c|c|c|}
\hline Analyses & $\begin{array}{l}\text { Eastern } \\
\text { Blend }\end{array}$ & $\begin{array}{l}\text { Pittsburgh- } \\
\text { Decker } \\
\text { Blend }\end{array}$ & $\begin{array}{l}\text { Rochelle- } \\
\text { Illinois \#6 } \\
\text { Blend }\end{array}$ \\
\hline $\begin{array}{l}\text { Moisture (\% coal, wet) } \\
\text { Ultimate (\% coal, dry) }\end{array}$ & $\overline{0.72}$ & 9.96 & 6.13 \\
\hline C & 77.95 & 75.73 & 70.25 \\
\hline $\mathrm{H}$ & 4.79 & 5.09 & 4.84 \\
\hline 0 & 5.51 & 10.52 & 13.64 \\
\hline $\mathbf{N}$ & 1.43 & 1.34 & 1.04 \\
\hline $\mathbf{S}$ & 1.65 & 1.1 & 1.37 \\
\hline Ash & 8.67 & 6.15 & 8.80 \\
\hline Proximate (\% coal, dry) & & & \\
\hline Fixed Carbon & 61.06 & 52.83 & 48.34 \\
\hline Volatile Matter & 30.27 & 41.02 & 42.86 \\
\hline $\begin{array}{l}\text { Heating Value (Btu/lb) } \\
\text { As Fired (Dry) } \\
\text { Dulong }\end{array}$ & 13933 & 13415 & \\
\hline $\begin{array}{ll}\text { A s.h } & \text { Chemistry } \\
(\% \text { dry coal }) & \end{array}$ & & & \\
\hline $\mathrm{SiO} 2$ & 4.251 & 2.374 & 3.187 \\
\hline $\mathrm{Al} 2 \mathrm{O} 3$ & 2.127 & 1.303 & 1.387 \\
\hline $\mathrm{TiO} 2$ & 0.087 & 0.061 & 0.086 \\
\hline $\mathrm{Fe} 2 \mathrm{O} 3$ & 1.477 & 0.776 & 0.903 \\
\hline $\mathrm{CaO}$ & 0.2 & 0.508 & 1.054 \\
\hline $\mathrm{MgO}$ & 0.075 & 0.106 & 0.275 \\
\hline $\mathrm{K} 2 \mathrm{O}$ & 0.173 & 0.069 & 0.099 \\
\hline $\mathrm{Na} 2 \mathrm{O}$ & 0.031 & 0.199 & 0.128 \\
\hline SO3 & 0.166 & 0.662 & 1.657 \\
\hline P2O5 & 0.032 & 0.043 & 0.047 \\
\hline Undetermined Ash & 0.052 & 0.049 & 0.002 \\
\hline Free Silica/Total Silicon & 0.41 & 0.353 & \\
\hline Pyritic Iron/Total Iron & 0.751 & 0.77 & \\
\hline $\begin{array}{l}\mathrm{Cl}(\text { bomb) } \\
\mathrm{Cl} \text { in ash }\end{array}$ & & 0.066 & 0.057 \\
\hline $\begin{array}{l}\text { Forms of Sulfur (\% dry } \\
\text { coal) }\end{array}$ & & & \\
\hline Sulfatic & 0.01 & 0.03 & \\
\hline Pyritic & 0.89 & 0.48 & \\
\hline Organic & 0.75 & 0.59 & \\
\hline
\end{tabular}


Table 3.A.10

Acid Soluble Alkali, Fusion Temperature (Reducing and Oxidizing), and Particle Size Distribution Analyses of Coal Blends used in baseline tests in the MFC: Eastern Blend, Pittsburgh-Decker Blend, Rochelle-Illinois \#6 Blend.

\begin{tabular}{|l|c|c|c|}
\hline Analyses & $\begin{array}{c}\text { Eastern } \\
\text { Blend }\end{array}$ & $\begin{array}{c}\text { Pittsburgh- } \\
\text { Decker } \\
\text { Blend }\end{array}$ & $\begin{array}{c}\text { Rochelle- } \\
\text { Illinois \#6 } \\
\text { Blend }\end{array}$ \\
\hline $\begin{array}{l}\text { Acid Soluble Alkali (ppm) } \\
\mathrm{Na}\end{array}$ & & & \\
$\mathrm{Mg}$ & & & \\
$\mathrm{Ca}$ & & & \\
$\mathrm{K}$ & & & \\
\hline Fusion Temperatures & 2133 & 2169 & 2042 \\
( ${ }^{\circ}$, Reducing) & 2429 & 2234 & 2114 \\
Initial Deformation & 2449 & 2268 & 2195 \\
Spherical & 2500 & 2337 & 2273 \\
Hemispherical & & & \\
Fluid & 2497 & 2332 & 2152 \\
\hline Fusion Temperatures & 2574 & 2344 & 2180 \\
$\left({ }^{\circ} \mathrm{F}\right.$, Oxidizing) & 2602 & 2386 & 2274 \\
Initial Deformation & 2632 & 2423 & 2350 \\
Spherical & & & \\
Hemispherical & & & \\
Fluid & 0.0 & 0.0 & 0.0 \\
Size Distribution (mass \% & & 0.1 & 0.0 \\
of sample) & & & \\
$\mathrm{d}_{\mathrm{p}}>600 \mu \mathrm{m}$ & 1.3 & 3.1 & 1.3 \\
$600 \mu \mathrm{m}>\mathrm{d}_{\mathrm{p}}>300 \mu \mathrm{m}$ & 0.0 & 25.0 & 30.0 \\
$300 \mu \mathrm{m}>\mathrm{d}_{\mathrm{p}}>149 \mu \mathrm{m}$ & 26.3 & 26.9 & 29.8 \\
$149 \mu \mathrm{m}>\mathrm{d}_{\mathrm{p}}>74 \mu \mathrm{m}$ & 26.3 & 38.9 \\
$74 \mu \mathrm{m}>\mathrm{d}_{\mathrm{p}}>44 \mu \mathrm{m}$ & 26.3 & 45.0 & \\
$44 \mu \mathrm{m}>\mathrm{d}_{\mathrm{p}}$ & 46.1 & & \\
\hline
\end{tabular}




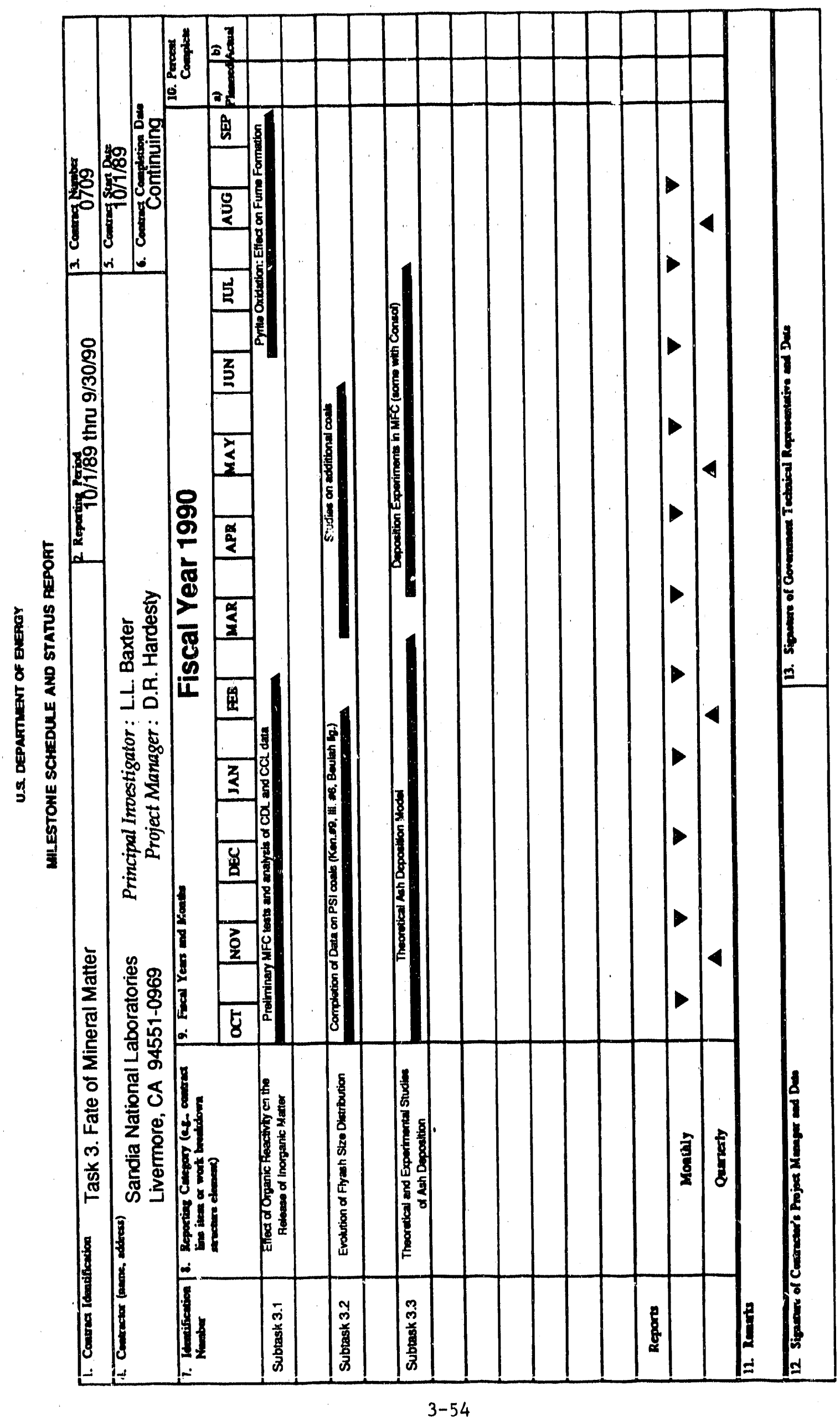



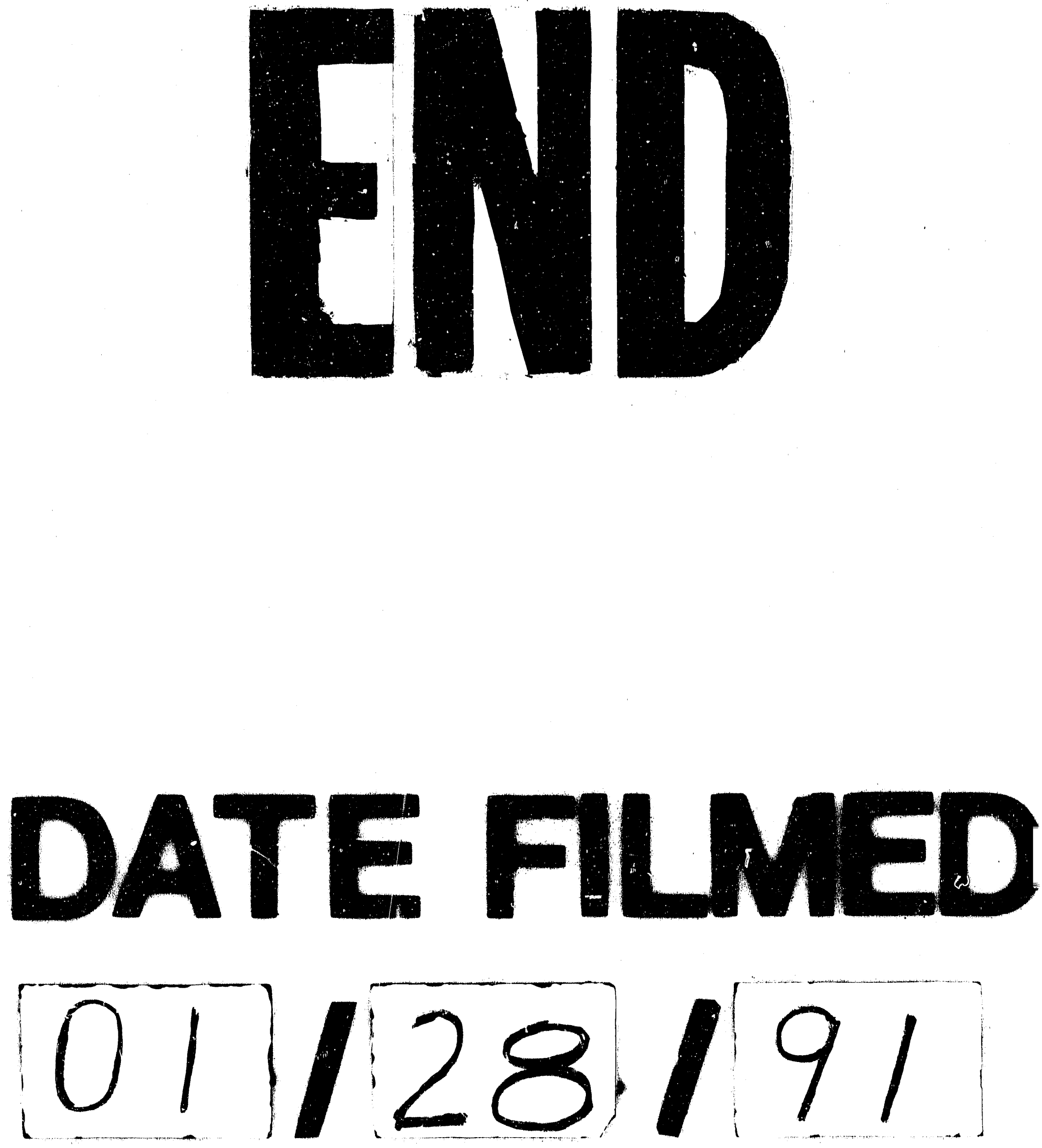
